\section{Pacific Northwest}

National Laboratory

Operated by Battelle for the

U.S. Department of Energy

\title{
Qualification Tests for the New Air Sampling System at the 296-Z-1 Stack
}

\author{
J. A. Glissmeyer \\ A. D. Maughan \\ T. T. Jarvis
}

September 2002

Prepared for the U.S. Department of Energy under Contract DE-AC06-76RL01830 


\title{
DISCLAIMER
}

This report was prepared as an account of work sponsored by an agency of the United States Government. Neither the United States Government nor any agency thereof, nor Battelle Memorial Institute, nor any of their employees, makes any warranty, express or implied, or assumes any legal liability or responsibility for the accuracy, completeness, or usefulness of any information, apparatus, product, or process disclosed, or represents that its use would not infringe privately owned rights. Reference herein to any specific commercial product, process, or service by trade name, trademark, manufacturer, or otherwise does not necessarily constitute or imply its endorsement, recommendation, or favoring by the United States Government or any agency thereof, or Battelle Memorial Institute. The views and opinions of authors expressed herein do not necessarily state or reflect those of the United States Government or any agency thereof.

\author{
PACIFIC NORTHWEST NATIONAL LABORATORY \\ operated by \\ BATTELLE \\ for the \\ UNITED STATES DEPARTMENT OF ENERGY \\ under Contract DE-ACO6-76RLO183O
}

Printed in the United States of America
Available to DOE and DOE contractors from the
Office of Scientific and Technical Information,
P.O. Box 62, Oak Ridge, TN 37831-0062;
ph: (865) 576-8401
fax: (865) 576-5728
email: reports@adonis.osti.gov

\author{
Available to the public from the National Technical Information Service, \\ U.S. Department of Commerce, 5285 Port Royal Rd., Springfield, VA 22161 \\ ph: (800) 553-6847 \\ fax: (703) 605-6900 \\ email: orders@ntis.fedworld.gov \\ online ordering: http://www.ntis.gov/ordering.htm
}




\section{Qualification Tests for the New Air Sampling System at the 296-Z-1 Stack}

J. A. Glissmeyer

A. D. Maughan

T. T. Jarvis

September 2002

Prepared for

the U.S. Department of Energy

under Contract DE-AC06-76RL01830

Pacific Northwest National Laboratory

Richland, WA 99352 


\section{Summary}

This report documents tests performed by Pacific Northwest National Laboratory to verify that the replacement air monitoring system for the 296-Z-1 ventilation exhaust stack meets the applicable regulatory criteria regarding the placement of the air sampling probe and sample transport. These criteria ensure that the contaminants in the stack are well mixed with the airflow at the location of the probe (at approximately the $50-\mathrm{ft}$ level of the stack) so that the collected sample represents the whole. The sequence of tests addresses the

- acceptability of the flow angle relative to the probe

- uniformity of air velocity and gaseous and particle tracers in the cross section of the stack

- delivery of the sample from the sampler nozzle to the collection filter.

The tests conducted on the air monitoring system demonstrated that the location for the air-sampling probe meets all performance criteria for air sampling systems at nuclear facilities. The performance criterion for particle transport was also met. All tests were successful and all acceptance criteria were met. 


\section{Acknowledgments}

This work was supported by the U.S. Department of Energy under Contract DE-AC06-76RL01830, with project funding from the Nuclear Materials Stabilization Project managed by Fluor Hanford, Inc. The authors wish to acknowledge the technical assistance of Roni Swan, Karl Hadley, and James W. Kelly of Environmental Compliance; and Johnny D. Dick and craft services of the Plutonium Finishing Plant, Fluor Hanford, Inc. for invaluable technical assistance. 


\section{Contents}

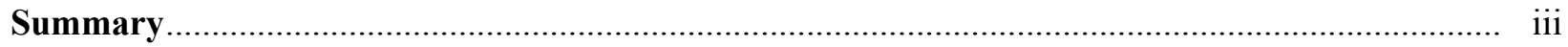

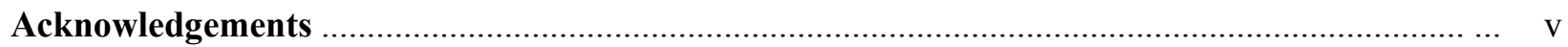

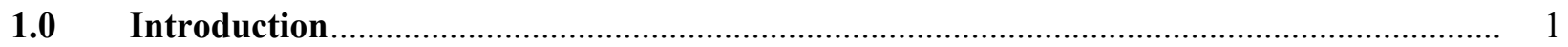

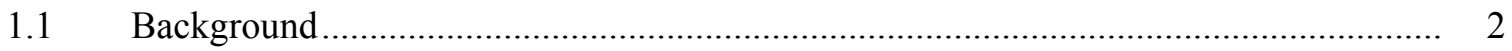

$1.2 \quad$ Ventilation Exhaust Stack Description ........................................................ 2

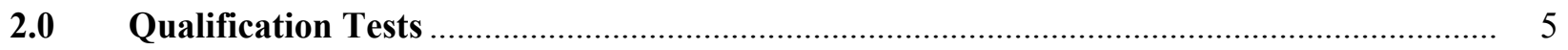

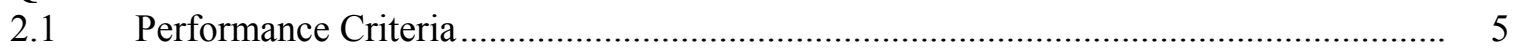

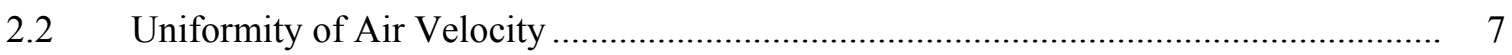

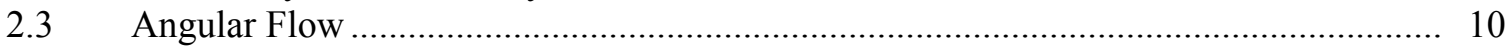

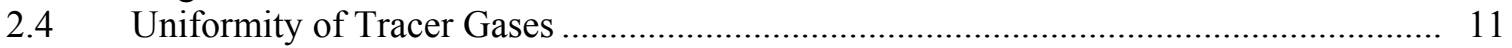

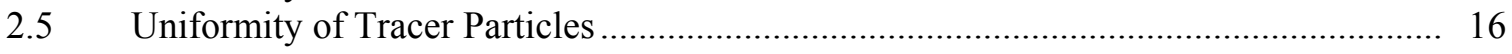

2.6 Sample Extraction and Transport System Performance …......................................... 18

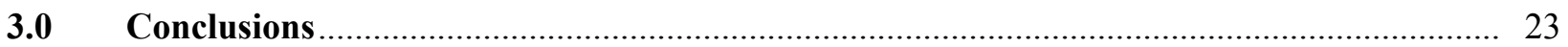

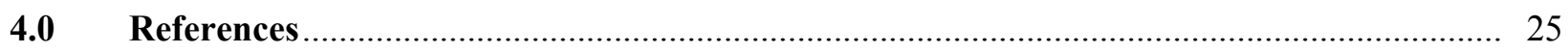

Appendix A $\quad$ Scaling Parameters Stack Model Schematics ........................................................... A.1

Appendix B $\quad$ Support of Scale Model Test Results ..................................................................... B.1

Appendix C $\quad$ Fan Speed vs. Flow Rate Correlation Procedure ........................................................... C. 1

Appendix D $\quad$ Fan Speed vs. Flow Rate Correlation Data Plots .................................................... D.1

Appendix E $\quad$ Air Velocity Uniformity Testing Procedure ............................................................... E. 1

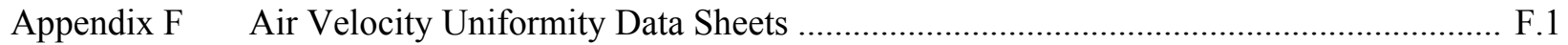

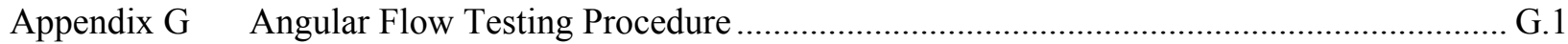

Appendix H Angular Flow Data Sheets and Plots ....................................................................... H.1

Appendix I Tracer Gas Uniformity Testing Procedure .................................................................. I.1

Appendix J Tracer Gas Uniformity Data Sheets ....................................................................... J.1

Appendix K $\quad$ Tracer Particle Uniformity Testing Procedure............................................................. K.1

Appendix L Tracer Particle Uniformity Data Sheets ....................................................................... L.1 


\section{List of Figures}

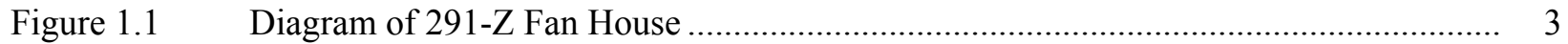

Figure 1.2 296-Z-1 Ventilation Exhaust Stack.............................................................. 4

Figure 2.1 Velocity Uniformity Measuring Equipment ...................................................... 9

Figure 2.2 Bar Graph of Velocity Measurement from Run VT-4 _.............................................. 10

Figure 2.3 Type-S Pitot Tube and Protractor Level Used to Measure Angular Flow .................... 12

Figure 2.4 Tracer Gas Injection Location ................................................................... 14

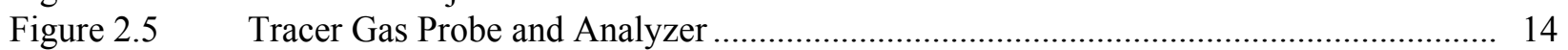

Figure 2.6 Particle Generator and Injection Point ............................................................... 17

Figure 2.7 Optical Particle Counter and Probe Arrangement for a Particle Uniformity Test ......... 17

Figure 2.8 Diagram of the Sampling System Tubing Elements ............................................... 19

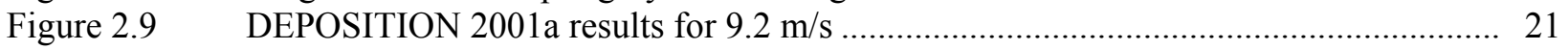

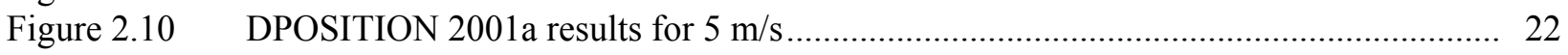

\section{List of Tables}

Table 2.1

Table 2.2

Table 2.3

Table 2.4

Table 2.5

Table 2.6

Table 2.7

Table 2.8

Table 2.9

Table 3.1
Fan Schematic.....

Fan Configuration for Emergency Backup Operating Condition

Fan Configuration for Normal Operating Conditions

Velocity Uniformity Results

Velocity Uniformity Comparison of Scale Model and Stack Tests.

Flow Angle Results

Summarization of Gas Tracer Uniformity Results

Particle Tracer Uniformity Results for the Center Two-Thirds of the Stack

DEPOSITION 2001a Input Parameters

Conclusions on Air Sampling System Tests

3
4
9
10
12
4
4
17
17
19
1
22

4.




\subsection{Introduction}

The Plutonium Finishing Plant is in the 200 West Area at the U.S. Department of Energy's (DOE) Hanford Site, near Richland, Washington. Radiological work is conducted within the Plutonium Finishing Plant (PFP). PFP's main ventilation exhaust stack is designated 296-Z-1 and is located to the south of the building and adjacent to the exhaust fan building. The stack monitoring system that measures any radiation escaping via the stack is the subject of this report.

In 2000 and 2001, brief increases in emissions, as measured with the stack monitoring system, occurred that did not correlate with plant operations. Visual examination of sample filters showed visible deposits. During the previous decades of plant operations, ventilation filter and ductwork failures are suspected of causing a buildup and deposition of airborne particulate residues in the ventilation system (Mahoney, et al.. 1996). It was suspected that a buildup of particulate in the airmonitoring probe might also have occurred. In December 2001, a visual inspection of the probe interior was made with a fiber-optic camera. The inspection showed some buildup of deposited particulate in the probe.

It was determined that the deposited material would have to be removed and analyzed to assess the effect on reported emissions. This would be accomplished by removal of the existing probe for analysis and installation of a new probe. It was determined to replace the probe with a probe compliant with ANSI/HPS N13.1-1999 (ANSI 1999). To do so would require a demonstration that the probe location would meet the criteria for uniform mixing for potential contaminants. Consequently, a test program was implemented to determine the compliance with mixing and particle transport criteria.

The size and access limitations of the 291-Z-1 stack make it impractical to conduct the qualification tests on the stack. Therefore, the ANSI/HPS N13.1-1999 criteria for scale model qualification testing were also applied to this stack. A scale model was built and used for the complete qualification testing. Repeating the velocity uniformity test on the actual stack is required for the scale model data to apply.

This report verifies that the proposed new air monitoring system at the 296-Z-1 ventilation exhaust stack will meet the applicable criteria regarding the placement of the air-sampling probe and the transport of the sample to the collection device. The performance criterion, test methods, results, and conclusions are discussed. The detailed test procedures and data sheets are included in the appendices. The governing standard is ANSI/HPS N13.1-1999 (ANSI 1999). Pacific Northwest National Laboratory ${ }^{1}$ staff conducted these tests.

\footnotetext{
${ }^{1}$ Pacific Northwest National Laboratory is operated by Battelle for the U.S. Department of Energy.
} 


\subsection{Background}

On December 15, 1989, 40 CFR 61, Subpart H, "National Emission Standards for Emissions of Radionuclides Other than Radon from Department of Energy Facilities," came into effect. This regulation governs portions of the design and implementation of facility effluent air sampling. Further, 40 CFR 61, Subpart $\mathrm{H}$ requires the use of isokinetic sampling nozzles as described in American National Standards Institute (ANSI) N13.1-1969 (ANSI 1982). This standard has been replaced by ANSI/HPS N13.1-1999 (ANSI 1999), though this version has yet to be formally incorporated into the U.S. Environmental Protection Agency (EPA) regulation (40 CFR 61, Subpart $\mathrm{H})$. In the interim, EPA has accepted the key features of the updated standard as an accepted alternative to the older version $\left(\mathrm{Nichols}^{2}\right)^{3}$.

\subsection{Ventilation Exhaust Stack Description}

Historically, the 296-Z-1 stack has discharged airborne emissions from the process glovebox and the general ventilation air from the 232-Z, 234-5Z, and 236-Z buildings. Currently, there is no airflow coming from the 232-Z building. All exhaust air is filtered through two-stage, high-efficiency particulate air (HEPA) filters prior to discharge.

Fans located in the 291-Z building power the ventilation exhaust flow as diagrammed in Figure 1.1. The air enters a central plenum through ducts from the 232-Z, 234-5Z, and 236-Z buildings. Fans draw the exhaust air from the plenum and force it up the stack. In normal operation, four of seven electric fans are operating and the system airflow is about $280,000 \mathrm{cfm}$. The operating fans are rotated among the seven fans available. In case of the failure of electrical power, two steam driven fans are automatically started to ensure the flow of air through the plant and the maintenance of the direction of air flow from non-process to process areas to the HEPA filters. The steam driven fans are tested at least monthly, and have a combined airflow of about 192,000 cfm.

The stack has an internal diameter of 16-ft at the base and is about 200 feet tall. Figure 1.2 shows the stack and the shack housing the air sampling probe and monitoring systems. The approximate number of stack diameters from the bottom of the stack to the sampling probe is 3.3.

\footnotetext{
${ }^{2}$ Letter from M. D. Nichols (EPA, Assistant Administrator for Air Radiation) to R. F. Pelletier (DOE). 1994, Washington, D.C.

${ }^{3}$ 40CFR61, Subpart H, has been amended to incorporate the newer version of the standard. The effective date is October 9, 2002.
} 


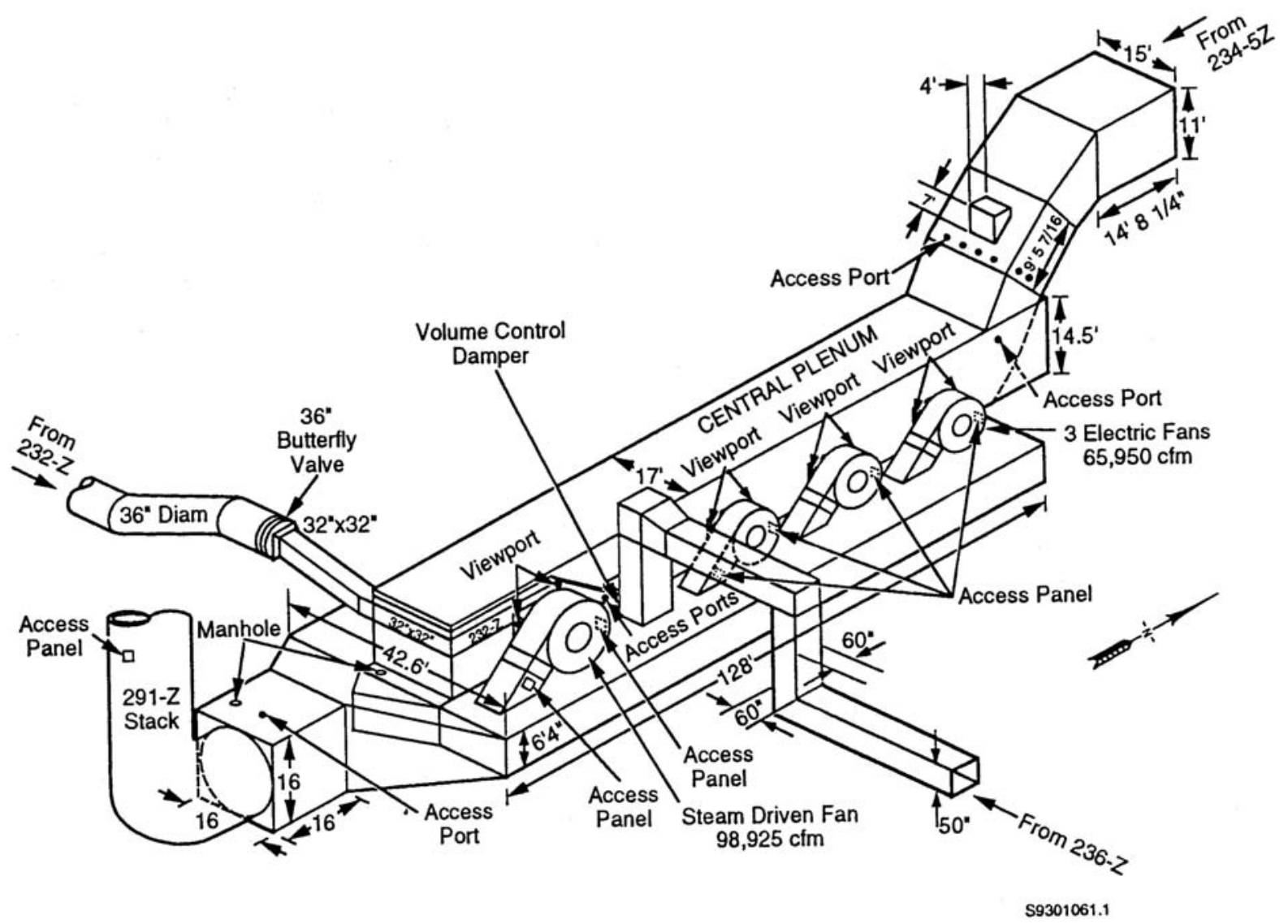

Figure 1.1 Diagram of 291-Z Fan House. 


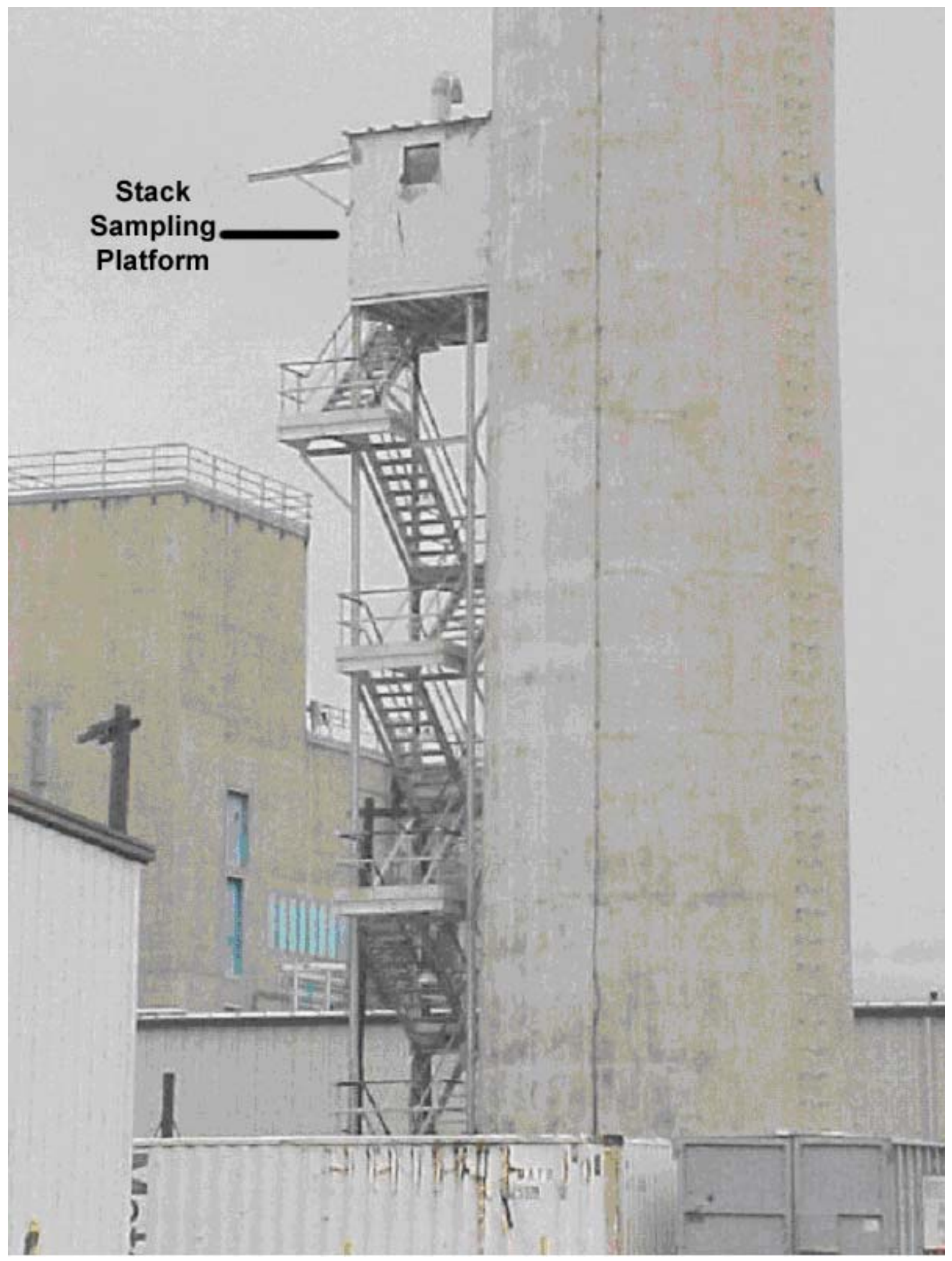

Figure 1.2 296-Z-1 Ventilation Exhaust Stack. 


\subsection{Qualification Tests}

\subsection{Performance Criteria}

The ANSI/HPS N13.1-1999 performance criteria for sampling nozzle placement and particle transport are described as follows.

1. Uniform Air Velocity - It is important that the gas momentum across the stack cross-section where the sample is extracted be well mixed or uniform. Consequently, the velocity is measured at several points in the stack at the elevation of the sampling nozzle. The uniformity is expressed as the variability of the measurements about the mean. This is expressed using the relative coefficient of variance (COV), which is the standard deviation divided by the mean and expressed as a percentage. The lower the coefficients of variation value, the more uniform the velocity. The acceptance criterion is that the coefficient of variation of the air velocity must be $\leq 20 \%$ across the center two-thirds of the area of the stack.

2. Angular Flow - Sampling nozzles are usually aligned with the axis of the stack. If the air travels up the stack in cyclonic fashion, the air velocity vector approaching the nozzle could be misaligned with the sampling nozzles enough to impair the extraction of particles. Consequently, the flow angle is measured in the stack at the elevation of the sampling nozzle. The average airvelocity angle must not deviate from the axis of the stack and sampling nozzle by more than $20^{\circ}$.

3. Uniform Concentration of Tracer Gases - A uniform contaminant concentration in the sampling plane enables the extraction of samples that represent the true concentration. This is first tested using a tracer gas. The fan is a good mixer, so injecting the tracer downstream of the fan provides worst-case results ${ }^{4}$. The acceptance criteria are that 1 ) the coefficient of variation of the measured tracer gas concentration is $\leq 20 \%$ across the center two-thirds of the sampling plane and 2 ) at no point in the sampling plane does the concentration vary from the mean by $>30 \%$.

4. Uniform Concentration of Tracer Particles - Uniformity in contaminant concentration at the sampling elevation is further demonstrated using tracer particles large enough to exhibit inertial effects. Particles of 10- $\mu \mathrm{m}$ aerodynamic diameter (AD) are used by default unless it is known that larger particles are present in the air stream. The acceptance criterion is that the coefficient of variation of particle concentration is $\leq 20 \%$ across the center two-thirds of the sampling plane.

5. Sample Extraction and Transport System Performance - The criteria are that 1) nozzle transmission ratio for a $10-\mu \mathrm{m} A D$ particle is 0.8 to $1.3,2$ ) nozzle aspiration ratio for a $10-\mu \mathrm{m} A D$ particle is 0.8 to 1.5 , and 3 ) the test particle penetration through transport system is $\geq 50 \%$ for 10 $\mu \mathrm{m}$ AD particles.

Because a scale model was used to qualify the stack-sampling location, the following additional criteria from ANSI/HPS N13.1-1999 apply.

\footnotetext{
${ }^{3}$ Worst-case results are those that might be observed if the fan itself became contaminated and later released contaminants.
} 
1. The model is geometrically similar to the actual stack.

2. The model meets all of the qualification requirements.

3. The actual sampling location is geometrically similar to the model.

4. The product of mean velocity times the hydraulic diameter for the actual stack and the scale model is within a factor of 6 .

5. The velocity uniformity of the actual stack meets the qualification requirements.

6. The difference between the actual and model stack velocity coefficients of variation is not more than $5 \%$.

Measurements of velocity uniformity at the actual stack are compared with those from the model to validate the applicability of the model.

Appendix A presents the scaling parameters and performance requirements of the scale model, while Appendix B presents the performance data that supports the model's use. The scale model was approximately 23-feet long and 5-feet wide (i.e., constructed of plywood). The model's 24-inch stack was 9-feet tall and constructed of 24-inch polyvinyl chloride (PVC) duct. All joints were caulked and painted to provide a smooth inside surface. Four 5-horsepower fans were utilized in two configurations for the stack airflow tests. The fans were controlled with a variable speed drive to produce the scaled stack air velocities. The two tracers (gas and particle) were injected in the fan discharge and collected at the stack probe.

In the actual fan house, there are seven electric fans, four of which are used at a time. There are also two steam driven fans for emergency backup that would be used at the same time. The capacities of the electric fans are about $66,000 \mathrm{cfm}$ each. The capacity of the steam-driven fans is about 96,000 $\mathrm{cfm}$ each. The fans are located alongside both sides of a central plenum, from which they draw air. In turn, the central plenum draws from 234-5Z. The fans draw from the central plenum and discharge down into ducts on both sides of the central plenum. These side ducts join and discharge into the stack. Table 2.1 is a representation of the fan positions. The turbine fans are denoted as ET 8 and ET9. The electric fans are denoted as EF1 through EF7.

When the electric fans are used, which is by far most of the time, the operating fans are typically EF1; one of EF3 or EF4; and EF6 and EF1 or EF5 and EF2 for a total of four at a time. The steam-driven fans are usually only run 15 to 30 min per month for testing. The housings of fans EF1 and EF5 have been found to more contaminated than the others. Also, EF4 and EF3 have modulating dampers for control of negative pressure in 234-5Z. 
Table 2.1. Fan Schematic

\begin{tabular}{|c|c|c|c|c|}
\hline \multicolumn{5}{|c|}{ To Stack } \\
\hline \multirow{5}{*}{$\begin{array}{l}\text { Side } \\
\text { Duct } \\
\text { East }\end{array}$} & ET8 & \multirow{5}{*}{$\begin{array}{l}\text { Central } \\
\text { Plenum } \\
\text { (Air from } \\
\text { 234-5Z) }\end{array}$} & ET9 & \multirow{5}{*}{$\begin{array}{l}\text { Side } \\
\text { Duct } \\
\text { West }\end{array}$} \\
\hline & & & EF4 & \\
\hline & EF7 & & EF3 & \\
\hline & EF6 & & EF2 & \\
\hline & EF5 & & EF1 & \\
\hline
\end{tabular}

Table 2.2 and Table 2.3 schematically show the two fan configurations tested, with the fans operating as indicated by highlighted backgrounds. Table 2.2 is the emergency backup operating condition, while Table 2.3 is the worst case of normal operation conditions because EF4 is the fan closest to the stack.

Table 2.2. Fan Configuration for Emergency Backup Operating Condition

\begin{tabular}{|c|c|c|c|c|}
\hline \multicolumn{5}{|c|}{ To Stack } \\
\hline \multirow{5}{*}{$\begin{array}{l}\text { Side } \\
\text { Duct } \\
\text { East }\end{array}$} & ET8 & \multirow{5}{*}{$\begin{array}{l}\text { Central } \\
\text { Plenum } \\
\text { (Air from } \\
\text { 234-5Z) }\end{array}$} & ET9 & \multirow{5}{*}{$\begin{array}{l}\text { Side } \\
\text { Duct } \\
\text { West }\end{array}$} \\
\hline & & & EF4 & \\
\hline & EF7 & & EF3 & \\
\hline & EF6 & & EF2 & \\
\hline & EF5 & & EF1 & \\
\hline
\end{tabular}

Table 2.3. Fan Configuration for Normal Operating Conditions

\begin{tabular}{|c|c|c|c|c|}
\hline \multicolumn{5}{|c|}{ To Stack } \\
\hline \multirow{5}{*}{$\begin{array}{l}\text { Side } \\
\text { Duct } \\
\text { East }\end{array}$} & ET8 & \multirow{5}{*}{$\begin{array}{l}\text { Central } \\
\text { Plenum } \\
\text { (Air from } \\
\text { 234-5Z) }\end{array}$} & ET9 & \multirow{5}{*}{$\begin{array}{l}\text { Side } \\
\text { Duct } \\
\text { West }\end{array}$} \\
\hline & & & EF4 & \\
\hline & EF7 & & EF3 & \\
\hline & EF6 & & EF2 & \\
\hline & EF5 & & EF1 & \\
\hline
\end{tabular}

\subsection{Uniformity of Air Velocity}

The uniformity of air velocity in the stack cross section where the air sample is being extracted ensures that the air momentum in the stack is well mixed. The method used to demonstrate air velocity uniformity and the results obtained are detailed in the following sections. 


\subsubsection{Method}

To facilitate the performance of this and subsequent tests, it was first necessary to correlate fan speed control (a variable frequency drive) settings and the desired stack flowrates. Following the procedure in Appendix C, the first velocity uniformity measurement (Run VT-1) was made at the maximum set point to identify a single measurement point that best represented the average velocity. The air velocity was then measured at that point as a function of fan control setting. The results are plotted in Appendix D. Set points for the desired flowrates were estimated from the plot and used in the test runs (Runs VT-2 to VT-4) to measure velocity uniformity. Run VT-1 also provided a data point for velocity uniformity.

The method to determine velocity uniformity is an adaptation of 40 CFR 60, Appendix D, Methods 1 and 2. The equipment included a standard Prandtl-type pitot tube and a calibrated electronic manometer as shown in Figure 2.1. The procedure is detailed in Appendix E. The grid of measurement points was laid out in accordance with the EPA procedure for eight points on each of two linear traverses, arranged perpendicular to each other. The center point was added for additional information over what is otherwise a long distance between points 4 and 5. Thus, there were 9 points along the north-east/south-west direction and also along the south-east/north-west direction.

To verify the applicability of the scale model results, air velocity data was obtained on the actual stack by plant forces. Only one test port was available on the stack, limiting the data obtained to that single direction across the stack. These data were otherwise obtained in accordance with the EPA methods. Data was also obtained from 1976 and 1977 measurements (Glissmeyer, 1992) taken with a thermal anemometer and not in accordance with EPA methods. These data are compared in the following section (PNL 1992).

\subsubsection{Results of scale model tests}

The acceptance criterion for uniformity of air velocity is:

1) coefficient of variation of the air velocity must be $\leq 20 \%$ across the center two-thirds of the area of the stack.

The measured coefficients of variation across the center two-thirds of the area of the scale model stack are listed in Table 2.4. The data sheets are included in Appendix F. All of the scale model test results for velocity uniformity meet the criterion that the air velocity coefficient of variation be $\leq 20 \%$. Figure 2.2 shows a bar graph of the mean velocity measured at each point for Run VT-4, one of the scale model results, which most closely correspond to the actual stack. 
Table 2.4 Velocity Uniformity Results

\begin{tabular}{|l|l|l|l|}
\hline Runs & $\begin{array}{l}\text { Fan Frequency } \\
\text { Setting, Hz }\end{array}$ & $\begin{array}{l}\text { Stack Flow rate } \\
\text { acfm }\end{array}$ & COV \\
\hline \multicolumn{3}{|c|}{ Four Electric Fan Configuration } \\
\hline VT-1 & 51 & 5973 & 7.5 \\
VT-2 & 30 & 3462 & 7.5 \\
VT-3 & 50 & 5868 & 7.2 \\
VT-4 & 50 & 5750 & 7.1 \\
\hline \multicolumn{4}{|c|}{ Two Turbine Fan Configuration } \\
\hline VT-5 & 60 & 4036 & 13.7 \\
VT-6 & 60 & 4031 & 12.4 \\
VT-7 30- & 60 & 4077 & 13.5 \\
degree port & & \\
\hline
\end{tabular}

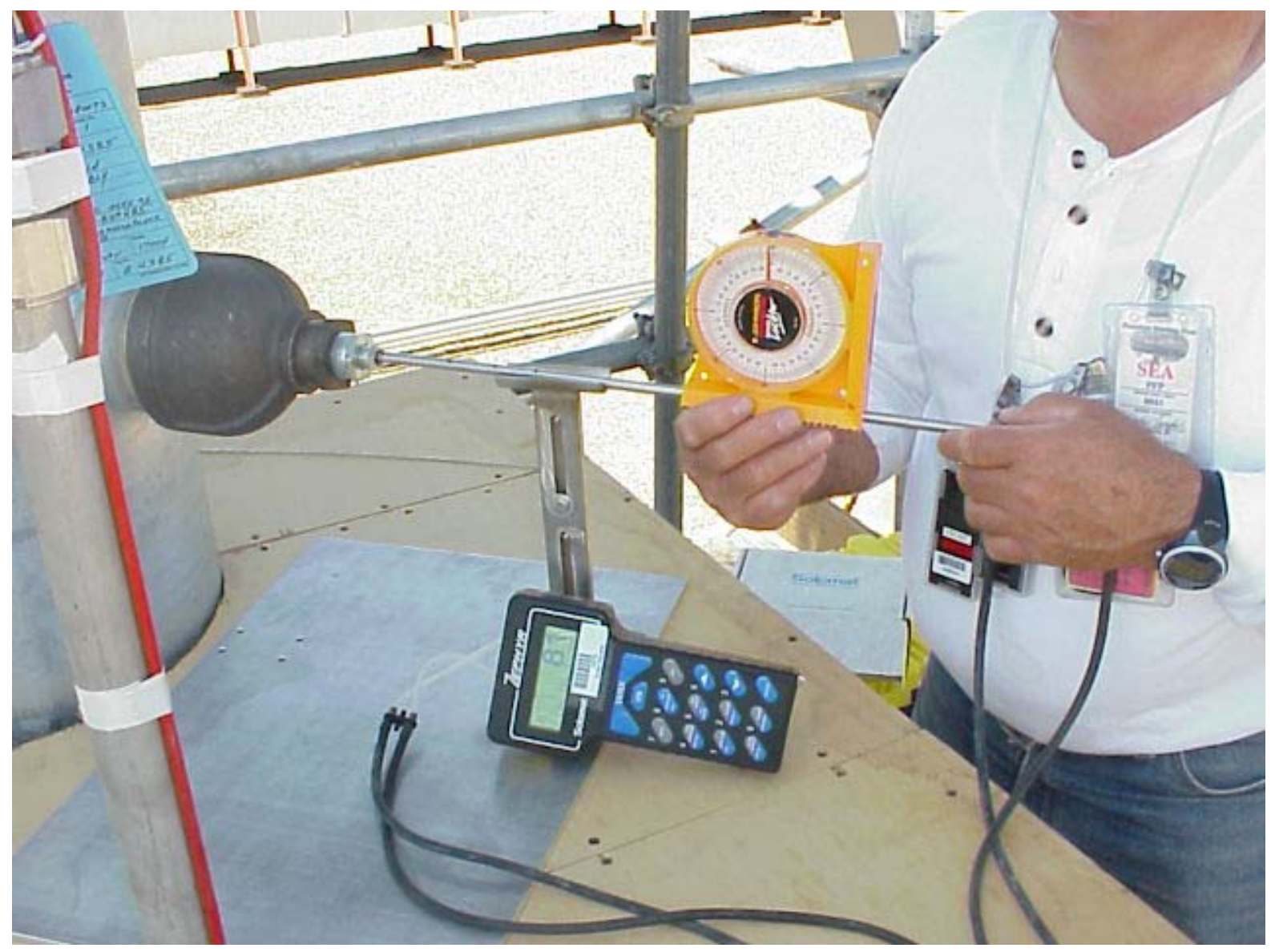

Figure 2.1. Velocity Uniformity Measuring Equipment 


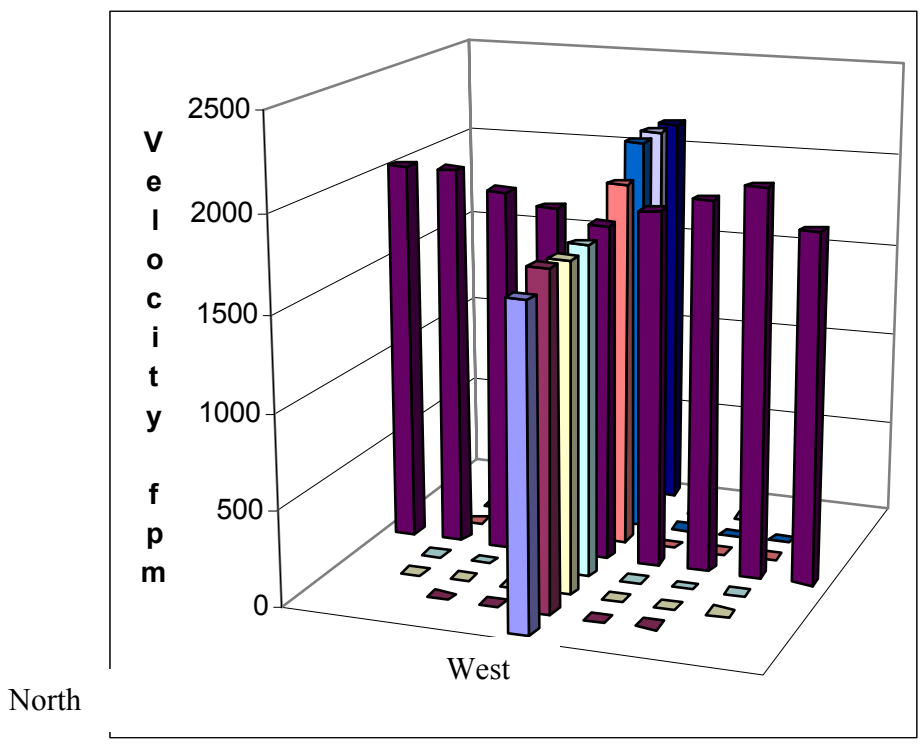

Figure 2.2. Bar graph of velocity measurements from Run VT-4

\subsubsection{Comparison of model and actual stack results}

Only the single port ( $30^{\circ}$ east of north) was available for measurements on the actual stack, and only four of the electric fans were operating. The velocity data from the recently obtained measurements (PNL 1992) and the scale model results are tabulated in Appendix F. The uniformity results for these data are listed in Table 2.5 for comparison. The upper portion of Table 2.5 show the velocity uniformity results from the scale model, using only the data from the electric fan configuration and for the single transect (the ports 15 degrees from North, except as noted). The recent measurements from the actual stack and the data from PNL (1992) are also listed in the lower portion of Table 2.5. The average of the data from the scale model was $9.4 \%$ coefficient of variation, and the acceptance range is then 4.4 to $14.4 \%$ coefficient of variation. The scale model and the actual stack data all fall within the acceptance range and met the criterion for the validity of the scale model tests.

\subsection{Angular Flow}

Angular flow testing assures an absence of cyclonic flow at the sampling location. That is, the airvelocity vector approaching the sample nozzle should be aligned with the axis of the nozzle within an acceptable angle so sample extraction performance is not degraded. Cyclonic flow must be absent so the contaminant concentration is nearly uniform across the stack. Testing was conducted on the scale model stack. 
Table 2.5. Velocity Uniformity Comparison of Scale Model and Stack Tests

\begin{tabular}{|l|l|}
\hline \multicolumn{2}{|c|}{$\begin{array}{c}\text { \% Coefficient of Variation Results for North/South } \\
\text { Direction }\end{array}$} \\
\hline 2001 Scale Model - Electric Fans \\
\hline VT 1 & 9.8 \\
\hline VT 2 & 9.6 \\
\hline VT 3 & 9.0 \\
\hline VT 4 & 9.3 \\
\hline Actual Stack - Electric Fans \\
\hline 1977 12-Point Method 1 Grid & 7.5 \\
\hline $\begin{array}{l}\text { 2001 8-Point Method 1 Grid } \\
\text { 30 degree port }\end{array}$ & 12.8 \\
\hline $\begin{array}{l}\text { 2001 16-Point Method 1 Grid } \\
\text { 30 degree port }\end{array}$ & 11.1 \\
\hline
\end{tabular}

\subsubsection{Method}

The test method used was based on 40 CFR 60, Appendix D, Method 1, Section 2.4, "Verification of the Absence of Cyclonic Flow." This test was conducted at the normal flow rate in the stack. Measurements were made using a type-S pitot tube, a slant tube or electronic manometer, and a protractor level attached to the pitot tube as shown in Figure 2.3. The flow angle was measured at the elevation of the sampling nozzle and at the same points as those used for the velocity uniformity test. The pitot tube was rotated until a null differential pressure reading was obtained, and the angle of rotation was then recorded. Appendix G provides the detailed procedure.

\subsubsection{Results}

The acceptance criteria for angular flow is:

1) an average flow-angle of $<20^{\circ}$ across the sampling plane.

Measurements were made at the same grid points as for the velocity uniformity, and for the grid rotated around the stack another $15^{\circ}$. The acceptance criterion ( $\leq 20$ degrees) was met in all cases. The results range from 1.8 to 3.9 degrees. Table 2.6 shows a summary of the angular flow testing results. Data sheets for angular flow are presented in Appendix $\mathrm{H}$.

\subsection{Uniformity of Tracer Gases}

A uniform gas contaminant concentration at the sampling plane enables the extraction of samples that represent the true gas concentration within the stack. Testing for uniformity of tracer gases at the sampling plane was conducted on the scale model stack. 
Table 2.6. Flow Angle Results

\begin{tabular}{|l|l|l|}
\hline Runs & $\begin{array}{l}\text { Fan } \\
\text { Frequency } \\
\text { Setting, Hz }\end{array}$ & Mean Flow Angle \\
\hline \multicolumn{3}{|c|}{ Four Electric Fan Configuration } \\
\hline FA-1 & 50 & 2 \\
\hline \multicolumn{3}{|c|}{ Two Turbine Fan Configuration } \\
\hline FA-2 & 60 & 1.8 \\
\hline $\begin{array}{l}\text { FA-3 30- } \\
\text { degree port }\end{array}$ & 60 & 3.9 \\
\hline
\end{tabular}

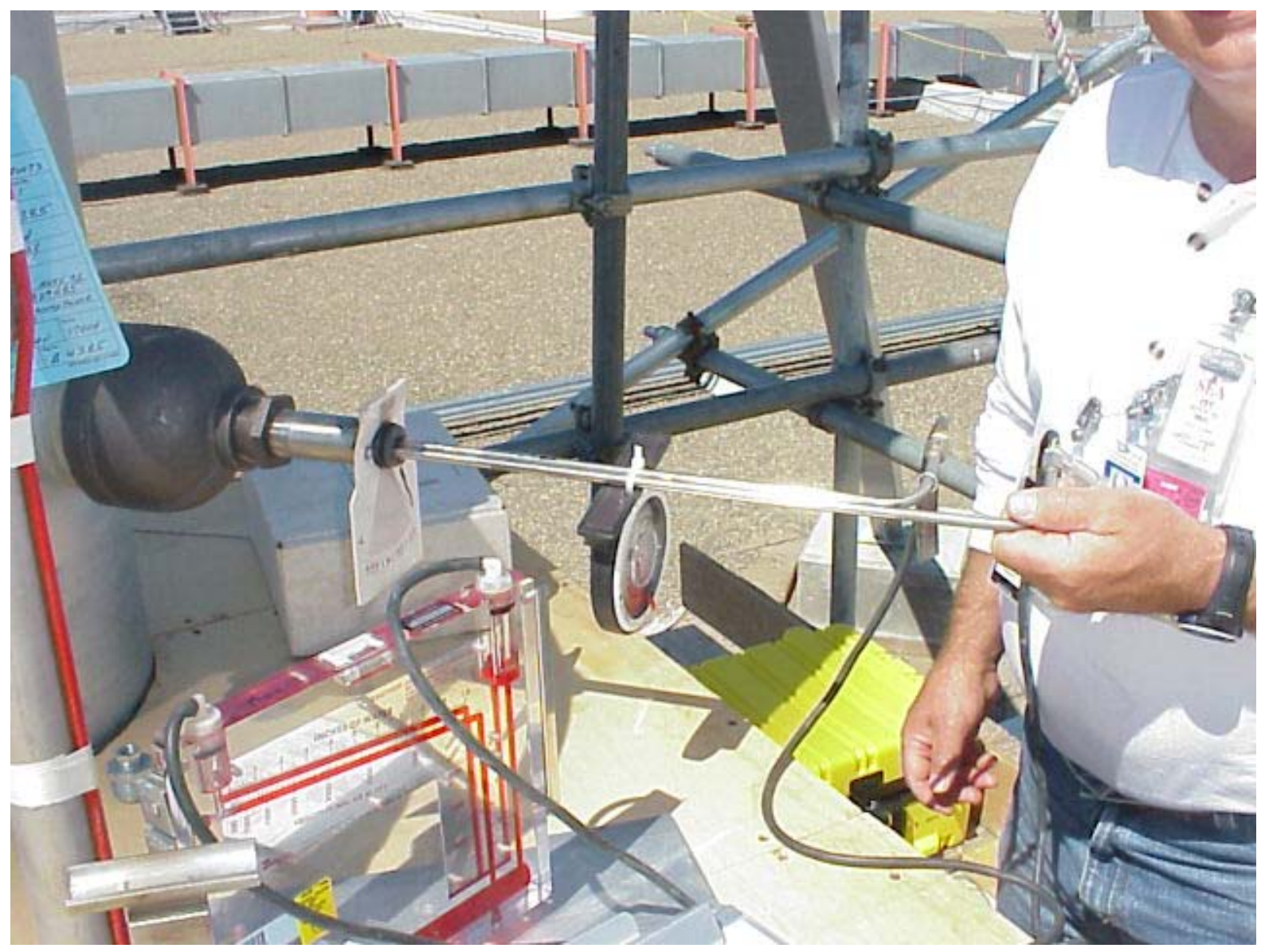

Figure 2.3. Type-S pitot tube and protractor level used to measure Angular Flow 


\subsubsection{Method}

The concentration uniformity is demonstrated with a tracer gas (sulfur hexafluoride) injected into the exhaust duct, downstream of the fan, between the dampers and the stack as shown if Figure 2.4. The concentration of the tracer gas is then measured near the sampling probe using the same grid of points as used in the other tests. From the measurements, the coefficient of variation and maximum deviation from the mean are calculated as measures of uniformity.

The gas samples are withdrawn from the stack through a simple probe and a gas analyzer shown in Figure 2.5. A Bruel and Kjaer (Naerum, Denmark) Model 1302 gas analyzer, calibrated for the tracer gas, is used for the measurements. The procedure data sheets are detailed in Appendix I and Appendix J, respectively.

\subsubsection{Results}

The acceptance criteria for uniformity of tracer gases are:

1) the coefficient of variation of the tracer gas concentration be $\leq 20 \%$ across the center twothirds of the sampling plane

2) the average concentration, for each measurement point, differ from the mean concentration by $>30 \%$.

Table 2.7 lists the tests performed and their results. In the electric fan configuration, detailed tests were performed with the tracer injected at the outlets of Fans EF4 (assumed to be the worst case) and EF7 (assumed to be the next worst case). Five injection points were used in each case - centerline or the indicated corners. Corner injections were made within 1.5 inches ( $25 \%$ of a hydraulic diameter) of the corners of the duct from the fan to the plenum (see Figure 2.4). Tests were also made with centerline injections at the other two fans. Uniformity results ranged from 0.7 to $4.0 \%$ coefficient of variation. The maximum deviations from the means ranged from 1.6 to $5.3 \%$.

In the turbine fan configuration, it was assumed that the two fans were symmetrically discharging to the stack. Multiple injection positions were used for Fan ET9 and just the centerline position was used for Fan ET8. As expected, the uniformity results and maximum deviations were somewhat higher for this configuration than for the electric fan configuration. This was because these fans are the closest to the stack base. The results when the measurement ports were rotated $15^{\circ}$ farther around the stack were comparable to those for the ports $15^{\circ}$ from North.

In all cases, the acceptance criteria were met. This was surprising given that the sampling point was only 3.3 stack diameters above the base of the stack and that the airflow from both sides of the fan house joins just upstream of the stack base. It is speculated that this junction of the two streams is turbulent enough to provide good mixing, even when the tracer is injected on one side of the fan house. 


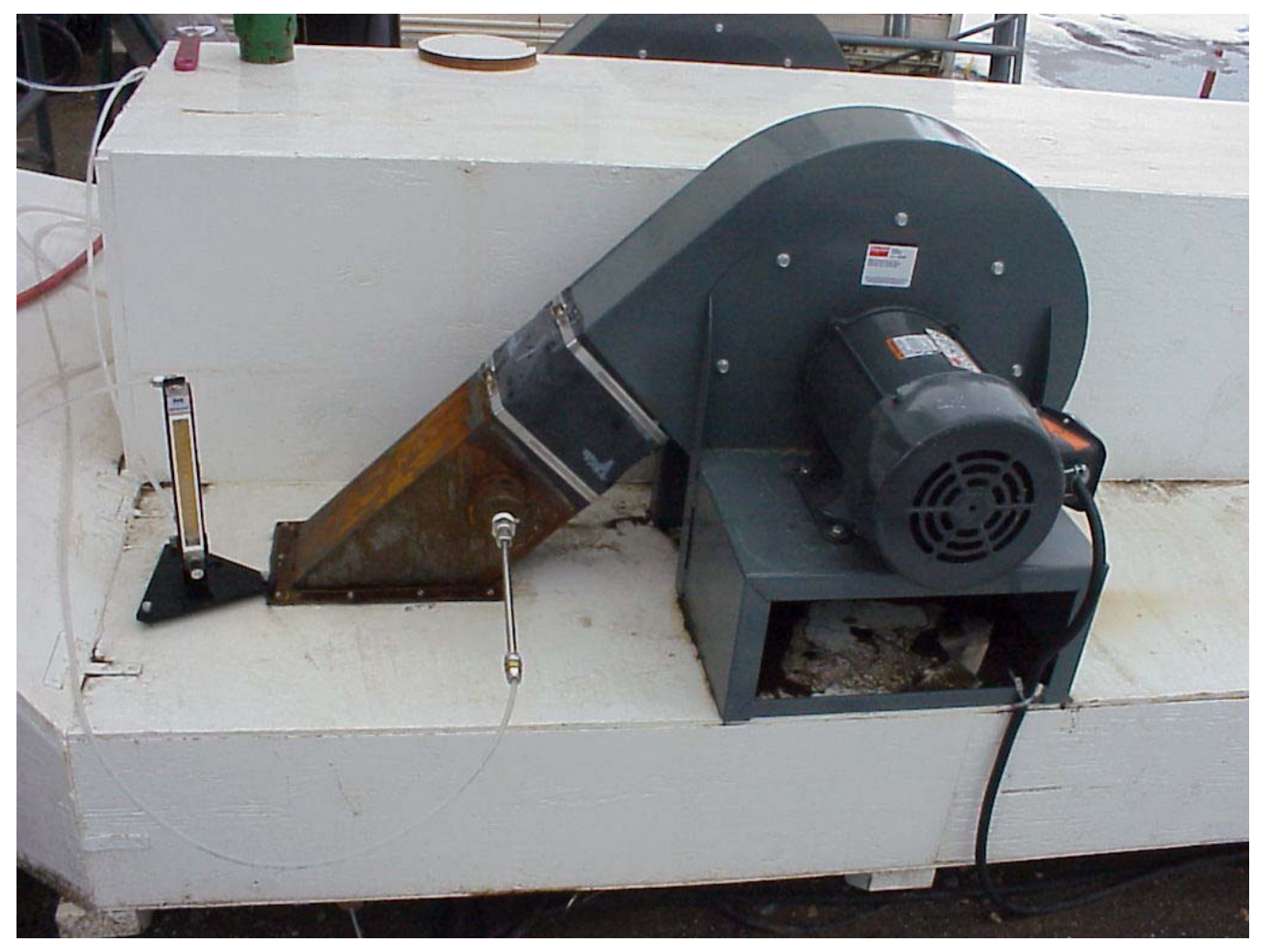

Figure 2.4 Tracer Gas Injection Location

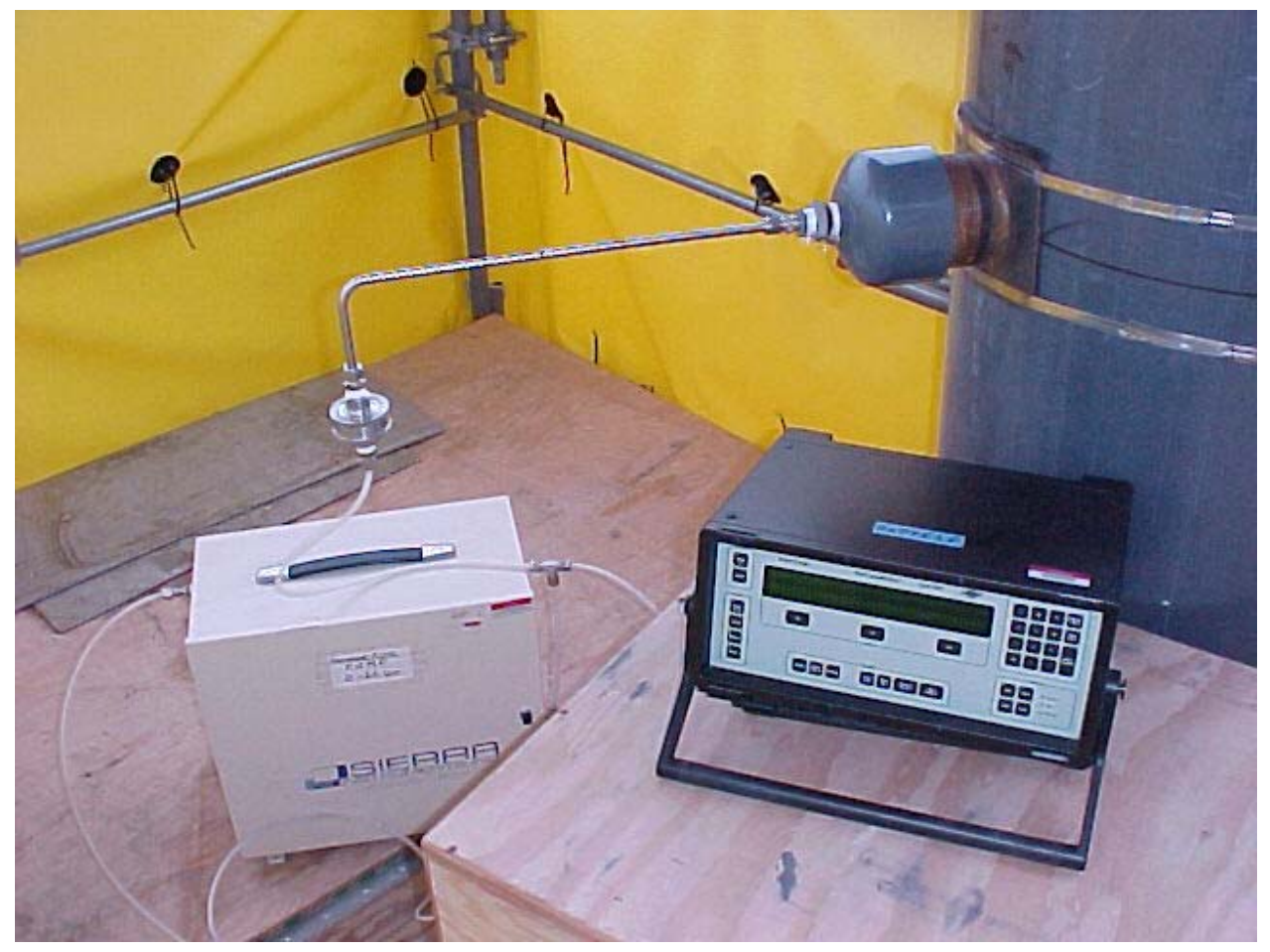

Figure 2.5 Tracer Gas Probe and Analyzer 
Table 2.7. Summarization of Gas Tracer Uniformity Results

Four Electric Fan Configuration

\begin{tabular}{|l|l|c|r|}
\hline Run & Injection Point & \% COV & Max \% Dev \\
\hline & Fan EF4 & & \\
GT-1 & Center & 0.8 & -1.9 \\
GT-2 & Top-west & 1.9 & 4.2 \\
GT-3 & Top-east & 1.8 & -2.9 \\
GT-4 & Bottom-west & 1.7 & 3.9 \\
GT-5\&13 & Bottom East & $4.0,0.8$ & $-5.3,2.2$ \\
\hline & Fan EF7 & & \\
GT-6 & Center & 0.7 & 1.6 \\
GT-7 & Top-west & 1.2 & -3.3 \\
GT-8 & Top-east & 0.7 & -1.4 \\
GT-9 & Bottom-west & 1.5 & 2.7 \\
GT-10 & Bottom-east & 1.3 & 2.9 \\
\hline GT-11 & EF5 Center & 1.0 & 2.4 \\
\hline GT-12 & EF1 Center & 1.0 & 1.8 \\
\hline
\end{tabular}

Two Turbine Fan Configuration

\begin{tabular}{|c|c|c|c|}
\hline Run & Injection Point & $\% \mathrm{COV}$ & Max \% Dev \\
\hline & Fan ET9 & & \\
\hline GT-14 & Center & 5.0 & 9.0 \\
\hline GT-15 & West side & 4.4 & -8.9 \\
\hline GT-16 & East side & 3.6 & 7.5 \\
\hline GT-17 & Bottom-east & 4.3 & 8.3 \\
\hline GT-18 & Bottom-west & 4.6 & -9.3 \\
\hline GT-19 & Top-west & 4.3 & 9.9 \\
\hline GT-20 & Top-east & 4.1 & 8.1 \\
\hline & $\begin{array}{l}\text { Fan ET8 } \\
\text { Centerline }\end{array}$ & & \\
\hline GT-21, & 15 degree port & $4.6,4.0$ & $-8.2,8.0$ \\
\hline $\begin{array}{l}22 \\
\text { GT-23 }\end{array}$ & 30 degree port & 3.7 & 7.1 \\
\hline
\end{tabular}




\subsection{Uniformity of Tracer Particles}

A uniform particulate contaminant concentration at the sampling plane enables the extraction of samples that represent the true particulate concentration within the stack. Testing for uniformity of tracer particles at the sampling plane was conducted on the scale model stack.

\subsubsection{Method}

The test method for uniformity of tracer particles is similar to the test for uniformity of tracer gases, with the tracer gas replaced by tracer particles. However, only the centerline injection position is required. The concentration of the tracer particles, in the size range of interest, was measured at the same test points used in the other tests. Spraying vacuum-pump oil through a nozzle mounted inside a chamber produced the particles measured by the testing. These particles were then injected into the duct entrained in a stream of compressed air as shown in Figure 2.6.

A simple probe was used to extract the sample from the stack and transport it to the optical particle counter ${ }^{5}$ arranged as shown in Figure 2.7. The optical particle counter sorts the number of particles into six size channels. Only the reading from the size channel that measures particles in the 9 to 11 um size range are used for statistical calculations. Each data point consists of the number of particles counted during a one-minute sampling period. Three readings were taken at each point and averaged. The coefficient of variation of the average concentration readings at each point is calculated and the result compared to the acceptance criterion for uniformity. The detailed procedure and data sheets are included in Appendix K and Appendix L, respectively.

\footnotetext{
${ }^{5}$ Optical Particle Counter (OPC), Met-One Model A2408, Grants Pass, Oregon.
} 


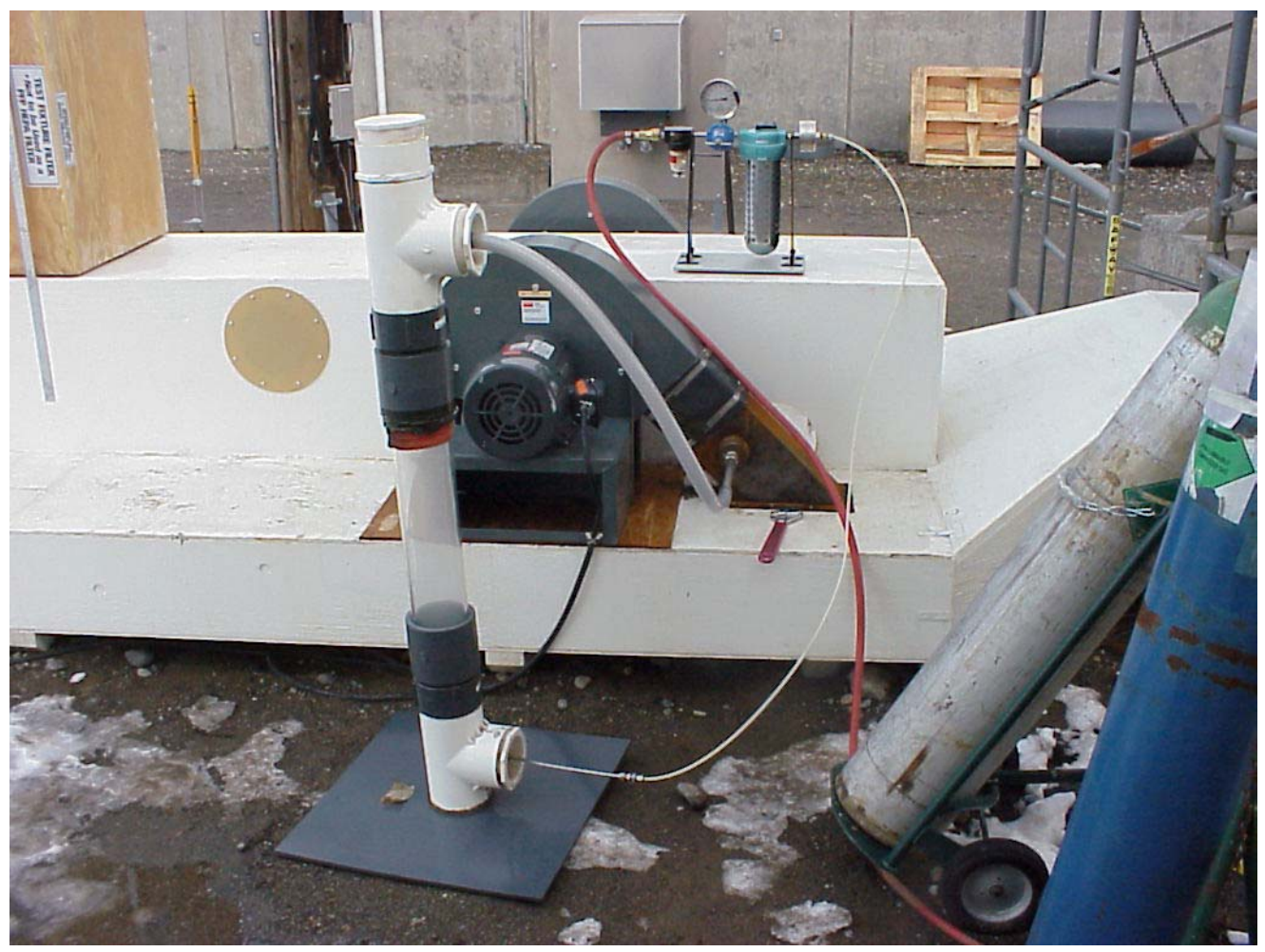

Figure 2.6. Particle Generator and Injection Point

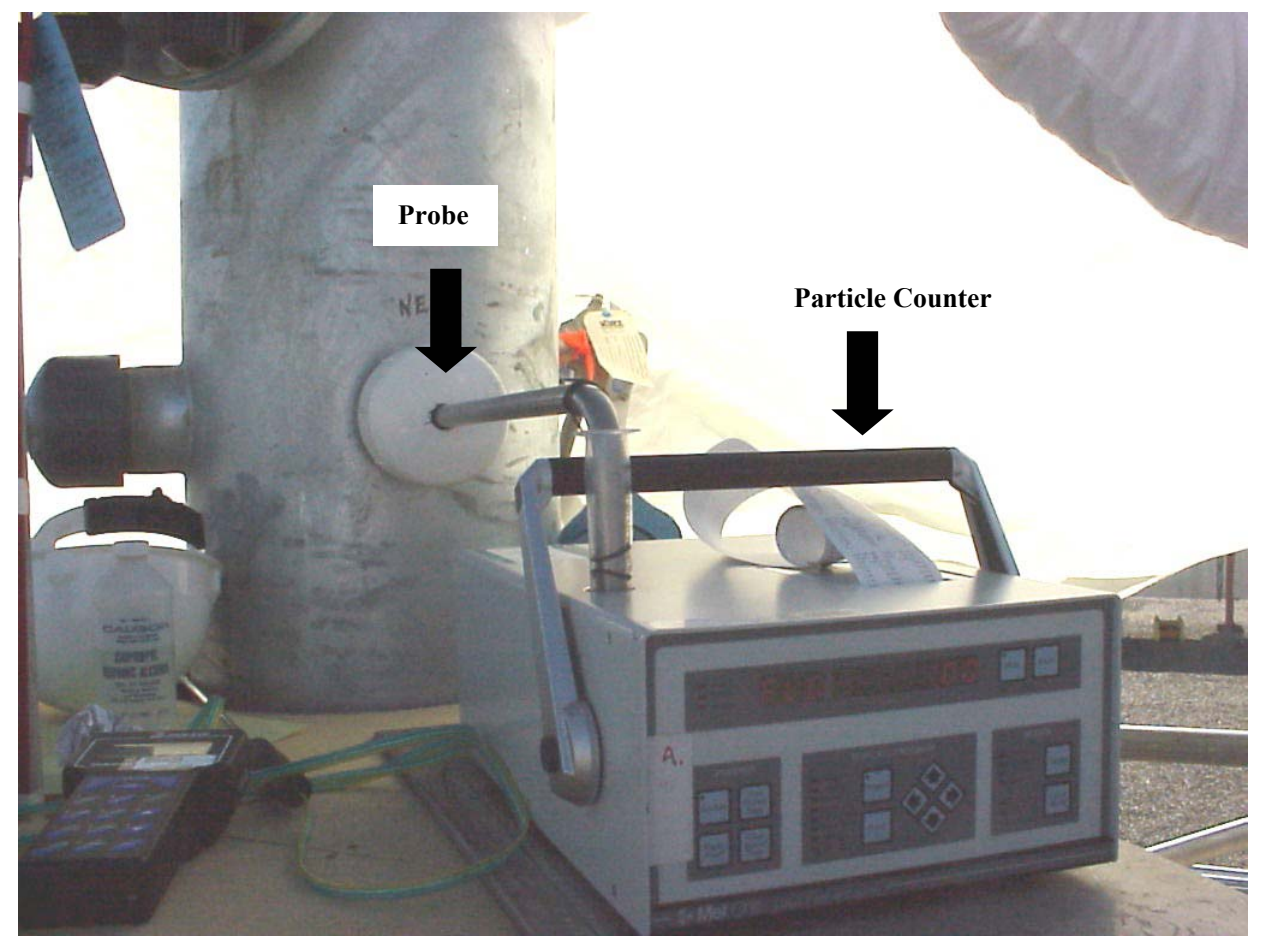

Figure 2.7. Optical Particle Counter and Probe Arrangement for a Particle Uniformity Test 


\subsubsection{Results}

The acceptance criteria for uniformity of tracer particle is:

1) a coefficient of variation less than $20 \%$, for the tracer particles of the $10-\mu \mathrm{m}$ ranges, across the center two-thirds of the sampling plane.

Tests were conducted for both fan configurations. The results are summarized in Table 2.8 and the data sheets are included in Appendix L. The results show slightly more uniformity for the electric fan configuration than for the turbine fan configuration. However, in all cases, the performance criterion was easily met. Figure 2.8 is a bar chart showing the normalized concentration data for the first test at $1733 \mathrm{acfm}$.

The coefficients of variation results labeled "raw" are without any normalization with time. The results after normalization also are shown. The normalization method adjusts all of the concentration readings by the same amount so that the center point readings taken from the two traverse directions were equalized. The effect of normalization would be more pronounced in cases where there was a shift in concentration with time.

Table 2.8. Particle Tracer Uniformity Results for the Center Two-Thirds of the Stack

\begin{tabular}{|l|l|c|c|}
\hline Runs & Injection Point & $\begin{array}{c}\text { Un-normalized } \\
\% \text { COV }\end{array}$ & $\begin{array}{c}\text { Normalized \% } \\
\text { COV }\end{array}$ \\
\hline \multicolumn{3}{|c|}{ Four Electric Fan Configuration } \\
\hline PT-1 & EF-4 Center & 5.8 & 3.0 \\
PT-2 & EF-7 Center & 9.1 & 3.1 \\
PT-3 & EF-7 Center & 8.1 & 2.6 \\
PT-4 & EF-7 Center & 11.7 & 2.9 \\
\hline \multicolumn{3}{|c|}{ Two Turbine Fan Configuration } \\
\hline PT-5 & ET-8 Center & 7.5 & 5.6 \\
PT-6 & ET-9 Center & 6.7 & 5.6 \\
PT-7 & ET-8 Center & 10.3 & 4.6 \\
PT-8 & ET-9 Center-30 & 5.8 & 5.8 \\
& degree port & \\
\hline
\end{tabular}

\subsection{Sample Extraction and Transport System Performance}

The acceptance criteria for sample extraction and transport system performance are:

1) nozzle transmission ratio for a $10 \mu \mathrm{m} \mathrm{AD}$ particle is 0.8 to 1.3

2) nozzle aspiration ratio for a $10 \mu \mathrm{m} \mathrm{AD} \mathrm{particle} \mathrm{is} 0.8$ to 1.5

3) the test particle penetration through transport system is $\geq 50 \%$ for $10 \mu \mathrm{m} \mathrm{AD} \mathrm{particles.}$

The nozzle characteristics are inherent in the design and were verified in wind-tunnel tests (McFarland et al. 1989; Glissmeyer and Ligotke 1995) and in the manufacturer's submittals. 
Particle penetration through the sampling lines was assessed using the DEPOSITION 2001a code (McFarland, et. al., 2002). The sample transport elements modeled in the code include sampling nozzles, straight tubes at any angle to the horizontal plane, bends, splitters, and expansions and contractions in tube size. The nozzle design factors are addressed in DEPOSITION; however, the results are combined into the overall transmission result for the nozzle and not stated separately.

Figure 2.8 is a DEPOSITION 2001a rendered diagram of the segments of the sampler tubing. The DEPOSITION input parameters and characteristics of the sampling system elements are listed in Table 2.9. Total penetration results were calculated assuming a constant sample flow rate $(2 \mathrm{cfm}$ per branch of the splitter) and a stack velocity of 5 and $9.2 \mathrm{~m} / \mathrm{s}$ (992 and $1811 \mathrm{fpm})$. This range of stack velocity should cover the range of conditions using either the electric or turbine fans. The total penetration results at $9.2 \mathrm{~m} / \mathrm{s}$ were $86.2 \%$ and $84.3 \%$ for the left and right branches of the splitter outlet. The results at $5 \mathrm{~m} / \mathrm{s}$ were $80.7 \%$ and $78.8 \%$ for the left and right branches respectively. These exceed the acceptance criterion. Figures 2.9 and 2.10 show the detailed output of the code for the two stack air velocities.

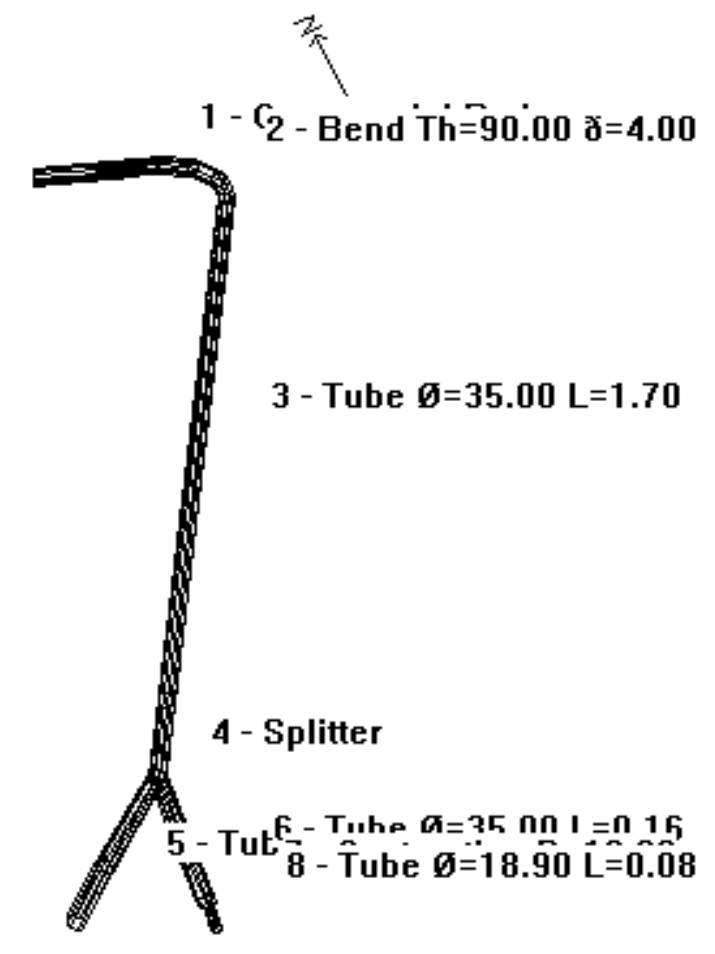

Figure 2.8. Diagram of the Sampling System Tubing Elements (view distorted to show all) parts) 
Table 2.9. DEPOSITION 2001a Input Parameters

\begin{tabular}{|c|c|c|}
\hline Element \# & Element & Notes \\
\hline 1. & Probe & $\begin{array}{l}\text { Probe diameter: } 18.3 \mathrm{~mm} \text {, Shroud } \\
\text { diameter: } 53.8 \mathrm{~mm} \text {, Velocity reduction } \\
\text { ratio } 3.31\end{array}$ \\
\hline 2. & Bend & Bend angle: $90.000^{\circ}$ \\
\hline 3. & Tube & $\begin{array}{l}\text { Length: } 1.700 \mathrm{~m} \text {, At } 0.000 \text { degrees } \\
\text { from horizontal }\end{array}$ \\
\hline 4. & Splitter & $30^{\circ}$ angle, Outlet Diameter: $24 \mathrm{~mm}$ \\
\hline \multicolumn{3}{|r|}{ Right Branch } \\
\hline 5. & Tube & $\begin{array}{l}\text { Length: } 0.160 \mathrm{~m} \text {, At } 0.000 \text { degrees } \\
\text { from horizontal }\end{array}$ \\
\hline 6. & $\begin{array}{l}\text { Contracti } \\
\text { on }\end{array}$ & $\begin{array}{l}\text { Half angle of contraction: } 45.000 \\
\text { degrees, Area ratio: } 0.292 \text {, Outlet } \\
\text { Diameter: } 18.9 \mathrm{~mm}\end{array}$ \\
\hline 7. & Tube & $\begin{array}{l}\text { Length: } 0.083 \mathrm{~m} \text {, At } 0.000 \text { degrees } \\
\text { from horizontal }\end{array}$ \\
\hline \multicolumn{3}{|r|}{ Left Branch } \\
\hline 8. & Tube & Length: $0.186 \mathrm{~m}$ \\
\hline \multicolumn{3}{|c|}{ Ambient temperature (deg. C): 25.0} \\
\hline \multicolumn{3}{|c|}{ Ambient pressure $(\mathrm{mm} \mathrm{Hg}): 760$} \\
\hline \multicolumn{3}{|c|}{ Flow rate $(\mathrm{L} / \mathrm{min}): 113.2$} \\
\hline \multicolumn{3}{|c|}{ Free stream velocity $(\mathrm{m} / \mathrm{s}): 5-9.2$} \\
\hline \multicolumn{3}{|c|}{ Particle diameter $(\mu \mathrm{m}): 10.0$} \\
\hline
\end{tabular}




\begin{tabular}{|c|c|c|c|}
\hline Total & Ienetration: & 36.25 & \\
\hline \# & Cowponent & & Fenetration \\
\hline 1 & comwercial & 1 Inobe & 98.85 \\
\hline 2 & Bend & & 98.55 \\
\hline .9 & Tube & & 90.98 \\
\hline 4 & splitter & & 90.45 \\
\hline 5 & Twbe & & 99.08 \\
\hline Stores & s Mumber: & 0.0168 & \\
\hline Remol & lds ruwber: & 4380 & \\
\hline
\end{tabular}

MOTES:

1. Denetration is only ralid for the flow rate of 114.

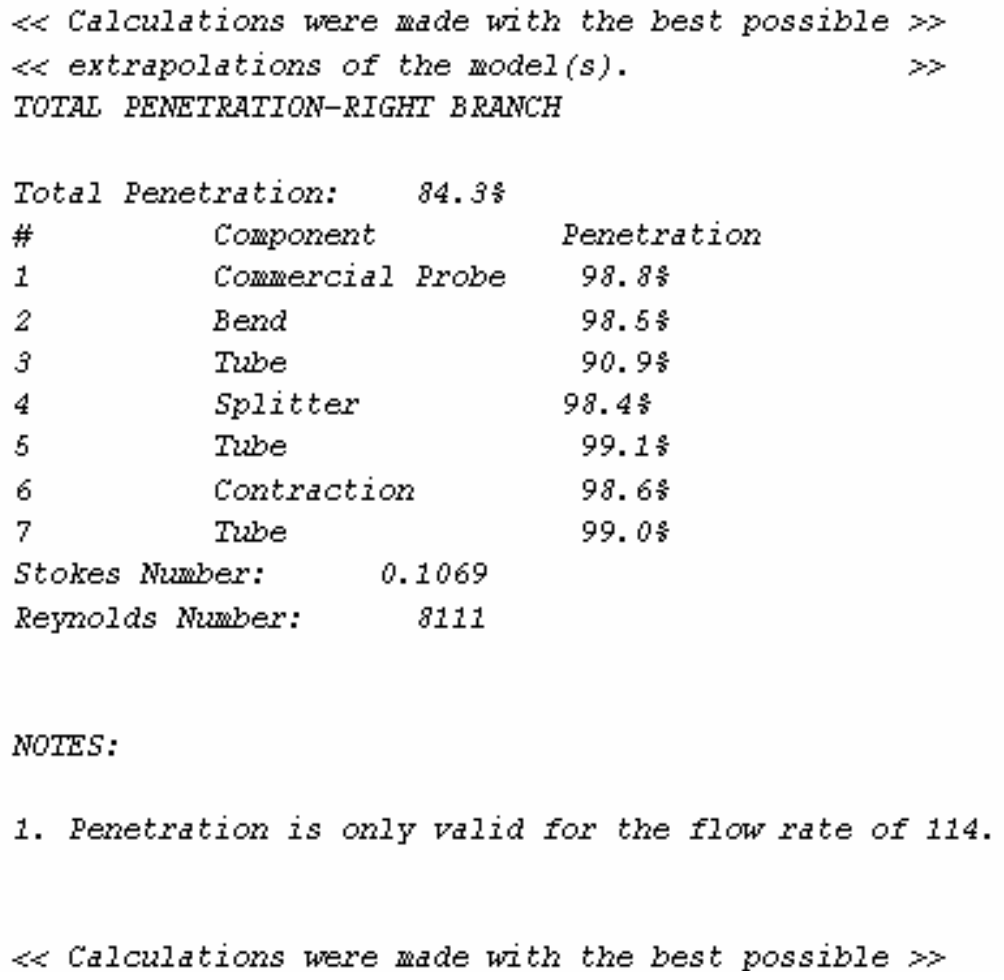

MOTES:

1. Penetration is only ralid for the flow rate of 114.

$\propto$ Calculations were made with the best possible $\gamma$

Figure 2.9 DEPOSITION 2001a results for $9.2 \mathrm{~m} / \mathrm{s}$ 
TOTAT PEMETRATION-LEFT BRANCH

Total Penetration: $\quad 80.78$

\# component Penetration

1 Comwercial Frobe $92.5 \%$

$2 \quad$ Bend $98.5 \%$

9 Tube 90.95

$4 \quad$ Splitter 98.48

5 Tube 99.09

Stokes muber: $\quad 0.0168$

Remolds nuwber: 4380

MOTES:

1. Penetration is only valid for the flow rate of 114 .

$<$ calculations were made with the best possible $\gamma$ \& extrapolations of the model $(s)$. TOTAT DEMETRATION-RIGHT BRANCH

Total Penetration: 78.89

\# component Fenetration

1 Commercial Probe $92.5 \%$

2 Bend $90.5 \%$

3 Tube $90.9 \%$

$4 \quad$ Splitter 98.49

5 Tube $99.1 \%$

6 Contraction 98.69

$7 \quad$ Tube $99.0 \mathrm{~s}$

Stokes Muber: $\quad 0.1069$

Remolds humber: $\quad 0111$

MOTES:

1. Penetration is only valid for the flow rate of 114.

colculations were wade with the best possible

Figure 2.10 Deposition 2001a results for $5 \mathrm{~m} / \mathrm{s}$ 


\subsection{Conclusions}

The tests conducted for the replacement air sampling probe for the 291-Z-1 stack demonstrated that the location for the air-sampling probe meets all performance criteria for air sampling systems at nuclear facilities. The tests on the scale model were shown to apply to the actual stack as indicated by the comparison of velocity uniformity results. Table 3.1 summarizes the conclusions for these tests.

With regard to the last row in the table, the compliance of the sampling nozzle with certain detailed acceptance criteria were not separately tested in connection with this installation. These two acceptance criteria for nozzles are that the transmission be in the 0.8 to 1.3 range and that the aspiration ratio be in the 0.8 to 1.5 range for $10-\mu \mathrm{m}$-AD particles. The nozzle characteristics are inherent in the design and were verified previously in wind tunnel tests (McFarland et al. 1989; Glissmeyer and Ligotke 1995) and in the manufacturer's submittals. These factors are addressed in the modeling done with DEPOSITION 2001a; however, the results are combined into the overall transmission result for the nozzle and not stated separately. This study concludes that these criteria are met.

Table 3.1. Conclusions on Air Sampling System Tests

\begin{tabular}{|c|c|c|c|c|}
\hline Test & Runs/Configuration & Results & Criteria & Meets \\
\hline \multirow{2}{*}{$\begin{array}{l}\text { Flow angle on } \\
\text { model stack }\end{array}$} & $1 \mathrm{w} /$ electric fan & $2^{\circ}$ & \multirow[t]{2}{*}{$<20^{\circ}$} & Yes \\
\hline & $2 \mathrm{w} /$ turbine fan & $1.8^{\circ}$ and $3.9^{\circ}$ & & Yes \\
\hline \multirow{2}{*}{$\begin{array}{l}\text { Velocity uni- } \\
\text { formity on model } \\
\text { stack }\end{array}$} & 4 w/electric fan & $7.1,7.2,7.5,7.5 \% \mathrm{COV}$ & \multirow[t]{2}{*}{$\mathrm{COV} \leq 20 \%$} & Yes \\
\hline & $3 \mathrm{w} /$ turbine fan & $13.7,12.4,13.5 \% \mathrm{COV}$ & & Yes \\
\hline \multirow{2}{*}{$\begin{array}{l}\text { Velocity uni- } \\
\text { formity } \\
\text { comparison, single } \\
\text { transect }\end{array}$} & $\begin{array}{l}4 \mathrm{w} / \text { model stack, } \\
\text { electric fan }\end{array}$ & $9.8,9.6,9.0,9.3 \% \mathrm{COV}$ & \multirow{2}{*}{$\begin{array}{l}\text { Agree } \\
\text { within }+/-5 \\
\% \mathrm{COV}\end{array}$} & \multirow[t]{2}{*}{ Yes } \\
\hline & $\begin{array}{l}2 \text { EPA grid } \\
\text { measurements on } \\
\text { actual stack }\end{array}$ & $12.8,11.1 \% \mathrm{COV}$ & & \\
\hline \multirow[t]{3}{*}{$\begin{array}{l}\text { Gas tracer uni- } \\
\text { formity on model } \\
\text { stack }\end{array}$} & $\begin{array}{l}6 \text { w/electric fan, } \\
\text { injected downstream } \\
\text { of EF4 }\end{array}$ & $\begin{array}{l}0.8-4.0 \% \mathrm{COV} \\
1.9-5.3 \% \text { deviation from mean }\end{array}$ & \multirow{3}{*}{$\begin{array}{l}\mathrm{COV} \leq 20 \% \\
\text { in center } 2 / 3 \\
\text { of stack } \\
\leq 30 \% \\
\text { maximum } \\
\text { deviation } \\
\text { from mean }\end{array}$} & Yes \\
\hline & $\begin{array}{l}5 \text { w/electric fan } \\
\text { injected downstream } \\
\text { of EF7 }\end{array}$ & $\begin{array}{l}0.7-1.5 \% \mathrm{COV}, \\
1.4-2.9 \% \text { deviation from mean }\end{array}$ & & Yes \\
\hline & $\begin{array}{l}1 \mathrm{w} / \text { electric fan } \\
\text { injected downstream } \\
\text { of EF5 }\end{array}$ & $\begin{array}{l}1.0 \% \mathrm{COV}, \\
2.4 \% \text { deviation from mean }\end{array}$ & & Yes \\
\hline
\end{tabular}




\begin{tabular}{|c|c|c|c|c|}
\hline & $\begin{array}{l}5 \text { w/electric fan } \\
\text { injected downstream } \\
\text { of EF1 }\end{array}$ & $\begin{array}{l}1.0 \% \mathrm{COV}, \\
1.8 \% \text { deviation from mean }\end{array}$ & & Yes \\
\hline & $\begin{array}{l}7 \mathrm{w} / \text { turbine fan } \\
\text { injected downstream } \\
\text { of ET9 }\end{array}$ & $\begin{array}{l}3.6-5.0 \% \mathrm{COV} \\
8.1-9.9 \% \text { deviation from mean }\end{array}$ & & Yes \\
\hline & $\begin{array}{l}3 \text { w/turbine fan } \\
\text { injected downstream } \\
\text { of ET8 }\end{array}$ & $\begin{array}{l}3.7-4.6 \% \mathrm{COV}, \\
7.1-8.2 \% \text { deviation from mean }\end{array}$ & & Yes \\
\hline \multirow{4}{*}{$\begin{array}{l}\text { Particle tracer } \\
\text { uniformity on } \\
\text { model stack. } \\
\text { Time normalized } \\
\text { results. }\end{array}$} & $\begin{array}{l}1 \mathrm{w} / \text { electric fan, } \\
\text { injected downstream } \\
\text { of EF4 }\end{array}$ & $3.0 \% \mathrm{COV}$ & \multirow[t]{4}{*}{$\begin{array}{l}\mathrm{COV} \leq 20 \% \\
\text { in center } 2 / 3 \\
\text { of stack }\end{array}$} & Yes \\
\hline & $\begin{array}{l}3 \text { w/electric fan, } \\
\text { injected downstream } \\
\text { of EF7 }\end{array}$ & $2.6-3.1 \% \mathrm{COV}$ & & Yes \\
\hline & $\begin{array}{l}2 \mathrm{w} / \text { turbine fan } \\
\text { injected downstream } \\
\text { of ET8 }\end{array}$ & $4.6-5.6 \% \mathrm{COV}$ & & Yes \\
\hline & $\begin{array}{l}2 \text { w/turbine fan } \\
\text { injected downstream } \\
\text { of ET9 }\end{array}$ & $5.6-5.8 \% \mathrm{COV}$ & & Yes \\
\hline \multirow{2}{*}{$\begin{array}{l}\text { Particle pene- } \\
\text { tration from free } \\
\text { stream to filter }\end{array}$} & $5 \mathrm{~m} / \mathrm{s}$ & $80.7 \& 78.8 \%$ L \& R branches & \multirow{2}{*}{$\begin{array}{l}\geq 50 \% \text { for } 10 \\
\mu \mathrm{m} \mathrm{AD} \\
\text { particles Yes }\end{array}$} & Yes \\
\hline & $9.2 \mathrm{~m} / \mathrm{s}$ & $86.2 \& 84.3 \%$ L \& R branches & & Yes \\
\hline
\end{tabular}




\subsection{References}

40 CFR 60, Appendix A, Method 1, as amended. U.S. Environmental Protection Agency. "Method 1 - Sample and Velocity Traverses for Stationary Sources." Code of Federal Regulations.

40 CFR 60, Appendix A, Method 2, as amended. U.S. Environmental Protection Agency. "Method 2 - Determination of Stack Gas Velocity and Volumetric Flow Rate.” Code of Federal Regulations.

40 CFR 61, Subpart H. U.S. Environmental Protection Agency. "National Emission Standards for Emissions of Radionuclides Other than Radon from Department of Energy Facilities." Code of Federal Regulations.

American National Standards Institute (ANSI). 1982. Guide to Sampling Airborne Radioactive Materials in Nuclear Facilities. AANSI N13.1-1969, American National Standards Institute, New York.

American National Standards Institute (ANSI). 1999. Sampling and Monitoring Releases of Airborne Radioactive Substances From the Stacks and Ducts of Nuclear Facilities. ANSI/HPS N13.1 - 1999, American National Standards Institute, New York.

Glissmeyer, J. A., and M. W. Ligotke. 1995. Generic Air Sampler Probe Tests. PNL-10816, Pacific Northwest Laboratory, Richland, Washington.

McFarland, A. R., C. A. Ortiz, M. E. Moore, R. E. DeOtte, Jr., and A. Somasundaram. 1989. “A Shrouded Aerosol Sampling Probe." Environ. Sci. Technol. 23:1487-1492.

McFarland, A. R., A. M. Nagaraj, H. Ramakrishna, J. L. Rea, J. Thompson. 2002. Deposition 2001. Aerosol Technology Laboratory, Department of Mechanical Engineering Texas A\&M University College Station TX. http://www.mengr.tamu.edu/research/AerosolLab/index.html

PNL. 1992. Experimental Performance Evaluation of Two Stack Sampling Systems in a Plutonium Facility, PNL-8037. J. A. Glissmeyer, Pacific Northwest Laboratory, Richland, Washington. 
Appendix A

Scaling Parameters Stack Model Schematics 


\section{A.1 Discussion}

A scaling factor of 1:8.5 was selected so the model's velocity at the scaled flowrate was about the same as in the actual stack. The key scaled dimensions are listed in Tables A.1 and A.2. Figure A.1 shows the assembled scale model with filters mounted on central plenum Figures A.2 and A.3 show the model's transition from round stack to side plenums, while Figure A.4 shows the key dimensions of the model.

Table A.1 Model Parameters

\begin{tabular}{|c|c|c|}
\hline Section & Prototype & Scale 1:X \\
\hline Round Duct & Stack & \\
\hline Section & base & 24 \\
\hline Diam, $\mathrm{ft}$ & 16.00 & 1.958 \\
\hline Area, $\mathrm{ft} 2$ & 201.1 & 3.01 \\
\hline $\begin{array}{l}\text { Flow at } \min Q / D, \\
\text { cfm }\end{array}$ & 280000 & 5712 \\
\hline Vel fpm & 1393 & 1896 \\
\hline $\mathrm{Re}$ & $2.4 \mathrm{E}+06$ & $3.9 \mathrm{E}+05$ \\
\hline Ratio $\mathrm{Re}$ & & 6.00 \\
\hline Rectangular Duct & ction & $\begin{array}{l}\text { South end, } 2 \text { electric fans } \\
\text { running }\end{array}$ \\
\hline height or diam., ft & 6.50 & 0.76 \\
\hline width or diam., $\mathrm{ft}$ & 14.83 & 1.75 \\
\hline Hyd Dia ft & 9.04 & 1.06 \\
\hline Area, $\mathrm{ft} 2$ & 96.4 & 1.3 \\
\hline $\begin{array}{l}\text { Flow at } \min Q / D, \\
\mathrm{cfm}\end{array}$ & 140000 & 2745 \\
\hline Vel fpm & 1452 & 2057 \\
\hline $\operatorname{Re}$ & $1.4 \mathrm{E}+06$ & $2.3 \mathrm{E}+05$ \\
\hline Ratio Re & & 6.00 \\
\hline Rectangular Duct & ction & South end, turbine fan running \\
\hline height or diam., ft & 6.50 & 0.76 \\
\hline width or diam., ft & 14.83 & 1.74 \\
\hline Hyd Dia ft & 9.04 & 1.06 \\
\hline Area, $\mathrm{ft} 2$ & 96.4 & 1.3 \\
\hline $\begin{array}{l}\text { Flow at } \min Q / D, \\
\mathrm{cfm}\end{array}$ & 96000 & 1882 \\
\hline Vel fpm & 996 & 1411 \\
\hline $\mathrm{Re}$ & $9.5 \mathrm{E}+05$ & $1.6 \mathrm{E}+05$ \\
\hline Ratio Re & & 6.00 \\
\hline
\end{tabular}


Table A.2. Key Scaled Dimensions

\begin{tabular}{|c|c|c|c|}
\hline \multicolumn{2}{|c|}{ Dimension scaling, 1:x } & \multirow{2}{*}{$\begin{array}{l}\text { Final } \\
\text { ft } \\
\quad 8.50 \\
\end{array}$} & \multirow{2}{*}{$\begin{array}{r}\text { Final in. } \\
8.50\end{array}$} \\
\hline Section & Prototype & & \\
\hline Stack diam base & 16 & 1.882 & $229 / 16$ \\
\hline Stack diam at probe & 15.7 & 1.847 & $223 / 16$ \\
\hline El. Of probe & 53.333 & 6.274 & $755 / 16$ \\
\hline Round horzntl length & 7 & 0.824 & $914 / 16$ \\
\hline Square block at base & 16 & 1.882 & $229 / 16$ \\
\hline block length & 16 & 1.882 & $229 / 16$ \\
\hline slope length & 19.333 & 2.274 & $275 / 16$ \\
\hline prow length & 9.66667 & 1.137 & $1310 / 16$ \\
\hline side width & 14.8333 & 1.745 & $2015 / 16$ \\
\hline side height & 6.5 & 0.765 & $93 / 16$ \\
\hline side length & 129.833 & 15.274 & $1835 / 16$ \\
\hline plenum width & 15 & 1.765 & $213 / 16$ \\
\hline plenum height & 20 & 2.353 & $28 \quad 4 / 16$ \\
\hline plenum length & 129.833 & 15.274 & $1835 / 16$ \\
\hline El Fan Dis Ht & 5.5417 & 0.652 & $713 / 16$ \\
\hline $\begin{array}{l}\text { El Fan Dis Width } \\
\text { Plenum to El. Fan }\end{array}$ & 3.0833 & 0.363 & $46 / 16$ \\
\hline C.L. & 5 & 0.588 & $71 / 16$ \\
\hline $\begin{array}{l}\text { Plenum-Steam fan CL } \\
\text { Ldg Edge Fan fr }\end{array}$ & 6 & 0.706 & $88 / 16$ \\
\hline $\begin{array}{l}\text { Transtn } \\
\text { Ldg Edge Fan fr }\end{array}$ & 6.5 & 0.765 & $93 / 16$ \\
\hline $\begin{array}{l}\text { Transtn } \\
\text { Ldg Edge Fan fr }\end{array}$ & 27.167 & 3.196 & $386 / 16$ \\
\hline $\begin{array}{l}\text { Transtn } \\
\text { Ldg Edge Fan fr }\end{array}$ & 51.167 & 6.020 & $724 / 16$ \\
\hline $\begin{array}{l}\text { Transtn } \\
\text { Ldg Edge Fan fr }\end{array}$ & 75.167 & 8.843 & $1062 / 16$ \\
\hline Transtn & 99.167 & 11.667 & 140 \\
\hline
\end{tabular}




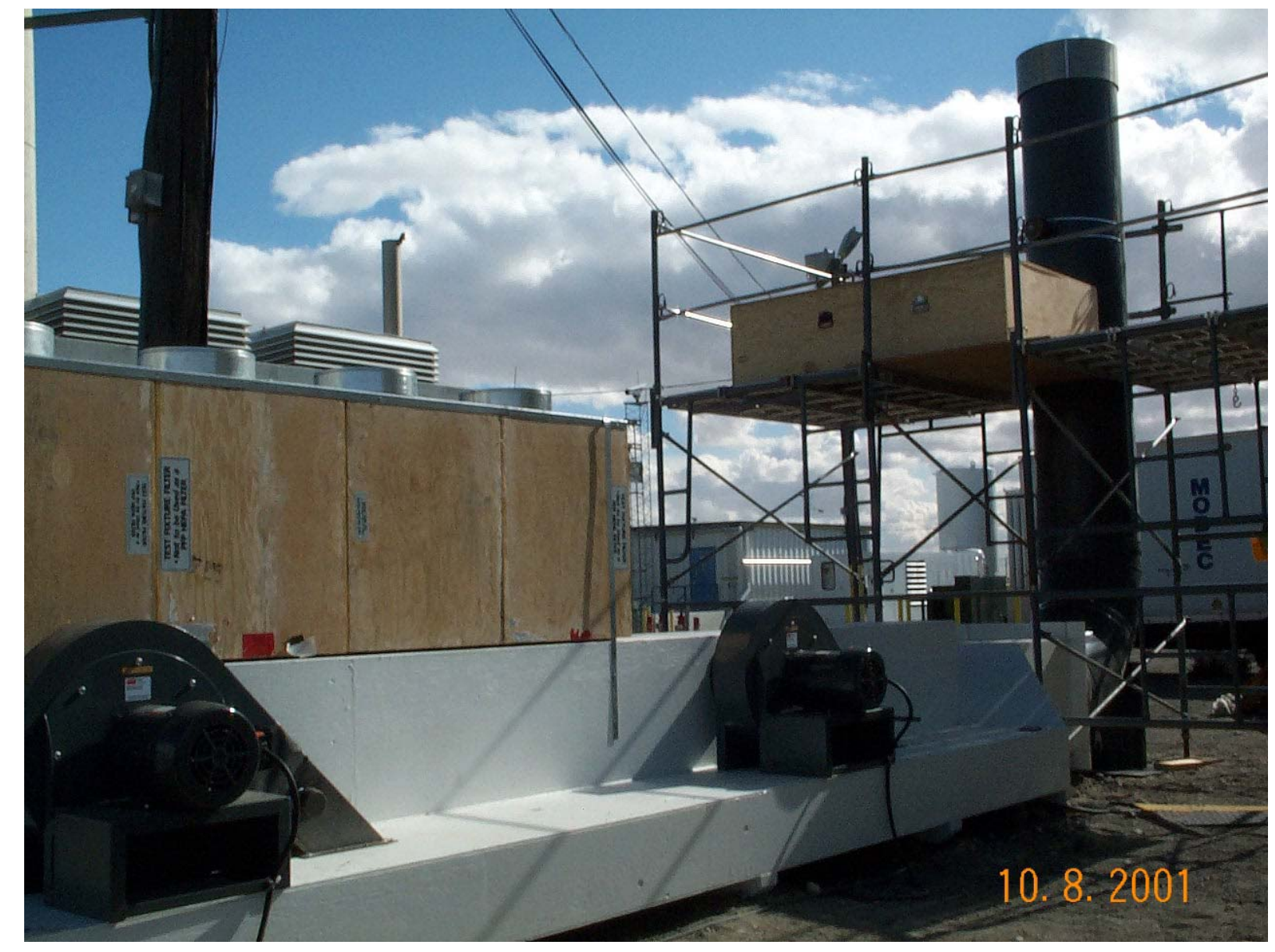

Figure A.1 Assembled scale model with filters mounted on central plenum 


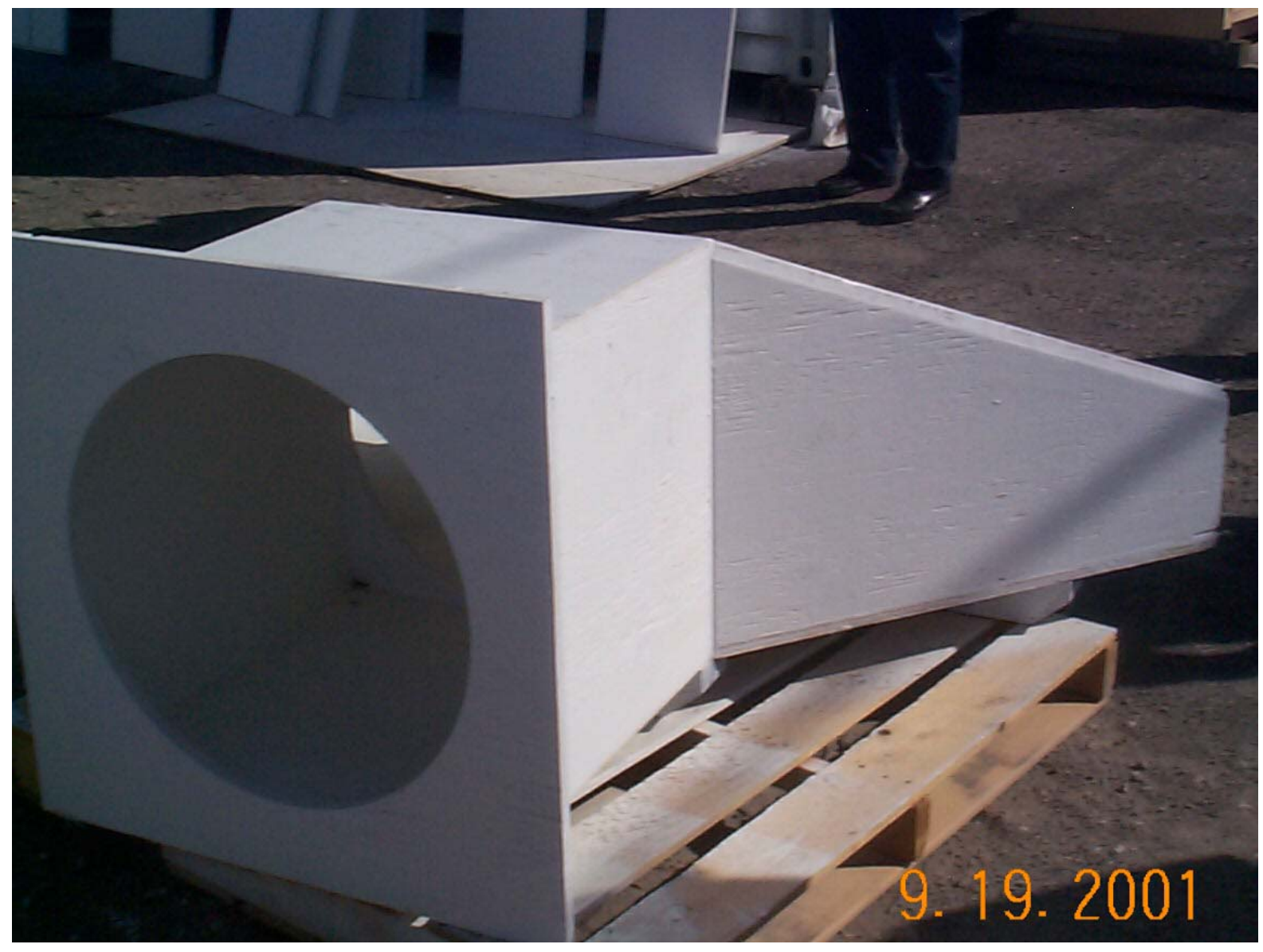

Figure A.2 Transition from round stack to side plenums 


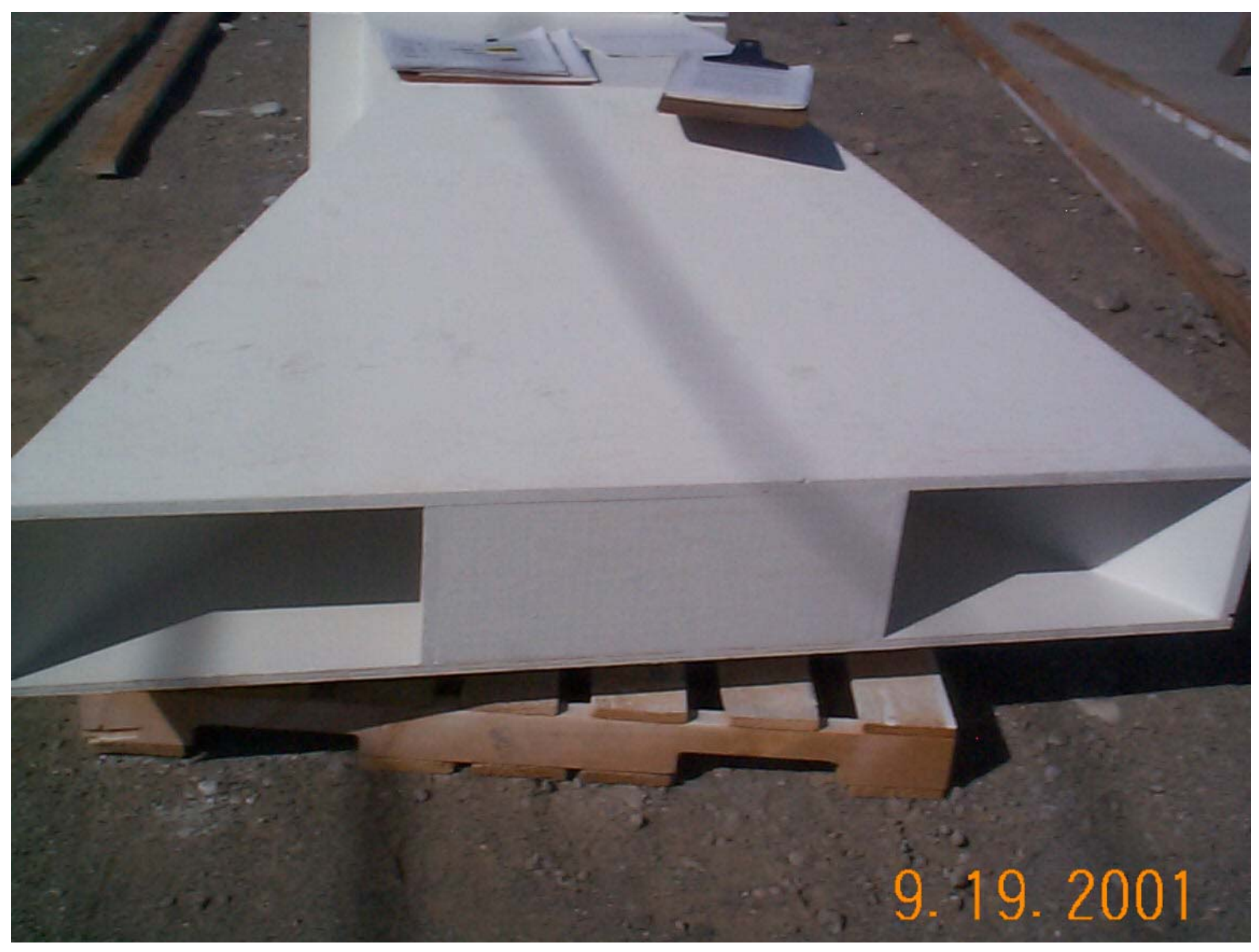

Figure A.3 Transition from round stack to side plenums 


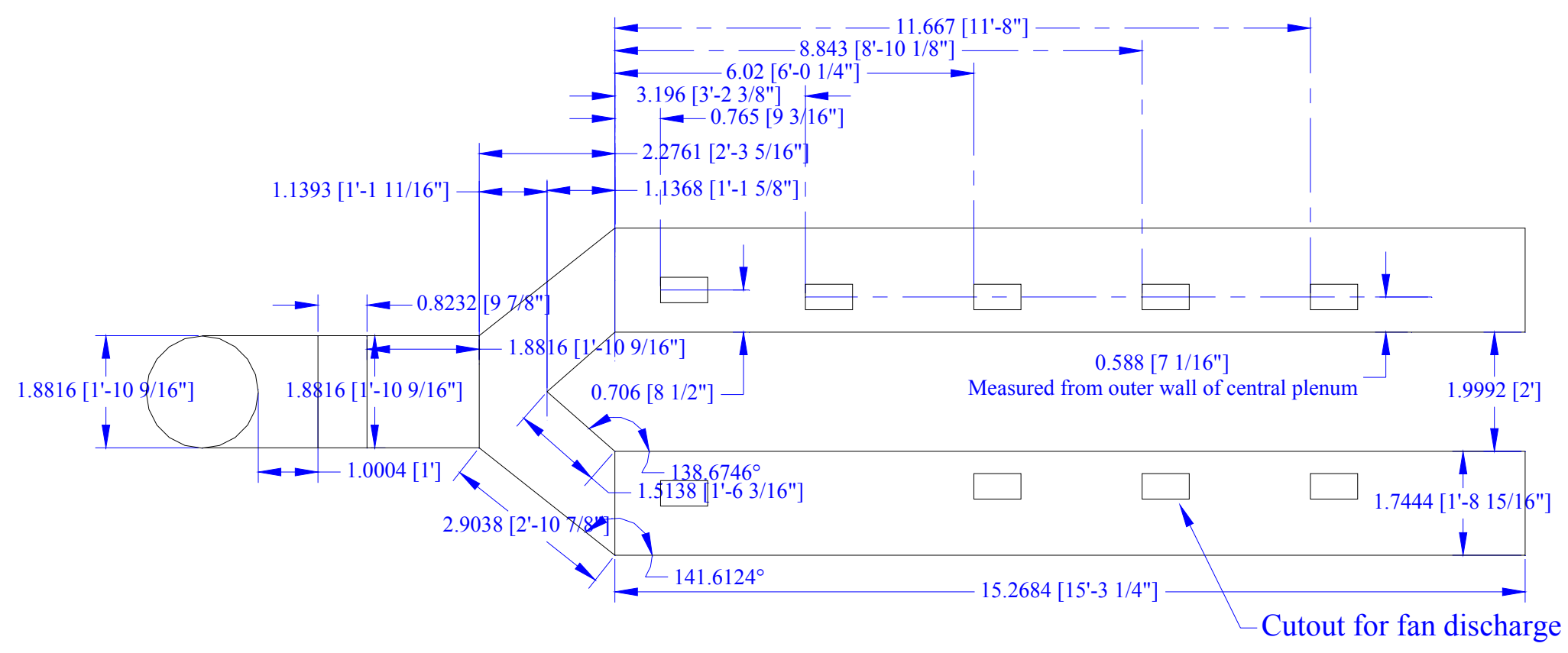

Figure A.4 Key model dimensions 
Appendix B

Fan Speed vs. Flow Rate Correlation Procedure 


\section{B.1 Purpose}

The performance of new stack sampling systems must be shown to satisfy the requirements of 40 CFR 61, Subpart H, "National Emission standards for Emissions of Radionuclides Other than Radon from Department of Energy Facilities." This regulation governs portions of the design and implementation of effluent air sampling. The stack sampler performance is adequately characterized when potential contaminants in the effluent are of a uniform concentration at the sampling location (plane) and line losses are within acceptable limits. This procedure is used when needed to facilitate testing these characteristics. This procedure is a means to quickly correlate flow control device settings with the ventilation flowrate in a stack or duct. This correlation is determined prior to other tests of the stack monitoring system. This correlation makes it easier to set the flow control to achieve repeatable values of flowrate. Other procedures that may follow address flow angle, uniformity of gas velocity, and uniformity of gas and aerosol contaminants.

\section{B.2 Applicability}

This procedure can be used in the field or on modeled stacks and ducts to determine the correlation between stack flow control settings and the measured stack flowrate. The tests are applicable to effluent stacks or ducts within the following constraints:

- The available range of adjustment in the ventilation flowrate of the system being tested or modeled.

- The operating limits of the air velocity measurement device used.

This procedure may need to be repeated if there are significant changes made in the ventilation system or loading of the ventilation filters.

\section{B.3 Prerequisites and Conditions}

Conditions and concerns that must be satisfied prior to performing this procedure are listed below:

- The job-hazards analysis for the work area must be prepared and followed.

- Safety glasses, hard toed or substantial shoes may be required in the work areas.

- Scaffold user training may be required to access the sampling ports of the stack.

- The flow ventilation control device must be installed and means available for its adjustment.

- Air velocity measurement equipment must be within calibration.

- The test instruction must be read and understood. 


\section{B.4 Precautions and Limitations}

Access to the test ports may require the use of ladders, scaffolding or manlifts, which may necessitate special training for sampling personnel and any observers. The training requirements will be indicated in the job hazard analysis.

\section{B.5 Equipment Used for Measurements}

The following are essential items of equipment:

- Calibrated slant tube or electronic manometer,

- Pitot tube,

- Platform, ladders, or manlifts as needed to access the test ports,

- Fittings to limit leakage around the pitot tube in the test port and to stabilize the pitot tube so it can be positioned repeatedly.

\section{B.6 Work Instructions for Setup, Measurements, and Data Reduction}

Job specific instructions given in the test instruction, illustrated in Exhibit D, will provide specific details and operating parameters necessary to perform this procedure.

Note. The grid of velocity measurement points is calculated in accordance with 40 CFR 60, Appendix A, Method 1. A center point is also added. 


\section{Preliminary Steps:}

Verify that the interior dimensions of the stack or duct at the measurement location agree with those used in calculating the grid of measurement points given in the test instruction or data sheet. The measurement location should be approximately the same as the air sampling nozzle openings.

Provide essential supplies at the sampling location. (pitot tube, manometer, connecting tubing, fittings to adapt pitot tube to the test ports, marking pens, data sheets, writing and pitot tube supporting platforms).

Verify that the flow control device is capable of the flow control settings given in the Test Instruction, particularly that setting to be used for the detailed velocity traverse.

Prepare a data sheet for the detailed velocity traverse. See illustration in Exhibit A. Label the columns of traverse data by the direction of the traverse. For example, if the first reading is closest to the east port, and the last reading is closest to the west port, then label the traverse east-west.

Mark the pitot tube for each point in the measurement grid. Use a permanent marker so the inlet can be placed at each successive measurement point.

Obtain barometric, temperature, and relative humidity information for the flow measurement location. Air temperature can be measured in the stack with a calibrated instrument during the velocity traverses.

Attach the manometer to the pitot tube. Insert the pitot tube in the stack and seal the opening around the pitot tube. 


\section{Flow Measurement}

Set the flow controller as instructed for the detailed velocity traverse.

Verify that the directional orientations and the numbered sample positions are consistent with the data sheet.

Measure and record, on the data sheet, the velocity or differential pressure reading at each measurement point in succession. If the readout device has an averaging feature, record the average of a series of several readings.

Repeat Step 6.2.3. Perform two or three repetitions of the measurements in each traverse direction, two if it is highly repeatable, three if not so repeatable.

Compare the results in Step 6.2.3 with those of 6.2.4. If the measurements are not highly reproducible, repeat again Step 6.2.3.

Calculate the average air velocity and identify the point(s) where the velocity most nearly equals the average. 


\section{Estimated Flow at Other Settings}

Prepare a data sheet for recording average air velocity measured over the range of flow control settings. (See Exhibit B.)

Place the pitot tube at the point of average velocity as determined in Step 6.2.6.

Record the velocity reading for each flow controller setting specified in the Test Instruction.

Repeat Step 6.3.3 two times for a total of three replicate measurements at each flow setting.

Calculate the mean velocity and flowrate corresponding to each flow controller setting.

Plot the mean velocity and flow versus flow controller setting as illustrated in Exhibit C. Calculate the equation of the line fitting the data.

Review the datasheets for completeness.

Sign and date the datasheets attesting to their validity. 
Figure B.1. Illustration of Detailed Velocity Traverse Data Sheet

\title{
VELOCITY TRAVERSE DATA FORM
}

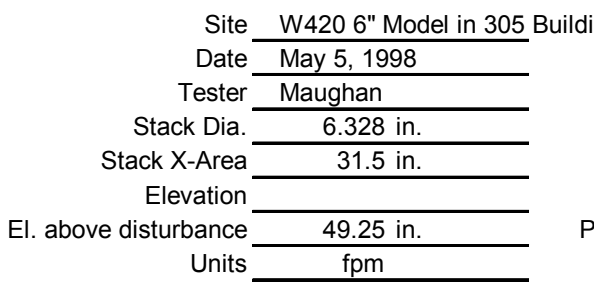

\author{
Run No. VT6May5_1 \\ Stack Temp $74 \operatorname{deg} \mathrm{F}$ \\ Stack RH $39 \%$
}

BP (sta. + static) $\overline{992+0.94}=\sim 993$ mbars

Fan Setting

Center $2 / 3$ from

Points in Center 2/3

$20 \mathrm{~Hz}$

\begin{tabular}{ll}
\hline 0.58 & to: \\
\hline 2 & to:
\end{tabular}

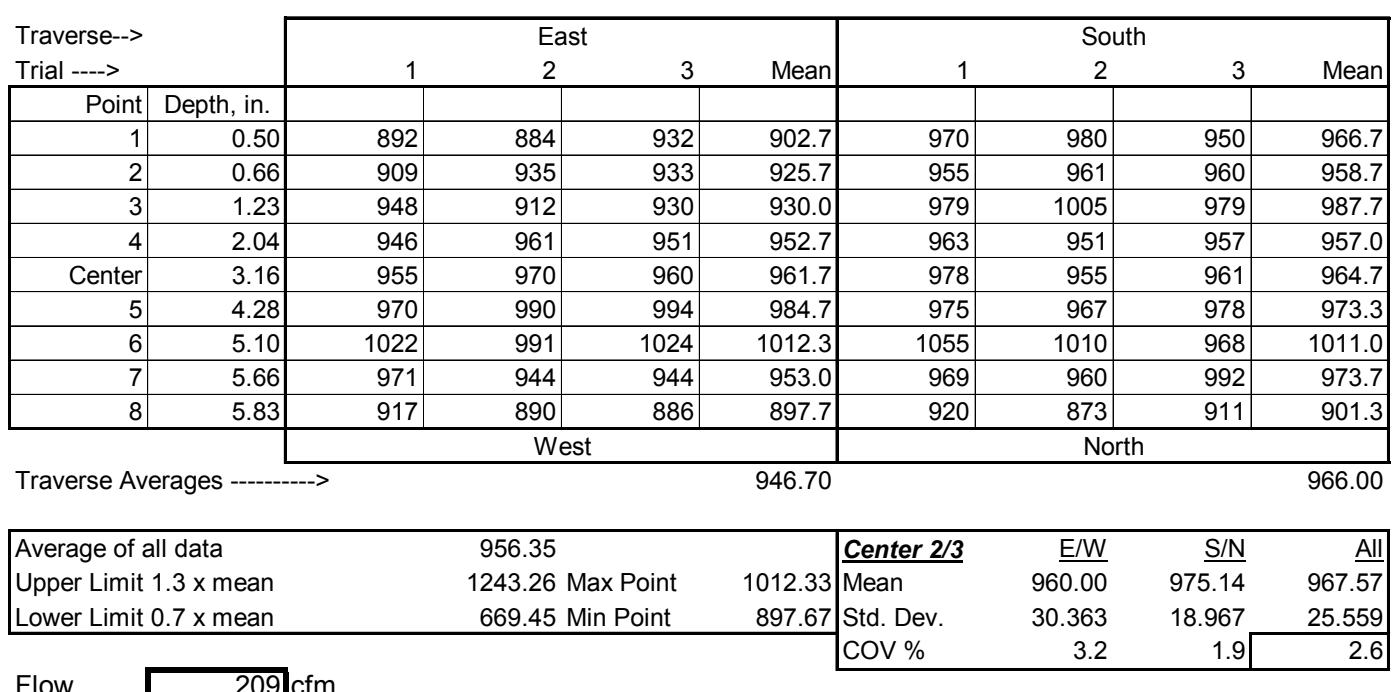

Flow $355 \mathrm{~m} 3 / \mathrm{hr}$

Notes:

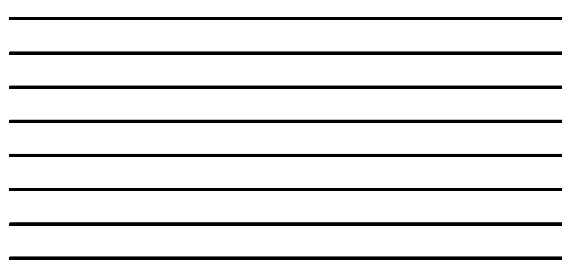

Instuments Used:

Solomat Zephyr $\quad \# 12951472$

Cal \# 521-28-09-001, Expires 5/1/99

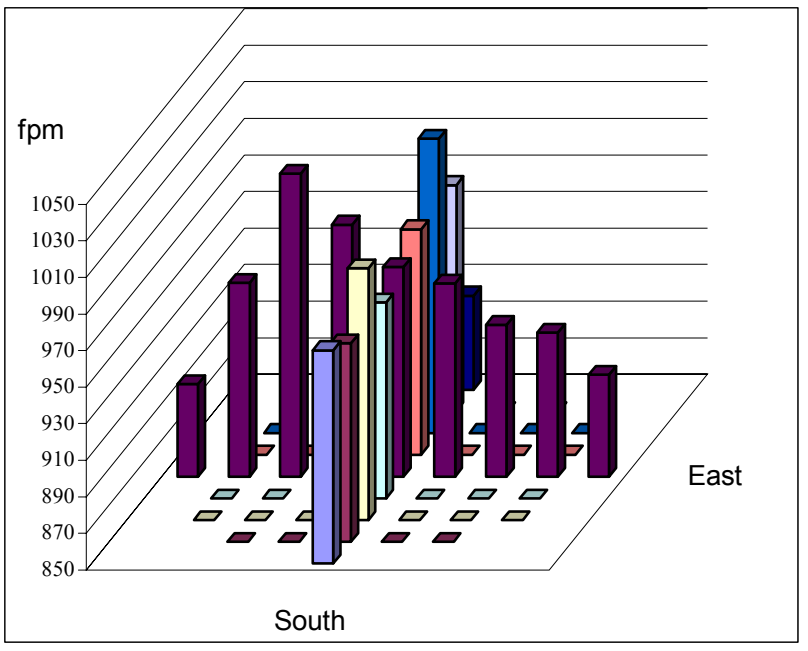

Signature signifying compliance with Procedure EMS-JAG-03

Signature/Date 


\section{Figure B.2. Illustration of Velocity vs. Flow Controller Setting Data Sheer}

\section{VELOCITY vS. FLOW CONTROL SETTING DATA FORM}

\begin{tabular}{|c|c|c|}
\hline \multicolumn{3}{|c|}{ Site W420 6-inch Stack, Bldg. 305} \\
\hline Date & \multicolumn{2}{|c|}{$5 / 6 / 98$} \\
\hline Tester & \multicolumn{2}{|c|}{ D. Maughan } \\
\hline Stack Dia. & \multicolumn{2}{|c|}{6.375 inch } \\
\hline Stack X-Area & 31.9 & sq. in. \\
\hline $\begin{array}{r}\text { Elevation } \\
\text { disturbance }\end{array}$ & & \\
\hline
\end{tabular}

El. above disturbance

$\begin{array}{rc}\text { Run No. } & \text { VFMay6_1 } \\ \text { Stack Temp } & \text { 72 deg. F } \\ \text { Stack RH\% } & 44 \% \text { outdoor } \\ \text { Baro Press } & 995 \text { mbar, sta. 300A; } \\ \text { Fan Setting } & \text { Static 5 Hz 0.05 mbar } \\ \text { Offset to index }\end{array}$

Pt. 5 on $\mathrm{S}>\mathrm{N}$ Transect

Velocity Readings, units $=\quad$ fpm

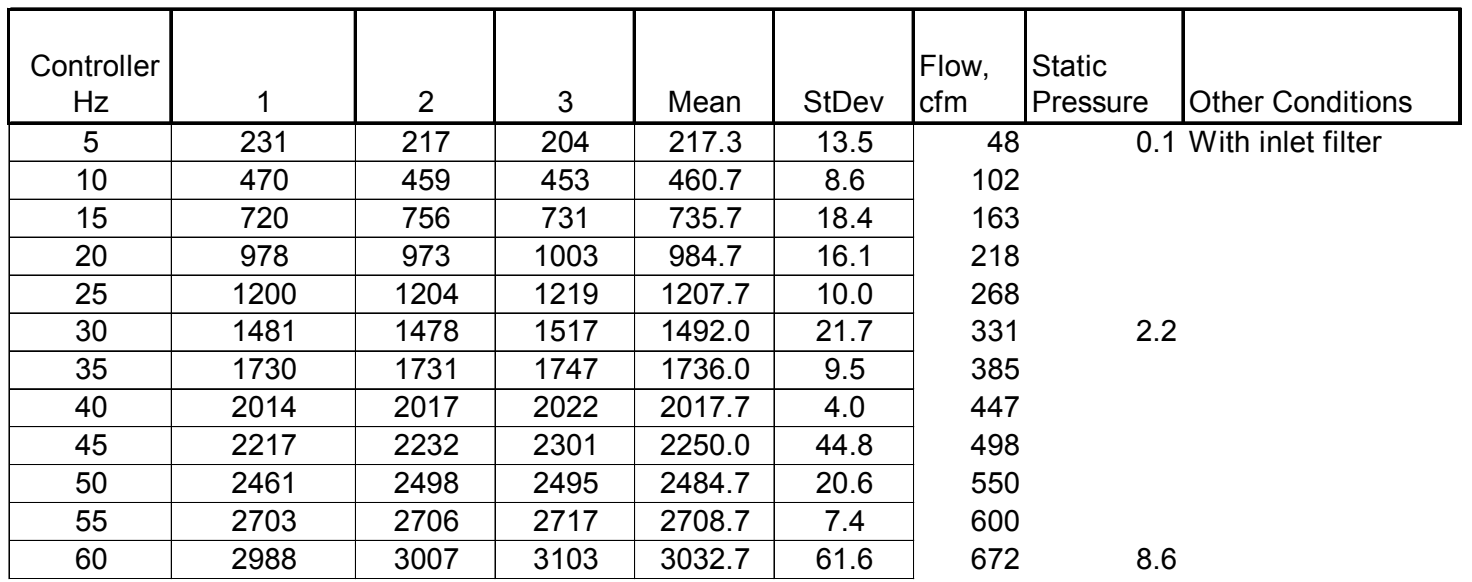

Notes:

Each reading is the running average of approximately 40 points

The stack inlet filter, before the HEPA, has a moderate dust loading.

Instuments Used:

Solomat Zephyr Ser\# 12951472, Cal\# 521-28-09-001

Cal Exp. Date:

2/7/99

Signature signifying compliance with Procedure EMS-JAG-03

Signature/Date 
Figure B.3. Plot of Flowrate vs. Controller Setting

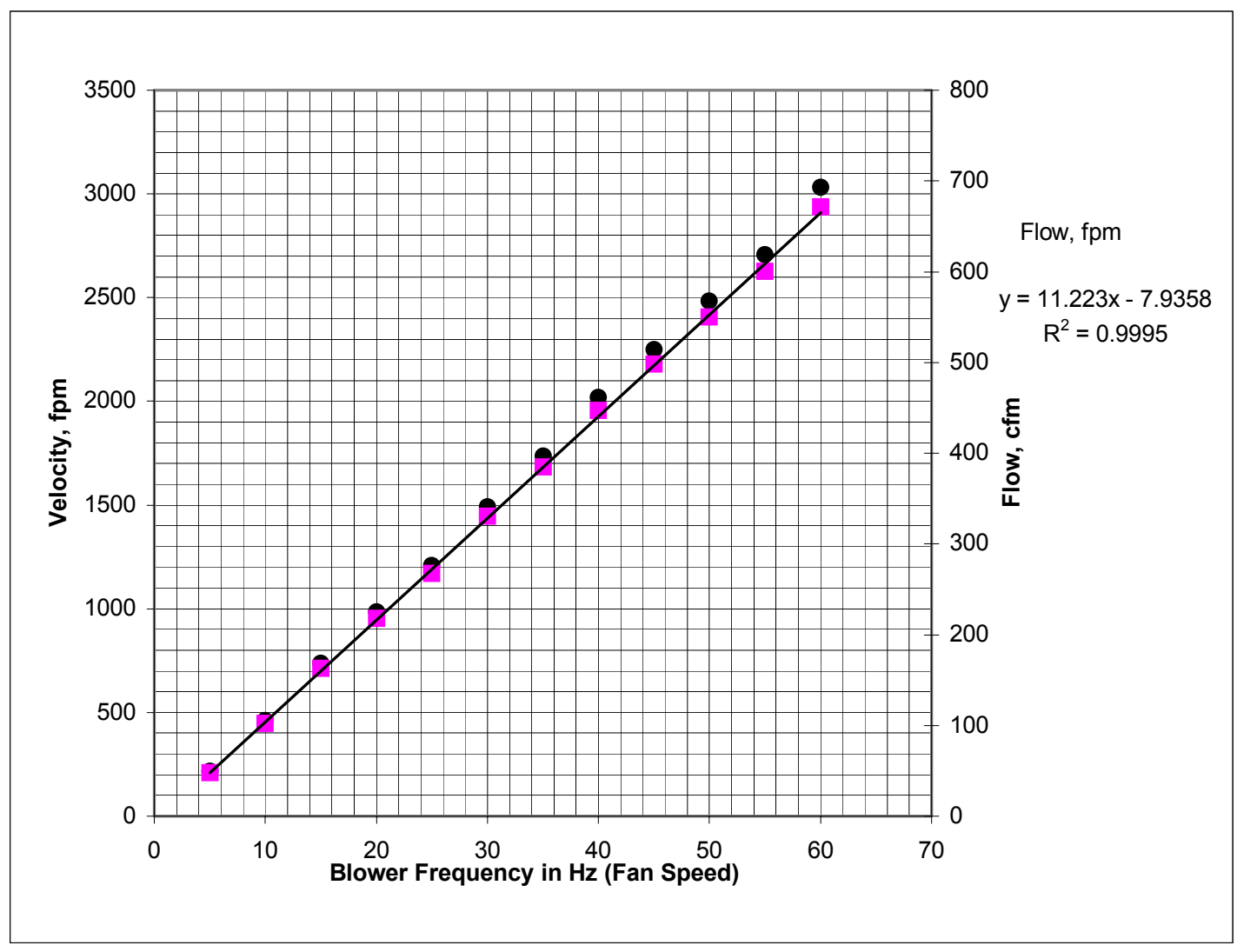

B. 8 
Figure B.4. Illustrative Test Instruction

\begin{tabular}{|c|c|c|}
\hline \multicolumn{3}{|c|}{ Test Instruction } \\
\hline $\begin{array}{l}\text { Project: W420 6" Stack } \\
\text { Calibration } 28361\end{array}$ & Date: August 19, 1998 & Work Package: K83017 \\
\hline \multicolumn{3}{|c|}{ Tests: Calibration of Ventilation Flow Controller for W420 6" Full-Scale Model Stack } \\
\hline \multicolumn{3}{|l|}{ Staff: David Maughan } \\
\hline \multicolumn{3}{|c|}{$\begin{array}{l}\text { Reference Procedures: } \\
\text { 1. Operating Manual for Solomat Zephyr } \\
\text { 2. } \quad \text { Procedure EMS-JAG-03 Test to Calibrate Ventilation Flow Controller, Rev. 0, Nov. } \\
\text { 20, } 1998\end{array}$} \\
\hline \multicolumn{3}{|l|}{$\begin{array}{l}\text { Equipment: } \\
\text { 1. W420 }\end{array}$} \\
\hline \multicolumn{3}{|c|}{$\begin{array}{l}\text { Safety Considerations: } \\
\text { Review and observe the applicable Numatec Job Hazard Analysis for the project }\end{array}$} \\
\hline \multicolumn{3}{|c|}{$\begin{array}{l}\text { Instructions: } \\
\text { 1. Assemble the equipment for the flow controller calibration test at the ports at the } \\
\text { elevation of the sampling probe } \\
\text { 2. Layout the measurement points with the following distances from the inside of the } \\
\text { stack wall: } 0.5,0.66,1.23,2.04,3.16,4.28,5.10,5.66,5.83 \text { inches } \\
\text { 3. Measure the velocity at each point with the flow controller set at } 30 \mathrm{~Hz} \text {. Repeat each } \\
\text { measurement thrice. } \\
\text { 4. Record data on velocity data sheets } \\
5 . \quad \text { Identify point of average velocity } \\
6 \text { Mount pitot tube at that point and measure velocity at } 5 \mathrm{~Hz} \text { increments on the controller } \\
\text { over the } 5 \text { - } 60 \mathrm{~Hz} \text { range } \\
\text { 7. Record and plot the data } \\
6 . \\
\quad \text { Diagram mounting fixtures and retain assembly for subsequent tests }\end{array}$} \\
\hline \multicolumn{3}{|l|}{ Desired Completion Date: } \\
\hline \multicolumn{3}{|l|}{ Approvals: } \\
\hline & & \\
\hline
\end{tabular}


Appendix C

Fan Speed vs. Flow Rate Correlation Data Plots 
Figure C.1. Flow vs. Velocity Correlations for Electric Fans
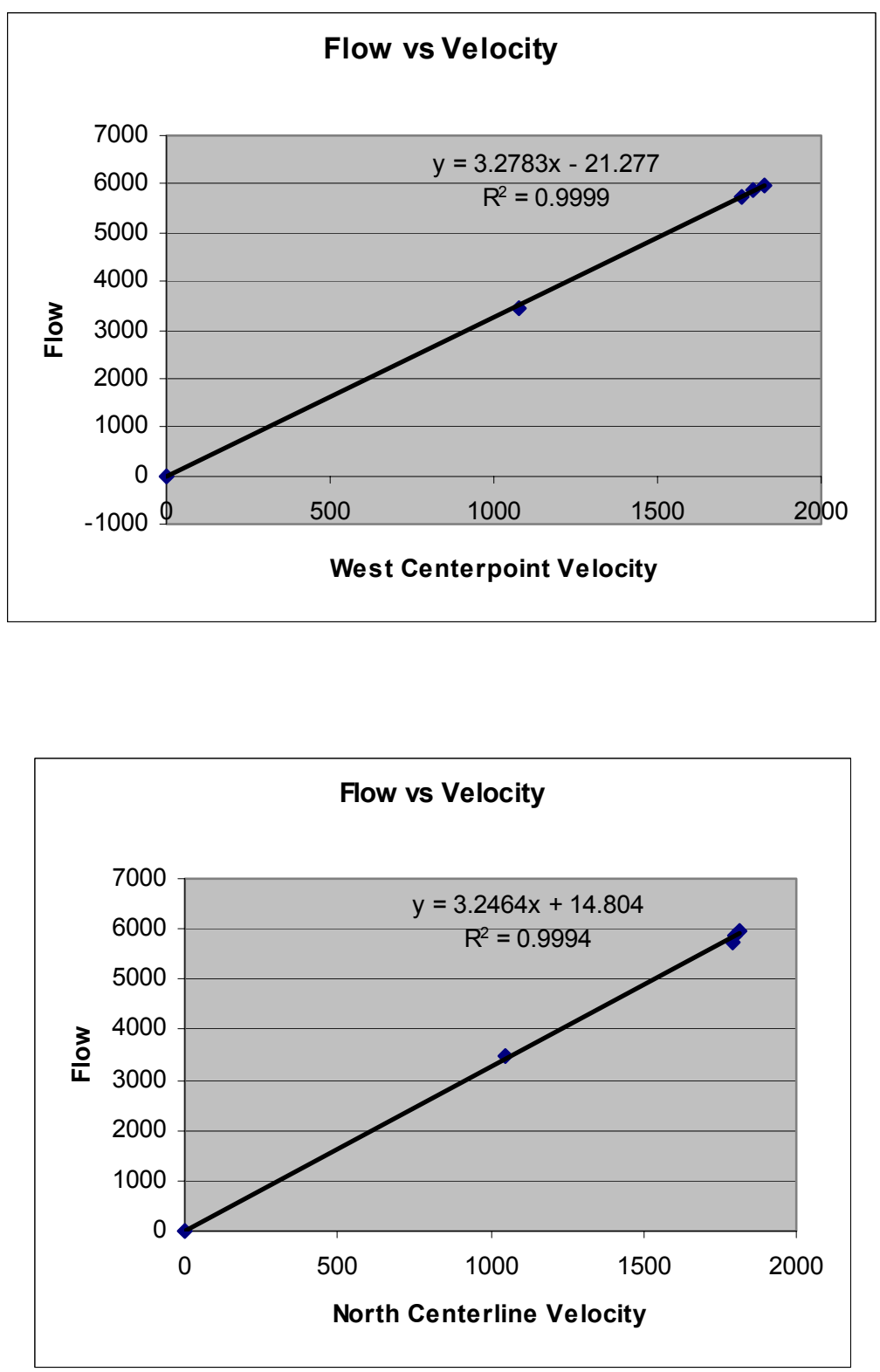

C. 1 
Figure C.2. Flow vs. Velocity Correlations for Turbine Fans
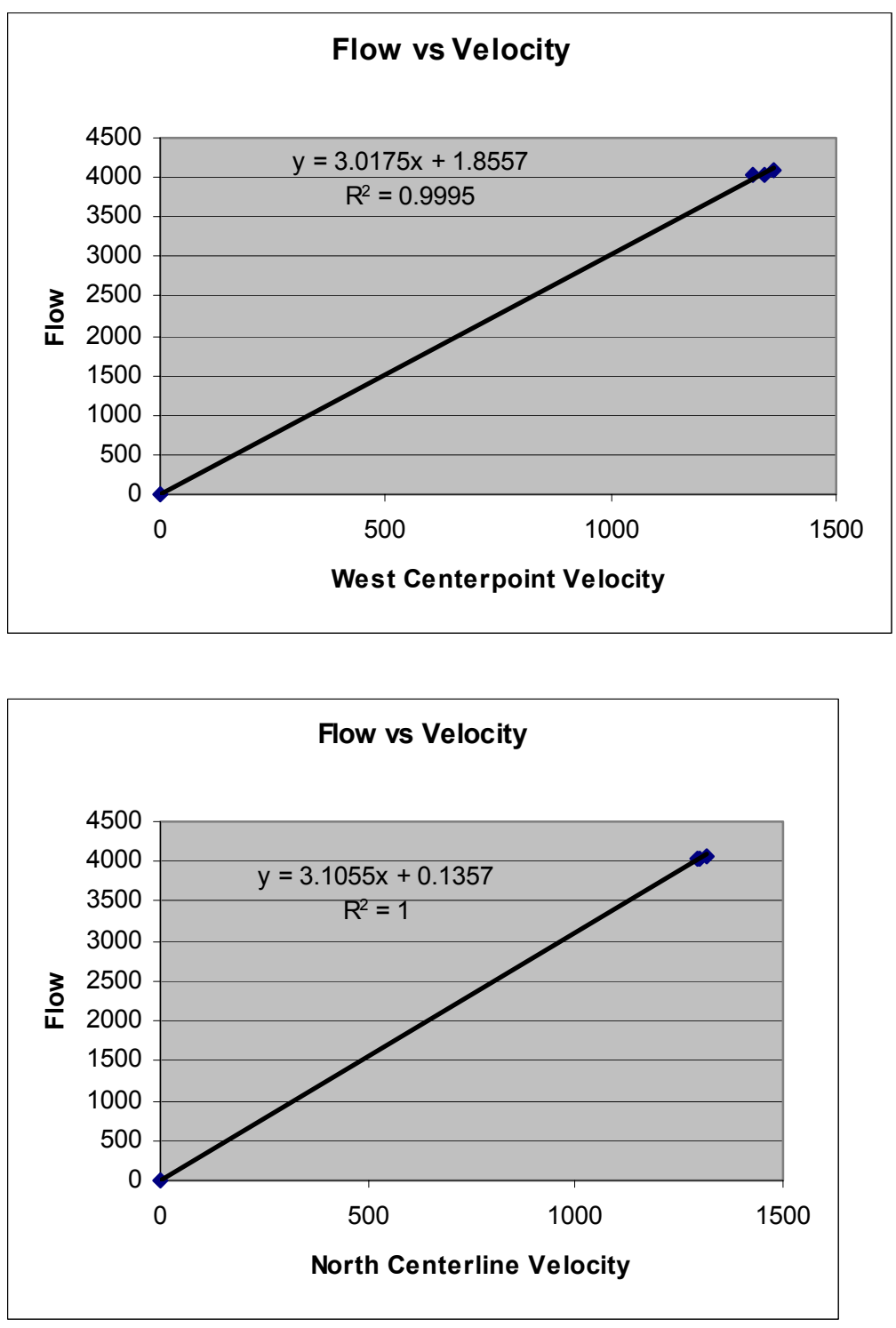
Figure C.3. Flow vs. Velocity Correlations for All Fans
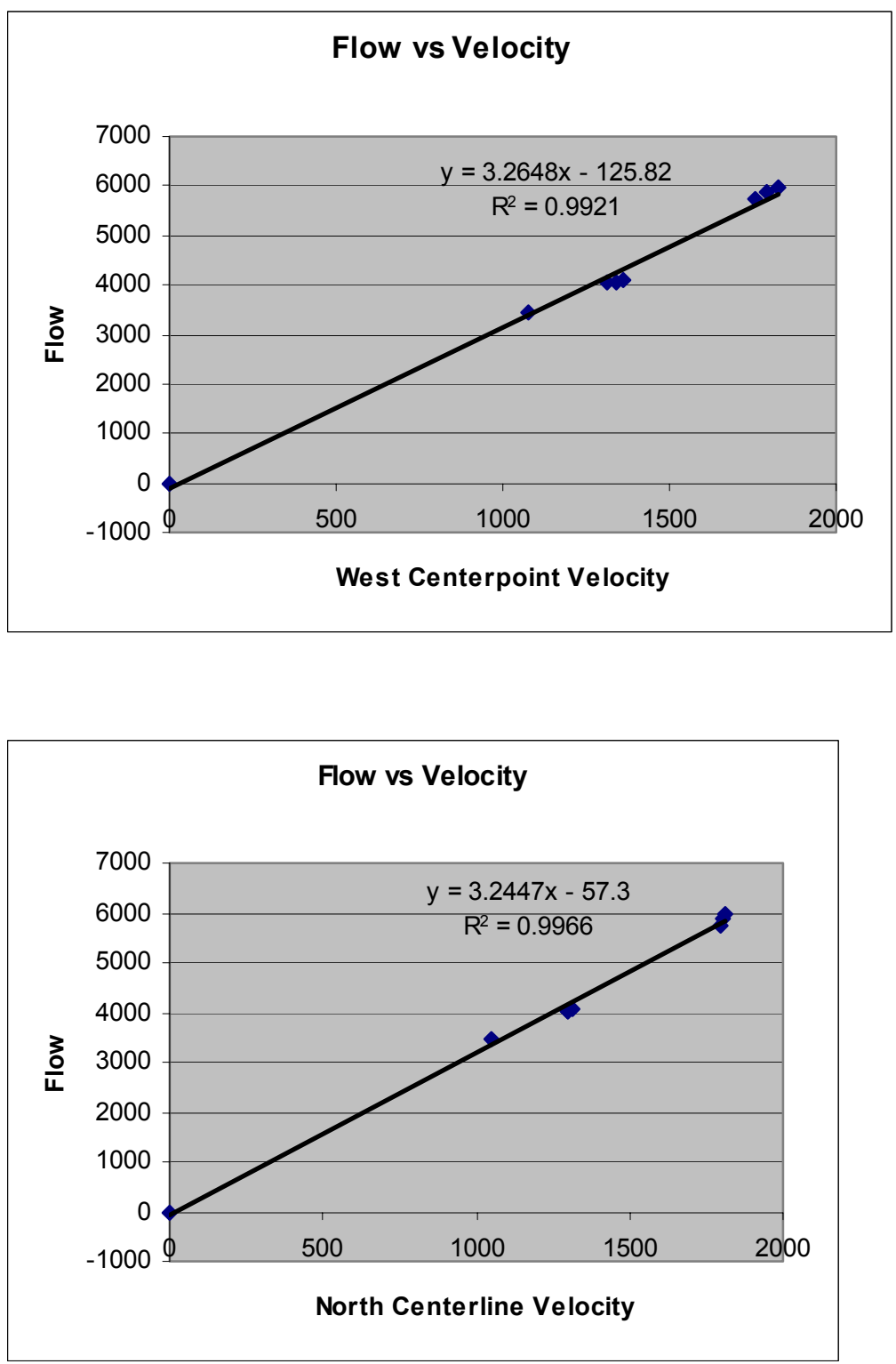
Appendix D

Air Velocity Uniformity Testing Procedure 


\section{D.1 Purpose}

The performance of new stack sampling systems must be shown to satisfy the requirements of 40 CFR 61, Subpart H, "National Emission standards for Emissions of Radionuclides Other than Radon from Department of Energy Facilities." This regulation governs portions of the design and implementation of effluent air sampling. The stack sampler performance is adequately characterized when potential contaminants in the effluent are of a uniform concentration at the sampling plane and line losses are within acceptable limits. (The sampling plane is the cross section of the stack or duct where the sampling nozzle inlet is located.) Uniformity of contaminant concentration is unlikely where the gas velocity throughout the sampling plane is significantly non-uniform. This procedure provides the means to determine the uniformity of gas velocity, and is performed prior to measurements of contaminant uniformity. This procedure is performed after the range of gas flow conditions are established. Other procedures that usually follow address flow angle, and uniformity of gas and aerosol contaminants.

\section{D.2 Applicability}

This procedure can be used in the field or on modeled stacks and ducts to determine the uniformity of air velocity throughout the sampling plane. The results also provide a detailed determination of the flowrate at the ventilation control settings used for the procedure. The tests are applicable within the following constraints:

- The operating limits of the air velocity measurement device used are observed.

- The air velocity sensor element does not occupy more than a few percent of the cross sectional area in the sampling plane.

This procedure may need to be repeated if there are changes made in the configuration of the ventilation system. If the system under test operates within a limited range of airflow that does not change more than $\pm 25 \%$, then this procedure is usually conducted once at the middle of the range. If the flow may vary more, then the procedure is performed at least at the extremes of flow.

\section{D.3 Prerequisites and Conditions}

Conditions and concerns that must be satisfied prior to performing this procedure are listed below:

- The job-hazards analysis for the work area must be prepared and followed.

- Safety glasses, hard toed or substantial shoes may be required in the work areas.

- Scaffold user training may be required to access the sampling ports of the stack.

- The flow ventilation control device must be installed and means available for its adjustment.

- Air velocity measurement equipment must be within calibration. 
- The test instruction must be read and understood.

\section{D.4 Precautions and Limitations}

Access to the test ports may require the use of ladders, scaffolding or manlifts, which may necessitate special training for sampling personnel and any observers. The training requirements will be indicated in the job hazard analysis.

\section{D.5 Equipment Used for Measurements}

The following are essential items of equipment:

- Air velocity measurement apparatus, which may consist of a calibrated slant tube or electronic manometer, pitot tube, or some other type of sensor;

- Platform, ladders, or manlifts as needed to access the test ports;

- Fittings to limit leakage around the velocity sensor and to stabilize the sensor so it can be repositioned repeatably.

Further details on specific equipment for the job are provided in the Test Instruction. The air velocity instrumentation may be either the types used in 40 CFR 60, Appendix A, Method 2, or other measurement device for discrete points, such as a rotating vane or thermal anemometer. The user must be aware that different devices may give readings in terms of different gas conditions.

\section{D.6 Work Instructions for Setup, Measurements, and Data Reduction}

Job specific instructions given in the Test Instruction, illustrated in Exhibit B, will provide details and operating parameters necessary to perform this procedure. 


\section{Preliminary Steps:}

Verify that the interior dimensions of the stack or duct at the sampling plane agree with those used in calculating the grid of measurement points given in the test instruction or data sheet.

Provide essential supplies at the sampling location (velocity measuring instrumentation, fittings to adapt the sensor to the test ports, marking pens, data sheets, writing and sensor supporting platforms).

Verify that the ventilation flow control device is capable of the flow control settings given in the Test Instruction.

Prepare a data sheet for the detailed velocity traverse. See illustration in Exhibit A. Label the columns of traverse data by the direction of the traverse.

Note. For example, if the first reading is closest to the east port, and the last reading is closest to the west port, then label the traverse east-west. Also the first point is the one closest to the port.

Note. The grid of velocity measurement points is calculated in accordance with 40 CFR 60, Appendix A, Method 1. A centerpoint is included as a common reference and for graphical purposes. The layout design divides the area of the sampling plane so that each point represents approximately an equal-sized area

Mark the velocity sensor body to indicate the insertion depth for each point in the measurement grid.

Obtain barometric pressure, relative humidity, and stack or duct temperature and static pressure if needed to convert the velocity sensor readings to velocity units.

Insert the velocity sensor in the stack or duct and seal the opening around it. 


\section{Velocity Uniformity Measurement}

Set the flow controller per the test instruction.

Verify that the directional orientations and the numbered measurement positions are consistent with the data sheet.

Measure and record, on the data sheet, the velocity or pressure reading at each measurement point in succession. If the readout device has an averaging feature, record the average of a series of several readings.

Repeat Step 6.2.3.

Compare the results in Step 6.2.3 with those of 6.2.4. If the measurements are not highly reproducible, repeat Step 6.2.3 again.

Calculate the average air velocity for each measurement point.

Calculate the overall average velocity and flowrate for the stack or duct, omitting the center point.

Calculate the coefficient of variance (COV, 100 times the standard deviation divided by the mean) using the average velocity for all points in the inner two-thirds of the cross section area (including the centerpoint).

Compare the observed COV for each run to the acceptance criterion. The acceptance criterion for the COV is \#20\% for the inner two-thirds of the stack diameter.

Review the datasheets for completeness.

Sign and date the datasheets attesting to their validity. 
Figure D.1. Illustration of Detailed Velocity Traverse Data Sheet

\section{VELOCITY TRAVERSE DATA FORM}

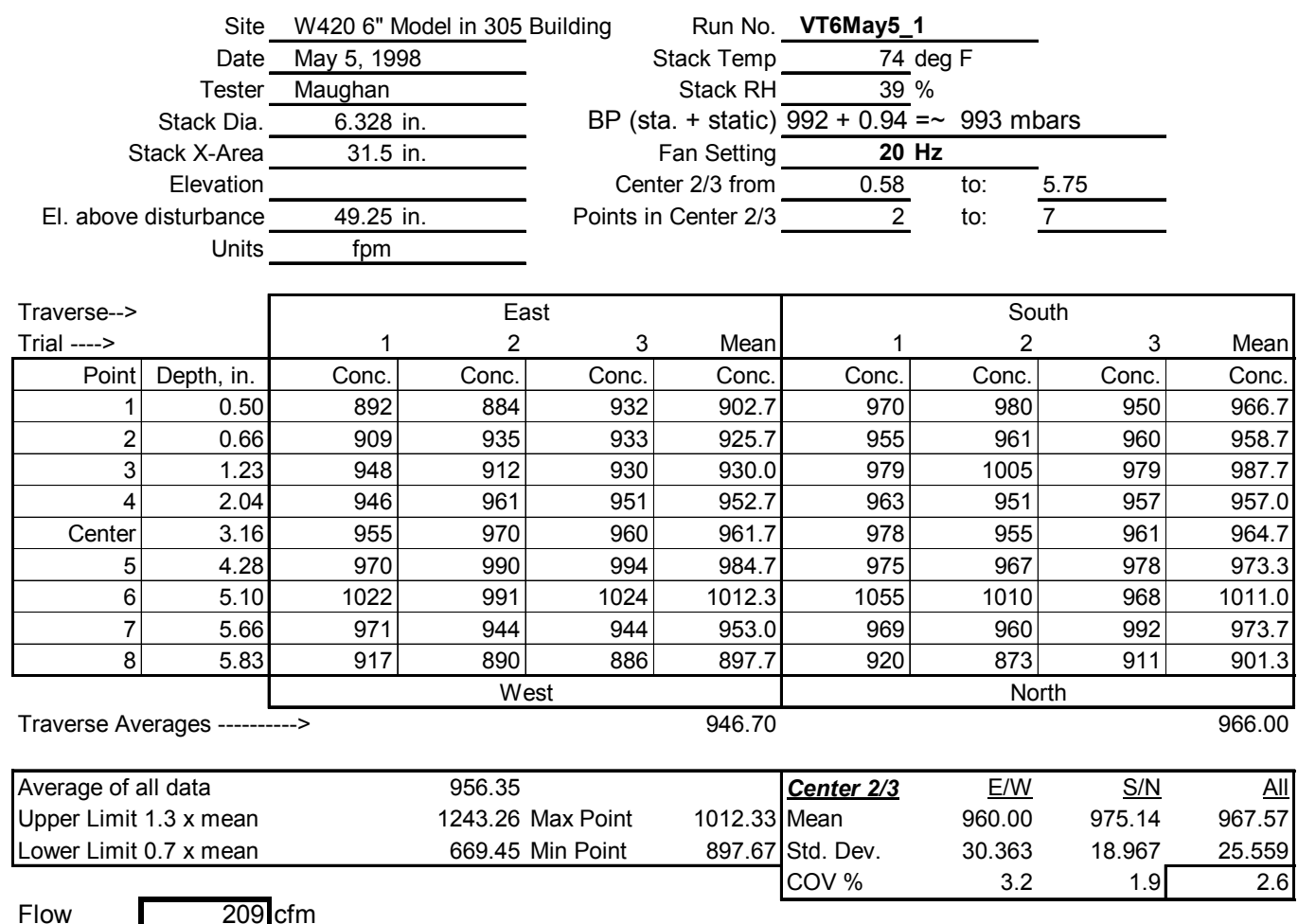

Flow $355 \mathrm{~m} 3 / \mathrm{hr}$

Notes:
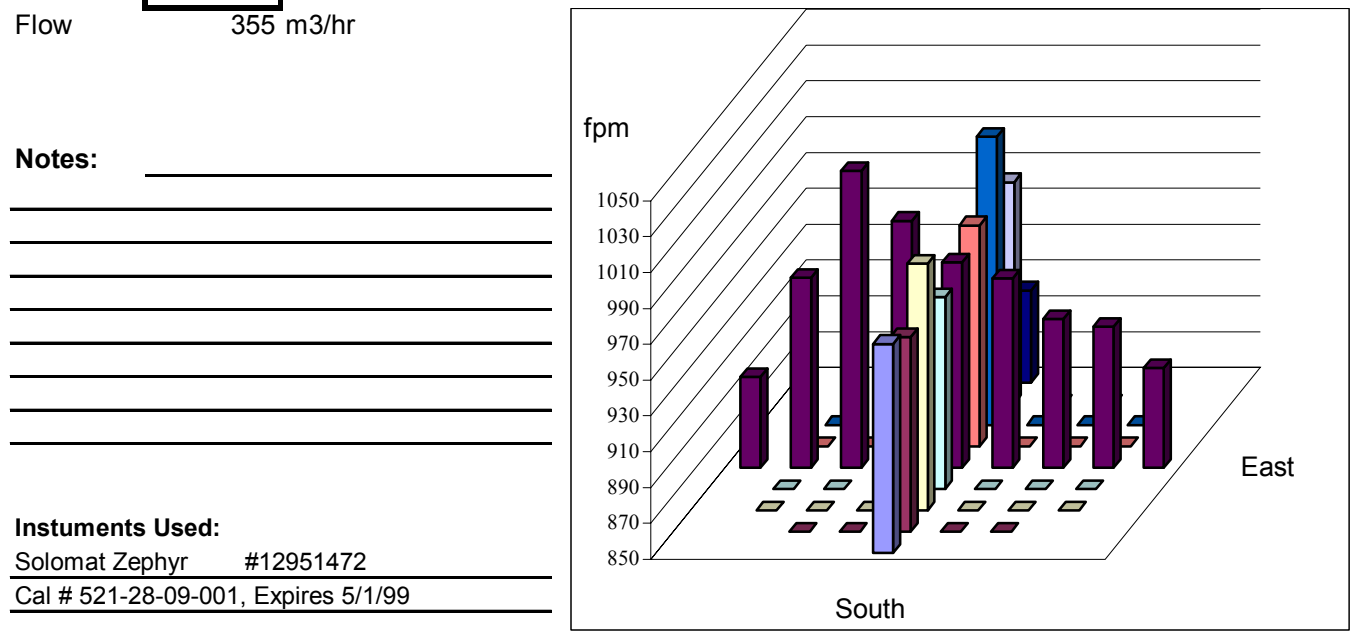

Signature signifying compliance with Procedure EMS-JAG-04

Signature/Date 
Figure D.2. Illustrative Test Instruction

\begin{tabular}{|c|c|c|}
\hline \multicolumn{3}{|c|}{ Test Instruction } \\
\hline $\begin{array}{l}\text { Project: W420 6" Stack } \\
\text { Calibration } 28361\end{array}$ & Date: August 19, 1998 & Work Package: K83017 \\
\hline \multicolumn{3}{|c|}{ Tests: Velocity Uniformity High Flow in W420 6" Full-Scale Model Stack } \\
\hline \multicolumn{3}{|l|}{ Staff: David Maughan } \\
\hline \multicolumn{3}{|c|}{$\begin{array}{l}\text { Reference Procedures: } \\
\text { 1. } \quad \text { Operating Manual for Solomat Zephyr } \\
\text { 2. } \quad \text { Test to Determine Uniformity of Gas Velocity at the Elevation of a Sampler Probe, } \\
\text { Procedure EMS-JAG-04 }\end{array}$} \\
\hline \multicolumn{3}{|c|}{$\begin{array}{l}\text { Equipment: } \\
\text { 1. } \quad \text { W420 6" Full-Scale Model Stack, Fan and Fan Speed Controller located in } 305 \text { Bldg. } \\
\text { 2. }\end{array}$} \\
\hline \multicolumn{3}{|c|}{$\begin{array}{l}\text { Safety Considerations: } \\
\text { Review and observe the applicable Numatec Job Hazard Analysis for the project }\end{array}$} \\
\hline \multicolumn{3}{|l|}{$\begin{array}{l}\text { 1. Assemble the equ } \\
\text { the sampling probe }\end{array}$} \\
\hline \multicolumn{3}{|c|}{$\begin{array}{l}\text { Layout the measurement points with the following distances from the inside of the } \\
\text { stack wall: } 0.5,0.66,1.23,2.04,3.16,4.28,5.10,5.66,5.83 \text { inches. } 3 \text {. Measure the } \\
\text { velocity at each point at the high }(400 \mathrm{cfm}) \text { extreme of stack flow. Repeat each measurement } \\
\text { twice. }\end{array}$} \\
\hline \multirow{2}{*}{\multicolumn{3}{|c|}{ Record data on velocity data sheets }} \\
\hline & & \\
\hline \multicolumn{3}{|c|}{ Desired Completion Date: $12 / 5 / 98$} \\
\hline \multicolumn{3}{|l|}{ Approvals: } \\
\hline John Glissm & oject manager & Date \\
\hline Test completed by: & & \\
\hline
\end{tabular}


Appendix E

Air Velocity Uniformity Data Sheets 


\section{VELOCITY TRAVERSE DATA FORM}

Site $291 \mathrm{Z1}$ Model

Date Oct. 16, 2001

Testers Glissmeyer and Maughan

Stack Dia.

Stack X-Area

Elevation

Distance to disturbance

Velocity units $\mathrm{ft} / \mathrm{min}$
Run No. VT-1

Fan Configuration 4-fan: EF1, EF4, EF5, EF7

Fan Setting $\mathbf{5 1 ~ H z}$

Stack Temp

1432-1530 hours

Center $2 / 3$ from

Points in Center 2/3

Data Files: NA

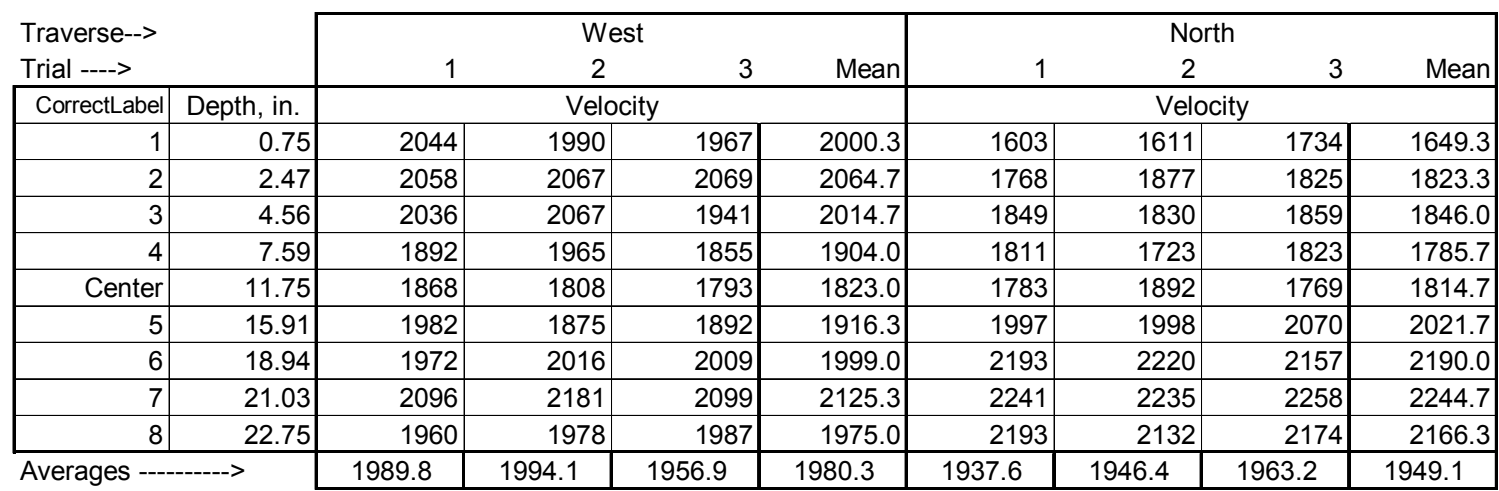

\begin{tabular}{|c|c|c|c|c|c|c|}
\hline$A I I$ & $\mathrm{ft} / \mathrm{min}$ & Dev. from mean & Center $2 / 3$ & West & North & All \\
\hline Mean & 1964.7 & & Mean & 1978.1 & 1960.9 & 1969.5 \\
\hline Min Point & 1649.3 & $-16.1 \%$ & Std. Dev. & 103.5 & 191.9 & 148.4 \\
\hline Max Point & 2244.7 & $14.3 \%$ & COV as $\%$ & 5.2 & 9.8 & 7.5 \\
\hline
\end{tabular}

Flow w/o C-Pt 5973 acfm

Vel Avg w/o C-Pt 1983 fpm

Stack temp

Equipment temp

Ambient temp

Stack static

Ambient pressure

Total Stack pressure

Ambient humidity

\begin{tabular}{|c|c|}
\hline Start & Finish \\
\hline 72.5 & 70.8 \\
\hline 71.6 & 75 \\
\hline 70 & 70.7 \\
\hline 0.5 & 0.52 \\
\hline 986.3 & 985.8 \\
\hline 986.8 & 986.3 \\
\hline $38 \%$ & $36 \%$ \\
\hline
\end{tabular}

Notes:

Initial trial run to evaluate stack and instrument configuration.

\section{Instuments Used:}

Pitot \#5, 36-in. standard

Solmat Zephyr SN 12951472 Cal. Due 7/26/02

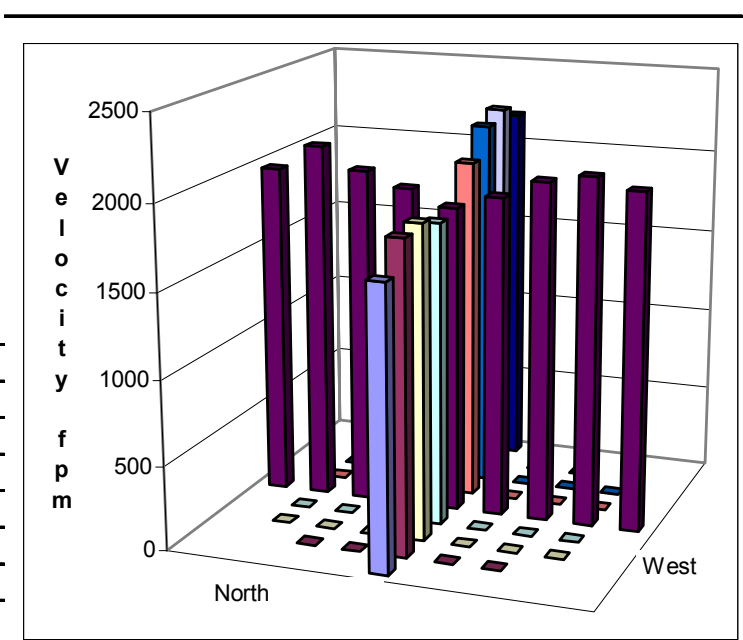




\section{VELOCITY TRAVERSE DATA FORM}

Site $291 \mathrm{Z1}$ Model

Date 18 Oct. 2001

Testers Maughan

Stack Dia.

Stack X-Area

Elevation

Distance to disturbance

Velocity units $\underline{\mathrm{ft} / \mathrm{min}}$
Run No. VT-2

Fan Configuration 4-fan: EF1, EF4, EF5, EF7

Fan Setting $30 \mathrm{~Hz}$

Stack Temp

$52.4 \operatorname{deg} \mathrm{F}$

Start/End Time $850-945 \mathrm{hrs}$

Center 2/3 from

Points in Center 2/3

Data Files: NA

\begin{tabular}{|c|c|c|c|c|c|c|c|c|c|}
\hline \multirow{2}{*}{\multicolumn{2}{|c|}{$\begin{array}{l}\text { Traverse--> } \\
\text { Trial ----> }\end{array}$}} & \multicolumn{4}{|c|}{ West } & \multicolumn{4}{|c|}{ North } \\
\hline & & \multicolumn{2}{|l|}{1} & 3 & Mean & 1 & 2 & 3 & Mean \\
\hline CorrectLabel & Depth, in. & \multicolumn{4}{|c|}{ Velocity } & \multicolumn{4}{|c|}{ Velocity } \\
\hline 1 & 0.75 & 1188 & 1178 & 1126 & 1164.0 & 959 & 1002 & 996 & 985.7 \\
\hline 2 & 2.47 & 1212 & 1250 & 1194 & 1218.7 & 1054 & 1101 & 1039 & 1064.7 \\
\hline 3 & 4.56 & 1141 & 1213 & 1163 & 1172.3 & 1054 & 1046 & 1014 & 1038.0 \\
\hline 4 & 7.59 & 1196 & 1129 & 1104 & 1143.0 & 1045 & 1095 & 1036 & 1058.7 \\
\hline Center & 11.75 & 1103 & 1083 & 1050 & 1078.7 & 1055 & 1056 & 1040 & 1050.3 \\
\hline 5 & 15.91 & 1097 & 1091 & 1054 & 1080.7 & 1205 & 1211 & 1129 & 1181.7 \\
\hline 6 & 18.94 & 1108 & 1199 & 1101 & 1136.0 & 1251 & 1224 & 1237 & 1237.3 \\
\hline 7 & 21.03 & 1257 & 1226 & 1221 & 1234.7 & 1350 & 1309 & 1281 & 1313.3 \\
\hline 8 & 22.75 & 1068 & 1180 & 1131 & 1126.3 & 1270 & 1201 & 1231 & 1234.0 \\
\hline Averages --- & $--->$ & 1152.2 & 1172.1 & 1127.1 & 1150.5 & 1138.1 & 1138.3 & 1111.4 & 1129.3 \\
\hline
\end{tabular}

\begin{tabular}{|c|c|c|c|c|c|c|}
\hline$A I I$ & $\mathrm{ft} / \mathrm{min}$ & Dev. from mean & Center 2/3 & West & North & All \\
\hline Mean & 1139.9 & & Mean & 1152.0 & 1134.9 & 1143.4 \\
\hline Min Point & 985.7 & $-13.5 \%$ & Std. Dev. & 61.2 & 109.4 & 85.6 \\
\hline Max Point & 1313.3 & $15.2 \%$ & COV as $\%$ & 5.3 & 9.6 & 7.5 \\
\hline
\end{tabular}

Flow w/o C-Pt Vel Avg w/o C-Pt

3462 acfm

$1149 \mathrm{fpm}$

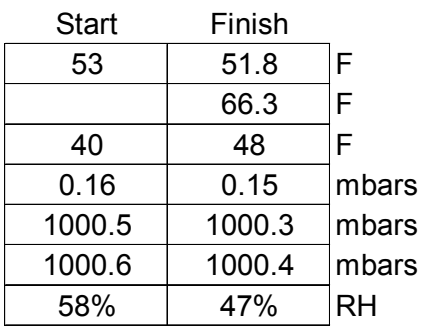

Notes: $\quad E / \mathrm{W}$ dimension $=235 / 16$ inches $\mathrm{N} / \mathrm{S}$ dimension $=23$ 9/16 inches

tack temp

Equipment temp

Ambient temp

Stack static

Ambient pressure

Total Stack pressure

Ambient humidity
Instuments Used:

Pitot \#5, 36-in. standard

Solmat Zephyr SN 12951472 Cal. Due 7/26/02

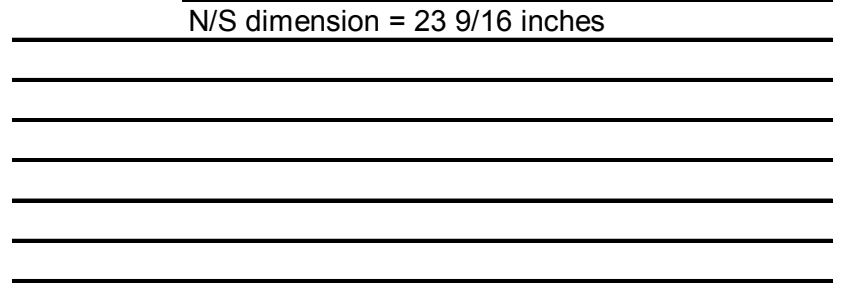

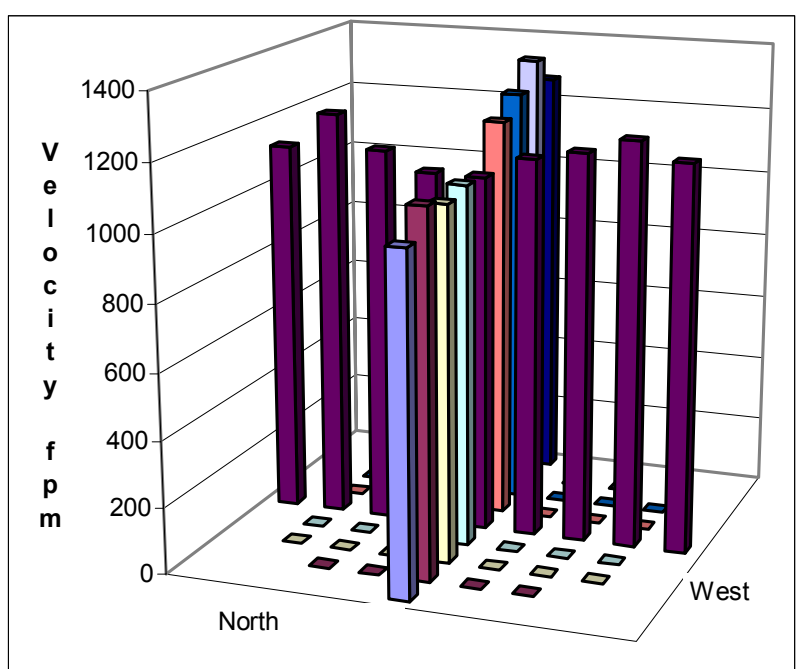




\begin{tabular}{|c|c|c|c|c|c|}
\hline \multicolumn{6}{|c|}{ VELOCITY TRAVERSE DATA FORM } \\
\hline \multicolumn{2}{|c|}{ Site $291 \mathrm{Z1}$ Model } & Run No. & VT-3 & & \\
\hline \multicolumn{2}{|c|}{ Date $\overline{18 \text { Oct. } 2001}$} & Fan Configuration & 4-fan: EF1, & 4, EF5, E & EFF7 \\
\hline \multicolumn{2}{|c|}{ Testers Glissmeyer/Maughan } & Fan Setting & $50 \mathrm{~Hz}$ & & \\
\hline Stack Dia. & $23.5 \mathrm{in}$. & Stack Temp & 69.5 & & \\
\hline Stack X-Area & 433.7 in. 2 & Start/End Time & $1320-1405$ & & \\
\hline Elevation & & Center $2 / 3$ from & 2.16 & to: & 21.34 \\
\hline Distance to disturbance & 75 inches & Points in Center $2 / 3$ & 2 & to: & 7 \\
\hline Velocity units & $\underline{\mathrm{ft} / \mathrm{min}}$ & Data Files: & $\overline{\mathrm{NA}}$ & & \\
\hline
\end{tabular}

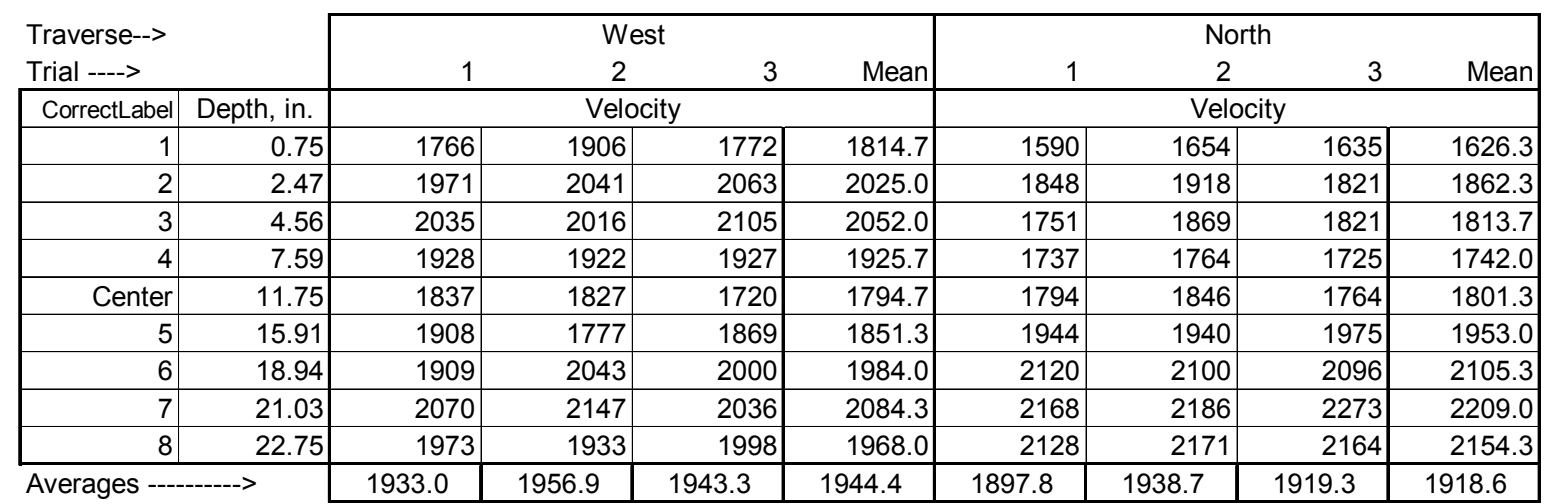

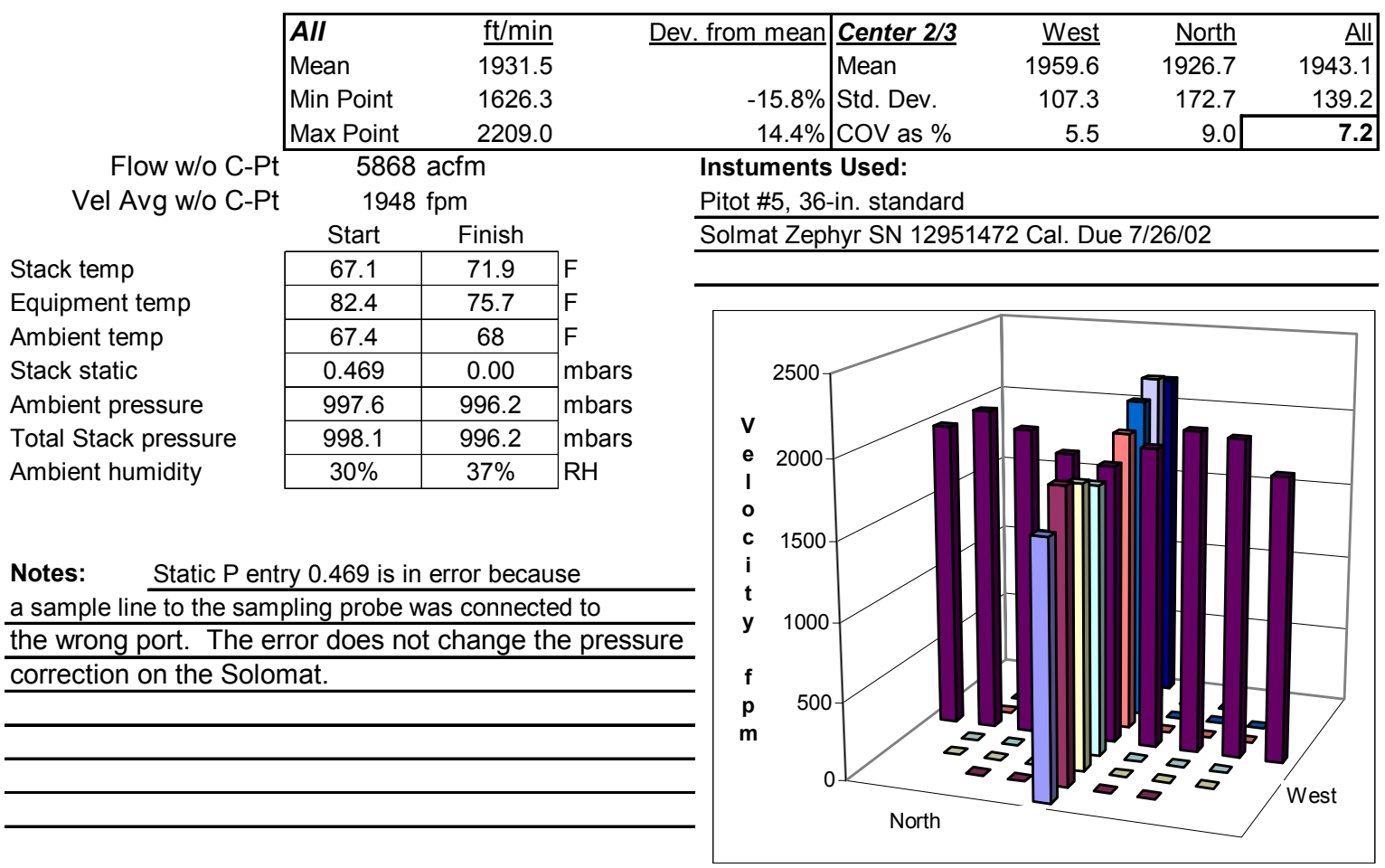




\section{VELOCITY TRAVERSE DATA FORM}

Site $291 \mathrm{Z1}$ Model Date 10/18/01

Testers Glissmeyer/Maughan

Stack Dia.

Stack X-Area

Elevation

Distance to disturbance

Velocity units $\underline{\mathrm{ft} / \mathrm{min}}$
Run No. VT-4

Fan Configuration 4-fan: EF1, EF4, EF5, EF7

Fan Setting $\mathbf{5 0 ~} \mathbf{~ z z}$

Stack Temp

Start/End Time $1510-1550$ hours

Center $2 / 3$ from $2.16 \quad$ to: 21.34

Points in Center $2 / 3 \overline{2}$ to: $\overline{7}$

Data Files: NA

\begin{tabular}{|c|c|c|c|c|c|c|c|c|c|}
\hline \multirow{2}{*}{\multicolumn{2}{|c|}{$\begin{array}{l}\text { Traverse---> } \\
\text { Trial ----> }\end{array}$}} & \multicolumn{4}{|c|}{ West } & \multicolumn{4}{|c|}{ North } \\
\hline & & 1 & 2 & 3 & Mean & 1 & 2 & 3 & Mean \\
\hline CorrectLabel & Depth, in. & \multicolumn{4}{|c|}{ Velocity } & \multicolumn{4}{|c|}{ Velocity } \\
\hline 1 & 0.75 & 1951 & 1728 & 1742 & 1807.0 & 1688 & 1710 & 1639 & 1679.0 \\
\hline 2 & 2.47 & 1997 & 2025 & 2001 & 2007.7 & 1764 & 1763 & 1760 & 1762.3 \\
\hline 3 & 4.56 & 1995 & 1860 & 1920 & 1925.0 & 1778 & 1757 & 1677 & 1737.3 \\
\hline 4 & 7.59 & 1893 & 1856 & 1795 & 1848.0 & 1757 & 1822 & 1679 & 1752.7 \\
\hline Center & 11.75 & 1724 & 1684 & 1863 & 1757.0 & 1774 & 1847 & 1764 & 1795.0 \\
\hline 5 & 15.91 & 1842 & 1734 & 1893 & 1823.0 & 1955 & 1992 & 1917 & 1954.7 \\
\hline 6 & 18.94 & 1874 & 1804 & 1986 & 1888.0 & 2134 & 2109 & 2123 & 2122.0 \\
\hline 7 & 21.03 & 1997 & 2007 & 1937 & 1980.3 & 2154 & 2121 & 2121 & 2132.0 \\
\hline 8 & 22.75 & 1910 & 2017 & 2019 & 1982.0 & 2124 & 2123 & 2132 & 2126.3 \\
\hline Averages -- & ------> & 1909.2 & 1857.2 & 1906.2 & 1890.9 & 1903.1 & 1916.0 & 1868.0 & 1895.7 \\
\hline
\end{tabular}

\begin{tabular}{|c|c|c|c|c|c|c|}
\hline$\overline{A I I}$ & $\mathrm{ft} / \mathrm{min}$ & Dev. from mean & Center 2/3 & West & North & Al \\
\hline Mean & 1893.3 & & Mean & 1889.9 & 1893.7 & 1891. \\
\hline Min Point & 1679.0 & $-11.3 \%$ & Std. Dev. & 88.7 & 175.1 & 133. \\
\hline Max Point & 2132.0 & $12.6 \%$ & COV as $\%$ & 4.7 & 9.2 & 7. \\
\hline
\end{tabular}

Flow w/o C-Pt

Vel Avg w/o C-Pt

Stack temp

Equipment temp

Ambient temp

Stack static

Ambient pressure

Total Stack pressure

Ambient humidity
5747 acfm

1908 fpm

\begin{tabular}{|c|c|c|}
\multicolumn{1}{r|}{ Start } & Finish & \\
\hline 71.9 & 68 & $\mathrm{~F}$ \\
\cline { 1 - 2 } 75.7 & 76.1 & $\mathrm{~F}$ \\
\cline { 1 - 2 } 68.0 & 68.7 & $\mathrm{~F}$ \\
\hline 0.00 & 0.00 & mbars \\
\cline { 1 - 2 } 996.2 & 995.5 & mbars \\
\cline { 1 - 2 } 996.2 & 995.5 & mbars \\
\cline { 1 - 2 } $37 \%$ & $27 \%$ & $\mathrm{RH}$ \\
\hline
\end{tabular}

Notes: $\quad E / W$ dimension $=235 / 16$ inches $\mathrm{N} / \mathrm{S}$ dimension $=239 / 16$ inches

Instuments Used:

Pitot \#5, 36-in. standard

\section{Solmat Zephyr SN 12951472 Cal. Due 7/26/02}

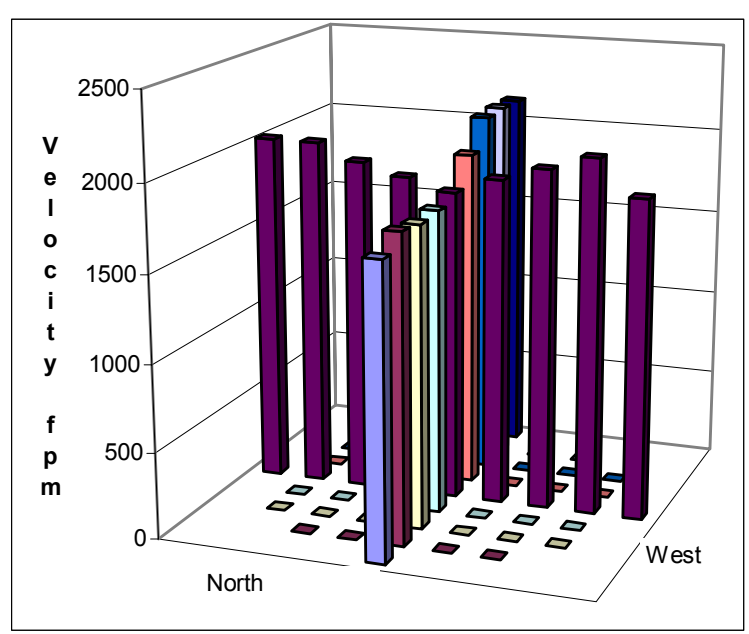




\section{VELOCITY TRAVERSE DATA FORM}

Site $291 \mathrm{Z1}$ Model

Date 11/13/2001

Testers Glissmeyer

Stack Dia.

Stack X-Area

Elevation N.A.

Distance to disturbance

Velocity units $\underline{\mathrm{ft} / \mathrm{min}}$
Run No. VT-5

Fan Configuration Turbine Fans

Fan Setting $60 \mathrm{~Hz}$

Stack Temp $61.0 \mathrm{deg} F$

Start/End Time 1011/1100

Center $2 / 3$ from

Points in Center $2 / 3$

Data Files: NA

\begin{tabular}{|c|c|c|c|c|c|c|c|c|c|}
\hline \multirow{2}{*}{\multicolumn{2}{|c|}{$\begin{array}{l}\text { Traverse--> } \\
\text { Trial ----> }\end{array}$}} & \multicolumn{4}{|c|}{ West } & \multicolumn{4}{|c|}{ North } \\
\hline & & 1 & 2 & 3 & \multirow[t]{2}{*}{ Mean } & \multirow{2}{*}{\multicolumn{2}{|c|}{$\frac{2}{\mathrm{Vel}}$}} & 3 & Mean \\
\hline CorrectLabel & Depth, in. & \multicolumn{3}{|c|}{ Velocity } & & & & \multicolumn{2}{|c|}{ Velocity } \\
\hline 1 & 0.75 & 1132 & 1327 & 1313 & 1257.3 & 856 & 905 & 946 & 902.3 \\
\hline 2 & 2.47 & 1371 & 1448 & 1360 & 1393.0 & 1038 & 1027 & 1043 & 1036.0 \\
\hline 3 & 4.56 & 1332 & 1385 & 1318 & 1345.0 & 1062 & 1053 & 1077 & 1064.0 \\
\hline 4 & 7.59 & 1251 & 1365 & 1402 & 1339.3 & 1142 & 1073 & 1160 & 1125.0 \\
\hline Center & 11.75 & 1300 & 1366 & 1363 & 1343.0 & 1263 & 1320 & 1302 & 1295.0 \\
\hline 5 & 15.91 & 1372 & 1319 & 1374 & 1355.0 & 1500 & 1504 & 1470 & 1491.3 \\
\hline 6 & 18.94 & 1475 & 1347 & 1462 & 1428.0 & 1578 & 1575 & 1676 & 1609.7 \\
\hline 7 & 21.03 & 1537 & 1503 & 1462 & 1500.7 & 1631 & 1668 & 1670 & 1656.3 \\
\hline 8 & 22.75 & 1377 & 1425 & 1407 & 1403.0 & 1561 & 1582 & 1461 & 1534.7 \\
\hline Averages --- & -------> & 1349.7 & 1387.2 & 1384.6 & 1373.8 & 1292.3 & 1300.8 & 1311.7 & 1301.6 \\
\hline
\end{tabular}

\begin{tabular}{|lrr|lrrr|}
\hline All & $\underline{\mathrm{ft} / \mathrm{min}}$ & Dev. from mean & Center 2/3 & $\underline{\text { West }}$ & $\underline{\text { North }}$ & $\underline{\text { All }}$ \\
Mean & 1337.7 & & Mean & 1386.3 & 1325.3 & 1355.8 \\
Min Point & 902.3 & $-32.5 \%$ & Std. Dev. & 60.0 & 261.7 & 185.2 \\
Max Point & 1656.3 & $23.8 \%$ & COV as $\%$ & 4.3 & 19.7 & $\mathbf{1 3 . 7}$ \\
\hline
\end{tabular}

Flow w/o C-Pt Vel Avg w/o C-Pt

Stack temp Equipment temp Ambient temp

Stack static

Ambient pressure

Total Stack pressure

Ambient humidity

\begin{tabular}{|c|c|l}
\multicolumn{1}{|c|}{ Start } & Finish & \\
\hline 57 & 65 & $\mathrm{~F}$ \\
\hline 66 & 76 & $\mathrm{~F}$ \\
\hline 44 & 50 & $\mathrm{~F}$ \\
\hline-0.006 & -0.01 & mbars \\
\hline 985.9 & 985.6 & mbars \\
\hline 985.9 & 985.6 & mbars \\
\hline $84 \%$ & $70 \%$ & $\mathrm{RH}$ \\
\hline
\end{tabular}

Instuments Used:

Pitot \#5, 36-in. standard

Solmat Zephyr SN 12951472 Cal. Due 7/26/02

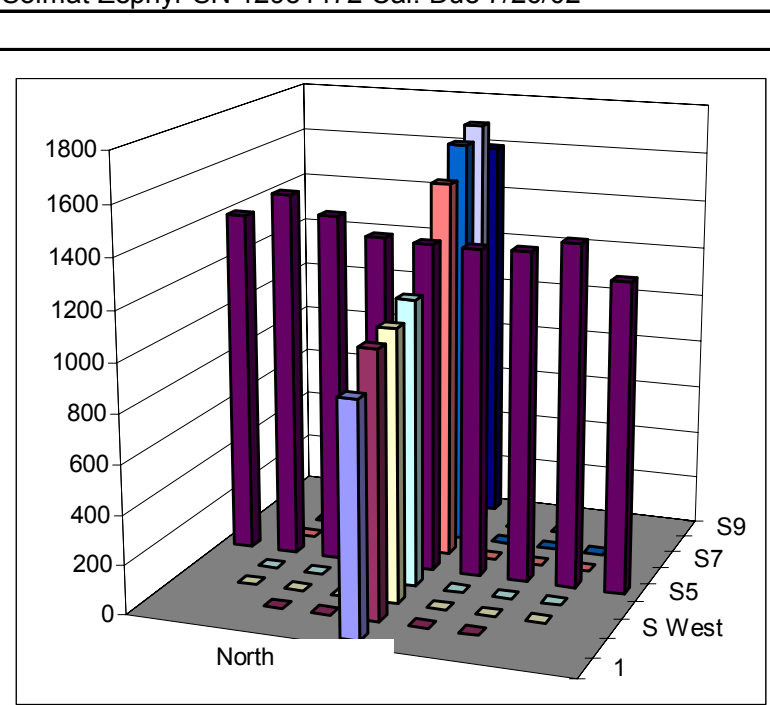




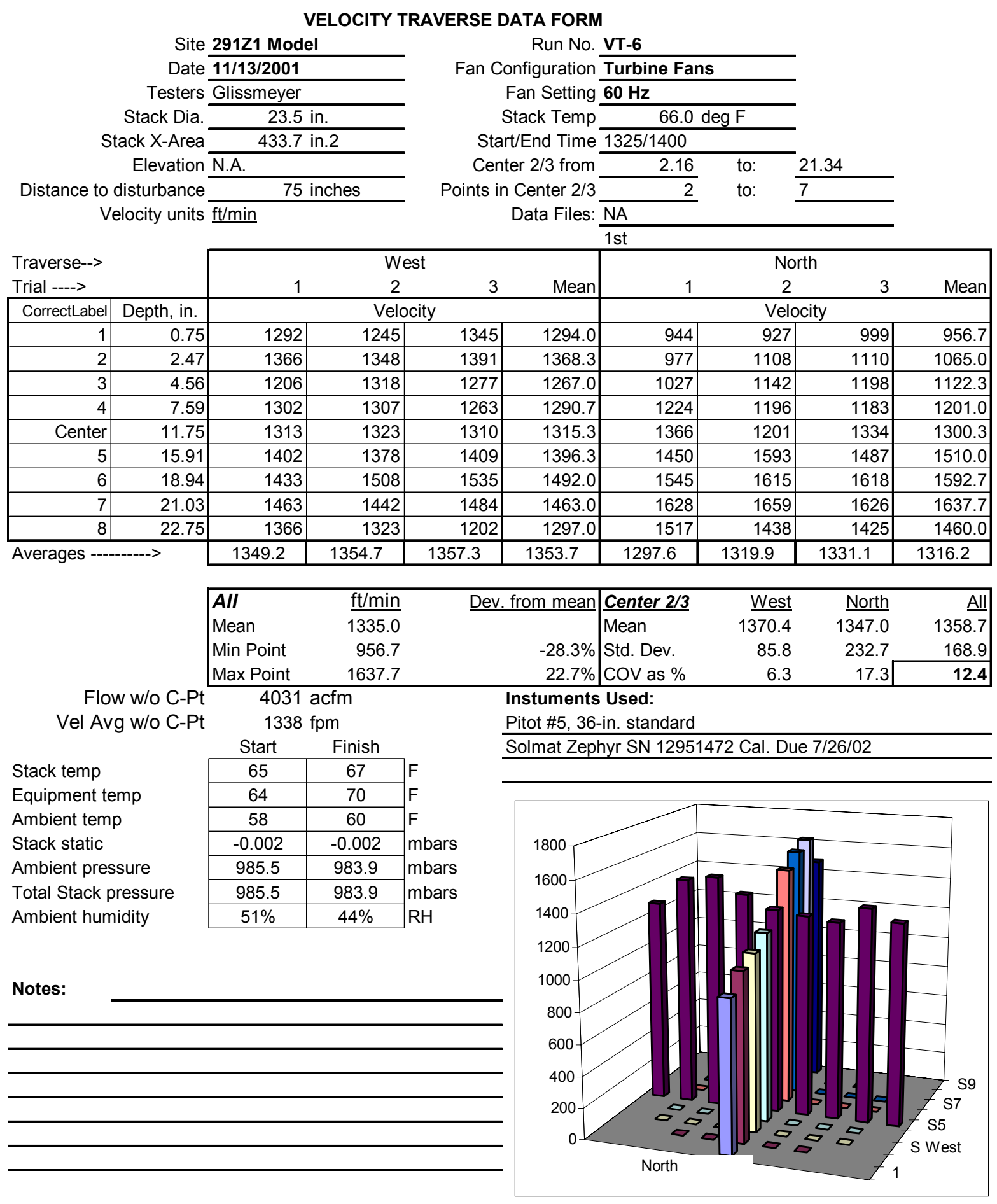




\section{VELOCITY TRAVERSE DATA FORM}

Site $291 Z 1$ Model

Date 11/26/01

Testers Glissmeyer

Stack Dia.

Stack X-Area

Elevation N.A.

Distance to disturbance

Velocity units $\underline{\mathrm{ft} / \mathrm{min}}$
Run No. VT-7

Fan Configuration Turbine Fans, 30 DEGREES EAST PORT

Fan Setting $60 \mathrm{~Hz}$

Stack Temp $55.5 \mathrm{deg} \mathrm{F}$

Start/End Time 1430/1515

Center $2 / 3$ from

Points in Center $2 / 3$

Data Files: $\overline{N A}$

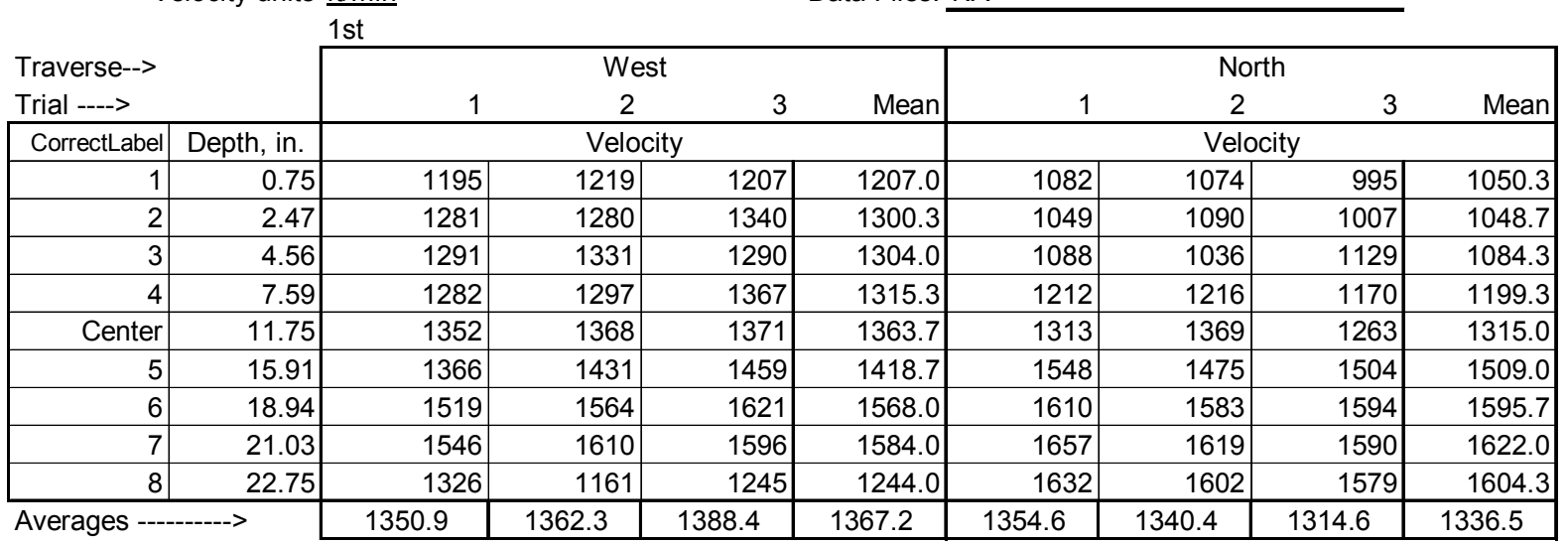

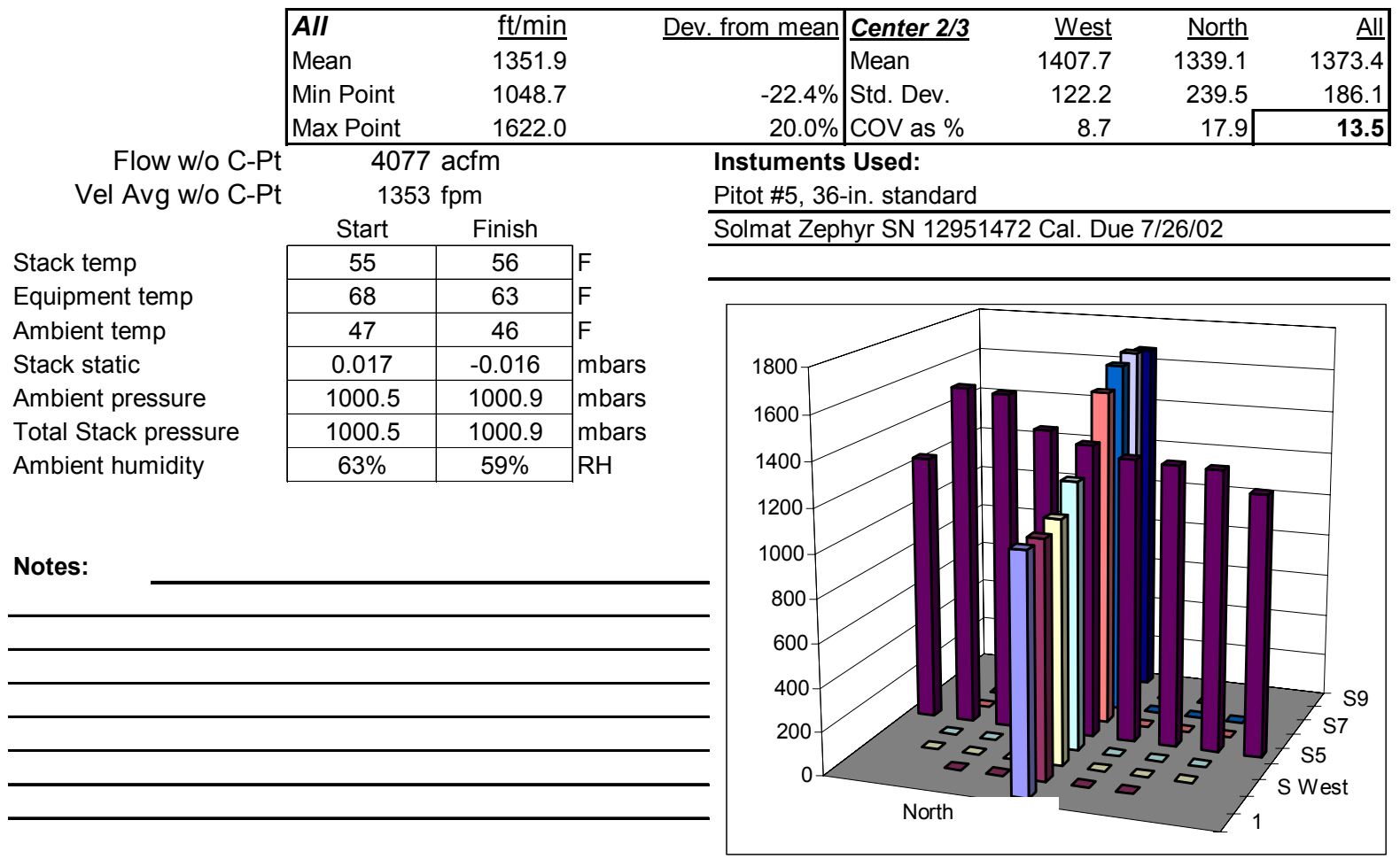




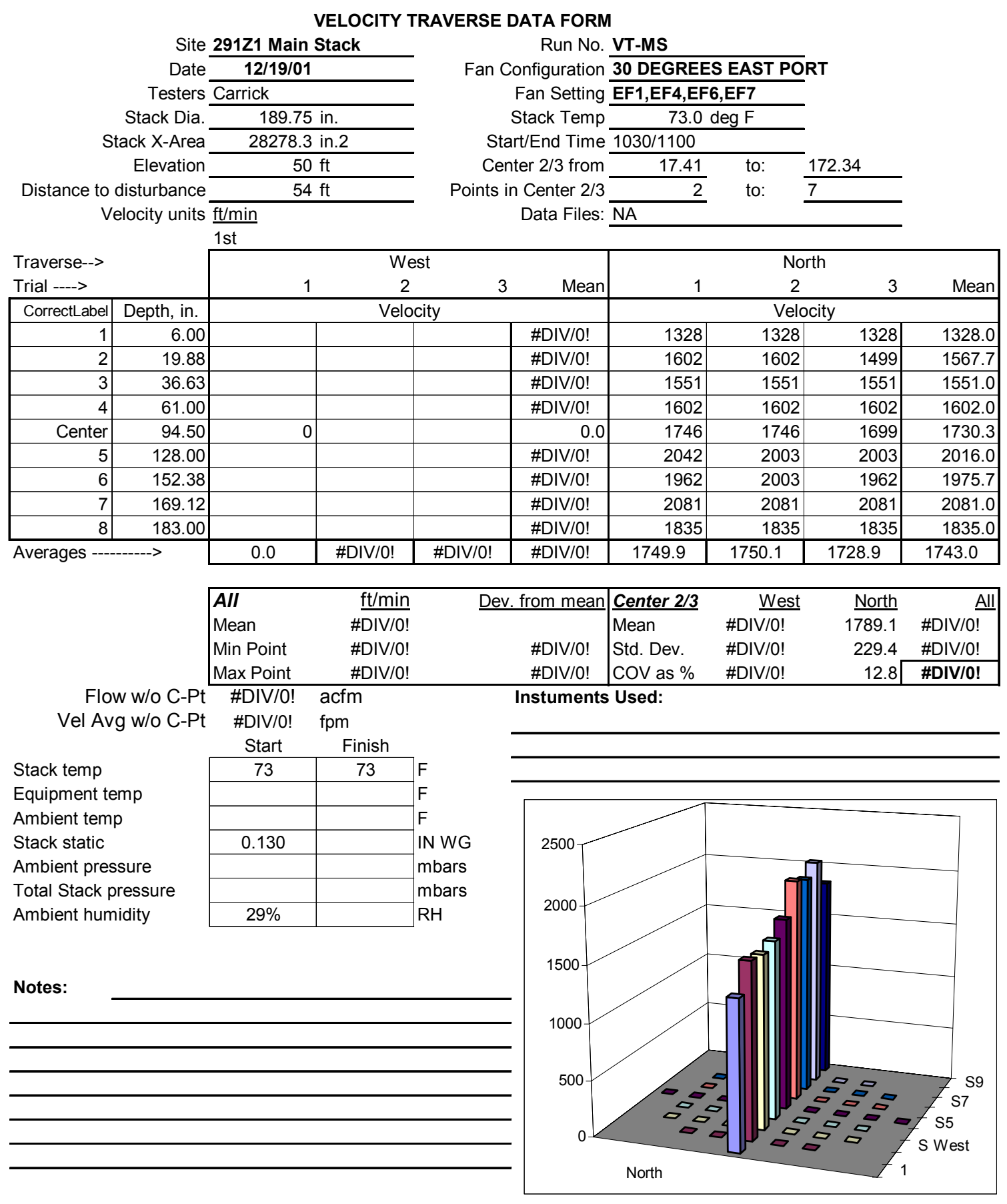




\section{VELOCITY TRAVERSE DATA FORM}

Site $291 \mathrm{Z1}$ Main Stack

Date 12/19/01

Testers Carrick

Stack Dia.

Stack X-Area

Elevation

Distance to disturbance

Velocity units $\underline{\mathrm{ft} / \mathrm{min}}$
189.75 in

28278.3 in. 2

$50 \mathrm{ft}$

$54 \mathrm{ft}$

1 st
Run No. VT-MS

Fan Configuration 30 DEGREES EAST PORT

Fan Setting EF1,EF4,EF6,EF7

Stack Temp $73.0 \mathrm{deg} F$

Start/End Time 1030/1100

Center $2 / 3$ from 17.41 to: 172.34

Points in Center 2/3

Data Files: NA

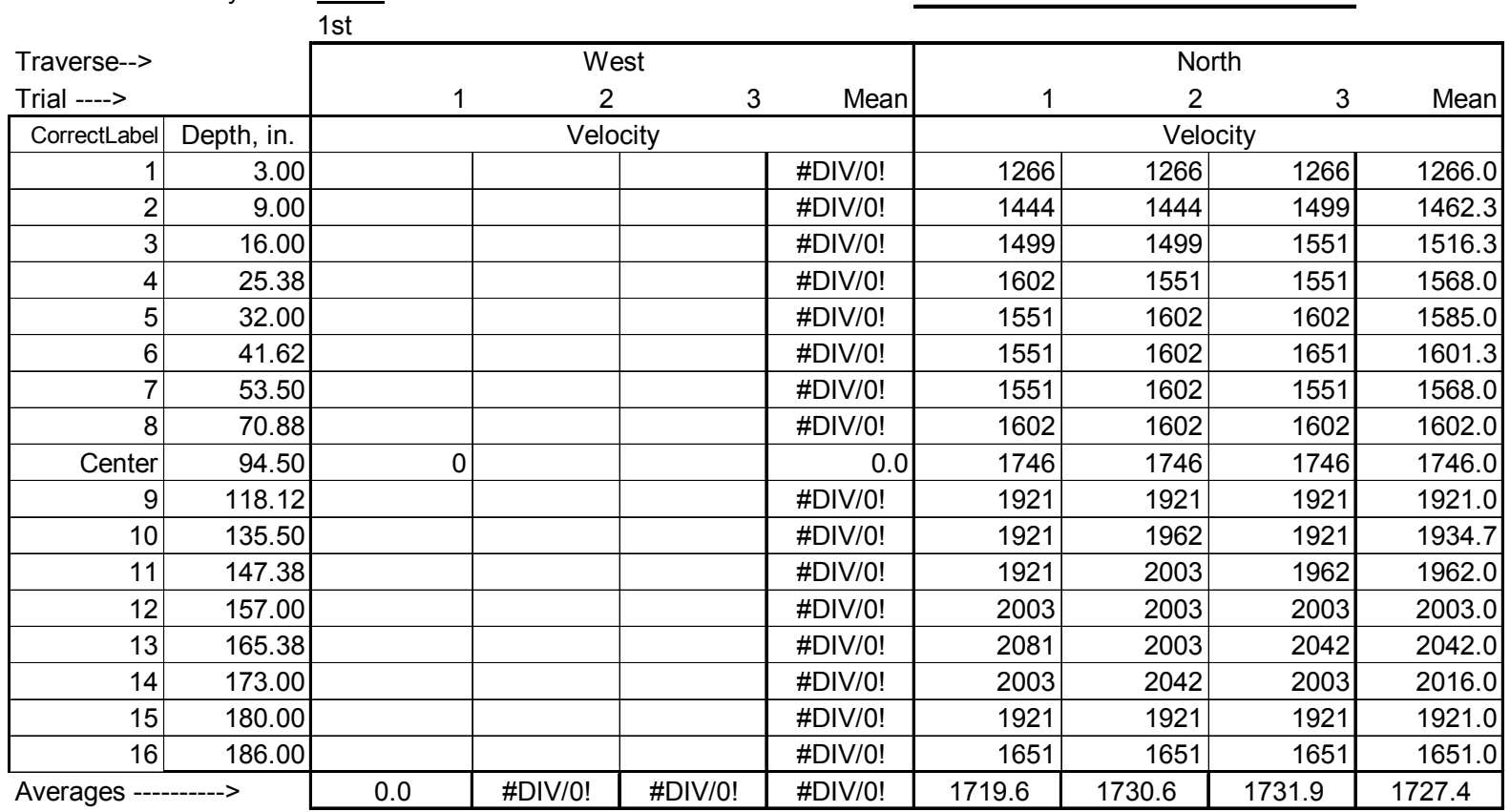

\begin{tabular}{|c|c|c|c|c|c|c|}
\hline II & $\mathrm{ft} / \mathrm{min}$ & Dev. from mean & Center 2/3 & West & North & All \\
\hline ean & \#DIV/0! & & Mean & \#DIV/O! & $1 \overline{1775.7}$ & \#DIV/O! \\
\hline oint & \#DIV/0! & \#DIV/O! & Std. Dev. & \#DIV/O! & 196.9 & \#DIV/O! \\
\hline Point & \#DIV/0! & \#DIV/0! & cov as $\%$ & \#DIV/0! & 11.1 & \#DIV/0! \\
\hline
\end{tabular}

Flow w/o C-Pt \#DIV/O! acfm Instuments Used:

Vel Avg w/o C-Pt \#DIV/0! fpm Pitot \#5, 36-in. standard

Stack temp

Equipment temp

Ambient temp

Stack static

Ambient pressure

Total Stack pressure

Ambient humidity

\begin{tabular}{|c|c|l|}
\multicolumn{1}{c|}{ Start } & \multicolumn{1}{c|}{ Finish } & \multicolumn{1}{c|}{73} \\
\hline 73 & 73 & $F$ \\
\hline & & $F$ \\
\hline & & F \\
\hline 0.130 & & in wg \\
\hline 29.4 & & in Hg \\
& & mbars \\
\hline $29 \%$ & & RH \\
\hline
\end{tabular}

Solmat Zephyr SN 12951472 Cal. Due 7/26/02

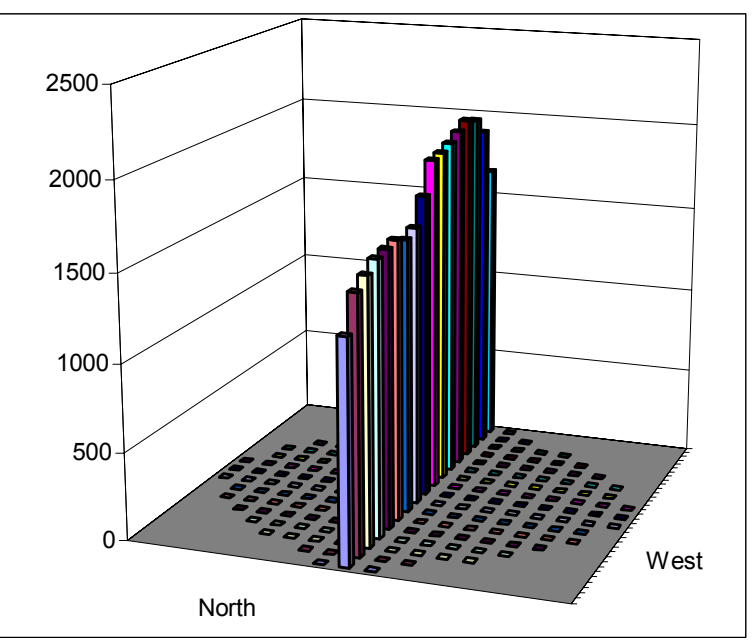




\section{Appendix F \\ Angular Flow Testing Procedure}




\section{F.1 Purpose}

The performance of new stack sampling systems must be shown to satisfy the requirements of 40 CFR 61, Subpart H, "National Emission standards for Emissions of Radionuclides Other than Radon from Department of Energy Facilities." This regulation governs portions of the design and implementation of effluent air sampling. The stack sampler performance is adequately characterized when potential contaminants in the effluent are of a uniform concentration at the sampling plane and line losses are within acceptable limits. (The sampling plane is the cross section of the stack or duct where the sampling nozzle inlet is located.) Uniformity of contaminant concentration is highly unlikely where the mean angle of the gas velocity throughout the cross section of the stack or duct is significantly non-zero. This condition would also mean that the air velocity approaches the sampling nozzle at an unacceptable angle, degrading the performance of the nozzle. This procedure provides the means to determine the mean flow angle, and is performed prior to measurements of contaminant uniformity. This procedure is performed after the range of gas flow conditions is established. Other associated procedures generally follow and address uniformity of flow and of gas and aerosol contaminants.

\section{F.2 Applicability}

This procedure can be used in the field or on modeled stacks and ducts to determine the angle of the air velocity relative to the axis of the duct or stack. The angle measured is the roll angle. This should be determined at the sampling plane. The tests are applicable within the following constraints:

- The operating limits of the air velocity measurement device used are observed.

- The air velocity sensor element does not occupy more than a few percent of the crosssectional area in the plane of the element.

This procedure may need to be repeated if there are changes made in the configuration of the ventilation system. If the system under test operates within a limited range of airflow that does not change more than $\pm 25 \%$, this procedure is usually conducted once at the middle of the range. If the flow varies more, the procedure is performed at least at the extremes of flow. 


\section{F.3 Prerequisites and Conditions}

listed below:

Conditions and concerns that must be satisfied prior to performing this procedure are

- The job-hazards analysis for the work area must be prepared and followed.

- Safety glasses, hard toed or substantial shoes may be required in the work areas.

- Scaffold user training may be required to access the sampling ports of the stack.

- A ventilation flow control device must be installed and means available for its adjustment.

- Air velocity measurement equipment must be within calibration.

- The test instruction must be read and understood.

\section{F.4 Precautions and Limitations}

Access to the test ports may require the use of ladders, scaffolding or manlifts, which may necessitate special training for sampling personnel and any observers. The training requirements will be indicated in the job hazard analysis.

\section{F.5 Equipment Used for Measurements}

The following are essential items of equipment:

- A Type-S pitot tube with sufficient length to reach across the diameter of the test stack,

- Slant tube or calibrated electronic manometer to indicate when the differential pressure reading of the pitot tube is about zero,

- Device for measuring the pitot tube angle at traverse points (e.g., a protractor level with good angle resolution). (Note: A three dimensional velocity probe capable of measuring both pitch and yaw angles of gas flow is also acceptable provided that modifications in the method outlined below are made),

- Tape or template to mark insertion depths on the pitot tube,

- Velocity sensor to check the stack airflow,

- Means to obtain temperature and barometric pressure for any corrections needed for the current test conditions,

- Platform, ladders, or manlifts as needed to support equipment and to access the test ports,

- Fittings to limit leakage around the pitot tube and to stabilize the tube so that it can be positioned repeatedly in the test stack at the same location.

Further details on specific equipment for the job are provided in the Test Instruction. The test method is based on 40 CFR 60, Appendix A, Method 1, Section 2.4, "Verification of the Absence of Cyclonic Flow." The measurement instrumentation may be either the type used in Method 1, or another measurement device designed for measuring the angle of the velocity vector at discrete points. The user should be aware that different devices may give different readings. 


\section{F.6 Work Instructions for Setup, Measurements, and Data Reduction}

Job specific instructions given in the Test Instruction, illustrated in Exhibit A, will provide details and operating parameters necessary to perform this procedure. Prior to determination of flow angles, measurements should be made to assess whether the stack velocity flow is within normal limits.

\section{Preliminary Steps:}

Verify that the interior dimensions of the stack or duct at the measurement locations agree with those used in calculating the grid of measurement points given in the test instruction or data sheet.

Note. The grid of measurement points is calculated in accordance with 40 CFR 60, Appendix A, Method 1. A centerpoint is included as a common reference and for graphical purposes. The layout design divides the area of the sampling plane so that each point represents approximately an equal-sized area

Provide essential supplies at the sampling location. (S-Type pitot tube, manometer, tubing, fittings to adapt the sensor to the test ports, marking pens, data sheets, writing and sensor supporting platforms).

Verify that the ventilation flow control device is capable of the flow control settings given in the Test Instruction.

Prepare a data sheet for the measurement traverse. See illustration in Exhibit B. Label the columns of traverse data by the direction of the traverse. For example, if the first reading is closest to the east port, and the last reading is closest to the west port, then label the traverse "east-west".

Mark the Type-S pitot tube to indicate the insertion depth for each point in the measurement grid.

Set the stack flow control per the test instruction. (Use a velocity or flow sensor to verify that correct flow has been achieved.)

Note. Flow verification can be based on a single point velocity reading. The single point can be the same one determined in the stack flow controller calibration in Procedure EMS-JAG-03. The barometric pressure, relative humidity, stack temperature and static pressure values may be needed to convert the velocity sensor readings to velocity units. 
Insert the Type-S pitot tube in the stack or duct, seal the opening around it, and check for smooth operation of the pitot tube.

Note. Good measurements are dependent upon making small repeatable rotations of the pitot tube in the available fittings.

Establish a convention for representing the angular direction of flow.

Note. If an inclined manometer is used, connect the flexible tubes between the connectors on the pitot tube and the manometer so that rotating the pitot tube assembly clockwise drives the meniscus to the right, i.e., to higher positive numbers.

Attach a circular protractor to the pitot tube near the tubing connectors. Generally the protractor hangs below the pitot tubes. When the parallel tubes are in horizontal position, the protractor should indicate zero degrees. If the tubing assembly is rotated clockwise, the resulting counter-clockwise movement of the angle indicator produces an angle that is read as a positive

Position the inclined manometer on a stable platform and level the device using the spirit level.

Note: Movement on the test platform may affect the manometer level. It should be checked frequently. Adjustments can be made at any time when the pitot tube is moved to the next position, but not during readings at any single noint

Connect the flexible tubes to the inclined manometer but disconnect them from the pitot tube.

Increase or decrease the red oil level in the inclined portion of the manometer to zero the meniscus. (This is done using a finger-adjustable screw at the base of the manometer.)

Reconnect the flexible tubes to the pitot tube. 


\section{$\underline{\text { Angular Flow Measurements }}$}

Verify that the directional orientations and the numbered measurement positions are consistent with the data sheet.

Measure and record, on the data sheet, the angular reading at each measurement point in succession. If the readout device has an averaging feature, record the average of a series of several readings.

Note: Each test relies on one repetition for each measurement point in each traverse direction, repeated three times. The repeats are made as three separate runs and not as three consecutive measurements at each point.

The readings may be erratic for some flow conditions and at some traverse positions. Care should be taken to approach these variable readings from both higher and lower angles to obtain the most accurate equilibrium reading.

\section{Repeat Step 6.3.3.}

Compare the results in Step 6.3.4 with those of 6.3.3. If the measurements are not highly reproducible, repeat Step 6.3.3 again.

Calculate the absolute average air-flow angle for each measurement point.

Calculate the average absolute flow angle for all measurement points.

Note: The acceptance criterion is that the average flow angle not exceed 20 Ansmons

$\underline{\text { Review the datasheets for completeness. }}$

Sign and date the datasheets attesting to their validity. 
Figure F.1. Illustrative Test Instruction

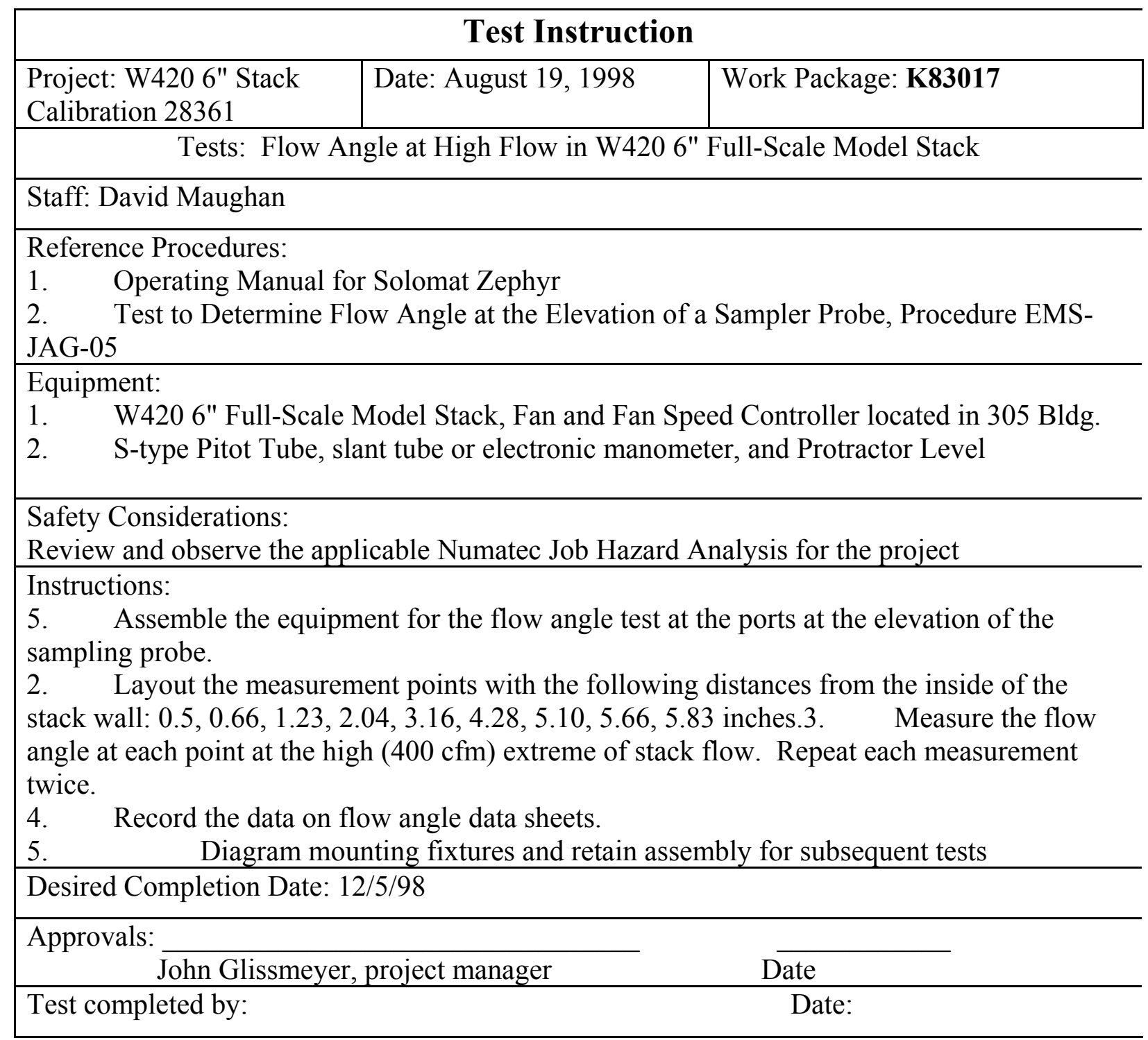




\section{Figure F.2. Illustration of Flow Angle Data Sheet}

\begin{tabular}{|c|c|c|c|c|}
\hline \multicolumn{5}{|c|}{ W420 296-C-5 FLOW ANGLE at High and Low Average Flow Rates } \\
\hline \multicolumn{3}{|c|}{ Site Bldg. 305} & \multicolumn{2}{|l|}{ Run No. } \\
\hline Date & $2 /$ & & Stack Temp & deg. $F$ \\
\hline Tester & & & Stack RH & percent \\
\hline Stack Dia. & 12 & in & Baro Press & mbar \\
\hline Stack X-Area & 113.1 & in2 & Fan Setting & $\mathrm{Hz}$ \\
\hline Elevation & & $-\mathrm{ft}$ & Fan input port & \\
\hline El. above disturbance & & in & Flowrate (pre- \& post-) & and \\
\hline Input air filtered? & & $\mathrm{Y}$ or $\mathrm{N}$ & Approx. avg. Flowrate & cfm at centerline \\
\hline
\end{tabular}

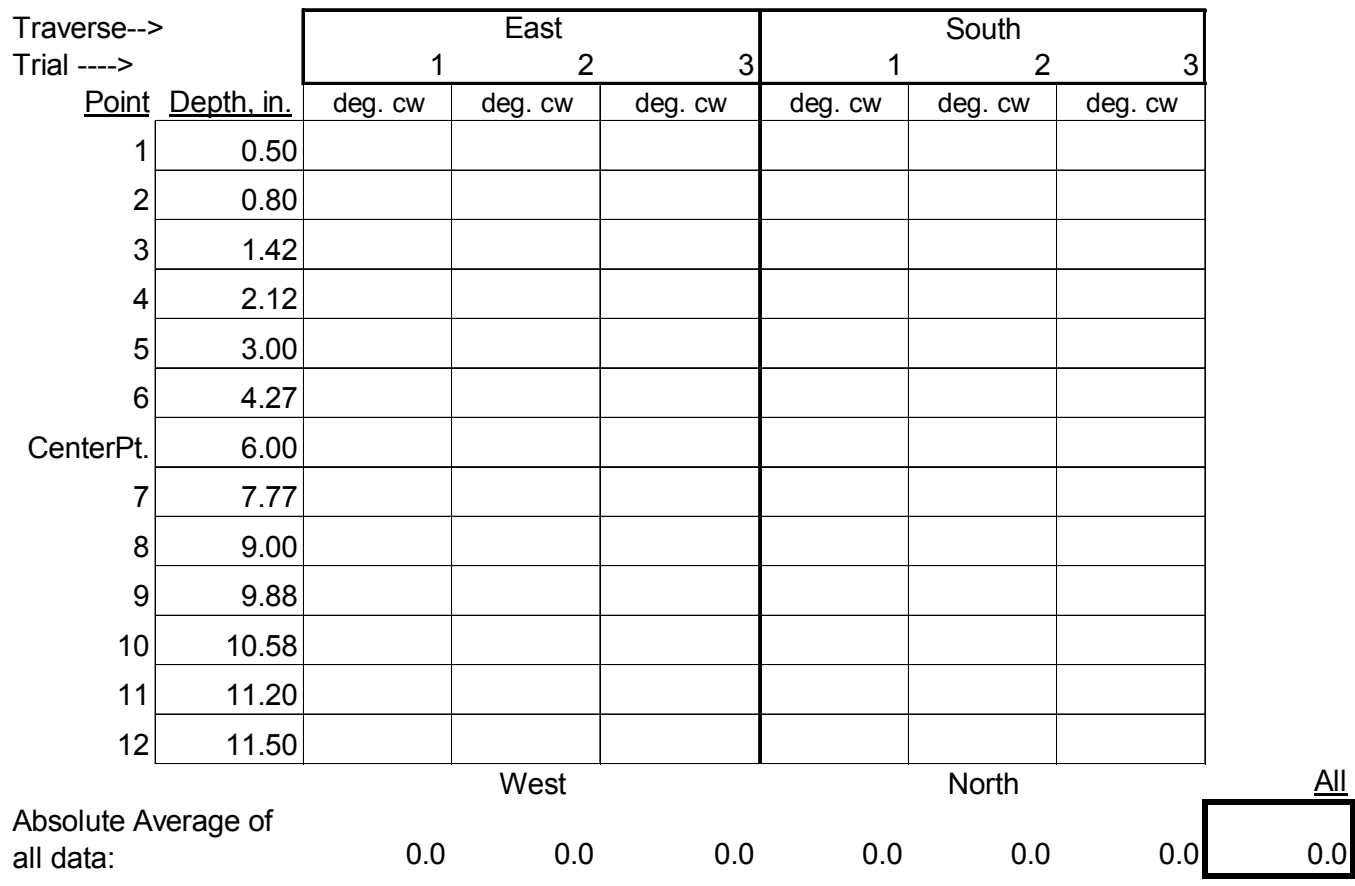

Instuments Used:

Cal Exp. Date:

Parallel-tube pitot with 90-deg. bends at sample ends, 24-inches in length.

NA

Dwyer Instruments 0-5 inch inclined manometer with red guage oil

zero'd and leveled (with connecting tubes open to room atmosphere).

Angles made using Empire \#36 circular protractor.

Notes:

To assure similar hose connections between the manometer and pitot tube, rotating the pitot tube assemble clockwise drives the meniscus to the right (to higher pos. numbers).

Signature signifies compliance with Procedure EMS-JAG-05

Signature/date 


\section{Appendix G}

Angular Flow Data Sheets and Plots 


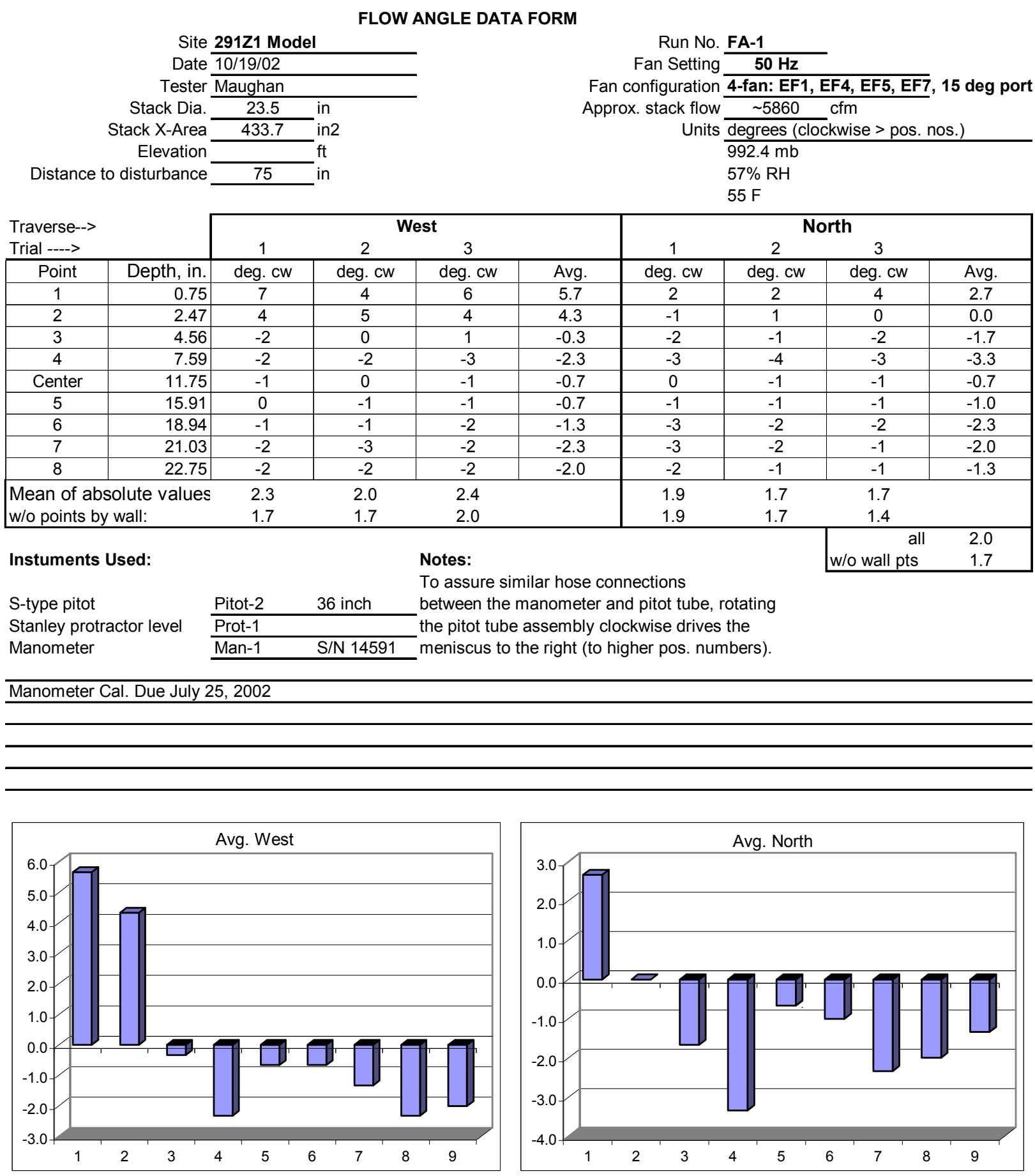


FLOW ANGLE DATA FORM

\begin{tabular}{|c|c|c|}
\hline \multicolumn{3}{|c|}{ Site $291 Z 1$ Model } \\
\hline \multicolumn{3}{|c|}{ Date $\overline{11 / 26 / 01}$} \\
\hline Tester & lissmeye & \\
\hline Stack Dia. & 23.5 & in \\
\hline Stack X-Area & 433.7 & in2 \\
\hline Elevation & NA & $\mathrm{ft}$ \\
\hline Distance to disturbance & 75 & in \\
\hline
\end{tabular}

Run No. FA-2

Fan Setting $60 \mathrm{~Hz}$

Fan configuration 2 Turbine fan, 15 degree port

Approx. stack flow $\mathrm{cfm}$

Units degrees (clockwise > pos. nos.)

1st

\begin{tabular}{|c|c|c|c|c|c|c|c|c|c|}
\hline \multirow{2}{*}{\multicolumn{2}{|c|}{$\begin{array}{l}\text { Traverse---> } \\
\text { Trial ----> } \\
\end{array}$}} & \multicolumn{4}{|c|}{ West } & \multicolumn{4}{|c|}{ North } \\
\hline & & 1 & 2 & 3 & & 1 & 2 & 3 & \\
\hline Point & Depth, in. & deg. CW & deg. cw & deg. Cw & Avg. & deg. CW & deg. CW & deg. CW & Avg. \\
\hline 1 & 0.75 & -3 & -3 & -3 & -3.0 & 0 & -1 & 0 & -0.3 \\
\hline 2 & 2.47 & 4 & 4 & 3 & 3.7 & 0 & 0 & -1 & -0.3 \\
\hline 3 & 4.56 & 0 & 0 & 0 & 0.0 & -3 & -2 & -1 & -2.0 \\
\hline 4 & 7.59 & -1 & 1 & -1 & -0.3 & -6 & -6 & -4 & -5.3 \\
\hline Center & 11.75 & 1 & -2 & 1 & 0.0 & -4 & -3 & -3 & -3.3 \\
\hline 5 & 15.91 & -1 & 0 & 0 & -0.3 & -3 & -3 & -2 & -2.7 \\
\hline 6 & 18.94 & 0 & -1 & -1 & -0.7 & -3 & -1 & -2 & -2.0 \\
\hline 7 & 21.03 & -1 & -2 & -3 & -2.0 & -1 & -1 & -1 & -1.0 \\
\hline 8 & 22.75 & 0 & -2 & -3 & -1.7 & -2 & -2 & -1 & -1.7 \\
\hline \multirow{2}{*}{\multicolumn{2}{|c|}{$\begin{array}{l}\text { Mean of absolute values } \\
\text { w/o points by wall: }\end{array}$}} & 1.2 & 1.7 & 1.7 & & 2.4 & 2.1 & 1.7 & \\
\hline & & 1.1 & 1.4 & 1.3 & & 2.9 & 2.3 & 2.0 & \\
\hline \multicolumn{2}{|c|}{ Instuments Used: } & \multicolumn{4}{|c|}{ Notes: } & & & $\begin{array}{r}\text { all } \\
\text { w/o wall pts } \\
\end{array}$ & $\begin{array}{l}1.8 \\
1.8 \\
\end{array}$ \\
\hline
\end{tabular}

Instuments Used:

To assure similar hose connections

S-type pitot $\quad$ Pitot-2 36 inch between the manometer and pitot tube, rotating

Stanley protractor level the pitot tube assembly clockwise drives the

Manometer

Man-1 S/N 14591 meniscus to the right (to higher pos. numbers).

Manometer Cal. Due July 25, 2002
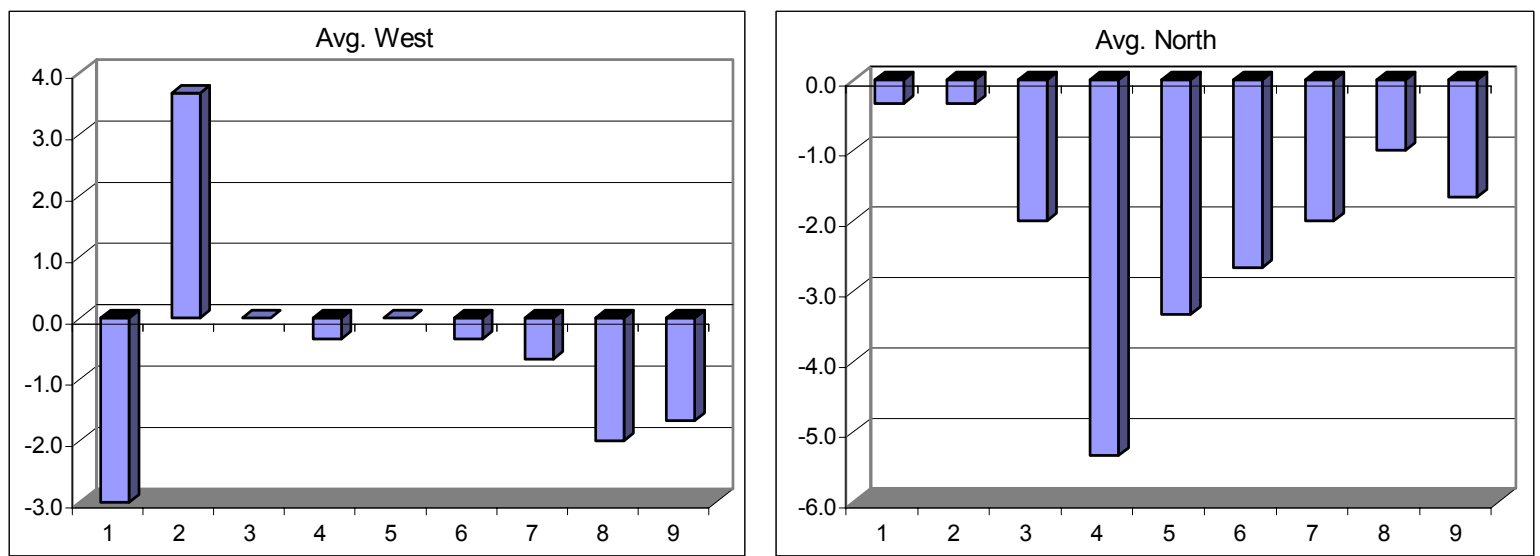


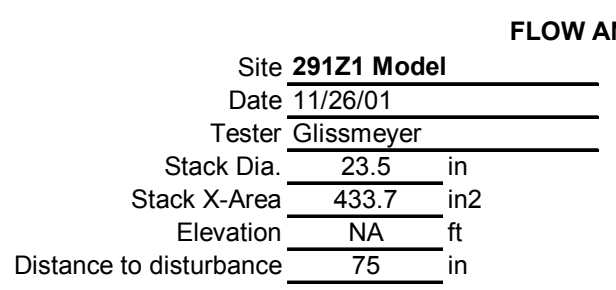

Run No. FA-3

Fan Setting $60 \mathrm{~Hz}$

Fan configuration 2 Turbine fan, 30 degree port

Approx. stack flow

$\mathrm{cfm}$

Units degrees (clockwise > pos. nos.)

$1 \mathrm{st}$

\begin{tabular}{|c|c|c|c|c|c|c|c|}
\hline \multirow{2}{*}{\multicolumn{2}{|c|}{$\begin{array}{l}\text { Traverse---> } \\
\text { Trial ----> }\end{array}$}} & \multicolumn{4}{|c|}{ West } & \multirow[b]{2}{*}{1} & \multirow[b]{2}{*}{2} \\
\hline & & 1 & 2 & 3 & & & \\
\hline Point & Depth, in. & deg. cw & deg. CW & deg. cw & Avg. & deg. cw & deg. \\
\hline 1 & 0.75 & -1 & 2 & 1 & 0.7 & -11 & -12 \\
\hline 2 & 2.47 & -2 & 3 & 2 & 1.0 & -9 & -12 \\
\hline 3 & 4.56 & -3 & -1 & 2 & -0.7 & -7 & -10 \\
\hline 4 & 7.59 & -3 & -1 & 0 & $\begin{array}{l}-1.3 \\
\end{array}$ & -9 & -8 \\
\hline Center & 11.75 & -2 & -1 & -1 & -1.3 & -5 & -7 \\
\hline 5 & 15.91 & -2 & -1 & -1 & -1.3 & -3 & -4 \\
\hline 6 & 18.94 & -2 & -2 & -1 & -1.7 & -2 & -3 \\
\hline 7 & 21.03 & -2 & -1 & -1 & -1.3 & -2 & -1 \\
\hline 8 & 22.75 & -2 & -1 & -2 & -1.7 & -2 & -2 \\
\hline \multirow{2}{*}{\multicolumn{2}{|c|}{$\begin{array}{l}\text { Mean of absolute values } \\
\text { w/o points by wall: }\end{array}$}} & 2.1 & 1.4 & \multirow{2}{*}{\multicolumn{2}{|c|}{$\begin{array}{l}1.2 \\
1.1 \\
\end{array}$}} & \multirow{2}{*}{\multicolumn{2}{|c|}{$\begin{array}{l}5.6 \\
5.3 \\
\end{array}$}} \\
\hline & & 2.3 & 1.4 & & & & \\
\hline \multicolumn{4}{|c|}{ Instuments Used: } & \multirow{4}{*}{\multicolumn{4}{|c|}{$\begin{array}{l}\text { Notes: } \\
\text { To assure similar hose connections } \\
\text { between the manometer and pitot tube, rotating } \\
\text {-the pitot tube assembly clockwise drives the } \\
\text { meniscus to the right (to higher pos. numbers). }\end{array}$}} \\
\hline \multirow{3}{*}{\multicolumn{2}{|c|}{$\begin{array}{l}\text { S-type pitot } \\
\text { Stanley protractor level } \\
\text { Manometer }\end{array}$}} & \multirow{2}{*}{\multicolumn{2}{|c|}{$\frac{\text { Pitot-2 }}{\text { Prot-1 }}$}} & & & & \\
\hline & & & & & & & \\
\hline & & Man-1 & S/N 14591 & & & & \\
\hline
\end{tabular}

Manometer Cal. Due July 25, 2002
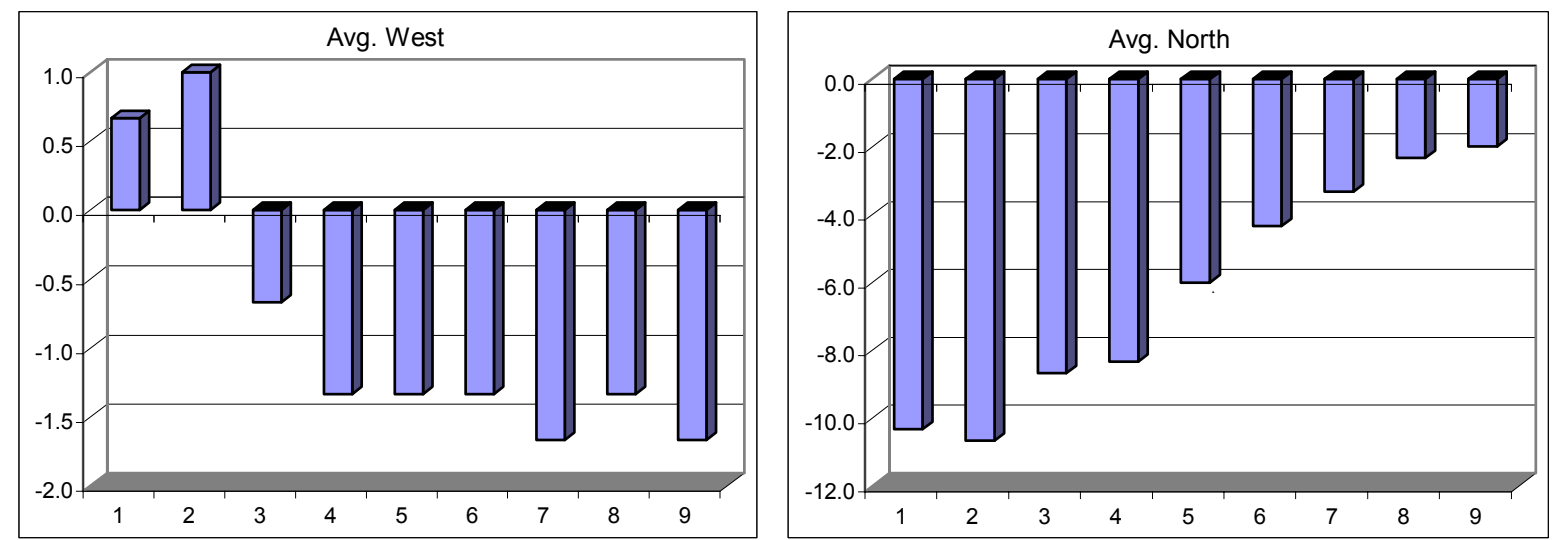
Appendix $\mathrm{H}$

Tracer Gas Uniformity Testing Procedure 


\section{H.1 Purpose}

The performance of new stack sampling systems must be shown to satisfy the requirements of 40 CFR 61, Subpart H, "National Emission standards for Emissions of Radionuclides Other than Radon from Department of Energy Facilities." This regulation governs portions of the design and implementation of effluent air sampling. The stack sampler performance is adequately characterized when potential contaminants in the effluent are of a uniform concentration at the sampling location (plane), and line losses are within acceptable limits. This procedure determines whether the concentration of gaseous contaminants is uniformly distributed in the area of the sampling probe. Other procedures address flow angle, uniformity of gas velocity, and uniformity of particulate contaminants. A contaminant concentration that is uniform at the sampling plane enables the extraction of samples that represent the true emission concentration.

The uniformity is expressed as the variability of the measurements about the mean. This is expressed using the relative coefficient of variance (COV), which is the standard deviation divided by the mean and expressed as a percentage. The lower the COV value, the more uniform the gas concentration. The acceptance criterion is that the COV of the measured gas concentrations be \# $20 \%$ across the center two-thirds of the area of the stack. Furthermore, the average concentration measured at any point cannot differ from the mean of all points by more than $30 \%$.

\section{H.2 Applicability}

This procedure can be used in the field or on modeled stacks to determine whether air-sampling probes can collect representative samples under normal operations. The tests are applicable to effluent stacks or ducts within the following constraints:

- The tracer gas tests are generally limited to stacks with flowrates greater than 50 cubic feet per minute range. The upper bound of flowrate is determined by the sensitivity of the gas analyzer, the background reading for the tracer gas, and the availability of the tracer.

- Environmental constraints - the gas analyzer will require the use of a controlled temperature environment to maintain the equipment above 55 degrees Fahrenheit.

\section{H.3 Prerequisites and Conditions}

Conditions and concerns that must be satisfied before sampling are listed below:

- Safety glasses and hard toed or substantial shoes are required in the work areas.

- Properly constructed and inspected work platforms may be needed to access the test ports.

- Scaffold-user or fall protection training may be required in some instances to access the sampling ports of the stack. 
- Alcohol may be used for equipment cleanup. A flammable equipment storage cabinet is required to flammable chemicals.

- Familiarity with the use and operation of gas delivery systems and the ability to detect concentration build-ups of the gas is essential to avoid exceeding ACGIH concentration for the tracer gas.

- Knowledge of the setup, use of, and operation of flowmeters, gas analyzers, and computers is essential.

- A job-hazards analysis may be required in certain cases.

\section{H.4 Precautions and Limitations}

Caution: The American Conference of Governmental Industrial Hygienists (ACGIH) 8hour time-weighted average limit for human exposure to sulfur hexafluoride gas is 1000 ppm $\left(6,000 \mathrm{mg} / \mathrm{m}^{3}\right)$. It is colorless and odorless.

During tests of stacks with high flow rates, sulfur hexafluoride will be injected at a high rate into the base of the stack to overcome the large dilution factor needed to detect the tracer at the sampling ports above. If a leak occurs in the gas delivery system, the potential is present for a buildup of $\mathrm{SF}_{6}$ to occur that could approach the 1000-ppm level. The gas is five times as heavy as air, so it will accumulate in confined spaces and in low areas. Leak tests of the delivery system will be made at least daily to prevent such an occurrence.

Access to the test ports may require the use of scaffolding or manlifts, either of which will necessitate special training for sampling personnel and any observers. The training requirements will be indicated in the job hazard analysis. This will limit access to the sampling ports to trained personnel.

If the purpose of a given run is to investigate the sensitivity of the COV determination to the tracer-injection location, the test may be invalid if the ending ambient concentration is elevated above that at the start of the test. This would indicate poor dispersion away from the test site and recirculation of the tracer to the inlet of the fan if the stack exhaust point is in view of and is reasonably close to the fan inlet. This may result in a false indication of good mixing.

\section{H.5 Equipment Used for Stack Measurements}

Specific calibration check concentration levels, probe dimensions, measurement grids, flow rates, and other special requirements will be provided in the specific Test Instruction. Exhibit A provides a typical layout for the test setup. The following are essential items of equipment:

- Sulfur hexafluoride calibration check gas 
- Sulfur hexafluoride bulk gas

- Bruel and Kjaer Model 1302 Gas analyzer

- Gas regulators and flowmeters

- Gas sampling probe

- Gas injection probe

- Vacuum pump (Sierra)

- Air velocity meter

The absolute calibration of the Model 1302 Gas Analyzer is not as important as its general response because the concentration data are used in a relative manner in calculating the COV and in plotting the concentrations at the measurement points. Consequently, the analyzer is Category 2 MTE (user calibrated) and will be checked against a calibrated gas mixture before and after the series of tests, and the instrument's response may be checked on a daily basis. Agreement within 10\% of the calibration gas is acceptable.

\section{H.6 Work Instructions for Setup, Measurements, and Data Reduction}

The steps taken to setup, configure, and operate the stack fans and test equipment are listed. Based on previous field measurements, the steps are ordered to achieve maximum efficiency in the testing. In addition to these steps, test instructions, which are developed for each test series, provide specific details and operating parameters.

\section{Preliminary Steps:}

Provide essential supplies at the sampling location. (gas cylinders and regulators, fittings and probe-port couplers, marking pens, data sheets, writing, and probe-supporting platforms).

\section{Fill in test information on data form.}

Obtain barometric, temperature, and relative-humidity

information for the gas analyzer.

Set up the gas analyzer system at the stack sampling port according to the illustrations in Exhibits $A$ and $B$.

Note: The sampling equipment consists of a stainless steel probe with enough length to reach across the inside diameter of the stack, allowing for fittings. The intake end should have a $90^{\circ}$ bend so that the open end of the tube faces downward or into the flow within the stack). The outlet end of the probe should terminate in a tee. One leg of the tee connects by flexible tubing to a rotameter and vacuum pump. This leg should draw from 1- to 10-1pm flow of air, depending on the volumetric flow in the stack. The other leg of the tee connects via flexible tubing to a coarse inline filter (47-mm-diameter glass fiber filter) and then to the Model 1302 gas analyzer inlet. To minimize tubing length to the analyzer, locate the gas analyzer near the test port on the stack. 


\section{$\underline{\text { System Startup }}$}

If not already running, start the stack fan, adjust the flow to the velocity called for in the test instruction, and record on the data sheet.

Verify the stack centerline air velocity in the sampling plane using a velocity flow meter, and record value on data sheet.

Turn-on the gas analyzer.

Program the analyzer for:

- 60-second samples,

- continuous operation,

- the current barometric pressure,

- moisture compensation if needed.

Note: Gas analyzer readings can be made with or without water-vapor correction. If the air is sufficiently dry ( $<$ than about $60 \%$ relative humidity) where the water vapor contribution is negligible $(<$ than about $14.5 \mathrm{E}+03$ ppm), the balance of the readings can be made with water vapor compensation but without water vapor measurement to reduce sample times.

Set the sample probe to the center position.

Note: Mark the sampling probe with a permanent marker so the inlet can be placed at each successive measurement point. The layout for the sample points is given in the test instruction.

Note: Sampling plane traverse points Use the grid of measurement points provided with the tests instruction and dataform. This is usually the same as used for the velocity uniformity test. A centerpoint, is included as a common reference and for graphical purposes. The layout design divides the area of the sampling plane so that each point represents approximately an equal- 


\section{$\underline{\text { Daily Tracer Gas Background Concentration Measurement }}$}

At the beginning of sampling each day and after the analyzer has stabilized (about 10 minutes), obtain at least six consecutive background readings. Do not proceed with the test if the background exceeds $5 \%$ of the anticipated average concentration in the stack.

Record these readings in the logbook designated for the tests.

\section{Gas Injection and Sample Collection}

The injection equipment consists of a pressurized cylinder of pure liquid sulfur hexafluoride that converts to gas when released. The setup is shown in the figure in Exhibit B and includes a gas regulator, valve, flowmeter (rotameter), flexible tubing, and a stainless steel injection probe with a $90 \mathrm{E}$ bend at the discharge end, which is secured at one of five positions. The connections and fittings should be checked to ensure that they are secure and leak free to prevent the loss of gas.

\section{Note: Location of Tracer Gas Injection Points}

Injection plane - The tests are repeated using five tracer gas injection points (at the centerpoint and at four orthogonally spaced points) within the injection plane. These four points are located near the corners if the duct cross section is rectangular. The distance from these four points to the corner or wall is less than $25 \%$ of the duct's hydraulic diameter (HD), which is calculated by

$$
H D=\frac{2 H W}{H+W}
$$

where $\mathrm{H}$ and $\mathrm{W}$ are the height and width of a rectangular duct $(\mathrm{H}$ and $\mathrm{W}$ are the same in a round duct). More specific dimensions are given in the Test Instruction.

Position the injection probe, according to the test instruction found as Attachment $A$.

Start injection of the tracer gas and adjust for flow rate specified in the test instruction and note the time.

Note: Estimation of Sulfur Hexafluoride Injection Rate

Estimate the $\mathrm{SF}_{6}$ injection rate so the average diluted concentration will be within the range of 10 to $100 \%$ of the concentration of the calibration check gas according to the following equation:

$$
\text { injection flowrate }=\text { stack flowrate } \times \frac{\text { target ppmv }}{10^{6}}
$$

The rotameter reading should be adjusted for the density of the $\mathrm{SF}_{6}$. The air equivalent reading is

$$
\text { rotameter reading }=k x \text { actual flowrate }
$$

where $k$ is 2.53 (the square-root of the density) for $\mathrm{SF}_{6}$. 
On the data sheet, label the columns of data according to the directions of the traverses.

Verify that the directional orientations and the numbered sample positions are consistent.

Position the sample probe at each measurement point in succession, and record the reading on the dataform.

Note: Each test relies on one repetition for each measurement point in each traverse direction, repeated three times. The repeats are made as three separate runs and not as three consecutive measurements at each point.

Perform two additional repetitions of Step 6.4.5. above

Switch the tests to the other direction and repeat Steps 6.4.5 and

6.4.6.

Check the data sheet for completeness. 


\section{$\underline{\text { Record the final }}$}

- Rotameter flow rate

- Time since the start of gas injection

- Pressure in the gas cylinder.

Shut down the delivery of tracer gas.

Continue operation of the gas analyzer for several minutes to purge any remaining gas through the analyzer.

Measure the background tracer gas concentration and record the levels on the data sheet.

$\underline{\text { Record any climatic conditions that have changed on the data }}$ sheet.

Enter the centerline stack velocity flow on the data sheet.

Record any deviations from the above procedure on the data sheet.

Repeat steps 6.4.1 - 6.4.15 for each run as indicated in the Test Instruction.

\section{Data Recording and Calculations}

Prepare the electronic data sheet on which to enter gas concentration readings and other information relevant to the test (see test instruction).

Review the raw data sheets for completeness.

Enter the data into the electronic data sheet.

\section{Calculate the COV for the run.}

Note: The EXCEL datasheet shown in Appendix C is set up to calculate the $\mathrm{COV}$ for each tracer gas concentration traverse using the average concentration data from all points in the inner two-thirds of the cross section area of the plane (including the center point).

Compare the observed COV for each run to the acceptance criterion.

Note: The test is acceptable if the COV is within \#20\% for the inner twothirds of the stack diameter and if no point differs from the mean by more than $30 \%$. This is determined by inspecting the average concentration at each measurement point. The $\mathrm{COV}$ is 100 times the standard deviation divided by the mean. 
Sign and date the data sheet attesting to its validity.

Note: A separate datasheet will be provided and signed-off for each test run.

\section{Gas Analyzer Calibration Check Steps}

Check the gas analyzer calibration by subjecting the analyzer to sulfur hexafluoride calibration gas. Refer to the analyzer's manual, parts 2 and 4 .

Set up the system for gas analysis with the regulator, the valve, flexible tubing, and a tee with one leg exhausting excess gas through a flowmeter and the other leg attached to the inlet of the Model 1302. Program the units of measurement as in Part 4.2.3. Enter the barometric pressure in $\mathrm{mm} \mathrm{Hg}$ pressure, standard temperature (that used by the calibration gas vendor), and the sampling tube length into the environmental setup (Part 4.2.4). Record the information on the data sheet.

Set the Model 1302's clock. Program the analyzer for water compensation, but not water measurement, at 1-minute continuous measurement mode (according to Part 4.4.2 in manual).

Program for a continuous monitoring task (4.2.5), and initiate monitoring (4.2.6).

Monitor room conditions, and record the data for several measurements by sampling zero air or room air for at least 5 minutes.

Note: If the test location has a buildup of the gas, a zero air cylinder or clean air supply will be needed. The $\mathrm{SF}_{6}$ concentration in the room should be several orders of magnitude below the calibration-gas. These settings optimize the low detection capabilities of the acoustically-based detection

Sample calibration gases (from lowest available concentrations to highest) for at least five readings each or until no observable trend is found. Record the identification of the calibration gas used. Record data and results in the Logbook. 
Note: Set the calibration gas flow rate high enough to ensure that the glass ball in the rotameter does not drop to zero during any of the observed steps of a sample cycle. As the calibration check continues, gas levels exhausted during the check will be released into the room, and the $\mathrm{SF}_{6}$ background concentrations will increase as the analyzer is checked. The $\mathrm{SF}_{6}$ reading should be within $10 \%$ of the calibration-gas concentration, and the water content should he much lower than ambient

\section{Obtain baseline tracer (calibration gas) readings at the end of}

the calibration check. Record results on the data sheet.

Note: The reading will generally be recorded from the digital concentration display. It may be convenient to record the data on a printer or computer, which can be coupled to the analyzer. See the Manual Part 12 (especially Part 12.2.5) for connecting to a printer in data $\log$ mode. 


\section{Figure H.1. Overview of Stack and Injection/Sampling Setups}

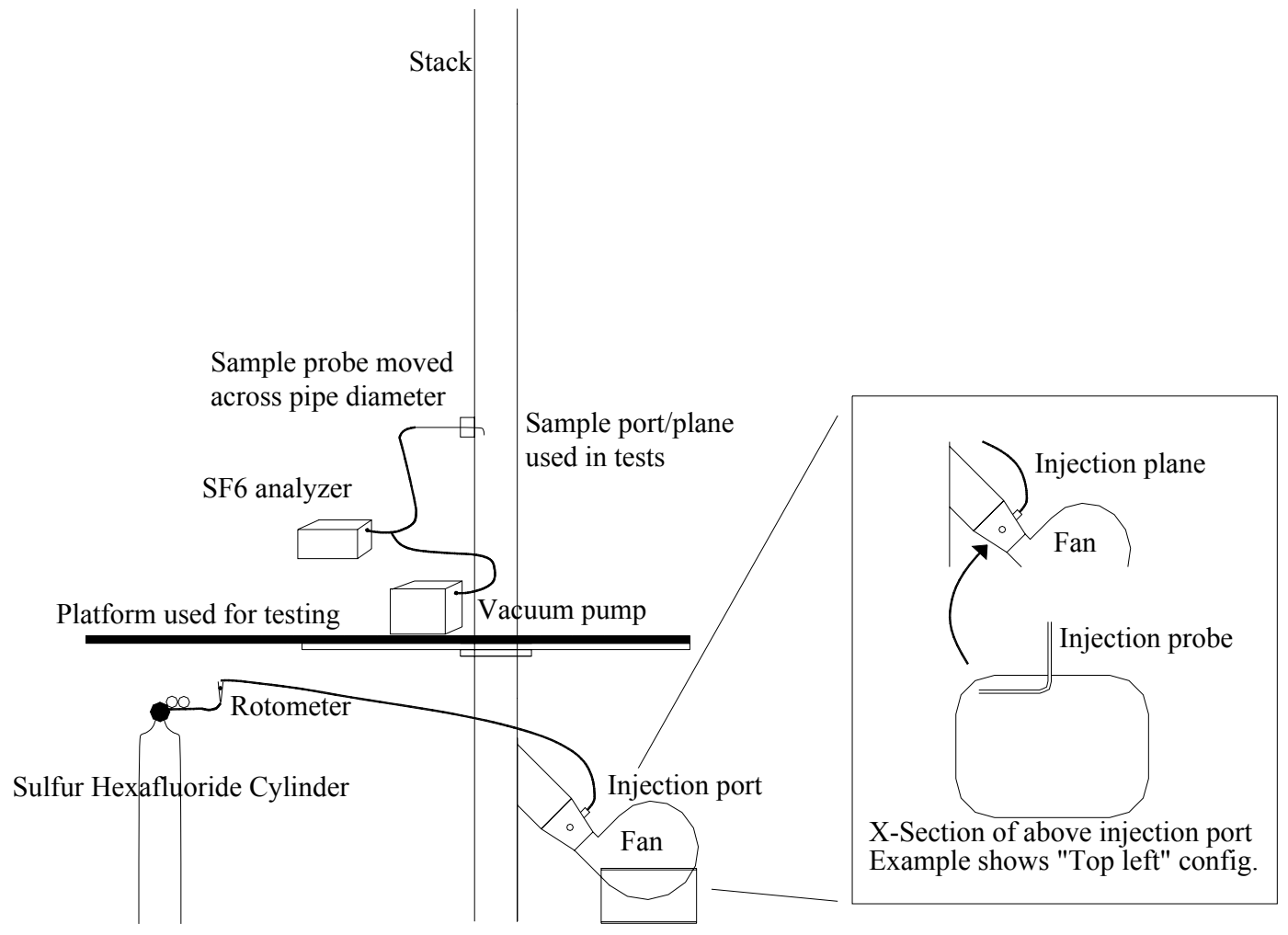


Figure H.2. Details for Stack Sampling Probe and Gas Analyzer Setup

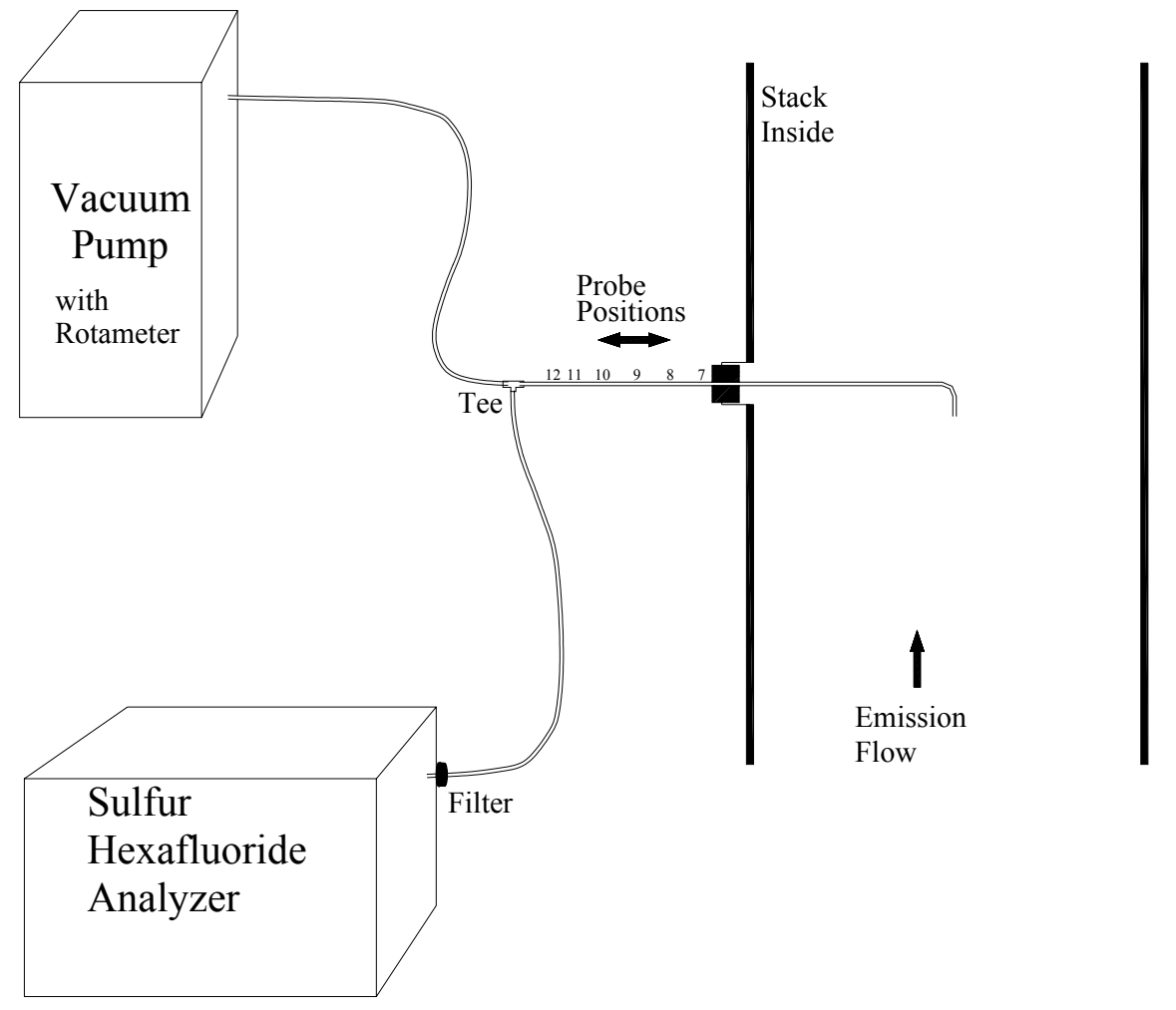


Figure H.3. Example EXCEL Data Sheet

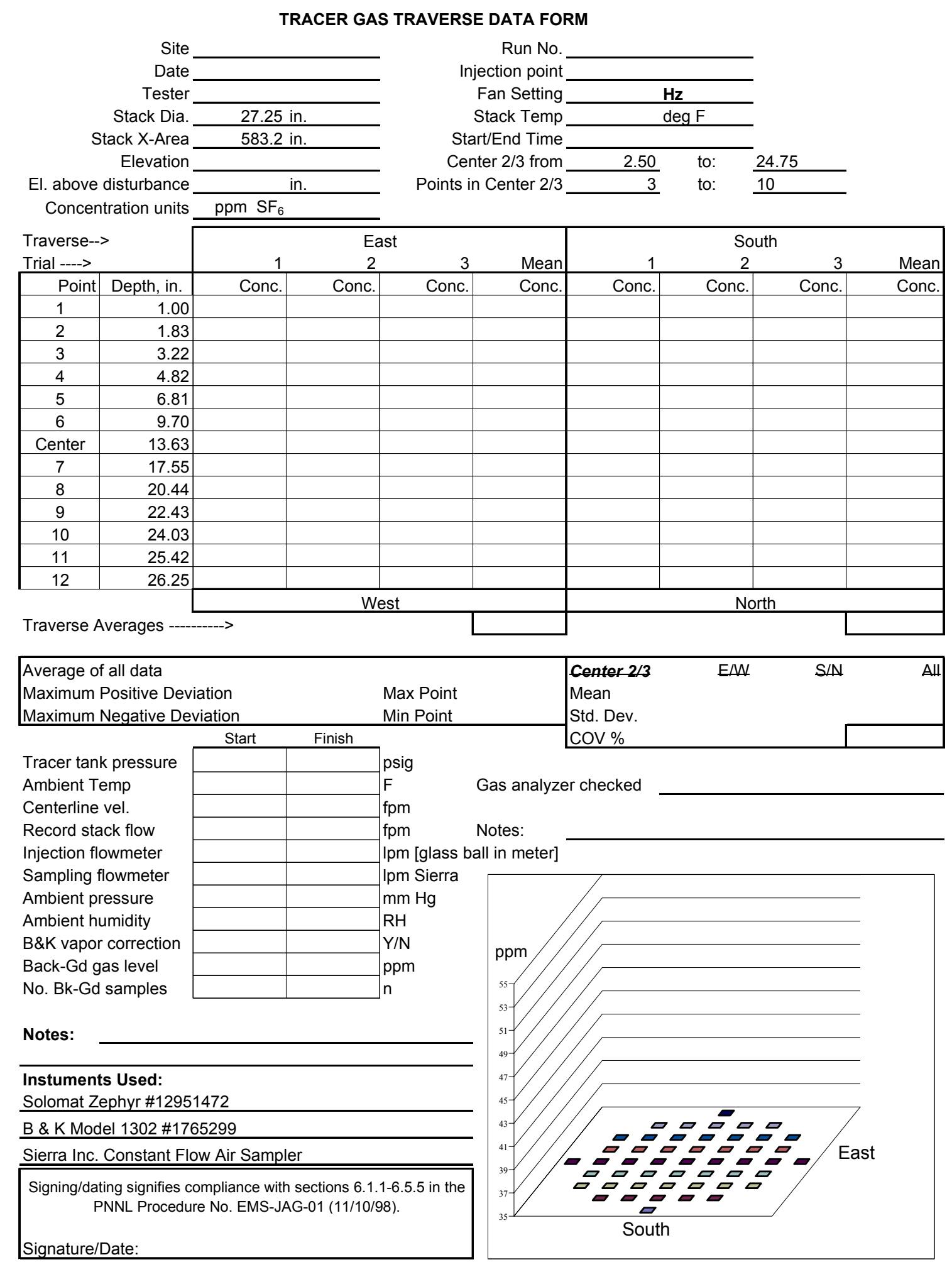


Figure H.4. Illustrative Test Instruction

\begin{tabular}{|c|c|c|}
\hline \multicolumn{3}{|c|}{ Test Instruction } \\
\hline $\begin{array}{l}\text { Project: Canister Storage } \\
\text { Stack Qualification, } 29303\end{array}$ & Date: November 10, 1998 & Work Package: K97052 \\
\hline \multicolumn{3}{|c|}{ Tests: Tracer Gas Uniformity of Full-Scale Stack } \\
\hline \multicolumn{3}{|c|}{ Staff: David Maughan, John Glissmeyer } \\
\hline \multicolumn{3}{|c|}{$\begin{array}{l}\text { Reference Procedures: } \\
\text { 1. Procedure EMS-JAG-01, Rev. 0, Test to Determine Uniformity of a Tracer Gas at a Sampler } \\
\text { Probe, Nov. 10, } 1998 \\
\text { 2. Operating Manual for Bruel and Kjaer Model } 1302 \text { Gas Analyzer }\end{array}$} \\
\hline \multicolumn{3}{|c|}{$\begin{array}{l}\text { Equipment: } \\
\text { 1. Canister Storage Stack and inspected work platforms } \\
\text { 2. Sulfur hexafluoride gas (pure and calibration gas), regulator, control valve, rotameter, } \\
\text { injection probe }(1 / 4 \text { in. OD } \times 36 \text { in. long stainless tubing), and tubing } \\
\text { 3. Bruel and Kjaer Model } 1302 \text { Gas Analyzer, probe, vacuum pump, fittings }\end{array}$} \\
\hline \multicolumn{3}{|c|}{$\begin{array}{l}\text { Safety Considerations: } \\
\text { Review and observe the applicable Duke Job Hazard Analysis for the project }\end{array}$} \\
\hline $\begin{array}{l}\text { Instructions: } \\
\text { 1. } \quad \text { Verify training on t } \\
\text { 2. } \quad \text { Weigh the tracer cy } \\
\text { 3. Obtain climatic inform } \\
\text { http://etd.pnl.gov:2080 } \\
\text { 4. Install equipment as di } \\
\text { 5. Mark sampling probe } \\
\text { 6. Verify that stack flow } \\
\text { 7. Set the injection flowr } \\
\text { 8. Set the sampler flowra } \\
\text { 9. Conduct one or more t } \\
\text { Stack Flow } \\
\text { Normal } \\
\text { (The injection plan } \\
\text { fan. Left and right } \\
\text { 10. Record data on copies } \\
\text { 11. Repeat the test with th } \\
\text { 12. Diagram mounting fix } \\
\text { 13. Weigh the tracer gas c }\end{array}$ & $\begin{array}{l}\text { procedure and verify } \\
\text { der before shipment to } \\
\text { on from the Hanford } \\
\text { MS/lastob.htm } \\
\text { ted in the procedures } \\
\text { the measurement poin } \\
\text { about the target flowra } \\
\text { at about } 0.76 \text { lpm for } \\
\text { at approximately } 10 \mathrm{lp} \\
\text { er mixing tests at the } \\
\text { Injection poi } \\
\text { Centerline, top left, } t \\
\text { ould be at the fittings } \\
\text { from the point of vie } \\
\text { the attached data shee } \\
\text { orst case result two ac } \\
\text { es and retain assembly } \\
\text { hder after these tests }\end{array}$ & $\begin{array}{l}\text { on the data sheet } \\
0(2232 \mathrm{fpm}) \\
\text { oncentration of } \sim 3 \mathrm{ppm} \\
\text { sets of conditions: } \\
\text { from fan to stack } \\
\text { bottom left, bottom right }\end{array}$ \\
\hline \multicolumn{3}{|c|}{ Desired Completion Date: 11/20/98 } \\
\hline Approvals: & roject Manager & Date \\
\hline Test completed by: & & Date: \\
\hline
\end{tabular}


Appendix I

Tracer Gas Uniformity Data Sheets 


\section{TRACER GAS TRAVERSE DATA FORM}

\begin{tabular}{|c|c|}
\hline \multicolumn{2}{|c|}{ Site 291-Z-1 Model } \\
\hline Date & $10 / 22 / 01$ \\
\hline \multicolumn{2}{|c|}{ Tester Glissmeyer } \\
\hline Stack Dia. & $23.5 \mathrm{in}$. \\
\hline Stack X-Area & 433.7 in.2 \\
\hline \multicolumn{2}{|c|}{ Elevation N.A. } \\
\hline Distance to disturbance & 75 inches \\
\hline
\end{tabular}

Run No. GT-1

Fan Configuration 4 fan: EF1, EF4, EF5, EF7

Fan Setting $\mathbf{5 0 ~ \mathbf { ~ z z }}$

Stack Temp $65 \mathrm{deg} F$

Start/End Time 1240/1407

Center $2 / 3$ from $2.16 \quad$ to: 21.34

Points in Center $2 / 3 \overline{2}$ to: $\underline{7}$

Injection Point Centerline EF4

\begin{tabular}{|c|c|c|c|c|c|c|c|c|c|}
\hline \multirow{2}{*}{\multicolumn{2}{|c|}{$\begin{array}{l}\text { Traverse--> } \\
\text { Trial ----> }\end{array}$}} & \multicolumn{4}{|c|}{ West } & \multicolumn{4}{|c|}{ North } \\
\hline & & \multicolumn{2}{|l|}{1} & 3 & Mean & 1 & 2 & 3 & Mean \\
\hline Point & Depth, in. & & \multicolumn{4}{|c|}{$\mathrm{ppm}$} \\
\hline 1 & 0.75 & 2.11 & 2.06 & 2.08 & 2.083 & 2.12 & 2.05 & 2.13 & 2.100 \\
\hline 2 & 2.47 & 2.11 & 2.08 & 2.12 & 2.103 & 2.11 & 2.06 & 2.07 & 2.080 \\
\hline 3 & 4.56 & 2.07 & 2.07 & 2.06 & 2.067 & 2.05 & 2.11 & 2.07 & 2.077 \\
\hline 4 & 7.59 & 2.05 & 2.13 & 2.08 & 2.087 & 2.06 & 2.08 & 2.10 & 2.080 \\
\hline Center & 11.75 & 2.05 & 2.05 & 2.13 & 2.077 & 2.12 & 2.10 & 2.06 & 2.093 \\
\hline 5 & 15.91 & 2.05 & 2.07 & 2.03 & 2.050 & 2.09 & 2.08 & 2.12 & 2.097 \\
\hline 6 & 18.94 & 2.08 & 2.11 & 2.10 & 2.097 & 2.13 & 2.11 & 2.10 & 2.113 \\
\hline 7 & 21.03 & 2.13 & 2.09 & 2.10 & 2.107 & 2.08 & 2.13 & 2.09 & 2.100 \\
\hline 8 & 22.75 & 2.06 & 2.10 & 2.07 & 2.077 & 2.08 & 2.10 & 2.16 & 2.113 \\
\hline Averages ---- & 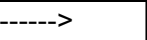 & 2.079 & 2.084 & 2.086 & 2.083 & 2.093 & 2.091 & 2.100 & 2.095 \\
\hline
\end{tabular}

Avg. Conc

\begin{tabular}{|lr}
\hline All & $\mathrm{ppm}$ \\
Mean & 2.09 \\
Min Point & 2.05 \\
Max Point & 2.11 \\
\hline
\end{tabular}

\begin{tabular}{|c|c|c|c|c|}
\hline \multirow{2}{*}{ Dev. from mean } & Center $2 / 3$ & West & North & All \\
\hline & Mean & 2.08 & 2.09 & 2.09 \\
\hline$-1.9 \%$ & Std. Dev. & 0.02 & 0.01 & 0.02 \\
\hline & cov as $\%$ & 1.0 & 0.6 & \\
\hline
\end{tabular}

$2.089 \mathrm{ppm}$

Gas analyzer checked:

19-Oct-01

Tracer tank pressure Sample Port Temp

Centerline vel.

Injection flowmeter

Stack flow

Sampling flowmeter

Ambient pressure

Ambient humidity

B\&K vapor correction

\begin{tabular}{|c|c|c|}
\hline Start & Finish & \\
\hline 200 & 200 & psig \\
\hline 65 & 65 & $\mathrm{~F}$ \\
\hline N 1756 & W 1595 & fpm \\
\hline 20 & 18 & ball ** \\
\hline 5700 & 5200 & $\mathrm{cfm}$ \\
\hline 10 & 10 & Ipm Sie \\
\hline 738.7 & 736.5 & $\mathrm{~mm} \mathrm{Hg}$ \\
\hline 45 & 57 & $\mathrm{RH}$ \\
\hline $\mathrm{Y}$ & $\mathrm{Y}$ & $\mathrm{Y} / \mathrm{N}$ \\
\hline
\end{tabular}

Back-Gd gas level 12,12,12,13,13,12 32,31,33,32 ppb

No. Bk-Gd samples

Ambient pressure

Instuments Used:

$$
\begin{array}{|r|c|l|}
\hline 6 & 4 & n \\
\hline 984.9 & 982.0 & \mathrm{mbar} \\
\hline
\end{array}
$$

B \& K Model $1302 \# 1765299$

Sierra Inc. Constant Flow Air Sampler

Solmat Zephyr SN 12951472 Cal. Due 7/26/02

Notes:

Centerline velocity should be in range $1757-1801 \mathrm{fpm}$

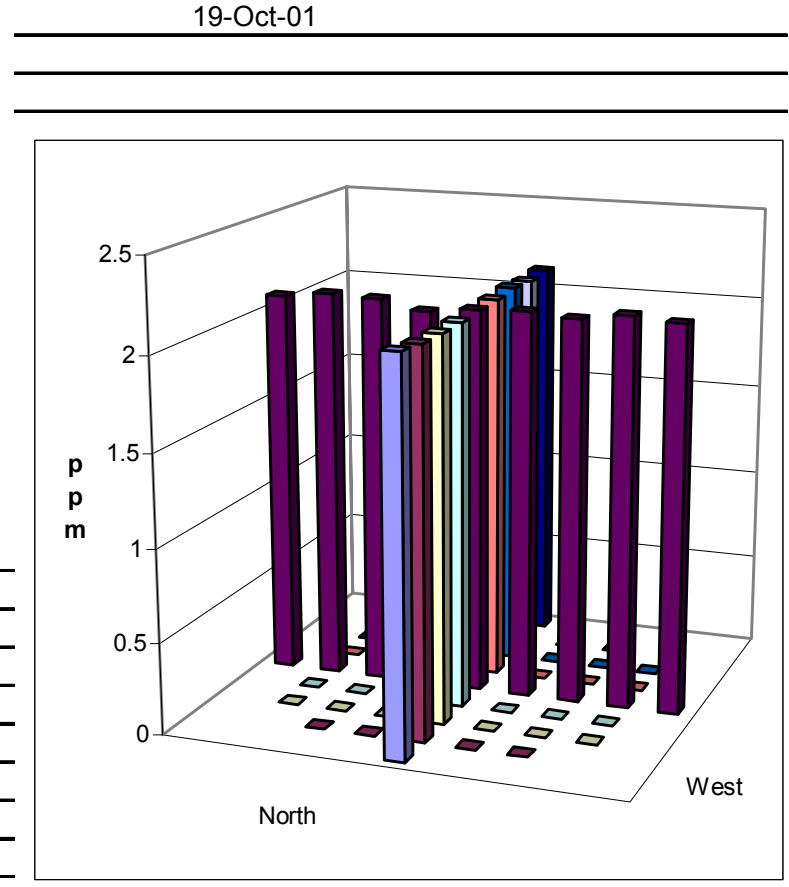


TRACER GAS TRAVERSE DATA FORM

Site 291-Z-1 Model

Date 10/22/01

Tester Glissmeyer

Stack Dia.

Stack X-Area

433.7 in. 2

Elevation N.A.

Distance to disturbance

Measurement units ppm SF6
Run No. GT-2

Fan Configuration 4 fan: EF1, EF4, EF5, EF7

Fan Setting $\overline{\mathbf{5 0 ~ H z}}$

Stack Temp

Start/End Time 1420/1525

Center $2 / 3$ from

Points in Center 2/3

Injection Point Top West EF4

\begin{tabular}{|c|c|c|c|c|c|c|c|c|c|}
\hline \multirow{2}{*}{\multicolumn{2}{|c|}{$\begin{array}{l}\text { Traverse--> } \\
\text { Trial ----> }\end{array}$}} & \multicolumn{4}{|c|}{ West } & \multicolumn{4}{|c|}{ North } \\
\hline & & 1 & 2 & 3 & Mean & 1 & 2 & 3 & Mean \\
\hline Point & Depth, in. & \multicolumn{4}{|c|}{ ppm } & \multicolumn{4}{|c|}{$\mathrm{ppm}$} \\
\hline 1 & 0.75 & 2.11 & 2.05 & 2.17 & 2.110 & 2.10 & 2.06 & 2.04 & 2.067 \\
\hline 2 & 2.47 & 2.07 & 2.10 & 2.17 & 2.113 & 2.12 & 2.06 & 2.06 & 2.080 \\
\hline 3 & 4.56 & 2.12 & 2.12 & 2.19 & 2.143 & 2.08 & 2.08 & 2.03 & 2.063 \\
\hline 4 & 7.59 & 2.08 & 2.24 & 2.16 & 2.160 & 2.09 & 2.12 & 2.04 & 2.083 \\
\hline Center & 11.75 & 2.09 & 2.13 & 2.21 & 2.143 & 2.10 & 2.08 & 2.07 & 2.083 \\
\hline 5 & 15.91 & 2.01 & 2.21 & 2.16 & 2.127 & 2.07 & 2.13 & 2.07 & 2.090 \\
\hline 6 & 18.94 & 2.09 & 2.22 & 2.18 & 2.163 & 2.10 & 2.11 & 2.09 & 2.100 \\
\hline 7 & 21.03 & 2.10 & 2.27 & 2.25 & 2.207 & 2.14 & 2.12 & 2.12 & 2.127 \\
\hline 8 & 22.75 & 2.16 & 2.22 & 2.08 & 2.153 & 2.04 & 2.13 & 2.17 & 2.113 \\
\hline Averages --- & ----> & 2.092 & 2.173 & 2.174 & 2.147 & 2.093 & 2.099 & 2.077 & 2.090 \\
\hline
\end{tabular}

Avg. Conc.

\begin{tabular}{|lr}
\hline All & $\mathrm{ppm}$ \\
Mean & 2.12 \\
Min Point & 2.06 \\
Max Point & 2.21 \\
\hline
\end{tabular}

$2.119 \mathrm{ppm}$

Tracer tank pressure Sample Port Temp

Centerline vel.

Injection flowmeter

Stack flow

Sampling flowmeter

Ambient pressure

Ambient humidity

B\&K vapor correction

Back-Gd gas level

No. Bk-Gd samples

Ambient pressure

Instuments Used:

\begin{tabular}{|c|c|c|}
\hline Start & Finish & \\
\hline 200 & 200 & psig \\
\hline 65 & 65 * & $F$ \\
\hline W 1595 & N 1646 & fpm \\
\hline 20 & 20 & ball ${ }^{* *}$ \\
\hline 5200 & 5400 & $\mathrm{cfm}$ \\
\hline 10 & 10 & Ipm Sierra \\
\hline 736.5 & 734.5 & $\mathrm{~mm} \mathrm{Hg}$ \\
\hline 57 & 70 & $\mathrm{RH}$ \\
\hline $\bar{Y}$ & $\mathrm{Y}$ & $\mathrm{Y} / \mathrm{N}$ \\
\hline $25,28,22,22$ & $72,31,29,27$ & $\mathrm{ppb}$ \\
\hline 4 & 4 & $n$ \\
\hline 982.0 & 979.3 & mbar \\
\hline
\end{tabular}

B \& K Model $1302 \# 1765299$

Sierra Inc. Constant Flow Air Sampler

Solmat Zephyr SN 12951472 Cal. Due 7/26/02

\section{Notes:}

Centerline velocity should be in range $1757-1801 \mathrm{fpm}$ * Solomat temperature sensor wet and not functional for awhile, then stabilized

\begin{tabular}{|c|c|c|c|c|}
\hline Dev. from mean & Center 2/3 & $\underline{\text { West }}$ & North & All \\
\hline & Mean & 2.15 & 2.09 & 2.12 \\
\hline$-2.6 \%$ & Std. Dev. & 0.03 & 0.02 & 0.04 \\
\hline $4.2 \%$ & COV as $\%$ & 1.4 & 0.9 & 1.9 \\
\hline
\end{tabular}

Gas analyzer checked:

19-Oct-01

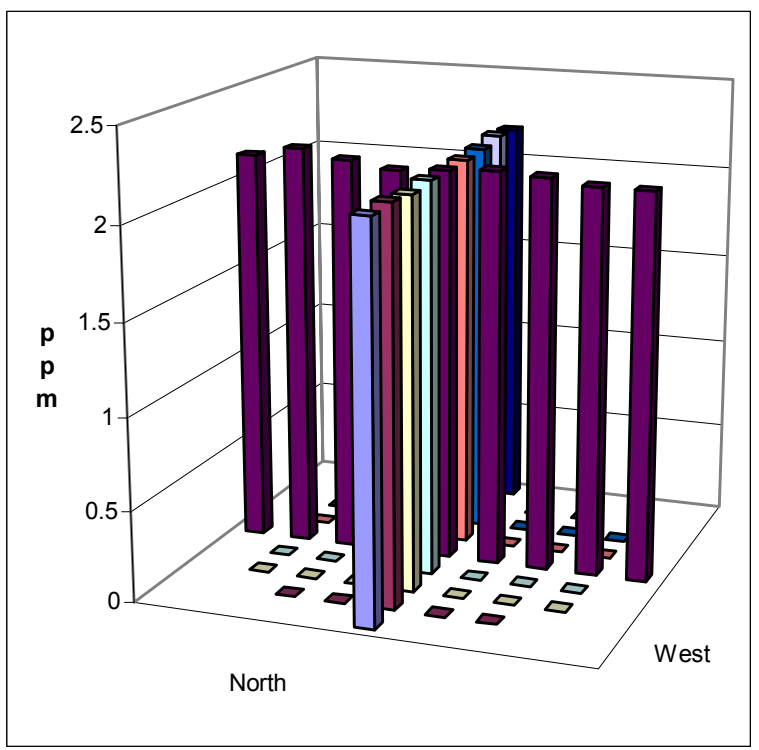


TRACER GAS TRAVERSE DATA FORM

Site 291-Z-1 Model

Date 10/25/01

Tester Glissmeyer/Maughan

Stack Dia

Stack X-Area 433.7 in. 2

Elevation N.A.

Distance to disturbance Measurement units ppm SF6
Run No. GT-3

Fan Configuration 4 fan: EF1, EF4, EF5, EF7

Fan Setting $50 \mathbf{~ H z}$

Stack Temp $59.15 \operatorname{deg} \mathrm{F}$

Start/End Time 0952/1120

Center $2 / 3$ from 21.34

Points in Center $2 / 3 \overline{2}$ to: $\overline{7}$

Injection Point EF4 Top East

\begin{tabular}{|c|c|c|c|c|c|c|c|c|c|}
\hline \multirow{2}{*}{\multicolumn{2}{|c|}{$\begin{array}{l}\text { Traverse--> } \\
\text { Trial ----> }\end{array}$}} & \multicolumn{4}{|c|}{ West } & \multicolumn{4}{|c|}{ North } \\
\hline & & 1 & 2 & 3 & Mean & 1 & 2 & 3 & Mean \\
\hline \begin{tabular}{l|} 
Point \\
\end{tabular} & Depth, in. & \multicolumn{4}{|c|}{$\mathrm{ppm}$} & \multicolumn{4}{|c|}{ ppm } \\
\hline 1 & 0.75 & 2.16 & 2.14 & 2.10 & 2.133 & 2.04 & 2.15 & 2.12 & 2.103 \\
\hline 2 & 2.47 & 2.11 & 2.10 & 2.11 & 2.107 & 2.06 & 2.13 & 2.12 & 2.103 \\
\hline 3 & 4.56 & 2.08 & 2.09 & 2.05 & 2.073 & 2.10 & 2.19 & 2.18 & 2.157 \\
\hline 4 & 7.59 & 2.13 & 2.10 & 2.07 & 2.100 & 2.09 & 2.13 & 2.15 & 2.123 \\
\hline Center & 11.75 & 2.10 & 2.07 & 2.03 & 2.067 & 2.17 & 2.18 & 2.14 & 2.163 \\
\hline 5 & 15.91 & 2.10 & 2.04 & 2.03 & 2.057 & 2.16 & 2.16 & 2.11 & 2.143 \\
\hline 6 & 18.94 & 2.07 & 2.11 & 2.06 & 2.080 & 2.18 & 2.14 & 2.11 & 2.143 \\
\hline 7 & 21.03 & 2.06 & 2.10 & 1.98 & 2.047 & 2.13 & 2.11 & 2.12 & 2.120 \\
\hline 8 & 22.75 & 2.19 & 2.05 & 2.04 & 2.093 & 2.15 & 2.04 & 2.18 & 2.123 \\
\hline Averages ----- & $----->$ & 2.111 & 2.089 & 2.052 & 2.084 & 2.120 & 2.137 & 2.137 & 2.131 \\
\hline
\end{tabular}

Avg. Conc.

$$
2.107 \mathrm{ppm}
$$

\begin{tabular}{|ll}
\hline All & $\mathrm{ppm}$ \\
Mean & 2.11 \\
Min Point & 2.05 \\
Max Point & 2.16
\end{tabular}

Tracer tank pressure Sample Port Temp

Centerline vel.

Injection flowmeter

Stack flow

Sampling flowmeter

Ambient pressure

Ambient humidity

B\&K vapor correction

Back-Gd gas ppb

No. Bk-Gd samples

\begin{tabular}{|c|c|c|}
\hline Start & Finish & \\
\hline 180 & 200 & psig \\
\hline 57.3 & 61 & $\mathrm{~F}$ \\
\hline N 1740 & W 1736 & $\mathrm{fpm}$ \\
\hline 20 & 20 & ball** \\
\hline 5700 & 5700 & $\mathrm{cfm}$ \\
\hline 10 & 10 & Ipm Sierra \\
\hline 997.1 & 998.0 & mbar \\
\hline 79 & 47 & $\mathrm{RH}$ \\
\hline$Y$ & $\bar{Y}$ & $\mathrm{Y} / \mathrm{N}$ \\
\hline $15 / 13 / 22 / 4$ & $67 / 64 / 72 / 72 / 58$ & $58 / 59$ \\
\hline 4 & 6 & $\mathrm{n}$ \\
\hline
\end{tabular}

Instuments Used:

B \& K Model $1302 \# 1765299$

Sierra Inc. Constant Flow Air Sampler

Solmat Zephyr SN 12951472 Cal. Due 7/26/02

Notes: $\quad$ Equipment on stack covered in layer of sand. At 9:00 AM, B\&P wouldn't start. Took it indoors to warm up. Then it operated properly.

Injection flow adjusted up from 19 to 20 shortly after switching from West to North traverse.

\begin{tabular}{|c|c|c|c|c|}
\hline Dev. from mean & Center 2/3 & West & North & All \\
\hline & Mean & 2.08 & 2.14 & 2.11 \\
\hline$-2.9 \%$ & Std. Dev. & 0.02 & 0.02 & 0.04 \\
\hline $2.6 \%$ & cov as $\%$ & 1.1 & 1.0 & 1.8 \\
\hline
\end{tabular}

Gas analyzer checked:

19-Oct-01

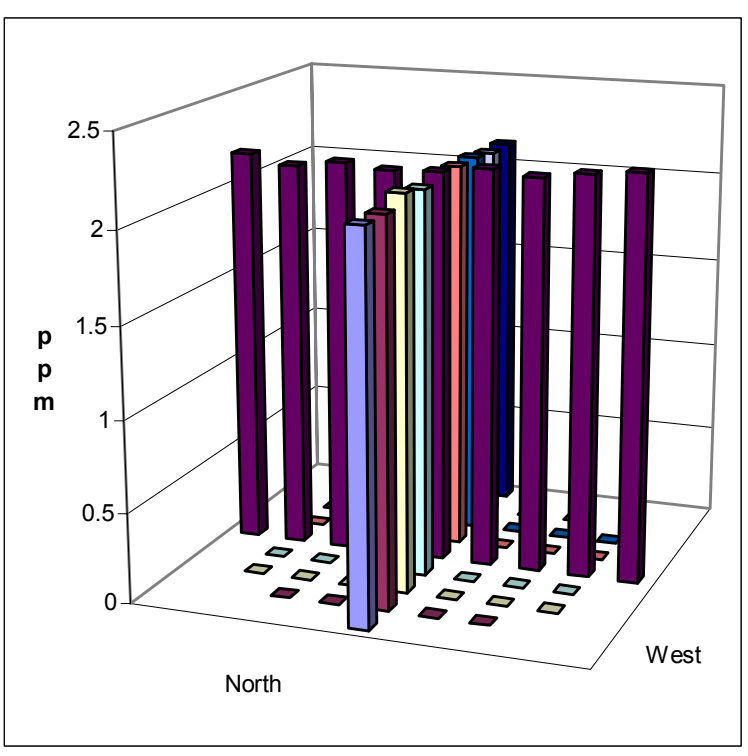


TRACER GAS TRAVERSE DATA FORM

Site 291-Z-1 Model

Date 10/25/01

Tester Glissmeyer/Maughan

Stack Dia.

$23.5 \mathrm{in}$.

Stack X-Area $433.7 \mathrm{in.2}$

Elevation N.A.

Distance to disturbance

Measurement units ppm SF6
Run No. GT-4

Fan Configuration 4 fan: EF1, EF4, EF5, EF7

Fan Setting $\mathbf{5 0 ~ \mathbf { ~ z z }}$

Stack Temp

Start/End Time 1240/1350

Center 2/3 from

Points in Center $2 / 3$ 2.16 to: 21.34

Injection Point EF4 Bottom West

\begin{tabular}{|c|c|c|c|c|c|c|c|c|c|}
\hline \multirow{2}{*}{\multicolumn{2}{|c|}{$\begin{array}{l}\text { Traverse--> } \\
\text { Trial ----> }\end{array}$}} & \multicolumn{4}{|c|}{ West } & \multicolumn{4}{|c|}{ North } \\
\hline & & 1 & 2 & 3 & Mean & 1 & 2 & 3 & Mean \\
\hline Point & Depth, in. & \multicolumn{4}{|c|}{ ppm } & \multicolumn{4}{|c|}{ ppm } \\
\hline 1 & 0.75 & 2.11 & 2.06 & 2.09 & 2.087 & 2.16 & 2.11 & 2.07 & 2.113 \\
\hline 2 & 2.47 & 2.11 & 2.08 & 2.10 & 2.097 & 2.17 & 2.11 & 2.07 & 2.117 \\
\hline 3 & 4.56 & 2.13 & 2.03 & 2.01 & 2.057 & 2.15 & 2.17 & 2.07 & 2.130 \\
\hline 4 & 7.59 & 2.06 & 2.04 & 2.07 & 2.057 & 2.14 & 2.21 & 2.07 & 2.140 \\
\hline Center & 11.75 & 2.09 & 2.10 & 2.02 & 2.070 & 2.15 & 2.12 & 2.12 & 2.130 \\
\hline 5 & 15.91 & 2.06 & 2.10 & 2.07 & 2.077 & 2.19 & 2.17 & 2.05 & 2.137 \\
\hline 6 & 18.94 & 2.10 & 2.04 & 2.04 & 2.060 & 2.15 & 2.16 & 2.14 & 2.150 \\
\hline 7 & 21.03 & 2.09 & 2.06 & 2.10 & 2.083 & 2.17 & 2.13 & 2.11 & 2.137 \\
\hline 8 & 22.75 & 2.08 & 2.09 & 2.02 & 2.063 & 2.22 & 2.17 & 2.17 & 2.187 \\
\hline Averages ---- & - & 2.092 & 2.067 & 2.058 & 2.072 & 2.167 & 2.150 & 2.097 & 2.138 \\
\hline
\end{tabular}

Avg. Conc.

\begin{tabular}{|lr}
\hline All & ppm \\
Mean & 2.11 \\
Min Point & 2.06 \\
Max Point & 2.19 \\
\hline
\end{tabular}

2.106 ppm

Tracer tank pressure Sample Port Temp Centerline vel. Injection flowmeter Stack flow

Sampling flowmeter Ambient pressure Ambient humidity B\&K vapor correction Back-Gd gas ppb No. Bk-Gd samples

\begin{tabular}{|c|c|c|}
\hline Start & Finish & \\
\hline 200 & 200 & psig \\
\hline 64 & 68 & $F$ \\
\hline w 1737 & n 1733 & fpm \\
\hline 20 & 20 & ball ${ }^{* *}$ \\
\hline 5700 & 5600 & $\mathrm{cfm}$ \\
\hline 10 & 10 & Ipm Sierra \\
\hline 998.0 & 997.6 & mbar \\
\hline 47 & 42 & $\mathrm{RH}$ \\
\hline$Y$ & $\mathrm{Y}$ & $\mathrm{Y} / \mathrm{N}$ \\
\hline $17 / 2 / 3 / 3$ & $2 /-3 / 25 / 43 / 7 / 19$ & \\
\hline 4 & 6 & n \\
\hline
\end{tabular}

Instuments Used:

B \& K Model $1302 \# 1765299$

Sierra Inc. Constant Flow Air Sampler

Solmat Zephyr SN 12951472 Cal. Due 7/26/02

\section{Notes:}

\begin{tabular}{|c|c|c|c|c|}
\hline Dev. from mean & Center 2/3 & West & North & All \\
\hline & Mean & 2.07 & 2.13 & 2.10 \\
\hline$-2.3 \%$ & Std. Dev. & 0.02 & 0.01 & 0.03 \\
\hline $3.9 \%$ & COV as $\%$ & 0.7 & 0.5 & 1.7 \\
\hline
\end{tabular}

Gas analyzer checked:

19-Oct-01

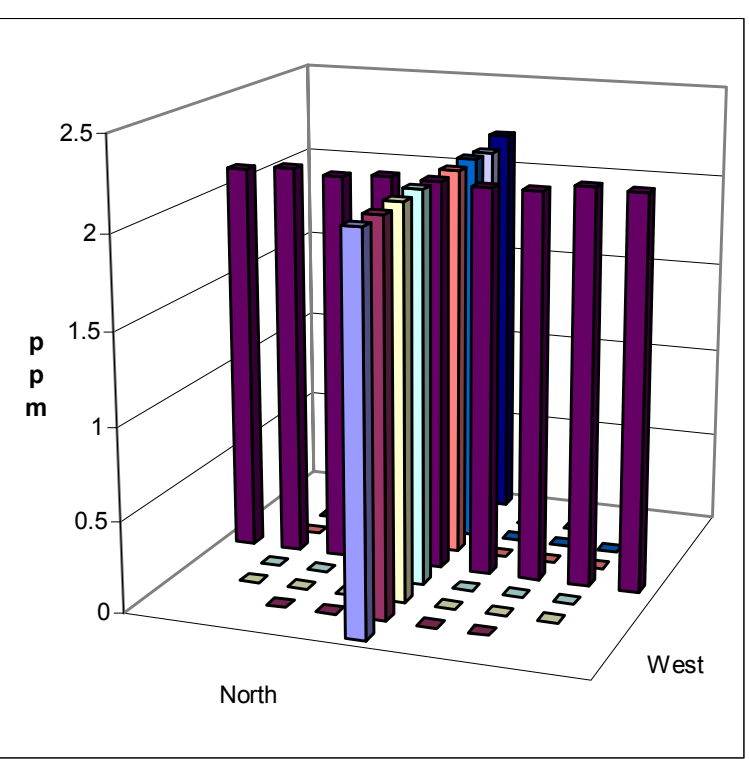


TRACER GAS TRAVERSE DATA FORM

$\begin{aligned} \text { Site } & \frac{291-Z-1 \text { Model }}{\text { Date }} \\ \text { Tester } & \frac{10 / 25 / 01}{\text { Glissmeyer/Maughan }} \\ \text { Stack Dia. } & \frac{23.5 \text { in. }}{433.7 \text { in.2 }} \\ \text { Stack X-Area } & \frac{45 \text { inches }}{\text { Elevation }}\end{aligned}$

Run No. GT-5

Fan Configuration 4 fan: EF1, EF4, EF5, EF7

Fan Setting $\mathbf{5 0 ~ \mathbf { ~ H z }}$

Stack Temp $67 \mathrm{deg} \mathrm{F}$

Start/End Time 1350/1500

Center $2 / 3$ from

Points in Center 2/3 $\frac{2.16}{2}$ to: $\frac{21.34}{7}$

Injection Point EF4 Bottom East

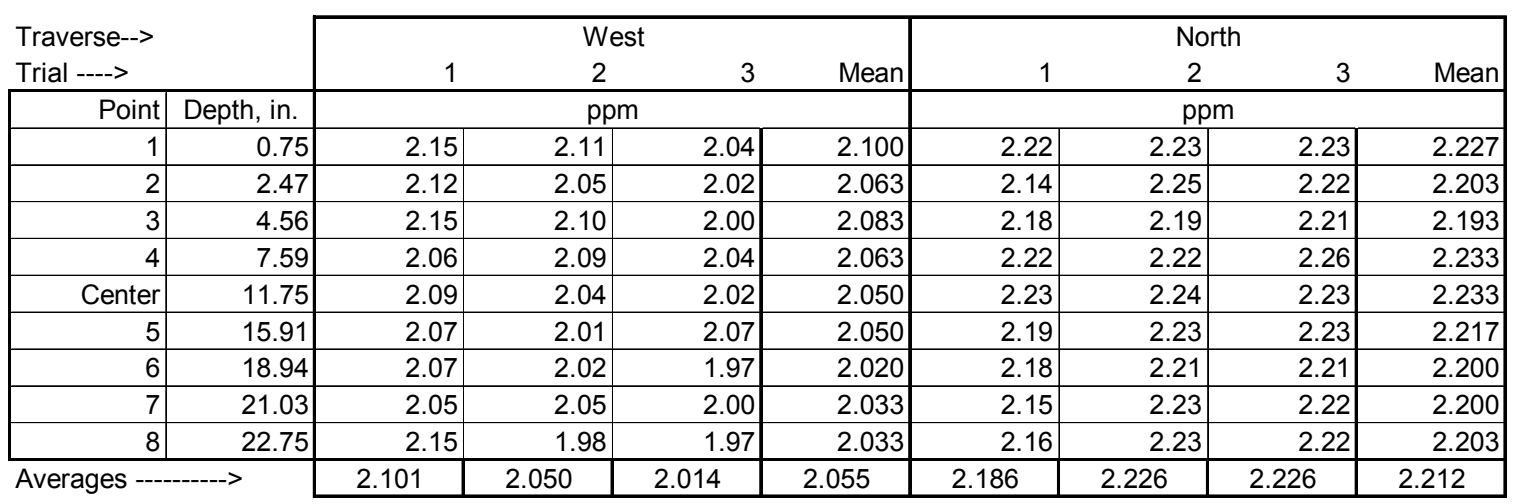

Avg. Conc.

$2.133 \mathrm{ppm}$

\begin{tabular}{|lc}
\hline All & $\mathrm{ppm}$ \\
Mean & 2.13 \\
Min Point & 2.02 \\
Max Point & 2.23 \\
\hline
\end{tabular}

Tracer tank pressure Sample Port Temp Centerline vel. Injection flowmeter Stack flow Sampling flowmeter Ambient pressure Ambient humidity B\&K vapor correction Back-Gd gas ppb No. Bk-Gd samples

\begin{tabular}{|c|c|c|}
\hline Start & Finish & \\
\hline 200 & 200 & 7 psig \\
\hline 68 & 66 & $\mathrm{~F}$ \\
\hline n 1733 & w 1672 & fpm \\
\hline 20 & 21 & ball ${ }^{* *}$ \\
\hline 5600 & 5500 & $\mathrm{cfm}$ \\
\hline 10 & 10 & Ipm Sierra \\
\hline 997.6 & 997.3 & mbar \\
\hline 42 & 40 & $\mathrm{RH}$ \\
\hline $\bar{Y}$ & $Y$ & $\mathrm{Y} / \mathrm{N}$ \\
\hline$-3 / 25 / 43 / 7 / 19 /-3$ & $2 / 28 / 19 / 36 / 28$ & \\
\hline 6 & 5 & $n$ \\
\hline
\end{tabular}

Instuments Used:

B \& K Model 1302 \#1765299

Sierra Inc. Constant Flow Air Sampler

Solmat Zephyr SN 12951472 Cal. Due 7/26/02

\section{Notes:}

Injection flow adjusted up from 19 to 20 shortly after switching traverse directions.

\begin{tabular}{|c|c|c|c|c|}
\hline Dev. from mean & Center $2 / 3$ & West & North & All \\
\hline & Mean & 2.05 & 2.21 & 2.13 \\
\hline$-5.3 \%$ & Std. Dev. & 0.02 & 0.02 & 0.08 \\
\hline $4.7 \%$ & COV as $\%$ & 1.0 & 0.7 & 4.0 \\
\hline
\end{tabular}

Gas analyzer checked: 19-Oct-01

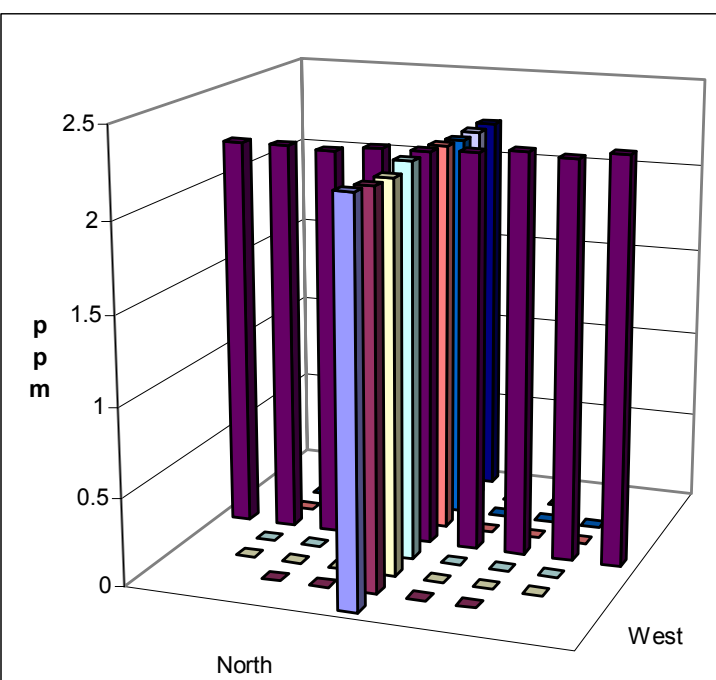


TRACER GAS TRAVERSE DATA FORM

Site 291-Z-1 Model

Date 10/25/01

Tester Glissmeyer/Maughan

Stack Dia.

Stack X-Area

Elevation N.A.

Distance to disturbance Measurement units ppm SF6
Run No. GT-6

Fan Configuration 4 fan: EF1, EF4, EF5, EF7

Fan Setting $50 \mathbf{~ H z}$

Stack Temp $68.5 \operatorname{deg} \mathrm{F}$

Start/End Time $1510 / 1610$

Center $2 / 3$ from 2.16 to: 21.34

Points in Center $2 / 3 \frac{2}{2}$ to: $\frac{21.34}{7}$ Injection Point EF7 Center

\begin{tabular}{|c|c|c|c|c|c|c|c|c|c|}
\hline \multirow{2}{*}{\multicolumn{2}{|c|}{$\begin{array}{l}\text { Traverse--> } \\
\text { Trial ----> }\end{array}$}} & \multicolumn{4}{|c|}{ West } & \multicolumn{4}{|c|}{ North } \\
\hline & & 1 & 2 & 3 & Mean & 1 & 2 & 3 & Mean \\
\hline Point & Depth, in. & \multicolumn{4}{|c|}{ ppm } & \multicolumn{4}{|c|}{ ppm } \\
\hline 1 & 0.75 & 2.23 & 2.20 & 2.16 & 2.197 & 2.25 & 2.14 & 2.18 & 2.190 \\
\hline 2 & 2.47 & 2.17 & 2.19 & 2.15 & 2.170 & 2.21 & 2.21 & 2.25 & 2.223 \\
\hline 3 & 4.56 & 2.17 & 2.17 & 2.20 & 2.180 & 2.22 & 2.20 & 2.17 & 2.197 \\
\hline 4 & 7.59 & 2.22 & 2.12 & 2.22 & 2.187 & 2.21 & 2.20 & 2.18 & 2.197 \\
\hline Center & 11.75 & 2.20 & 2.18 & 2.19 & 2.190 & 2.16 & 2.15 & 2.19 & 2.167 \\
\hline 5 & 15.91 & 2.18 & 2.26 & 2.17 & 2.203 & 2.17 & 2.17 & 2.17 & 2.170 \\
\hline 6 & 18.94 & 2.19 & 2.15 & 2.23 & 2.190 & 2.24 & 2.20 & 2.12 & 2.187 \\
\hline 7 & 21.03 & 2.19 & 2.21 & 2.13 & 2.177 & 2.19 & 2.16 & 2.20 & 2.183 \\
\hline 8 & 22.75 & 2.16 & 2.20 & 2.20 & 2.187 & 2.25 & 2.16 & 2.15 & 2.187 \\
\hline Averages --. & ------> & 2.190 & 2.187 & 2.183 & 2.187 & 2.211 & 2.177 & 2.179 & 2.189 \\
\hline
\end{tabular}

Avg. Conc.

\begin{tabular}{|ll}
\hline All & ppm \\
Mean & 2.19 \\
Min Point & 2.17 \\
Max Point & 2.22 \\
\hline
\end{tabular}

$2.189 \mathrm{ppm}$

Tracer tank pressure Sample Port Temp Centerline vel. Injection flowmeter Stack flow Sampling flowmeter Ambient pressure Ambient humidity B\&K vapor correction Back-Gd gas ppb No. Bk-Gd samples

\begin{tabular}{|c|c|c|}
\hline Start & Finish & \\
\hline 200 & 200 & psig \\
\hline 66 & 71 & $\mathrm{~F}$ \\
\hline w 1672 & n 1650 & $\mathrm{fpm}$ \\
\hline 21 & 20 & ball** \\
\hline 5500 & 5400 & $\mathrm{cfm}$ \\
\hline 10 & 10 & Ipm Sierra \\
\hline 997.3 & 997.0 & mbar \\
\hline 40 & 41 & $\mathrm{RH}$ \\
\hline $\bar{Y}$ & $\mathrm{Y}$ & $\mathrm{Y} / \mathrm{N}$ \\
\hline $2 / 28 / 19 / 36 / 28$ & $53 / 16 / 21$ & \\
\hline 5 & 3 & $n$ \\
\hline
\end{tabular}

Instuments Used:

B \& K Model $1302 \# 1765299$

Sierra Inc. Constant Flow Air Sampler

Solmat Zephyr SN 12951472 Cal. Due 7/26/02

\section{Notes:}

\begin{tabular}{|c|c|c|c|c|}
\hline Dev. from mean & Center 2/3 & $\underline{\text { West }}$ & North & All \\
\hline & Mean & 2.19 & 2.19 & 2.19 \\
\hline$-1.0 \%$ & Std. Dev. & 0.01 & 0.02 & 0.02 \\
\hline $1.6 \%$ & COV as $\%$ & 0.5 & 0.9 & 0.7 \\
\hline
\end{tabular}

Gas analyzer checked:

19-Oct-01

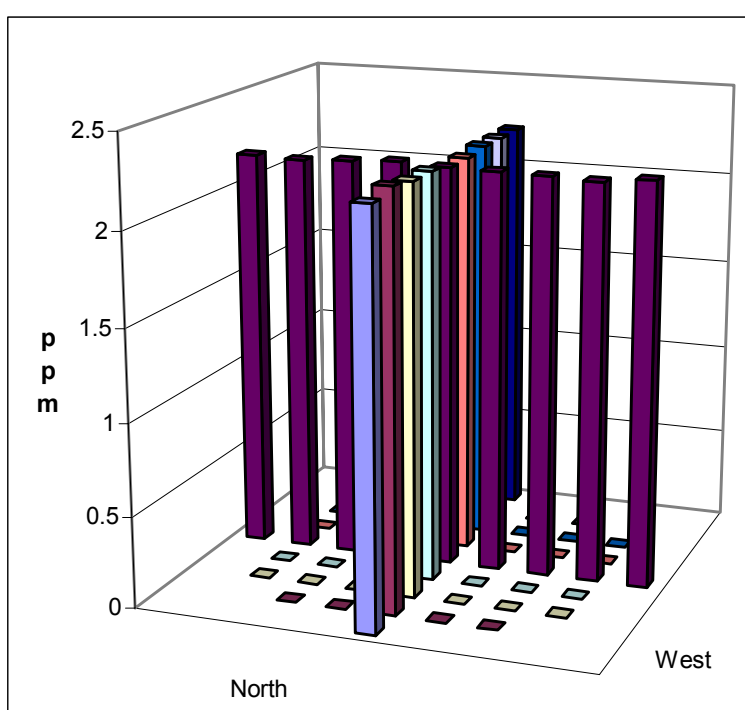


TRACER GAS TRAVERSE DATA FORM

$\begin{aligned} \text { Site } & \\ \text { Date } & \frac{291-Z-1 \text { Model }}{10 / 29 / 01} \\ \text { Tester } & \text { Glissmeyer } \\ \text { Stack Dia. } & 23.5 \text { in. } \\ \text { Stack X-Area } & 433.7 \text { in.2 } \\ \text { Elevation } & \text { N.A. } \\ \text { to disturbance } & 75 \text { inches }\end{aligned}$

Measurement units ppm SF6
Run No. GT-7

Fan Configuration 4 fan: EF1, EF4, EF5, EF7

Fan Setting $50 \mathrm{~Hz}$

Stack Temp

Start/End Time 1245/1400

Center $2 / 3$ from

Points in Center $2 / 3 \frac{2.16}{2}$ to: $\frac{21.34}{7}$

Injection Point EF7 Top West

\begin{tabular}{l} 
Traverse--> \\
\cline { 2 - 11 } Trial ---->
\end{tabular}

Avg. Conc

\begin{tabular}{|lc}
\hline All & $\mathrm{ppm}$ \\
Mean & 1.83 \\
Min Point & 1.77 \\
Max Point & 1.87 \\
\hline
\end{tabular}

$$
1.832 \mathrm{ppm}
$$

Tracer tank pressure Sample Port Temp Centerline vel. Injection flowmeter Stack flow Sampling flowmeter Ambient pressure Ambient humidity B\&K vapor correction Back-Gd gas ppb No. Bk-Gd samples

\begin{tabular}{|c|c|c|}
\hline Start & Finish & \\
\hline 200 & 200 & psig \\
\hline 57 & 57 & $\mathrm{~F}$ \\
\hline N1807 & W 1884 & fpm \\
\hline 20 & 18 & ball ${ }^{* *}$ \\
\hline & & $\mathrm{cfm}$ \\
\hline 10 & 10 & Ipm Sierra \\
\hline 997.5 & 997.3 & mbar \\
\hline 58 & 78 & $\mathrm{RH}$ \\
\hline $\mathrm{Y}$ & $Y$ & $\mathrm{Y} / \mathrm{N}$ \\
\hline $13 / 5 / 18 / 19$ & $72 / 24 / 27 / 21 / 1$ & $4 / 16$ \\
\hline 4 & 6 & $n$ \\
\hline
\end{tabular}

Instuments Used:

B \& K Model 1302 \#1765299

Sierra Inc. Constant Flow Air Sampler Solmat Zephyr SN 12951472 Cal. Due 7/26/02

\section{Notes:}

After delays in the morning, this test was finally started at 1245 , so the starting parameters had to be updated. New prefilters were installed on the intakes of the HEPA filters.

\begin{tabular}{|c|c|c|c|c|}
\hline Dev. from mean & Center $2 / 3$ & $\underline{\text { West }}$ & North & All \\
\hline & Mean & 1.84 & 1.82 & 1.83 \\
\hline$-3.3 \%$ & Std. Dev. & 0.01 & 0.03 & 0.02 \\
\hline $2.1 \%$ & COV as $\%$ & 0.5 & 1.4 & 1.2 \\
\hline
\end{tabular}

Gas analyzer checked: 19-Oct-01

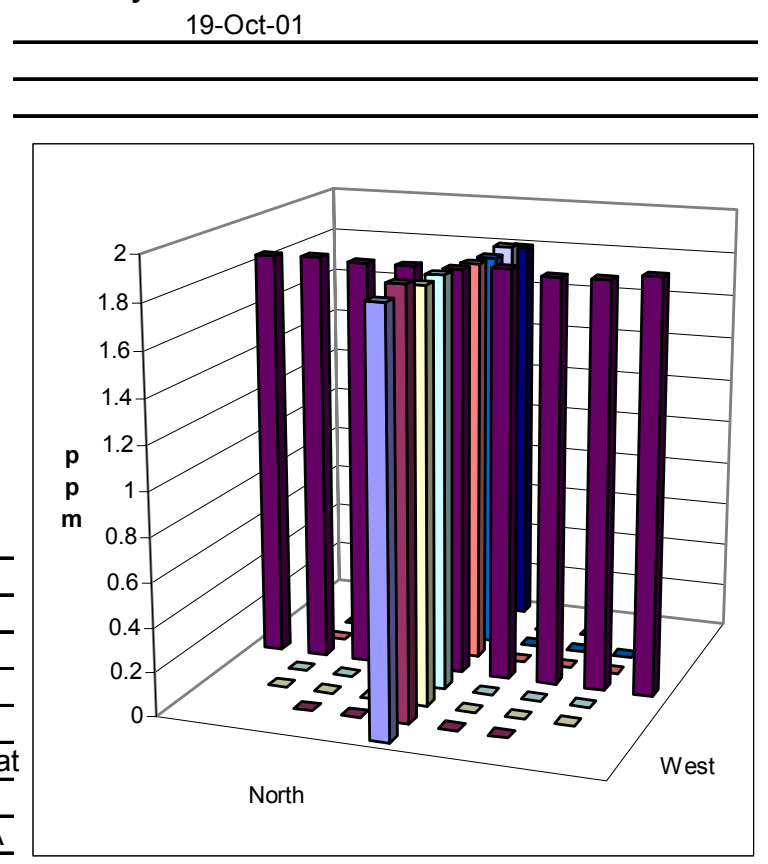

North 
TRACER GAS TRAVERSE DATA FORM

Site 291-Z-1 Model

Date 10/29/01

Tester Glissmeyer

Stack Dia.

Stack X-Area

433.7 in. 2

Elevation N.A.

Distance to disturbance

Measurement units ppm SF6
Run No. GT-8

Fan Configuration 4 fan: EF1, EF4, EF5, EF7

Fan Setting $\overline{50 ~ \mathbf{~ z}}$

Stack Temp

Start/End Time 1400/1513

Center $2 / 3$ from

Points in Center 2/3

Injection Point EF7 Top East

\begin{tabular}{|c|c|c|c|c|c|c|c|c|c|}
\hline \multirow{2}{*}{\multicolumn{2}{|c|}{$\begin{array}{l}\text { Traverse--> } \\
\text { Trial ----> }\end{array}$}} & \multicolumn{4}{|c|}{ West } & \multicolumn{4}{|c|}{ North } \\
\hline & & 1 & 2 & 3 & Mean & 1 & 2 & 3 & Mean \\
\hline Point & Depth, in. & \multicolumn{4}{|c|}{ ppm } & \multicolumn{4}{|c|}{ ppm } \\
\hline 1 & 0.75 & 2.08 & 2.07 & 2.03 & 2.060 & 2.08 & 2.07 & 2.04 & 2.063 \\
\hline 2 & 2.47 & 1.98 & 2.06 & 2.05 & 2.030 & 2.06 & 2.06 & 2.09 & 2.070 \\
\hline 3 & 4.56 & 2.00 & 2.02 & 2.05 & 2.023 & 2.09 & 2.04 & 2.05 & 2.060 \\
\hline 4 & 7.59 & 2.02 & 2.07 & 2.07 & 2.053 & 2.07 & 2.02 & 2.04 & 2.043 \\
\hline Center & 11.75 & 2.03 & 2.01 & 2.02 & 2.020 & 2.08 & 2.06 & 2.06 & 2.067 \\
\hline 5 & 15.91 & 2.02 & 2.08 & 2.08 & 2.060 & 2.06 & 2.05 & 2.03 & 2.047 \\
\hline 6 & 18.94 & 2.08 & 2.04 & 2.01 & 2.043 & 2.06 & 2.03 & 2.04 & 2.043 \\
\hline 7 & 21.03 & 2.09 & 2.03 & 2.02 & 2.047 & 2.04 & 2.05 & 2.07 & 2.053 \\
\hline 8 & 22.75 & 2.00 & 2.09 & 2.06 & 2.050 & 2.08 & 1.99 & 2.08 & 2.050 \\
\hline Averages --- & 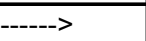 & 2.033 & 2.052 & 2.043 & 2.043 & 2.069 & 2.041 & 2.056 & 2.055 \\
\hline
\end{tabular}

Avg. Conc.

\begin{tabular}{|ll}
\hline AII & ppm \\
Mean & 2.05 \\
Min Point & 2.02 \\
Max Point & 2.07 \\
\hline
\end{tabular}

$2.050 \mathrm{ppm}$

Tracer tank pressure Sample Port Temp

Centerline vel.

Injection flowmeter

Stack flow

Sampling flowmeter

Ambient pressure

Ambient humidity

B\&K vapor correction

Back-Gd gas ppb

No. Bk-Gd samples

\begin{tabular}{|c|c|c|}
\hline Start & Finish & \\
\hline 200 & 200 & psig \\
\hline 57 & 58 & $\mathrm{~F}$ \\
\hline w 1884 & n 1820 & $\mathrm{fpm}$ \\
\hline 20 & 20 & ball ${ }^{\star *}$ \\
\hline 6200 & 5900 & $\mathrm{cfm}$ \\
\hline 10 & 10 & Ipm Sierr \\
\hline 997.3 & 996.3 & mbar \\
\hline 78 & 72 & $\mathrm{RH}$ \\
\hline $\mathrm{Y}$ & $\mathrm{Y}$ & $\mathrm{Y} / \mathrm{N}$ \\
\hline $24 / 27 / 21 / 14 / 16$ & $25 / 21 / 17 / 19$ & \\
\hline 6 & 4 & $n$ \\
\hline
\end{tabular}

Instuments Used:

B \& K Model $1302 \# 1765299$

Sierra Inc. Constant Flow Air Sampler

Solmat Zephyr SN 12951472 Cal. Due 7/26/02

\section{Notes:}

\begin{tabular}{|c|c|c|c|c|}
\hline Dev. from mean & Center 2/3 & West & North & All \\
\hline & Mean & 2.04 & 2.05 & $2 . \overline{05}$ \\
\hline$-1.4 \%$ & Std. Dev. & 0.02 & 0.01 & 0.02 \\
\hline $1.0 \%$ & COV as $\%$ & 0.8 & 0.5 & 0.7 \\
\hline
\end{tabular}

Gas analyzer checked:

19-Oct-01

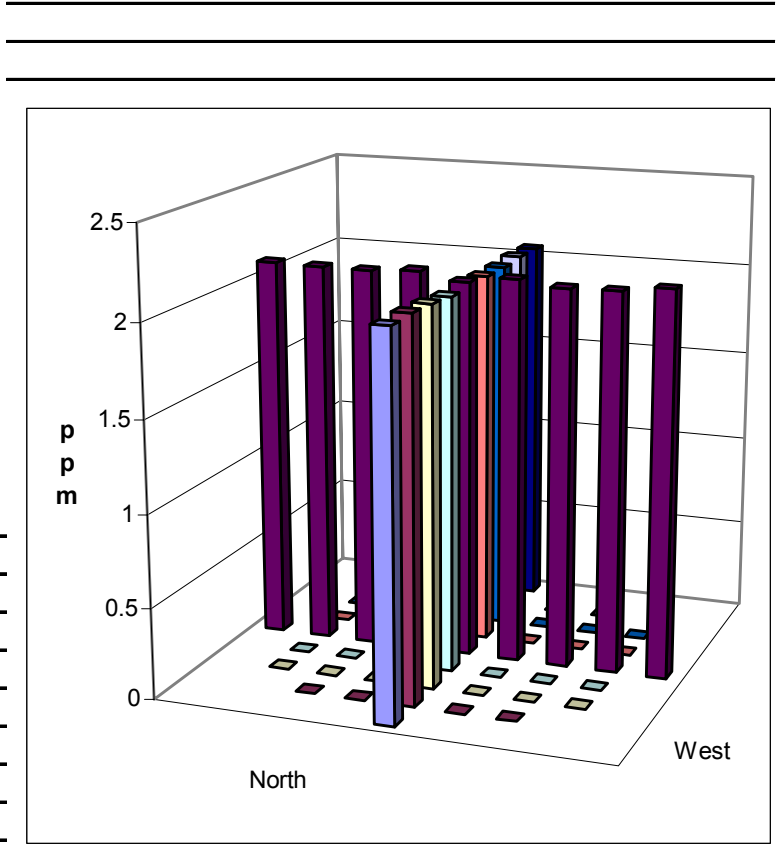


TRACER GAS TRAVERSE DATA FORM

\begin{tabular}{|c|c|}
\hline \multicolumn{2}{|c|}{ Site 291-Z-1 Model } \\
\hline Date & 11/1/01 \\
\hline \multicolumn{2}{|c|}{ Tester Glissmeyer } \\
\hline Stack Dia. & 23.5 in. \\
\hline Stack X-Area & 433.7 in. 2 \\
\hline \multicolumn{2}{|c|}{ Elevation N.A. } \\
\hline to disturbance & 75 inches \\
\hline
\end{tabular}

Run No. GT-9

Fan Configuration 4 fan: EF1, EF4, EF5, EF7

Fan Setting $\mathbf{5 0 ~ \mathbf { ~ z z }}$

Stack Temp

Start/End Time $1047-1150$

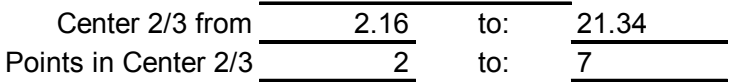

Injection Point EF7 Bottom West

\begin{tabular}{|c|c|c|c|c|c|c|c|c|c|}
\hline \multirow{2}{*}{$\begin{array}{l}\text { Traverse--> } \\
\text { Trial ----> }\end{array}$} & & \multicolumn{4}{|c|}{ West } & \multicolumn{4}{|c|}{ North } \\
\hline & & 1 & 2 & 3 & Mean & 1 & 2 & 3 & Mean \\
\hline Point & Depth, in. & \multicolumn{4}{|c|}{ ppm } & \multicolumn{4}{|c|}{$\mathrm{ppm}$} \\
\hline 1 & 0.75 & 1.98 & 1.94 & 1.94 & 1.953 & 2.02 & 1.99 & 1.98 & 1.997 \\
\hline 2 & 2.47 & 1.96 & 1.89 & 1.93 & 1.927 & 1.91 & 1.87 & 1.97 & 1.917 \\
\hline 3 & 4.56 & 1.91 & 1.92 & 1.93 & 1.920 & 1.97 & 2.01 & 2.03 & 2.003 \\
\hline 4 & 7.59 & 1.92 & 1.92 & 1.91 & 1.917 & 1.97 & 1.95 & 2.00 & 1.973 \\
\hline Center & 11.75 & 1.97 & 1.94 & 1.96 & 1.957 & 1.98 & 1.97 & 1.99 & 1.980 \\
\hline 5 & 15.91 & 1.94 & 2.00 & 1.91 & 1.950 & 2.03 & 1.92 & 2.00 & 1.983 \\
\hline 6 & 18.94 & 1.92 & 1.96 & 1.92 & 1.933 & 1.89 & 1.94 & 1.94 & 1.923 \\
\hline 7 & 21.03 & 1.94 & 1.87 & 1.94 & 1.917 & 1.94 & 1.93 & 1.91 & 1.927 \\
\hline 8 & 22.75 & 1.98 & 2.01 & 1.94 & 1.977 & 1.93 & 1.94 & 2.00 & 1.957 \\
\hline Averages --.. & $-\overline{---1}$ & 1.947 & 1.939 & 1.931 & 1.939 & 1.960 & 1.947 & 1.980 & 1.962 \\
\hline
\end{tabular}

\begin{tabular}{|c|c|c|c|c|c|c|}
\hline$A I I$ & ppm & Dev. from mean & Center $2 / 3$ & West & North & All \\
\hline Mean & 1.95 & & Mean & 1.93 & 1.96 & $1 . \overline{94}$ \\
\hline Min Point & 1.92 & $-1.7 \%$ & Std. Dev. & 0.02 & 0.03 & 0.03 \\
\hline Max Point & 2.00 & $2.7 \%$ & CoV as $\%$ & 0.8 & 1.8 & 1.5 \\
\hline
\end{tabular}

Avg. Conc. $\quad 1.948 \mathrm{ppm}$

Gas analyzer checked:

19-Oct-01

\begin{tabular}{|c|c|c|c|}
\hline \multirow[b]{2}{*}{ Tracer tank pressure } & Start & Finish & \\
\hline & 200 & 200 & \\
\hline Sample Port Temp & 63 & 61 & $F$ \\
\hline Centerline vel. & W 1794 & N 1759 & $\mathrm{fpm}$ \\
\hline Injection flowmeter & 20 & 20 & ball ${ }^{* *}$ \\
\hline Stack flow & 5900 & 5700 & $\mathrm{cfm}$ \\
\hline Sampling flowmeter & 10 & 10 & Ipm Sierra \\
\hline Ambient pressure & 992.0 & 991.8 & mbar \\
\hline Ambient humidity & 55 & 48 & $\mathrm{RH}$ \\
\hline B\&K vapor correction & $\mathrm{Y}$ & $Y$ & $\mathrm{Y} / \mathrm{N}$ \\
\hline Back-Gd gas ppb 21/36 & $28 / 56 / 27 / 32$ & $41 / 12 / 22 / 5$ & \\
\hline No. Bk-Gd samples & 6 & 4 & $n$ \\
\hline
\end{tabular}

Instuments Used:

B \& K Model 1302 \#1765299

Sierra Inc. Constant Flow Air Sampler

Solmat Zephyr SN 12951472 Cal. Due 7/26/02

\begin{tabular}{l}
\hline Notes: On start, the B\&K had pump test and vibration \\
\hline errors. Water drained from the bottom of the stack when \\
\hline the fans wre started. Ran fans $@ 60 \mathrm{~Hz}$ to dry stack. Run \\
\hline restarted later to get new regulator installed on gas cylinder
\end{tabular}

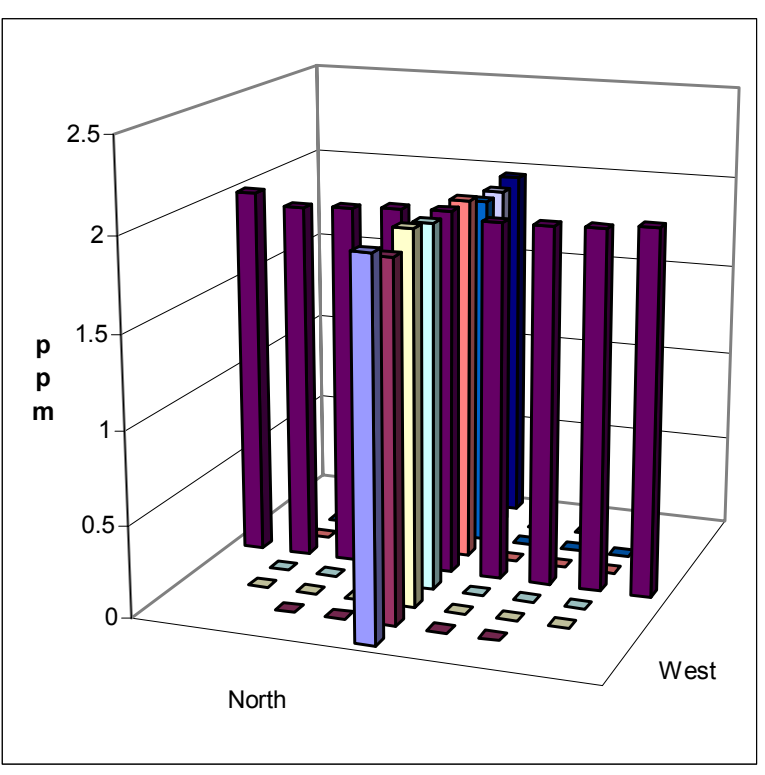

Starting parameters were updated. It rained steadily yesterday. 
TRACER GAS TRAVERSE DATA FORM

Site 291-Z-1 Model

Date 10/31/01

Tester Maughan

Stack Dia.

Stack X-Area

Elevation N.A.

Distance to disturbance

Measurement units ppm SF6
Run No. GT-10

Fan Configuration 4 fan: EF1, EF4, EF5, EF7

Fan Setting $5 \mathbf{5 0 ~} \mathbf{~ z}$

Stack Temp

Start/End Time 1425/1535

Center $2 / 3$ from

Points in Center $2 / 3$

Injection Point EF7 Bottom East

\begin{tabular}{|c|c|c|c|c|c|c|c|c|c|}
\hline \multirow{2}{*}{\multicolumn{2}{|c|}{$\begin{array}{l}\text { Traverse--> } \\
\text { Trial ----> }\end{array}$}} & \multicolumn{4}{|c|}{ West } & \multicolumn{4}{|c|}{ North } \\
\hline & & 1 & 2 & 3 & Mean & 1 & 2 & 3 & Mean \\
\hline Point & Depth, in. & \multicolumn{4}{|c|}{ ppm } & \multicolumn{4}{|c|}{$\mathrm{ppm}$} \\
\hline 1 & 0.75 & 2.02 & 2.00 & 1.92 & 1.980 & 2.00 & 1.99 & 2.05 & 2.013 \\
\hline 2 & 2.47 & 1.97 & 1.98 & 1.98 & 1.977 & 2.02 & 2.04 & 2.00 & 2.020 \\
\hline 3 & 4.56 & 1.96 & 1.93 & 1.97 & 1.953 & 2.06 & 2.09 & 2.04 & 2.063 \\
\hline 4 & 7.59 & 1.99 & 2.01 & 2.01 & 2.003 & 2.00 & 2.02 & 2.04 & 2.020 \\
\hline Center & 11.75 & 1.97 & 2.05 & 1.99 & 2.003 & 2.01 & 1.98 & 2.01 & 2.000 \\
\hline 5 & 15.91 & 2.04 & 1.99 & 2.04 & 2.023 & 2.01 & 2.02 & 2.03 & 2.020 \\
\hline 6 & 18.94 & 2.05 & 2.01 & 2.01 & 2.023 & 1.98 & 2.00 & 2.00 & 1.993 \\
\hline 7 & 21.03 & 1.97 & 2.04 & 2.00 & 2.003 & 2.02 & 1.99 & 1.96 & 1.990 \\
\hline 8 & 22.75 & 2.01 & 2.06 & 1.98 & 2.017 & 1.98 & 2.01 & 1.95 & 1.980 \\
\hline Averages --- & $----->$ & 1.998 & 2.008 & 1.989 & 1.998 & 2.009 & 2.016 & 2.009 & 2.011 \\
\hline
\end{tabular}

\begin{tabular}{|lrr|lrrr|}
\hline All & ppm & Dev. from mean & Center 2/3 & $\frac{\text { West }}{2.00}$ & $\frac{\text { North }}{2.02}$ & All \\
Mean & 2.00 & & Mean & 0.01 \\
Min Point & 1.95 & $-2.6 \%$ & Std. Dev. & 0.03 & 0.02 & 0.03 \\
Max Point & 2.06 & $2.9 \%$ & COV as \% & 1.3 & 1.2 & $\mathbf{1 . 3}$ \\
\hline
\end{tabular}

Avg. Conc.

$$
2.005 \mathrm{ppm}
$$

Tracer tank pressure Sample Port Temp Centerline vel. Injection flowmeter

Stack flow

Sampling flowmeter Ambient pressure Ambient humidity B\&K vapor correction Back-Gd gas ppb No. Bk-Gd samples

\begin{tabular}{|c|c|c|}
\hline Start & Finish & \\
\hline 200 & 200 & psig \\
\hline 67.2 & 67 & $\mathrm{~F}$ \\
\hline N1728 & W1804 & $\mathrm{fpm}$ \\
\hline 20 & 20 & ball ${ }^{* *}$ \\
\hline 5600 & 5900 & $\mathrm{cfm}$ \\
\hline 10 & 10 & Ipm Sierra \\
\hline 982.3 & 983.2 & mbar \\
\hline 38 & 36 & $\mathrm{RH}$ \\
\hline$Y$ & $Y$ & $Y / N$ \\
\hline $18 / 11 / 12 / 25$ & $64 / 9 / 21 / 20$ & \\
\hline 4 & 4 & $n$ \\
\hline
\end{tabular}

Instuments Used:

B \& K Model 1302 \#1765299

Sierra Inc. Constant Flow Air Sampler

Solmat Zephyr SN 12951472 Cal. Due 7/26/02

Notes: $\quad$ On start, the B\&K had pump test and vibration errors. Water drained from the bottom of the stack when the fans wre started. Ran fans $@ 60 \mathrm{~Hz}$ to dry stack. Run restarted later to get new regulator installed on gas cylinder

Starting parameters were updated. It rained steadily yesterday.
Gas analyzer checked:

19-Oct-01

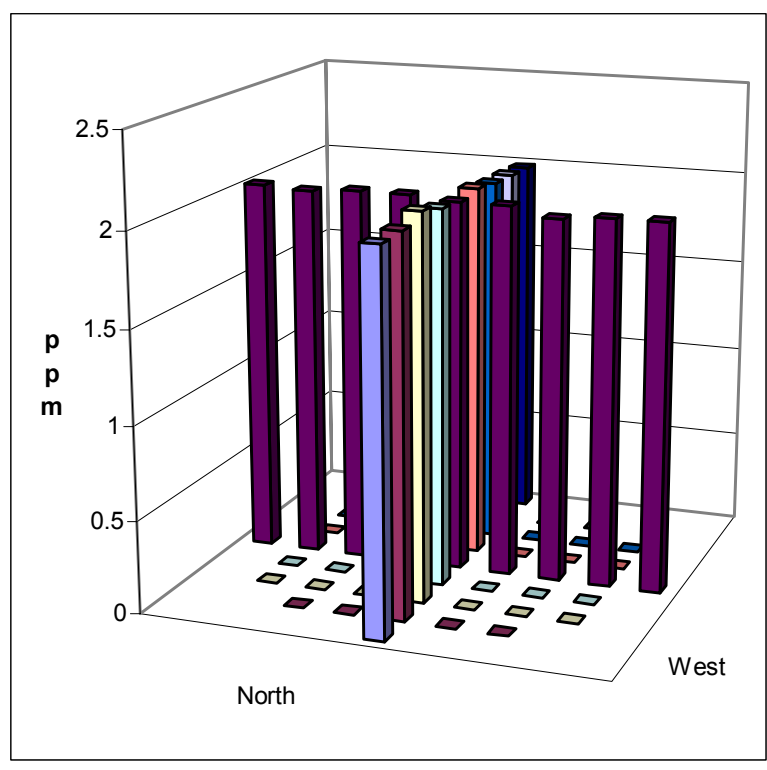


TRACER GAS TRAVERSE DATA FORM

Site 291-Z-1 Model

Date 11/1/01

Tester Glissmeyer

Stack Dia.

433.7 in. 2

Elevation N.A.

Distance to disturbance

Measurement units ppm SF6
Run No. GT-11

Fan Configuration 4 fan: EF1, EF4, EF5, EF7

Fan Setting $\mathbf{5 0 ~} \mathbf{~ z z}$

Stack Temp

Start/End Time $1200-1305$

Center $2 / 3$ from

Points in Center 2/3

Injection Point EF5 - Centerline

\begin{tabular}{|c|c|c|c|c|c|c|c|c|c|}
\hline \multirow{2}{*}{\multicolumn{2}{|c|}{$\begin{array}{l}\text { Traverse--> } \\
\text { Trial ----> }\end{array}$}} & \multicolumn{4}{|c|}{ West } & \multicolumn{4}{|c|}{ North } \\
\hline & & 1 & 2 & 3 & Mean & 1 & 2 & 3 & Mean \\
\hline Point & Depth, in. & \multicolumn{4}{|c|}{ ppm } & \multicolumn{4}{|c|}{$\mathrm{ppm}$} \\
\hline 1 & 0.75 & 2.00 & 2.06 & 2.02 & 2.027 & 2.01 & 2.03 & 2.05 & 2.030 \\
\hline 2 & 2.47 & 2.09 & 2.01 & 1.98 & 2.027 & 2.00 & 1.99 & 1.98 & 1.990 \\
\hline 3 & 4.56 & 1.99 & 2.00 & 1.99 & 1.993 & 2.03 & 1.99 & 2.00 & 2.007 \\
\hline 4 & 7.59 & 2.02 & 2.03 & 2.05 & 2.033 & 2.01 & 1.99 & 2.00 & 2.000 \\
\hline Center & 11.75 & 1.99 & 2.01 & 2.03 & 2.010 & 2.09 & 2.08 & 2.02 & 2.063 \\
\hline 5 & 15.91 & 2.00 & 2.03 & 2.06 & 2.030 & 2.06 & 2.03 & 2.04 & 2.043 \\
\hline 6 & 18.94 & 2.02 & 2.01 & 2.03 & 2.020 & 2.02 & 1.98 & 2.02 & 2.007 \\
\hline 7 & 21.03 & 2.00 & 2.01 & 2.00 & 2.003 & 2.03 & 1.99 & 2.02 & 2.013 \\
\hline 8 & 22.75 & 2.02 & 2.05 & 1.98 & 2.017 & 1.95 & 1.98 & 1.99 & 1.973 \\
\hline Averages ---- & ---' & 2.014 & 2.023 & 2.016 & 2.018 & 2.022 & 2.007 & 2.013 & 2.014 \\
\hline
\end{tabular}

Avg. Conc.

\begin{tabular}{|lr}
\hline All & $\mathrm{ppm}$ \\
Mean & 2.02 \\
Min Point & 1.97 \\
Max Point & 2.06 \\
\hline
\end{tabular}

$2.013 \mathrm{ppm}$

Tracer tank pressure Sample Port Temp

Centerline vel.

Injection flowmeter

Stack flow

Sampling flowmeter

Ambient pressure

Ambient humidity

B\&K vapor correction

Back-Gd gas ppb

No. Bk-Gd samples

\begin{tabular}{|c|c|c|}
\hline Start & Finish & \\
\hline 200 & 200 & psig \\
\hline 61 & 65 & $\mathrm{~F}$ \\
\hline N 1759 & W 1826 & fpm \\
\hline 20 & 20 & ball ${ }^{\star *}$ \\
\hline 5700 & 6000 & $\mathrm{cfm}$ \\
\hline 10 & 10 & Ipm Sierra \\
\hline 991.8 & 991.0 & mbar \\
\hline 48 & 52 & $\mathrm{RH}$ \\
\hline $\mathrm{Y}$ & $Y$ & $\mathrm{Y} / \mathrm{N}$ \\
\hline $5 / 25 / 9 /-3$ & $17 / 2 / 4 / 6$ & \\
\hline 4 & 4 & $n$ \\
\hline
\end{tabular}

Instuments Used:

B \& K Model 1302 \#1765299

Sierra Inc. Constant Flow Air Sampler

Solmat Zephyr SN 12951472 Cal. Due 7/26/02

\begin{tabular}{l}
\hline Notes: $\quad$ On start, the B\&K had pump test and vibration \\
\hline errors. Water drained from the bottom of the stack when \\
\hline the fans wre started. Ran fans @60Hz to dry stack. Run \\
\hline restarted later to get new regulator installed on gas cylinder \\
\hline Starting param
\end{tabular}

Starting parameters were updated. It rained steadily yesterday.

\begin{tabular}{|c|c|c|c|c|}
\hline Dev. from mean & Center 2/3 & West & North & All \\
\hline & $\overline{M e a n}$ & 2.02 & 2.02 & $2 . \overline{02}$ \\
\hline$-2.1 \%$ & Std. Dev. & 0.01 & 0.03 & 0.02 \\
\hline $2.4 \%$ & COV as $\%$ & 0.7 & 1.3 & 1.0 \\
\hline
\end{tabular}

Gas analyzer checked:

19-Oct-01

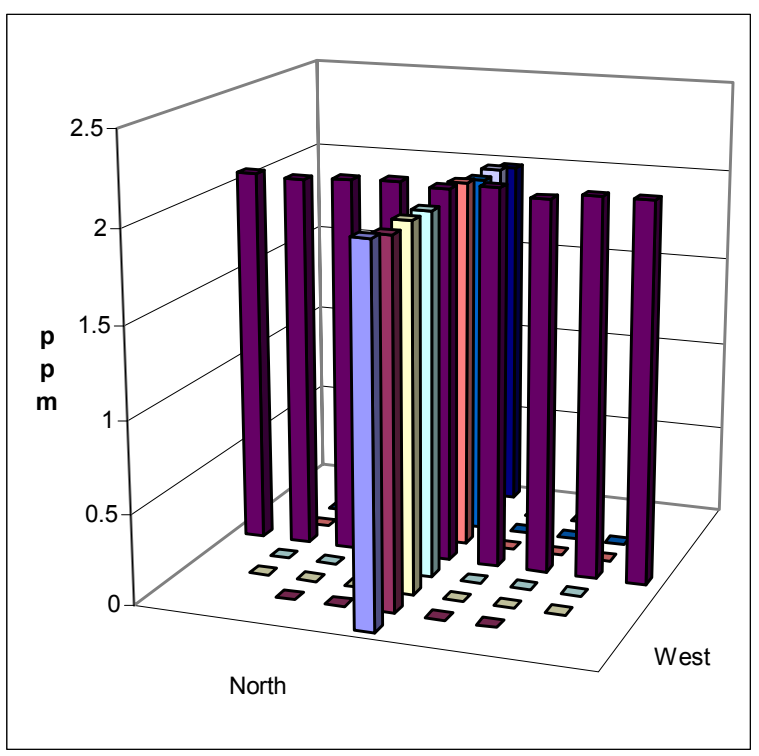


TRACER GAS TRAVERSE DATA FORM

\begin{tabular}{|c|c|}
\hline \multicolumn{2}{|c|}{ Site 291-Z-1 Model } \\
\hline Date & 11/1/01 \\
\hline \multicolumn{2}{|c|}{ Tester Glissmeyer } \\
\hline Stack Dia. & $23.5 \mathrm{in}$. \\
\hline Stack X-Area & 433.7 in. 2 \\
\hline \multicolumn{2}{|c|}{ Elevation N.A. } \\
\hline to disturbance & 75 inches \\
\hline
\end{tabular}

Run No. GT-12

Fan Configuration 4 fan: EF1, EF4, EF5, EF7

Fan Setting $50 \mathbf{~ H z}$

Stack Temp

Start/End Time $1305-1415$

Center $2 / 3$ from 21.34

Distance to disturbance 75 inches

Measurement units ppm SF6

Points in Center $2 / 3 \frac{2.16}{2}$ to: $\underline{7}$

Injection Point EF1 Centerline

\begin{tabular}{|c|c|c|c|c|c|c|c|c|c|}
\hline \multirow{2}{*}{\multicolumn{2}{|c|}{$\begin{array}{l}\text { Traverse--> } \\
\text { Trial ----> }\end{array}$}} & \multicolumn{4}{|c|}{ West } & \multicolumn{4}{|c|}{ North } \\
\hline & & 1 & 2 & 3 & Mean & 1 & 2 & 3 & Mean \\
\hline Point & Depth, in. & \multicolumn{4}{|c|}{ ppm } & \multicolumn{4}{|c|}{ ppm } \\
\hline 1 & 0.75 & 2.08 & 2.09 & 2.07 & 2.080 & 2.03 & 2.02 & 2.05 & 2.033 \\
\hline 2 & 2.47 & 1.99 & 2.09 & 2.12 & 2.067 & 1.98 & 2.05 & 2.07 & 2.033 \\
\hline 3 & 4.56 & 2.05 & 2.07 & 2.10 & 2.073 & 2.02 & 2.10 & 2.05 & 2.057 \\
\hline 4 & 7.59 & 2.06 & 2.11 & 2.04 & 2.070 & 2.04 & 2.05 & 2.03 & 2.040 \\
\hline Center & 11.75 & 2.03 & 2.12 & 2.06 & 2.070 & 2.04 & 2.06 & 2.06 & 2.053 \\
\hline 5 & 15.91 & 2.02 & 2.05 & 2.05 & 2.040 & 2.05 & 1.99 & 2.02 & 2.020 \\
\hline 6 & 18.94 & 2.02 & 2.02 & 2.03 & 2.023 & 2.07 & 2.09 & 2.10 & 2.087 \\
\hline 7 & 21.03 & 2.03 & 2.04 & 2.02 & 2.030 & 2.07 & 2.06 & 2.07 & 2.067 \\
\hline 8 & 22.75 & 2.04 & 2.13 & 2.09 & 2.087 & 2.12 & 2.10 & 2.06 & 2.093 \\
\hline Averages --- & ---->> & 2.036 & 2.080 & 2.064 & 2.060 & 2.047 & 2.058 & 2.057 & 2.054 \\
\hline
\end{tabular}

\begin{tabular}{|c|c|c|c|c|c|c|}
\hline$A I I$ & $\mathrm{ppm}$ & Dev. from mean & Center $2 / 3$ & West & North & All \\
\hline Mean & 2.06 & & Mean & 2.05 & 2.05 & 2.05 \\
\hline Min Point & 2.02 & $-1.8 \%$ & Std. Dev. & 0.02 & 0.02 & 0.02 \\
\hline Max Point & 2.09 & $1.8 \%$ & COV as $\%$ & 1.0 & 1.1 & 1.0 \\
\hline
\end{tabular}

Avg. Conc. $2.056 \mathrm{ppm}$

Gas analyzer checked:

19-Oct-01

Tracer tank pressure

Sample Port Temp

Centerline vel.

Injection flowmeter

Stack flow

Sampling flowmeter

Ambient pressure

Ambient humidity

B\&K vapor correction

Back-Gd gas ppb

No. Bk-Gd samples

\begin{tabular}{|c|c|c|}
\hline Start & Finish & \\
\hline 200 & 200 & psig \\
\hline 65 & 65 & $F$ \\
\hline W 1826 & $\mathrm{~N} 1732$ & fpm \\
\hline 20 & 21 & ball ${ }^{* *}$ \\
\hline 6000 & 5600 & $\mathrm{cfm}$ \\
\hline 10 & 10 & Ipm Sierra \\
\hline 991.0 & 991.1 & mbar \\
\hline 52 & 57 & $\mathrm{RH}$ \\
\hline$Y$ & $Y$ & $\mathrm{Y} / \mathrm{N}$ \\
\hline $17 / 2 / 4 / 6 / 6$ & $102 / 22 / 22 / 22$ & \\
\hline 5 & 4 & $n$ \\
\hline
\end{tabular}

Instuments Used:

B \& K Model 1302 \#1765299

Sierra Inc. Constant Flow Air Sampler

Solmat Zephyr SN 12951472 Cal. Due 7/26/02

\begin{tabular}{l}
\hline Notes: On start, the B\&K had pump test and vibration \\
\hline errors. Water drained from the bottom of the stack when \\
\hline the fans wre started. Ran fans @60Hz to dry stack. Run \\
\hline restarted later to get new regulator installed on gas cylinder
\end{tabular}

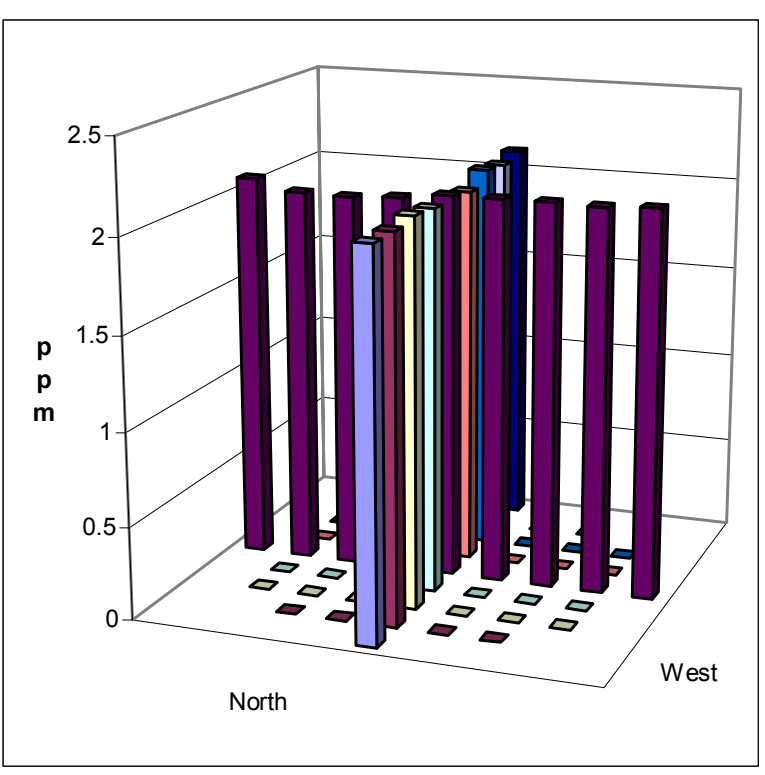

Starting parameters were updated. It rained steadily yesterday. 
TRACER GAS TRAVERSE DATA FORM

Site 291-Z-1 Model

Date 11/1/01

Tester Maughan

Stack Dia.

Stack X-Area

Elevation

Distance to disturbance

Measurement units ppm SF6
Run No. GT-13

Fan Configuration 4 fan: EF1, EF4, EF5, EF7

Fan Setting $\mathbf{5 0 ~ \mathbf { ~ z }}$

Stack Temp

Start/End Time $1450-1558$

Center $2 / 3$ from 21.34

Points in Center $2 / 3 \overline{2}$ to: $\frac{21}{7}$

Injection Point EF1 Bottom East

\begin{tabular}{|c|c|c|c|c|c|c|c|c|c|}
\hline \multirow{2}{*}{\multicolumn{2}{|c|}{$\begin{array}{l}\text { Traverse---> } \\
\text { Trial ----> }\end{array}$}} & \multicolumn{4}{|c|}{ West } & \multicolumn{4}{|c|}{ North } \\
\hline & & 1 & 2 & 3 & Mean & 1 & 2 & 3 & Mean \\
\hline Point & Depth, in. & \multicolumn{4}{|c|}{ ppm } & \multicolumn{4}{|c|}{ ppm } \\
\hline 1 & 0.75 & 2.03 & 2.01 & 2.04 & 2.027 & 2.02 & 1.96 & 2.00 & 1.993 \\
\hline 2 & 2.47 & 1.99 & 1.94 & 1.97 & 1.967 & 1.96 & 1.97 & 1.94 & 1.957 \\
\hline 3 & 4.56 & 1.97 & 2.00 & 1.95 & 1.973 & 2.00 & 1.98 & 1.99 & 1.990 \\
\hline 4 & 7.59 & 2.02 & 1.99 & 2.03 & 2.013 & 1.99 & 1.98 & 2.03 & 2.000 \\
\hline Center & 11.75 & 1.98 & 1.98 & 1.97 & 1.977 & 1.97 & 1.99 & 1.94 & 1.967 \\
\hline 5 & 15.91 & 2.01 & 1.97 & 2.02 & 2.000 & 2.01 & 1.96 & 1.98 & 1.983 \\
\hline 6 & 18.94 & 1.97 & 1.98 & 1.94 & 1.963 & 2.02 & 1.96 & 1.97 & 1.983 \\
\hline 7 & 21.03 & 1.98 & 1.98 & 2.02 & 1.993 & 1.97 & 1.95 & 1.99 & 1.970 \\
\hline 8 & 22.75 & 1.98 & 1.96 & 1.96 & 1.967 & 1.97 & 1.97 & 1.99 & 1.977 \\
\hline Averages --- & ------> & 1.992 & 1.979 & 1.989 & 1.987 & 1.990 & 1.969 & 1.981 & 1.980 \\
\hline
\end{tabular}

\begin{tabular}{|lrr|lrrr|}
\hline All & ppm & Dev. from mean & Center 2/3 & $\frac{\text { West }}{1.98}$ & $\frac{\text { North }}{1.98}$ & All \\
Mean & 1.98 & & Mean & & 1.98 \\
Min Point & 1.96 & $-1.3 \%$ & Std. Dev. & 0.02 & 0.01 & 0.02 \\
Max Point & 2.03 & $2.2 \%$ & COV as $\%$ & 0.9 & 0.8 & $\mathbf{0 . 8}$ \\
\hline
\end{tabular}

Avg. Conc.

$1.985 \mathrm{ppm}$

Tracer tank pressure

Sample Port Temp

Centerline vel.

Injection flowmeter

Stack flow

Sampling flowmeter

Ambient pressure

Ambient humidity

B\&K vapor correction

\begin{tabular}{|c|c|c|}
\hline Start & Finish & \\
\hline 200 & 200 & psig \\
\hline 65 & 67 & $\mathrm{~F}$ \\
\hline N 1690 & W 1732 & fpm \\
\hline 20 & 20 & ball ${ }^{* *}$ \\
\hline 5500 & 5700 & $\mathrm{cfm}$ \\
\hline 10 & 10 & Ipm Sier \\
\hline 991.1 & 991.0 & mbar \\
\hline 55 & 56 & $\mathrm{RH}$ \\
\hline $\mathrm{Y}$ & $\mathrm{Y}$ & $\mathrm{Y} / \mathrm{N}$ \\
\hline
\end{tabular}

Back-Gd gas ppb 10/4.1/17.6/-4.1/31.2 19.4/15.3/28.6/16

No. Bk-Gd samples

\begin{tabular}{|r|r|}
\hline 5 & 4 \\
\hline
\end{tabular}

Instuments Used:

B \& K Model $1302 \# 1765299$

Sierra Inc. Constant Flow Air Sampler

Solmat Zephyr SN 12951472 Cal. Due 7/26/02

Notes: Duplicate run on GT-5

\section{Gas analyzer checked:}

19-Oct-01

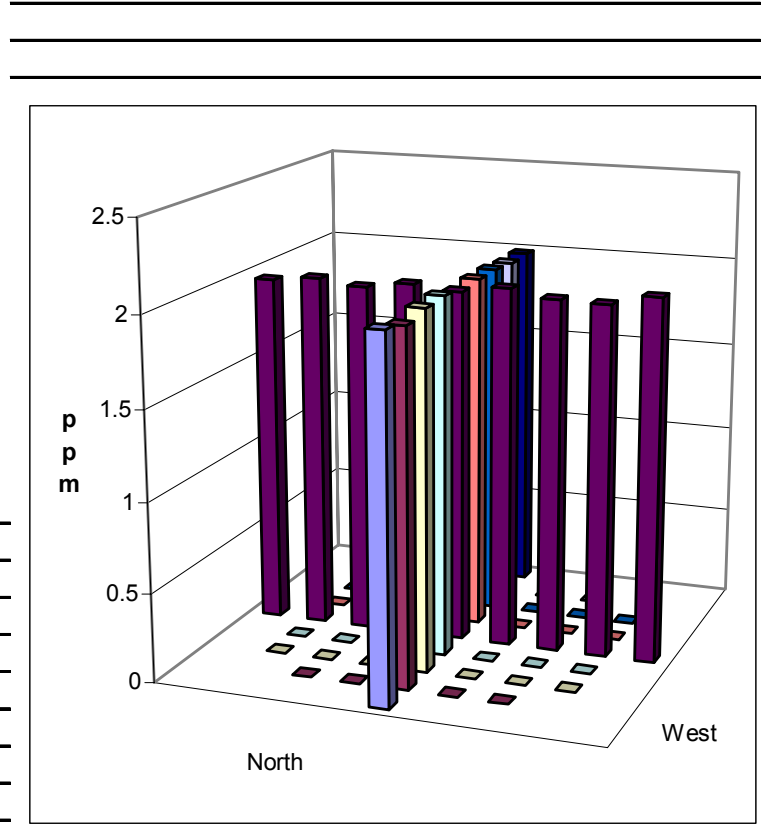


TRACER GAS TRAVERSE DATA FORM

Site 291-Z-1 Model

Date 11/15/01

Tester Glissmeyer

Stack Dia. $23.5 \mathrm{in}$

Stack X-Area 433.7 in. 2

Elevation

Distance to disturbance

Measurement units ppm SF6

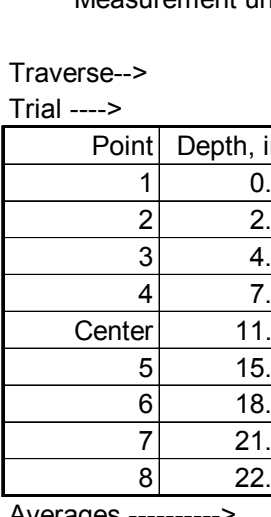

$$
1 \text { st }
$$

Run No. GT-14

Fan Configuration Turbine Fans

Fan Setting $60 \mathrm{~Hz}$

Stack Temp $65.5 \mathrm{deg} F$

Start/End Time 1040/1255

Center $2 / 3$ from

Points in Center 2/3 2 to: $\frac{21.34}{7}$ Injection Point ET9 Centerline

\begin{tabular}{|l|l|l|l|l|l|r|r|r|}
\hline & 22.75 & 2.57 & 2.56 & 2.55 & 2.560 & 2.81 & 2.89 & 2.850 \\
\hline Averages --------> & 2.783 & 2.777 & 2.796 & 2.785 & 2.770 & 2.783 & 2.786 & 2.782 \\
\hline
\end{tabular}

Avg. Conc.

\begin{tabular}{|ll}
\hline All & $\underline{\mathrm{ppm}}$ \\
Mean & 2.78 \\
Min Point & 2.56 \\
Max Point & 3.02 \\
\hline
\end{tabular}

$2.784 \mathrm{ppm}$

Tracer tank pressure Sample Port Temp Centerline vel. Injection flowmeter Stack flow

Sampling flowmeter Ambient pressure Ambient humidity B\&K vapor correction Back-Gd gas ppb No. Bk-Gd samples Ambient Temperature Instuments Used:

B \& K Model 1302 \#1765299

Sierra Inc. Constant Flow Air Sampler Solmat Zephyr SN 12951472 Cal. Due 7/26/02

Notes: $\quad$ Prefilters replaced today. Flow is up.

\begin{tabular}{|c|c|c|}
\hline Start & Finish & \\
\hline 150 & 180 & psig \\
\hline 63 & 68 & $\mathrm{~F}$ fpm \\
\hline N 1304 & W 1300 & $\mathrm{fpm}$ \\
\hline 20 & 20 & ball** \\
\hline 4000 & 4000 & $\mathrm{cfm}$ \\
\hline 10 & 10 & Ipm Sierra \\
\hline 984.4 & 984.3 & 3 mbar \\
\hline 75 & 59 & $\mathrm{RH}$ \\
\hline$Y$ & $Y$ & $\mathrm{Y} / \mathrm{N}$ \\
\hline $11 / 10 / 11 / 13 / 12$ & $24 / 20 / 19 / 17$ & \\
\hline 6 & 4 & $n$ \\
\hline 54 & 60 & $F$ \\
\hline
\end{tabular}

Dev. from mean

Center 2/3

$-8.0 \%$ Std. Dev.

$8.5 \%$ COV as \%

Gas analyzer checked:

19-Oct-01

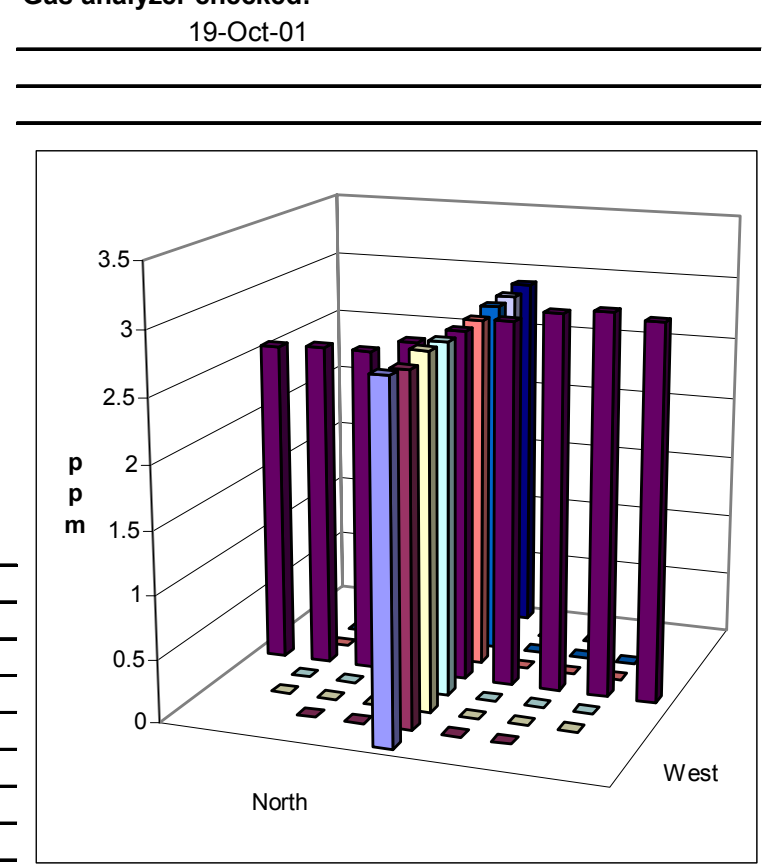


TRACER GAS TRAVERSE DATA FORM

$\begin{aligned} \text { Site } & \text { 291-Z-1 Model } \\ \text { Date } & \frac{11 / 15 / 01}{23.5 \text { in. }} \\ \text { Tester } & \text { Glissmeyer } \\ \text { Stack Dia. } & \frac{233.7 \text { in.2 }}{2} \\ \text { Stack X-Area } & \text { N.A. } \\ \text { Elevation } & \text { N5 inches }\end{aligned}$

Run No. GT-15

Fan Configuration Turbine Fans

Fan Setting $60 \mathrm{~Hz}$

Stack Temp $68.5 \mathrm{deg} F$

Start/End Time 1300/1500

Center $2 / 3$ from $2.16 \quad$ to: 21.34

Distance to disturbance 75 inches

Measurement units ppm SF6

Points in Center $2 / 3 \frac{2}{2}$ to: $\underline{7}$

Injection Point ET9 west side

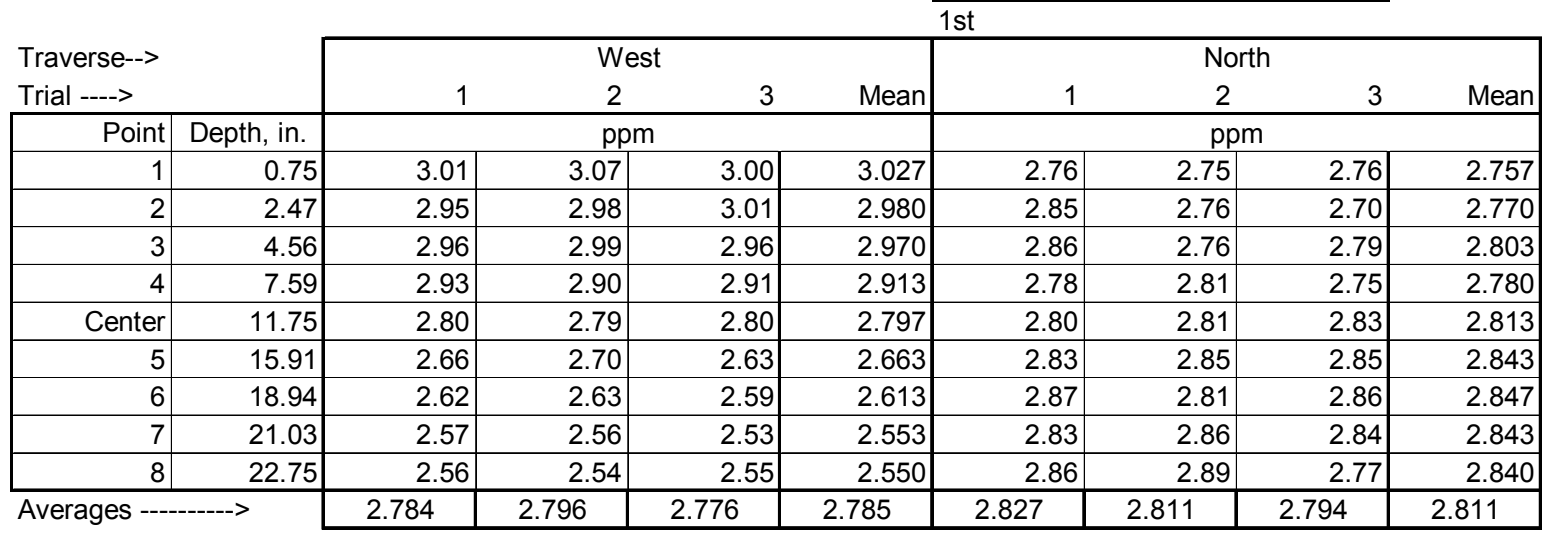

Avg. Conc.

\begin{tabular}{|lr}
\hline All & ppm \\
Mean & 2.80 \\
Min Point & 2.55 \\
Max Point & 3.03 \\
\hline
\end{tabular}

2.797 ppm

Tracer tank pressure Sample Port Temp Centerline vel. Injection flowmeter Stack flow Sampling flowmeter Ambient pressure Ambient humidity $\mathrm{B} \& \mathrm{~K}$ vapor correction Back-Gd gas ppb No. Bk-Gd samples Ambient Temperature Instuments Used:

\begin{tabular}{|c|c|c|}
\hline Start & Finish & \\
\hline 180 & 180 & psig \\
\hline 68 & 69 & $F$ \\
\hline W 1320 & N 1304 & fpm \\
\hline 20 & 20 & ball ${ }^{* *}$ \\
\hline 4000 & 4000 & $\mathrm{cfm}$ \\
\hline 10 & 10 & Ipm Sierra \\
\hline 984.3 & 983.2 & mbar \\
\hline 59 & 45 & $\mathrm{RH}$ \\
\hline $\mathrm{Y}$ & $Y$ & $\mathrm{Y} / \mathrm{N}$ \\
\hline 18/17/17/17 & $27 / 34 / 8 / 33$ & \\
\hline 4 & 4 & n \\
\hline 60 & 63 & $F$ \\
\hline
\end{tabular}

B \& K Model 1302 \#1765299

Sierra Inc. Constant Flow Air Sampler

Solmat Zephyr SN 12951472 Cal. Due 7/26/02

Notes: Quite windy.

\begin{tabular}{|c|c|c|c|c|}
\hline Dev. from mean & Center 2/3 & West & North & All \\
\hline & Mean & 2.78 & 2.81 & 2.80 \\
\hline$-8.9 \%$ & Std. Dev. & 0.18 & 0.03 & 0.12 \\
\hline $8.2 \%$ & COV as $\%$ & 6.3 & 1.1 & 4.4 \\
\hline
\end{tabular}

Gas analyzer checked:

19-Oct-01

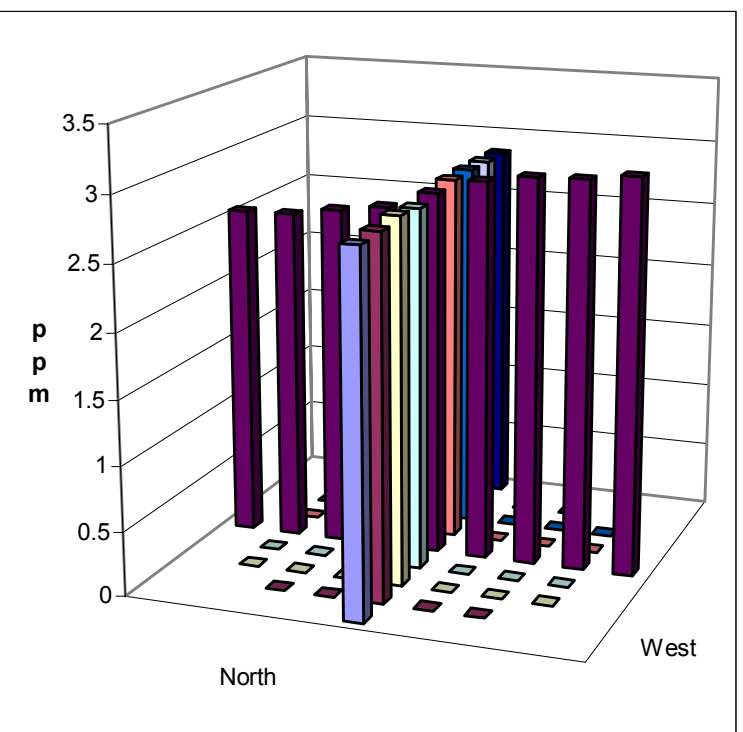


TRACER GAS TRAVERSE DATA FORM

Site 291-Z-1 Model

Date 11/15/01

Tester Glissmeyer

Stack Dia.

Stack X-Area

Elevation

Distance to disturbance

Measurement units

$\frac{23.5 \text { in. }}{433.7 \text { in. } 2}$

ppm SF6

Run No. GT-16

Fan Configuration Turbine Fans

Fan Setting $60 \mathrm{~Hz}$

Stack Temp $69 \operatorname{deg} \mathrm{F}$

Start/End Time 1504/1604

Center $2 / 3$ from

Points in Center 2/3 2.16 to: 21.34

Injection Point ET9 east side

\begin{tabular}{|c|c|c|c|c|c|c|c|c|c|}
\hline \multirow{3}{*}{\multicolumn{2}{|c|}{$\begin{array}{l}\text { Traverse--> } \\
\text { Trial ----> }\end{array}$}} & \multirow{2}{*}{\multicolumn{4}{|c|}{ West }} & & & & \\
\hline & & & & & & \multicolumn{4}{|c|}{ North } \\
\hline & & \multicolumn{2}{|l|}{1} & 3 & \multirow[t]{2}{*}{ Mean } & \multicolumn{2}{|r|}{2} & 3 & Mean \\
\hline Point & Depth, in. & \multicolumn{3}{|c|}{ ppm } & & \multicolumn{4}{|c|}{$\mathrm{ppm}$} \\
\hline 1 & 0.75 & 3.08 & 2.98 & 3.00 & 3.020 & 2.80 & 2.81 & 2.70 & 2.770 \\
\hline 2 & 2.47 & 2.95 & 3.00 & 2.97 & 2.973 & 2.77 & 2.74 & 2.74 & 2.750 \\
\hline 3 & 4.56 & 2.95 & 2.98 & 2.96 & 2.963 & 2.78 & 2.78 & 2.75 & 2.770 \\
\hline 4 & 7.59 & 2.89 & 2.92 & 2.93 & 2.913 & 2.76 & 2.76 & 2.78 & 2.767 \\
\hline Center & 11.75 & 2.80 & 2.84 & 2.80 & 2.813 & 2.80 & 2.79 & 2.83 & 2.807 \\
\hline 5 & 15.91 & 2.73 & 2.75 & 2.71 & 2.730 & 2.83 & 2.78 & 2.87 & 2.827 \\
\hline 6 & 18.94 & 2.63 & 2.64 & 2.67 & 2.647 & 2.89 & 2.85 & 2.85 & 2.863 \\
\hline 7 & 21.03 & 2.66 & 2.65 & 2.62 & 2.643 & 2.84 & 2.84 & 2.82 & 2.833 \\
\hline 8 & 22.75 & 2.63 & 2.67 & 2.60 & 2.633 & 2.84 & 2.86 & 2.84 & 2.847 \\
\hline Averages ---- & -----> & 2.813 & 2.826 & 2.807 & 2.815 & 2.812 & 2.801 & 2.798 & 2.804 \\
\hline
\end{tabular}

\begin{tabular}{|llr|lrrr|}
\hline All & ppm & Dev. from mean & Center 2/3 & West & North & All \\
Mean & 2.81 & & Mean & 2.81 & 2.80 & 2.81 \\
Min Point & 2.63 & $-6.3 \%$ & Std. Dev. & 0.14 & 0.04 & 0.10 \\
Max Point & 3.02 & $7.5 \%$ & CoV as \% & 5.1 & 1.5 & $\mathbf{3 . 6}$ \\
\hline
\end{tabular}

Avg. Conc. $\quad 2.809 \mathrm{ppm}$

Tracer tank pressure Sample Port Temp

Centerline vel.

Injection flowmeter

Stack flow

Sampling flowmeter

Ambient pressure

Ambient humidity

B\&K vapor correction

Back-Gd gas ppb

No. Bk-Gd samples

Ambient Temperature

\begin{tabular}{|c|c|c|}
\hline Start & Finish & \\
\hline 180 & 180 & psig \\
\hline 69 & 69 & $F$ \\
\hline N 1304 & W 1341 & fpm \\
\hline 20 & 20 & ball** \\
\hline 4000 & 4000 & $\mathrm{cfm}$ \\
\hline 10 & 10 & Ipm Sie \\
\hline 983.2 & 983.3 & mbar \\
\hline 59 & 49 & $\mathrm{RH}$ \\
\hline$Y$ & $\bar{Y}$ & $\mathrm{Y} / \mathrm{N}$ \\
\hline $27 / 34 / 8 / 33$ & $32 / 19 / 20 / 20$ & \\
\hline 4 & 4 & $n$ \\
\hline 63 & 60 & $\mathrm{~F}$ \\
\hline
\end{tabular}

Instuments Used:

B \& K Model $1302 \# 1765299$

Sierra Inc. Constant Flow Air Sampler

Solmat Zephyr SN 12951472 Cal. Due 7/26/02

Notes: Calm to light winds.
Gas analyzer checked:

19-Oct-01

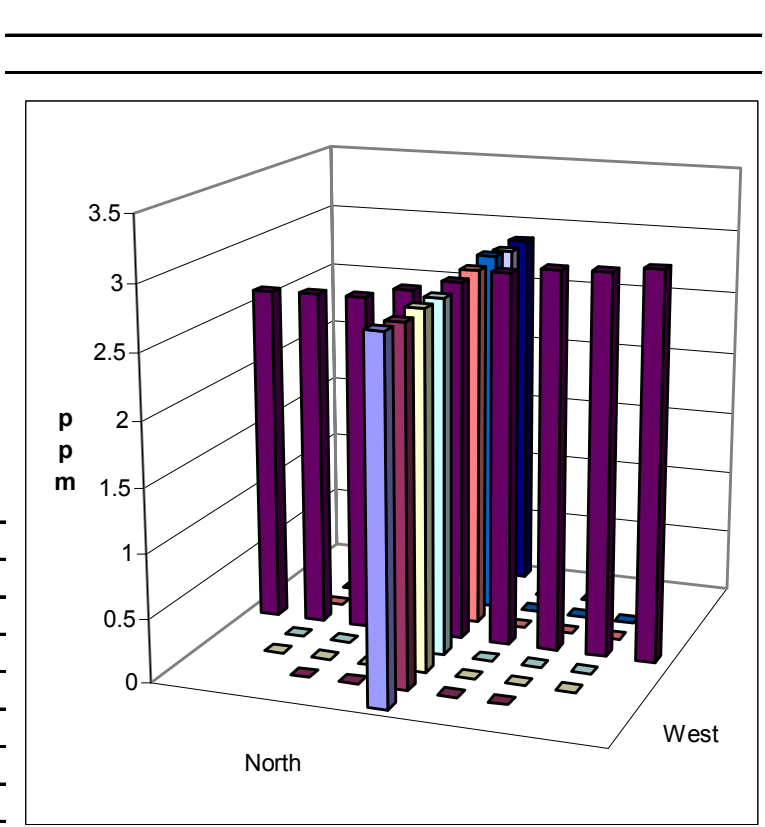


TRACER GAS TRAVERSE DATA FORM

Site 291-Z-1 Model

Date 11/16/01

Tester Glissmeyer

Stack Dia

Stack X-Area

Elevation

Distance to disturbance

Measurement units ppm SF
Run No. GT-17

Fan Configuration Turbine Fans

Fan Setting $60 \mathrm{~Hz}$

Stack Temp $61.5 \mathrm{deg} F$

Start/End Time 0936/1046

Center $2 / 3$ from

Points in Center 2/3 2.16 to: 21.34

Injection Point ET9 Bottom East

\begin{tabular}{|c|c|c|c|c|c|c|c|c|c|}
\hline \multirow{3}{*}{\multicolumn{2}{|c|}{$\begin{array}{l}\text { Traverse--> } \\
\text { Trial ----> }\end{array}$}} & \multirow{2}{*}{\multicolumn{4}{|c|}{ West }} & \multirow{2}{*}{\multicolumn{4}{|c|}{ North }} \\
\hline & & & & & & & & & \\
\hline & & \multirow[t]{2}{*}{1} & \multicolumn{2}{|c|}{2} & \multirow[t]{2}{*}{ Mean } & \multicolumn{2}{|l|}{1} & 3 & \multirow[t]{2}{*}{ Mean } \\
\hline Point & Depth, in. & & \multicolumn{2}{|c|}{ ppm } & & \multicolumn{3}{|c|}{$\mathrm{ppm}$} & \\
\hline 1 & 0.75 & 3.12 & 3.11 & 3.15 & 3.127 & 2.85 & 2.78 & 2.81 & 2.813 \\
\hline 2 & 2.47 & 3.09 & 3.09 & 3.12 & 3.100 & 2.76 & 2.87 & 2.83 & 2.820 \\
\hline 3 & 4.56 & 3.13 & 3.09 & 3.14 & 3.120 & 2.85 & 2.88 & 2.86 & 2.863 \\
\hline 4 & 7.59 & 2.98 & 3.02 & 3.01 & 3.003 & 2.87 & 2.88 & 2.87 & 2.873 \\
\hline Center & 11.75 & 2.92 & 2.90 & 2.86 & 2.893 & 2.91 & 2.90 & 2.91 & 2.907 \\
\hline 5 & 15.91 & 2.76 & 2.73 & 2.80 & 2.763 & 2.93 & 2.90 & 2.88 & 2.903 \\
\hline 6 & 18.94 & 2.72 & 2.69 & 2.71 & 2.707 & 2.90 & 2.87 & 2.88 & 2.883 \\
\hline 7 & 21.03 & 2.65 & 2.70 & 2.75 & 2.700 & 2.83 & 2.92 & 2.94 & 2.897 \\
\hline 8 & 22.75 & 2.68 & 2.69 & 2.67 & 2.680 & 2.87 & 2.90 & 2.97 & 2.913 \\
\hline \multicolumn{2}{|c|}{ Averages ---------> } & 2.894 & 2.891 & 2.912 & 2.899 & 2.863 & 2.878 & 2.883 & 2.875 \\
\hline
\end{tabular}

Avg. Conc.

\begin{tabular}{|ll}
\hline All & $\mathrm{ppm}$ \\
Mean & 2.89 \\
Min Point & 2.68 \\
Max Point & 3.13 \\
\hline
\end{tabular}

$$
2.885 \mathrm{ppm}
$$

\begin{tabular}{|c|c|c|}
\hline Start & Finish & \\
\hline 170 & 170 & psig \\
\hline 60 & 63 & $F$ \\
\hline w 1323 & n 1309 & $\mathrm{fpm}$ \\
\hline 20 & 21 & ball** \\
\hline 4100 & 4000 & $\mathrm{cfm}$ \\
\hline 10 & 10 & Ipm Sierra \\
\hline 998.0 & 989.1 & mbar \\
\hline 96 & 93 & $\mathrm{RH}$ \\
\hline$Y$ & Y & $\mathrm{Y} / \mathrm{N}$ \\
\hline
\end{tabular}

B\&K vapor correction

Back-Gd gas ppb

No. Bk-Gd samples

Ambient Temperature

\begin{tabular}{|r|r|}
\hline $8 / 13 / 10 / 14 / 13 / 11$ & $144 / 34 / 26 / 21$ \\
\hline
\end{tabular}

Tracer tank pressure Sample Port Temp

Centerline vel.

Injection flowmeter

Stack flow

Sampling flowmeter

Ambient pressure

Instuments Used:

B \& K Model 1302 \#1765299

Sierra Inc. Constant Flow Air Sampler

Solmat Zephyr SN 12951472 Cal. Due 7/26/02

\section{Notes:}

\begin{tabular}{|c|c|c|c|c|}
\hline Dev. from mean & Center 2/3 & West & North & All \\
\hline & Mean & 2.90 & 2.88 & 2.89 \\
\hline$-7.2 \%$ & Std. Dev. & 0.18 & 0.03 & 0.12 \\
\hline $8.3 \%$ & cov as $\%$ & 6.2 & 1.0 & 4.3 \\
\hline
\end{tabular}

Gas analyzer checked:

19-Oct-01

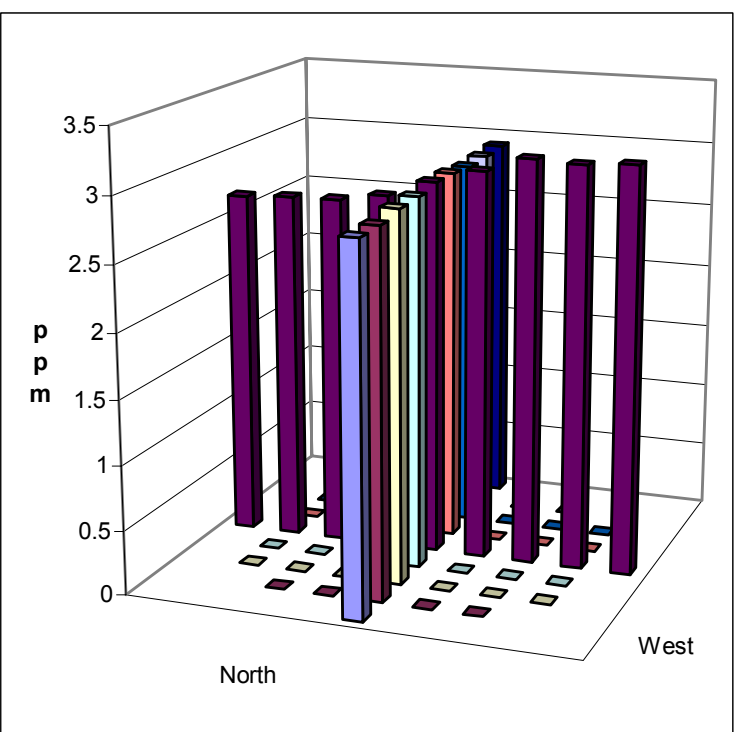




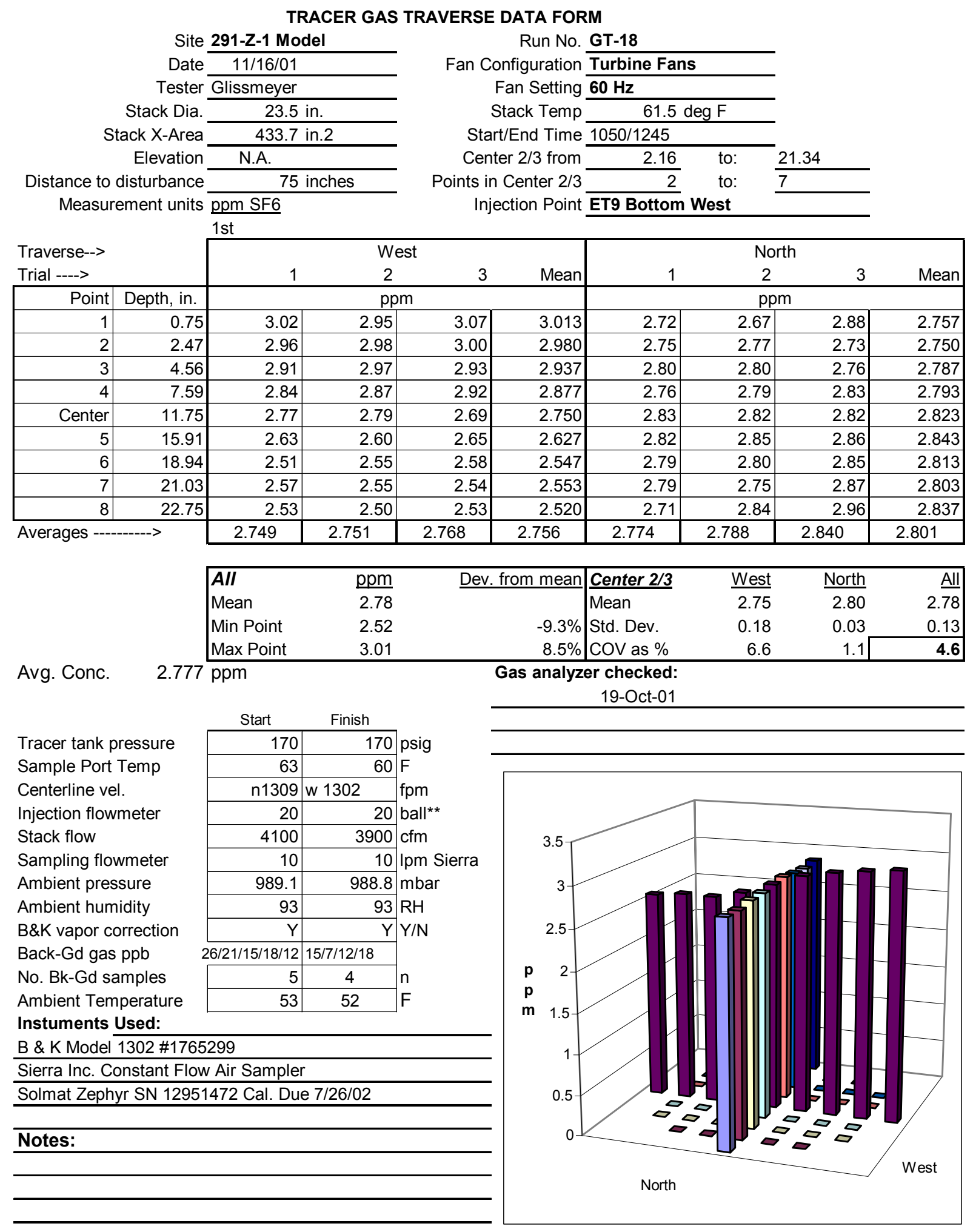


TRACER GAS TRAVERSE DATA FORM

Site 291-Z-1 Model

Date 11/19/01

Tester Glissmeyer

Stack Dia. Stack X-Area

Elevation

\begin{tabular}{l}
\hline 23.5 in. \\
\hline 433.7 in. 2 \\
\hline N.A. \\
\hline
\end{tabular}

Distance to disturbance

Measurement units ppm SF6
Run No. GT-19

Fan Configuration Turbine Fans

Fan Setting $60 \mathrm{~Hz}$

Stack Temp $54.5 \mathrm{deg} F$

Start/End Time 957/1245

Center $2 / 3$ from

Points in Center $2 / 3$ Injection Point $\overline{\text { ET9 Top West }}$

$\frac{2.16}{2}$ to: $\frac{21.34}{7}$

\begin{tabular}{|c|c|c|c|c|c|c|c|c|c|}
\hline \multirow{3}{*}{$\begin{array}{l}\text { Traverse--> } \\
\text { Trial ----> }\end{array}$} & & & & & & & & & \\
\hline & & \multicolumn{4}{|c|}{ West } & \multicolumn{4}{|c|}{ North } \\
\hline & & \multicolumn{2}{|l|}{1} & 3 & \multirow[t]{2}{*}{ Mean } & \multicolumn{3}{|c|}{$\begin{array}{l}\text { North } \\
2\end{array}$} & Mean \\
\hline Point & Depth, in. & \multicolumn{3}{|c|}{ ppm } & & \multicolumn{4}{|c|}{$\mathrm{ppm}$} \\
\hline 1 & 0.75 & 2.98 & 2.91 & 2.91 & 2.933 & 2.62 & 2.55 & 2.54 & 2.570 \\
\hline 2 & 2.47 & 2.89 & 2.90 & 2.90 & 2.897 & 2.53 & 2.50 & 2.64 & 2.557 \\
\hline 3 & 4.56 & 2.83 & 2.87 & 2.85 & 2.850 & 2.59 & 2.57 & 2.48 & 2.547 \\
\hline 4 & 7.59 & 2.82 & 2.80 & 2.84 & 2.820 & 2.60 & 2.64 & 2.63 & 2.623 \\
\hline Center & 11.75 & 2.71 & 2.71 & 2.72 & 2.713 & 2.57 & 2.61 & 2.66 & 2.613 \\
\hline 5 & 15.91 & 2.59 & 2.72 & 2.59 & 2.633 & 2.58 & 2.63 & 2.73 & 2.647 \\
\hline 6 & 18.94 & 2.64 & 2.67 & 2.53 & 2.613 & 2.63 & 2.68 & 2.72 & 2.677 \\
\hline 7 & 21.03 & 2.52 & 2.53 & 2.49 & 2.513 & 2.68 & 2.63 & 2.62 & 2.643 \\
\hline 8 & 22.75 & 2.57 & 2.51 & 2.56 & 2.547 & 2.62 & 2.67 & 2.69 & 2.660 \\
\hline Averages --- & 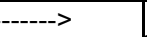 & 2.728 & 2.736 & 2.710 & 2.724 & 2.602 & 2.609 & 2.634 & 2.615 \\
\hline
\end{tabular}

\begin{tabular}{|lcr|lrrr|}
\hline All & ppm & Dev. from mean & Center 2/3 & $\frac{\text { West }}{2.72}$ & $\frac{\text { North }}{2.62}$ & All \\
Mean & 2.67 & & Mean & & 2.67 \\
Min Point & 2.51 & $-5.9 \%$ & Std. Dev. & 0.14 & 0.05 & 0.11 \\
Max Point & 2.93 & $9.9 \%$ & COV as \% & 5.2 & 1.8 & $\mathbf{4 . 3}$ \\
\hline
\end{tabular}

Avg. Conc.

$$
2.671 \mathrm{ppm}
$$

Tracer tank pressure Sample Port Temp

Centerline vel. Injection flowmeter Stack flow

Sampling flowmeter Ambient pressure Ambient humidity B\&K vapor correction Back-Gd gas ppb No. Bk-Gd samples Ambient Temperature

\begin{tabular}{|c|c|}
\hline Start & Finish \\
\hline 170 & $170 \mathrm{psig}$ \\
\hline 51 & $58 \mathrm{~F}$ \\
\hline
\end{tabular}
\begin{tabular}{r|r|r} 
w 1349 & n 1342 & $f p m$
\end{tabular} $4100 \quad 4200 \mathrm{cfm}$

$10 \quad 10$ lpm Sierra

$996.3 \quad 994.7 \mathrm{mbar}$

\begin{tabular}{r|r|r}
84 & 88 & $R H$ \\
\end{tabular}

\begin{tabular}{|r|r|}
\hline$Y$ & \\
\hline $12 / 37 / 21 / 19 / 15 / 17$ & $44 / 36 / 36 / 34$ \\
\hline 6 &
\end{tabular}

\begin{tabular}{|r|c|}
\hline 6 & 4 \\
\hline 42 & 44 \\
\hline
\end{tabular}

Instuments Used:

B \& K Model $1302 \# 1765299$

Sierra Inc. Constant Flow Air Sampler

Solmat Zephyr SN 12951472 Cal. Due 7/26/02

\section{Notes:}




\section{TRACER GAS TRAVERSE DATA FORM}

Site 291-Z-1 Model

Date 11/20/01

Tester Glissmeyer

Stack Dia. Stack X-Area

Elevation

\begin{tabular}{c}
23.5 in. \\
\hline 433.7 in. 2 \\
\hline N.A. \\
\hline 75 inches
\end{tabular}

Distance to disturbance Measurement units ppm SF6
Run No. GT-20

Fan Configuration Turbine Fan Configuration

Fan Setting $60 \mathrm{~Hz}$

Stack Temp

Start/End Time 1010/1240

Center $2 / 3$ from

Points in Center 2/3 Injection Point ET9 Top East

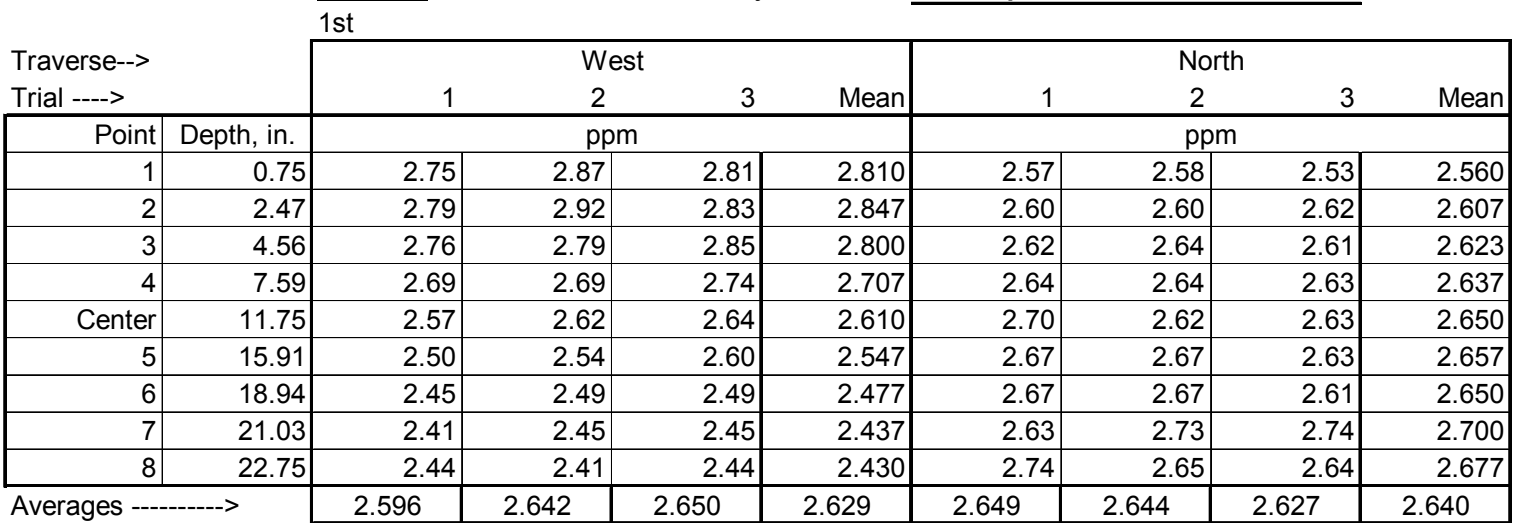

\begin{tabular}{|c|c|c|c|c|c|c|}
\hline$A / I$ & $\mathrm{ppm}$ & Dev. from mean & Center $2 / 3$ & West & North & All \\
\hline Mean & 2.63 & & Mean & 2.63 & 2.65 & 2.64 \\
\hline Min Point & 2.43 & $-7.8 \%$ & Std. Dev. & 0.16 & 0.03 & 0.11 \\
\hline Max Point & 2.85 & $8.0 \%$ & COV as $\%$ & 6.0 & 1.1 & 4.1 \\
\hline
\end{tabular}

Avg. Conc. $\quad 2.635$ ppm

Gas analyzer checked:

19-Oct-01

Tracer tank pressure Sample Port Temp

Centerline vel.

Injection flowmeter

Stack flow

Sampling flowmeter

Ambient pressure

Ambient humidity

B\&K vapor correction

Back-Gd gas ppb

No. Bk-Gd samples

Ambient Temp

\begin{tabular}{|c|c|c|}
\hline Start & Finish & \\
\hline 130 & 130 & psig \\
\hline 62 & 63 & $\mathrm{~F}$ \\
\hline N 1365 & W 1380 & fpm \\
\hline 20 & 20 & ball ${ }^{* *}$ \\
\hline 4200 & 4200 & $\mathrm{cfm}$ \\
\hline 10 & 10 & Ipm Sierra \\
\hline 991.1 & 988.7 & mbar \\
\hline 53 & 64 & $\mathrm{RH}$ \\
\hline $\mathrm{Y}$ & $\mathrm{Y}$ & Y/N \\
\hline
\end{tabular}

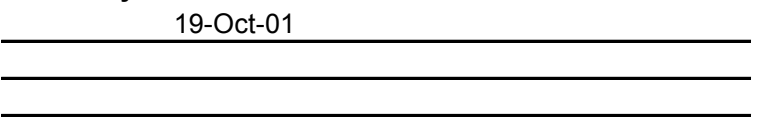

Instuments Used:

25/27/16/18/14/26 17/34/13/23

\begin{tabular}{|r|c|l}
\hline 6 & 4 & $\mathrm{n}$ \\
\hline 54 & 53 & $\mathrm{~F}$ \\
\hline
\end{tabular}

B \& K Model $1302 \# 1765299$

Sierra Inc. Constant Flow Air Sampler

Solmat Zephyr SN 12951472 Cal. Due 7/26/02

\section{Notes:}

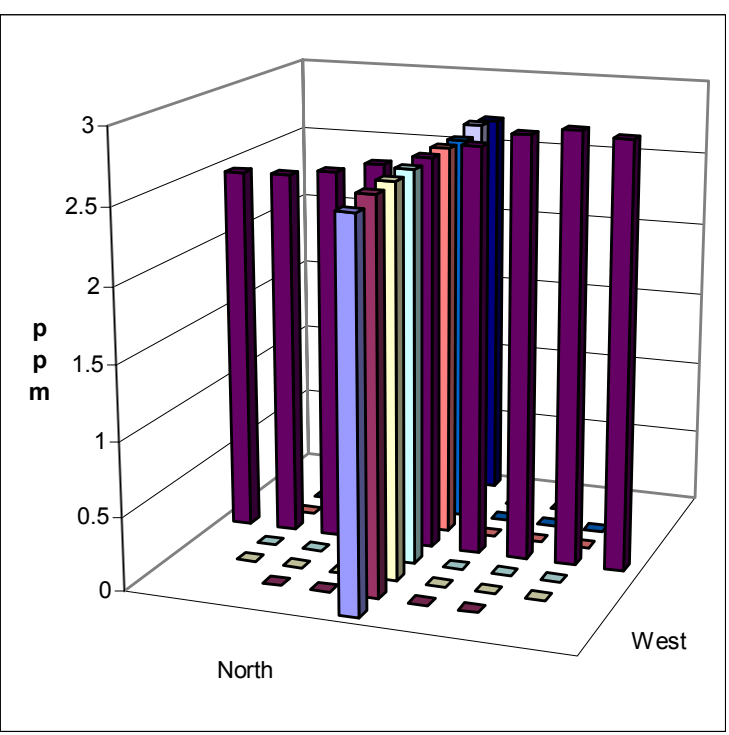


TRACER GAS TRAVERSE DATA FORM

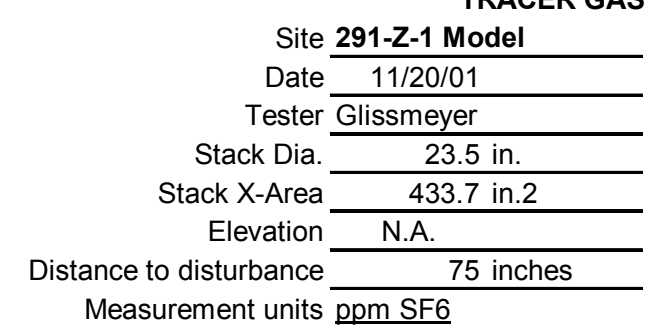

Site 291-Z-1 Model

Date 11/20/01

Tester Glissmeyer

Stack Dia.

23.5 in

X-Area

A

Measurement units ppm SF6
Run No. GT-21

Fan Configuration Turbine Fan Configuration

Fan Setting $60 \mathrm{~Hz}$

Stack Temp

Start/End Time 1258/1400

Center $2 / 3$ from

Points in Center $2 / 3$

Injection Point ET8 Centerline

$63 \operatorname{deg} \mathrm{F}$

1400

$\frac{2.16}{2}$ to: $\underline{21.34}$

st

$1 \mathrm{~s}$

\begin{tabular}{|c|c|c|c|c|c|c|c|c|c|}
\hline \multirow{3}{*}{\multicolumn{2}{|c|}{$\begin{array}{l}\text { Traverse--> } \\
\text { Trial ----> }\end{array}$}} & \multirow{2}{*}{\multicolumn{4}{|c|}{ West }} & \multirow{2}{*}{\multicolumn{4}{|c|}{ North }} \\
\hline & & & & & & & & & \\
\hline & & \multirow[t]{2}{*}{1} & \multicolumn{2}{|l|}{2} & \multirow[t]{2}{*}{ Mean } & \multicolumn{2}{|r|}{2} & 3 & Mean \\
\hline Point & Depth, in. & & \multicolumn{2}{|c|}{$\mathrm{ppm}$} & & \multicolumn{4}{|c|}{$\mathrm{ppm}$} \\
\hline 1 & 0.75 & 2.60 & 2.53 & 2.58 & 2.570 & 2.77 & 2.82 & 2.82 & 2.803 \\
\hline 2 & 2.47 & 2.56 & 2.60 & 2.50 & 2.553 & 2.83 & 2.82 & 2.79 & 2.813 \\
\hline 3 & 4.56 & 2.57 & 2.57 & 2.60 & 2.580 & 2.81 & 2.73 & 2.74 & 2.760 \\
\hline 4 & 7.59 & 2.67 & 2.65 & 2.67 & 2.663 & 2.81 & 2.78 & 2.84 & 2.810 \\
\hline Center & 11.75 & 2.77 & 2.78 & 2.76 & 2.770 & 2.79 & 2.79 & 2.75 & 2.777 \\
\hline 5 & 15.91 & 2.92 & 2.92 & 2.90 & 2.913 & 2.77 & 2.78 & 2.79 & 2.780 \\
\hline 6 & 18.94 & 2.98 & 2.94 & 2.99 & 2.970 & 2.76 & 2.77 & 2.75 & 2.760 \\
\hline 7 & 21.03 & 3.00 & 3.00 & 2.99 & 2.997 & 2.83 & 2.77 & 2.80 & 2.800 \\
\hline 8 & 22.75 & 2.98 & 2.96 & 3.01 & 2.983 & 2.75 & 2.83 & 2.77 & 2.783 \\
\hline rages ---- & ---- & 2.783 & 2.772 & 2.778 & 2.778 & 2.791 & 2.788 & 2.783 & 2.787 \\
\hline
\end{tabular}

\begin{tabular}{|c|c|c|c|c|c|c|}
\hline$A I I$ & $\mathrm{ppm}$ & Dev. from mean & Center 2/3 & West & North & All \\
\hline Mean & 2.78 & & Mean & 2.78 & 2.79 & 2.78 \\
\hline Min Point & 2.55 & $-8.2 \%$ & Std. Dev. & 0.19 & 0.02 & 0.13 \\
\hline Max Point & 3.00 & $7.7 \%$ & Cov as $\%$ & 6.7 & 0.8 & 4.6 \\
\hline
\end{tabular}

Avg. Conc. $\quad 2.784 \mathrm{ppm}$

Gas analyzer checked:

19-Oct-01

Tracer tank pressure

Sample Port Temp

Centerline vel.

Injection flowmeter

Stack flow

Sampling flowmeter

Ambient pressure

Ambient humidity

$B \& K$ vapor correction

Back-Gd gas ppb

No. Bk-Gd samples

Ambient Temp

Instuments Used:

\begin{tabular}{|c|c|c|}
\hline Start & Finish & \\
\hline 130 & 130 & psig \\
\hline 63 & 63 & $F$ \\
\hline W 1380 & n 1370 & fpm \\
\hline 20 & 20 & ball ${ }^{* *}$ \\
\hline 4200 & 4300 & $\mathrm{cfm}$ \\
\hline 10 & 10 & Ipm Sierra \\
\hline 988.7 & 987.1 & mbar \\
\hline 64 & 64 & $\mathrm{RH}$ \\
\hline$Y$ & $Y$ & $\mathrm{Y} / \mathrm{N}$ \\
\hline $17 / 34 / 13 / 23$ & $40 / 31 / 20 / 19$ & \\
\hline 4 & 4 & $n$ \\
\hline 53 & 53 & $F$ \\
\hline
\end{tabular}

B \& K Model 1302 \#1765299

Sierra Inc. Constant Flow Air Sampler

Solmat Zephyr SN 12951472 Cal. Due 7/26/02

\section{Notes:}


TRACER GAS TRAVERSE DATA FORM

Site 291-Z-1 Model

Date 11/20/01

Tester Glissmeyer

Stack Dia.

Stack X-Area

Elevation

Distance to disturbance

Measurement units ppm SF
Run No. GT-22

Fan Configuration Turbine Fan Configuration

Fan Setting $60 \mathrm{~Hz}$

Stack Temp $62.5 \operatorname{deg} \mathrm{F}$

Start/End Time 1445/1550

Center $2 / 3$ from 2.16 to: 21.34

Points in Center $2 / 3 \overline{2}$ to: $\overline{7}$ Injection Point ET8 Centerline

\begin{tabular}{|c|c|c|c|c|c|c|c|c|c|}
\hline \multirow{2}{*}{\multicolumn{2}{|c|}{$\begin{array}{l}\text { Traverse--> } \\
\text { Trial ----> }\end{array}$}} & \multicolumn{4}{|c|}{ West } & \multicolumn{4}{|c|}{ North } \\
\hline & & \multicolumn{2}{|l|}{1} & 3 & \multirow[t]{2}{*}{ Mean } & \multicolumn{2}{|r|}{2} & 3 & Mean \\
\hline Point & Depth, in. & \multicolumn{3}{|c|}{$\mathrm{ppm}$} & & \multicolumn{4}{|c|}{ ppm } \\
\hline 1 & 0.75 & 2.63 & 2.57 & 2.64 & 2.613 & 2.82 & 2.86 & 2.84 & 2.840 \\
\hline 2 & 2.47 & 2.61 & 2.61 & 2.58 & 2.600 & 2.80 & 2.93 & 2.76 & 2.830 \\
\hline 3 & 4.56 & 2.66 & 2.62 & 2.63 & 2.637 & 2.80 & 2.81 & 2.79 & 2.800 \\
\hline 4 & 7.59 & 2.68 & 2.70 & 2.67 & 2.683 & 2.84 & 2.82 & 2.82 & 2.827 \\
\hline Center & 11.75 & 2.81 & 2.77 & 2.81 & 2.797 & 2.81 & 2.80 & 2.85 & 2.820 \\
\hline 5 & 15.91 & 2.87 & 2.91 & 2.92 & 2.900 & 2.80 & 2.82 & 2.83 & 2.817 \\
\hline 6 & 18.94 & 2.97 & 2.98 & 2.99 & 2.980 & 2.86 & 2.82 & 2.83 & 2.837 \\
\hline 7 & 21.03 & 3.02 & 3.00 & 3.00 & 3.007 & 2.83 & 2.84 & 2.82 & 2.830 \\
\hline 8 & 22.75 & 3.06 & 3.00 & 3.06 & 3.040 & 2.81 & 2.78 & 2.85 & 2.813 \\
\hline verages -- & ---. & 2.812 & 2.796 & 2.811 & 2.806 & 2.819 & 2.831 & 2.821 & 2.824 \\
\hline
\end{tabular}

\begin{tabular}{|lrr|lrrr|}
\hline All & ppm & Dev. from mean & Center 2/3 & $\frac{\text { West }}{2.80}$ & $\frac{\text { North }}{2.82}$ & All \\
Mean & 2.82 & & Mean & & 2.81 \\
Min Point & 2.60 & $-7.6 \%$ & Std. Dev. & 0.17 & 0.01 & 0.11 \\
Max Point & 3.04 & $8.0 \%$ & CoV as \% & 5.9 & 0.4 & $\mathbf{4 . 0}$ \\
\hline
\end{tabular}

Avg. Conc. $\quad 2.816 \mathrm{ppm}$

Gas analyzer checked:

19-Oct-01

Tracer tank pressure Sample Port Temp

Centerline vel.

Injection flowmeter

Stack flow

Sampling flowmeter

Ambient pressure

Ambient humidity

B\&K vapor correction

Back-Gd gas ppb

No. Bk-Gd samples

Ambient Temp

\begin{tabular}{|c|c|c|}
\hline Start & Finish & \\
\hline 130 & 130 & psig \\
\hline 63 & 62 & $2 \mathrm{~F}$ \\
\hline n 1370 & w 1380 & fpm \\
\hline 20 & 20 & ball** \\
\hline 4300 & 4200 & $\mathrm{cfm}$ \\
\hline 10 & 10 & Ipm Sierra \\
\hline 987.1 & 985.2 & mbar \\
\hline 64 & 68 & $\mathrm{RH}$ \\
\hline$Y$ & $\mathrm{Y}$ & $\mathrm{Y} / \mathrm{N}$ \\
\hline $31 / 20 / 19$ & $28 / 41 / 32$ & \\
\hline 3 & 3 & $n$ \\
\hline 53 & 50 & $\mathrm{~F}$ \\
\hline
\end{tabular}

Instuments Used:

B \& K Model 1302 \#1765299

Sierra Inc. Constant Flow Air Sampler

Solmat Zephyr SN 12951472 Cal. Due 7/26/02

\section{Notes:}

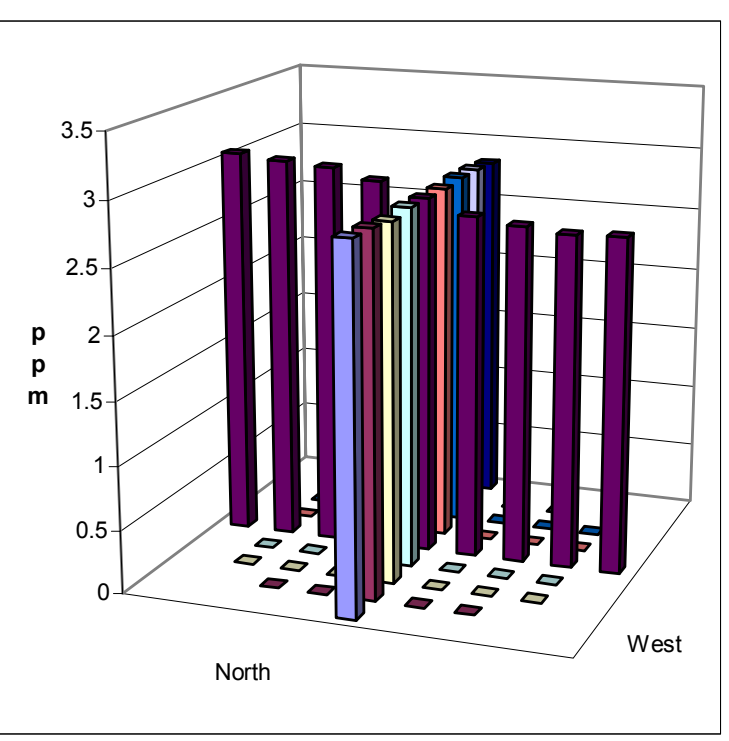


TRACER GAS TRAVERSE DATA FORM

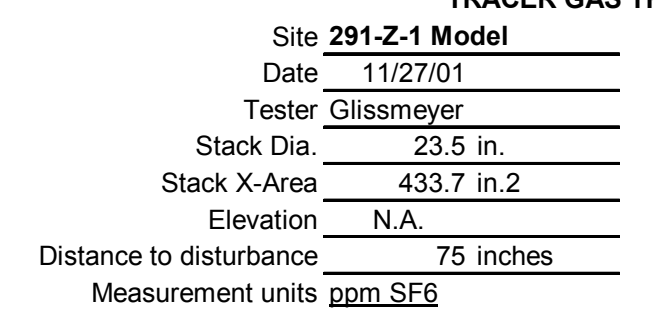
Fan Configuration Turbine Fans, 30 degree from North port Fan Setting $60 \mathrm{~Hz}$
Stack Temp $49 \mathrm{deg} \mathrm{F}$
Start/End Time 1315/1428
Center $2 / 3$ from 2.16 to:
Points in Center $2 / 3 \frac{2}{2}$ to: $\frac{21.34}{7}$
Injection Point ET8 centerline

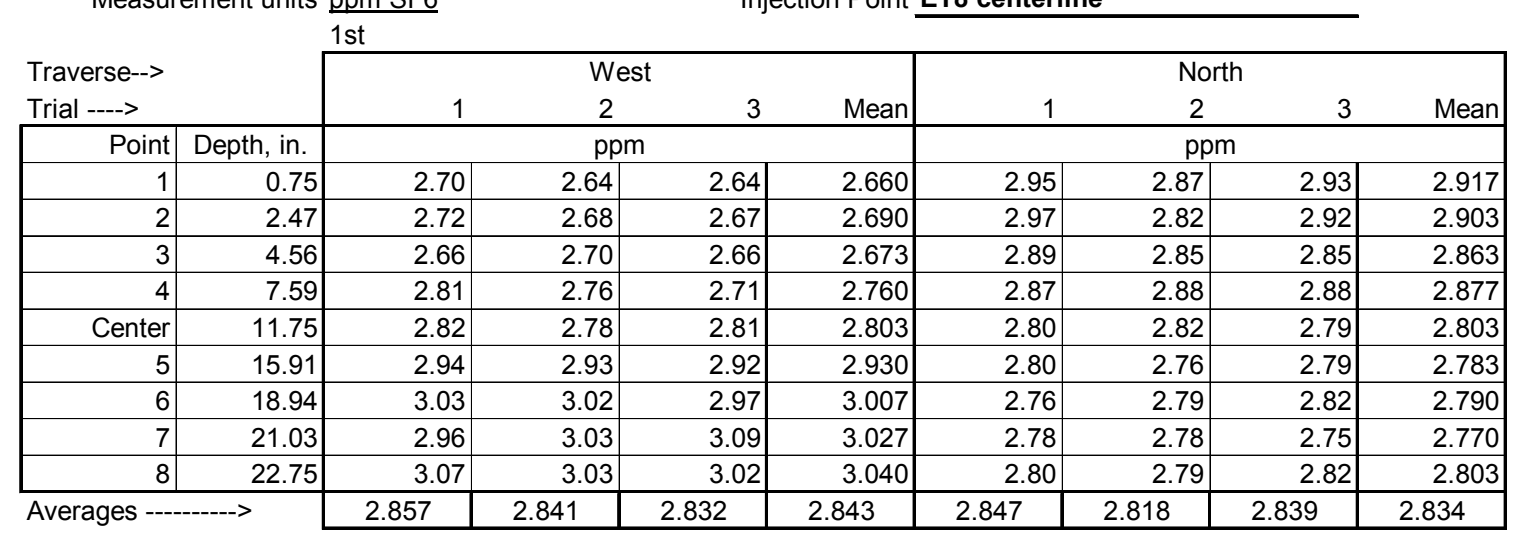

\begin{tabular}{|lrr|lrrr|}
\hline All & ppm & Dev. from mean & Center 2/3 & $\frac{\text { West }}{2.84}$ & $\frac{\text { North }}{2.83}$ & 2.83 \\
Mean & 2.84 & & Mean & & All \\
Min Point & 2.66 & $-6.3 \%$ & Std. Dev. & 0.15 & 0.05 & 0.11 \\
Max Point & 3.04 & $7.1 \%$ & COV as \% & 5.2 & 1.9 & 3.7 \\
\hline
\end{tabular}

Avg. Conc. $2.843 \mathrm{ppm}$

Gas analyzer checked:

19-Oct-01

Tracer tank pressure Sample Port Temp

Centerline vel.

Injection flowmeter

Stack flow

Sampling flowmeter

Ambient pressure

Ambient humidity

B\&K vapor correction

Back-Gd gas ppb

No. Bk-Gd samples

Ambient Temp, $F$

\begin{tabular}{|c|c|c|}
\hline Start & Finish & \\
\hline 100 & 100 & psig \\
\hline 49 & $48 / 38$ & $F^{*}$ \\
\hline n 1285 & w 1364/1330 & $\mathrm{fpm}^{*}$ \\
\hline 20 & 20 & ball ${ }^{\star *}$ \\
\hline 4000 & 4100 & $\mathrm{cfm}$ \\
\hline 10 & 10 & Ipm Sie \\
\hline 1001.5 & 1000.1 & mbar \\
\hline 98 & 99 & $\mathrm{RH}$ \\
\hline $\mathrm{Y}$ & $\mathrm{Y}$ & $\mathrm{Y} / \mathrm{N}$ \\
\hline
\end{tabular}

21/21/14/20/16/16 44/49/30/18/12/31

Instuments Used:

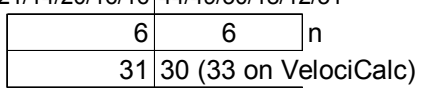

B \& K Model $1302 \# 1765299$

Sierra Inc. Constant Flow Air Sampler

Solmat Zephyr SN 12951472 Cal. Due 7/26/02

Notes:

*First readings from Solomat. Second from out of cal TSI Velocicalc SN 305039. Solomat suspected of reading several degrees high. This has no effect on the particle uniformity results.

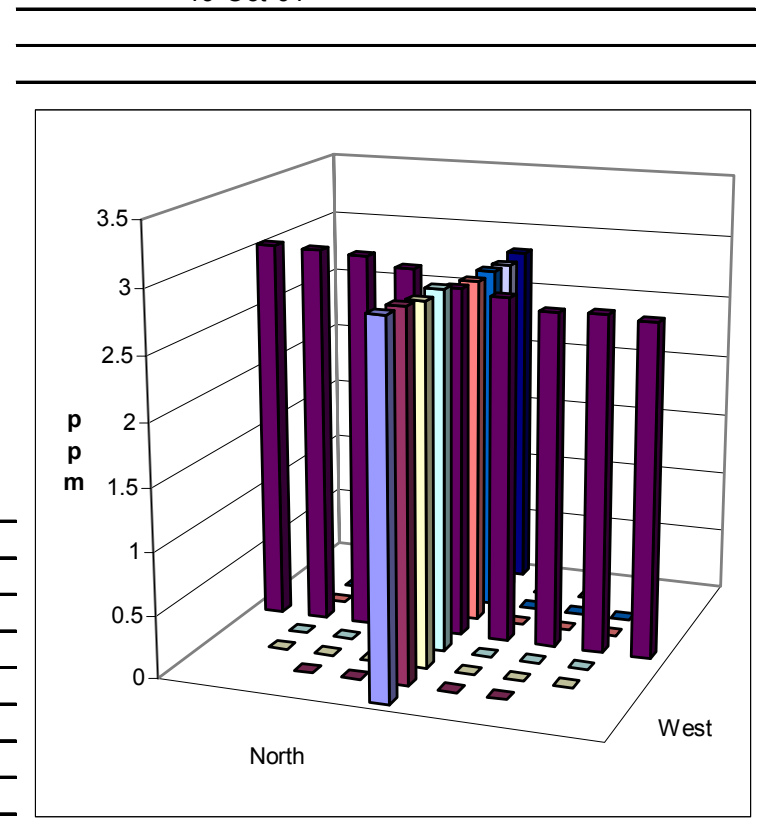




\section{Appendix $\mathbf{J}$ \\ Tracer Particle Uniformity Testing Procedure}




\section{J.1 Purpose}

The performance of new stack sampling systems must be shown to satisfy the requirements of 40 CFR 61, Subpart H, "National Emission standards for Emissions of Radionuclides Other than Radon from Department of Energy Facilities." This regulation governs portions of the design and implementation of effluent air sampling. The stack sampler performance is adequately characterized when potential contaminants in the effluent are of a uniform concentration at the sampling location (plane), and line losses are within acceptable limits. This procedure determines whether the concentration of aerosol particulate contaminants is uniformly distributed in the area of the sampling probe. Other procedures address flow angle, uniformity of gas velocity, and uniformity of gas contaminants. A contaminant concentration that is uniform at the sampling plane enables the extraction of samples that represent the true emission concentration.

The uniformity is expressed as the variability of the measurements about the mean. This is expressed using the relative coefficient of variance (COV), which is the standard deviation divided by the mean and expressed as a percentage. The lower the COV value, the more uniform the particle concentration. The acceptance criterion is that the COV of the measured particle concentrations be \# $20 \%$ across the center two-thirds of the area of the stack.

\section{J.2 Applicability}

This procedure can be used in the field or on modeled stacks to determine whether air-sampling probes can collect representative samples under normal operations. The tests are applicable to effluent stacks or ducts within the following constraints:

- The aerosol particulate tests are generally limited to stacks with flowrates greater than 50 cubic feet per minute range. The upper bound of flowrate is determined by the output capacity of the aerosol generator, the background reading for particulate aerosols, and the operational detection range of the optical particle counters.

- Environmental constraints - optical particle counters will require the use of a controlled temperature environment to maintain the equipment above 55 degrees Fahrenheit.

\section{J.3 Prerequisites and Conditions}

Conditions and concerns that must be satisfied before sampling are listed below:

- Safety glasses and hard toed or substantial shoes are required in work areas.

- Test ports for tracer injection and sampling.

- Properly constructed and inspected work platforms may be needed to access the test ports.

- Scaffold-user or fall protection training may be required to access the sampling ports of the stack.

- Alcohol may be used for equipment cleanup. A flammable equipment storage cabinet is required to hold chemicals. Material Safety Data Sheets must be provided. 
- Air pressure (up to about 75 psi) is used to aerosolize oil into fine particles. Knowledge of the use and operation of pressurized air-lines, and the careful observations of any buildup of oil mist outside of the generator is essential to prevent exceeding American Conference of Governmental Industrial Hygienists (ACGIH) levels listed below.

- Knowledge of the setup, use of, and operation of flowmeters, particle counters, and computers is essential.

- A job-hazards analysis may be required in certain cases.

\section{J.4 Precautions and Limitations}

\section{Caution: The ACGIH 8-hour time-weighted average limit for human exposure to mineral oil mist is $5 \mathrm{mg} / \mathrm{m}^{3}$. It is odorless.}

During tests of stacks with high flowrates, oil droplets will be injected into the base of the stack to overcome the large dilution factor needed to detect selected particles at the sampling ports above. The potential is present for a buildup of oil mist to occur outside of the aerosol generator that could approach the $5 \mathrm{mg} / \mathrm{m}^{3}$ caution level. The undiluted mist is heavier than air, so it may accumulate in confined spaces and in low areas if allowed to escape. Visual inspections of the delivery system will be made at least daily to prevent such an occurrence.

Access to the test ports may require the use of scaffolding or manlifts, either of which will necessitate special training for sampling personnel and any observers. The training requirements will be indicated in the job hazard analysis.

The test may be invalid if the ending ambient concentration of mist is elevated above that observed at the start of the test. This would indicate poor dispersion away from the test site caused by recirculation of the tracer to the inlet of the fan and will only occur if the stack exhaust point is in view of and is reasonably close to the fan inlet. This may result in a false indication of good mixing.

\section{J.5 Equipment Used for Stack Measurements}

Specific calibration check concentration levels, probe dimensions, measurement grids, flowrates, and other special requirements will be provided in the specific Test Instruction. Exhibit A provides a typical layout for the test setup. The following are essential items of equipment:

- Vacuum pump oil

- Oil mist generator

- Compressed air, compressed air hoses, and precision air regulators

- Oil mist injection probe

- Aerosol sampling probes

- Mechanism for accurate placement of sampling probe

- Optical particle counters

- Computers linked to particle counters 
- Velocity flow measurement meter.

Two optical particle counters (OPCs) may be used simultaneously to count particles that are approximately in the10-micron size range. A mobile OPC is designated to make point-by-point measurements in the orthogonal traverses. An optional reference OPC may be used to note trends in aerosol generator output over time and to validate the mobile sampler results. The operation of the reference OPC, at some fixed position in the stack, may be contingent on whether a suitable port is available on the test stack.

The counters, rechecked annually for calibration by the manufacturer, are synchronized for time, sample mode, flow, and count range to monitor their field performance. The absolute calibration of the OPCs is not as important as the general response because the concentration data are used in a relative manner in calculating the $\mathrm{COV}$ and in plotting the concentrations at the measurement points.

The aerosol generator siphons oil from a reservoir and forces the air/oil mixture through a spray nozzle to produce polydisperse particles. Non-hazardous oil with a low vapor pressure (such as Fisherbrand 19 vacuum pump oil) should be used in the reservoir. The quantity of aerosol generated is controlled by the amount of compressed air pressure, which should be filtered and controlled by a precision regulator. The nozzle is mounted in a large diameter, clear-plastic pipe (4-inches diameter or larger) so the output level can be observed. The aerosol generator output should connect to an injection tube with an inside diameter of at least 0.5 inches to minimize collisions with the inner wall of the tubing. Optimal operation depends on uniformly "wetting" the inner surfaces of the generator and transfer tubes; thus, a warm up period of up to $1 / 2$ hour is needed for a constant aerosol output.

\section{J.6 Work instructions for Setup, Measurements, and Data Reduction}

The steps taken to set up, configure, and operate the stack fans and test equipment are listed. Based on previous field measurements, the steps are ordered to achieve maximum efficiency in the testing. In addition to these steps, the test instruction illustrated in Attachment A will provide specific details and operating parameters. 


\section{Preliminary Steps:}

Provide essential supplies at the sampling location (particulate generation equipment, supply air and regulators, fittings and probe-port couplers, marking pens, data sheets, writing and probe-supporting platforms).

Fill in test information on dataform.

Observe the current flow setting for the test stack and record on the data sheet.

Obtain barometric, temperature, and relative humidity information for the particle counter location.

Measure the stack centerline air velocity in the sampling plane using a velocity flow meter, and record value on data sheet.

Mark the sampling probe with a permanent marker so the inlet can be placed at each successive measurement point.

Note: Sampling plane traverse points. Use the grid of measurement points provided with the test's instruction and dataform. This is usually the same as used for the velocity uniformity test. A center point is included as a common reference and for graphical purposes. The layout design divides the area of the sampling plane so that each point represents approximately an enilal-sized area

\section{Couple the OPCs and probes to the stack sampling ports according to the illustration in Exhibit $A$.}

Note: The sampling equipment consists of stainless steel probes with $3 / 4$ outside diameter and thinwall tubing with sufficient length to reach across the inside diameter of the stack while allowing for fittings. The sampling probe should have gradual $90^{\circ}$ bends to minimize the inertial impact of particles with inner walls at bends, and the open end of the tube should face downward or into the flow in the stack. The outlet end of the probe should terminate at the OPC inlet. Minimize tubing length to minimize particle losses.

The sampling probes for both OPCs should be similar and of a simple design. The elevation of the intake nozzle of the traversing unit should be approximately in the same as the sampling plane. The intake nozzle for the reference unit may be located anywhere within the stack at an elevation near that of the sampling plane; however, the two probes should not interfere with each other, either physically or by causing flow disturbances for each other. The intake nozzles may be of sub-isokinetic or of shrouded design to optimize the collection of 10 -micron particles.

The aerodynamic characteristics of the probes for both OPCs should be the same so that they have similar line-loss (penetration) values. For optimal particle collection, the probes should be of a fixed and rigid configuration. The mobile OPC with its attached probe should be mounted together on a sliding platform to move as a unit along the axis of the sampling port. 


\section{Turn-on the mobile and reference optical}

\section{particle counters.}

Note: Ensure that internal air circulation fans in the OPCs are on and that the sample probes are tightly connected to and are directly above or apart from the OPC sample inlet openings. Also ensure that the sliding platform supporting the mobile sampler is aligned for easy, free movement at the correct height for its stack port.

\section{Program and synchronize the OPCs for}

- 60 -second samples

- 9- to 11-micron particle counting

- the current time

- cumulative counting mode.

\section{$\underline{\text { Daily Particulate Background Concentration Measurement }}$}

\section{At the beginning of each sampling day before starting the aerosol generator, obtain at least six consecutive background readings for both mobile and reference OPCs. \\ Record these readings on the data sheet and in the logbook designated for the tests.}

\section{Start and run the aerosol generator for approximately} 30 minutes to stabilize its output.

\section{$\underline{\text { Particle Injection and Sample Collection }}$}

The injection equipment includes an air regulator, a precision air pressure gauge, and other components described in Section 5. The 3/4-inch (OD) (or larger) injection probe with a $90 \mathrm{E}$ bend (with an approximately 3 -inch radius of turn) will inject aerosol particles in the direction of emission flow. The connections and fittings should be checked to ensure that they are secure and leak free.

\section{Note: Location of the Injection Point}

Injection plane -- The tests are repeated using the centerpoint as the aerosol release point. 
Position the injection probe, according to the test instruction.

\section{Start injection of the aerosol and adjust the flowrate to the input capabilities of the OPCs.}

Note: Aerosol injection is not precisely controlled. At air pressure readings above about 10 psi for the specific PNNL generator used, a dense oil mist is created in the generator and is available for injection. However, if the back-pressure, caused by a high rate of airflow past the port in the stack, at the injection port is high, carrier air may be required to inject the aerosol into the base of the stack. Under these conditions, the overall aerosol output will be low (less than perhaps 200 particles measured at the counter).

In contrast, if there is little back-pressure, most of the generated aerosol, minus that lost from interactions with internal generator system and line walls, becomes available for injection. Here the output will be high (hundreds to thousands of particles injected per minute).

Note: The OPC draws air from the stack, via the sample probe, at a fixed rate (one cubic foot per minute). Within the OPC, the air stream with particles passes through a laser beam where the particles are counted and placed in six size categories. In the less than 0.5-micron category, several hundred thousand differential counts are typical; but in the 9- to 11-micron category, oil mists greater than about 3,000 cpm cause a sensor overload condition. Thus, at the OPC, the flow rate is fixed, and a ceiling exists on the measurement of particles. Essentially, there is no adjustment of particle counting capability at the OPC, and the aerosol generator becomes the

\section{Record the initial}

- injection system dispersion pressure in psi

- flowrate for the mobile and reference OPC

- centerline flow velocity for the test stack.

On the data sheet, label the columns of data according to the directions of the traverses.

Verify that the directional orientations and the numbered sample positions are consistent.

Position the OPC and sample probe at each measurement point in succession, and record the reading on the data form.

Note: In each test, the measurement at each point is the average of three readings. The repeats are made as three separate runs and not as three consecutive measurements at each point. 


\section{Perform two additional repetitions of Step 6.3.6.}

Switch the tests to the other direction and repeat steps 6.3.6 and 6.3.7.

\section{Check the data sheet for completeness.}

$\underline{\text { Record the final }}$

- $\quad$ injection system dispersion pressure in psi

- flowrate for the mobile and reference OPC

Shut off the air pressure to the aerosol generator.

Continue operation of the OPCs for several minutes to purge any remaining test aerosol from the stack.

Measure the centerline background particulate concentrations at the mobile monitor and record the levels on the data sheet.

Record any climatic conditions that have changed on the data sheet.

Measure the final centerline stack velocity flow on the data sheet.

Record any deviations from the above procedure on the data sheet.

Repeat steps 6.3.1 to 6.3.16 for each run as indicated in the test instruction.

\section{Data Recording and Calculations}

Prepare the electronic data sheet on which to enter particle-count readings and other information relevant to the test (see test instruction).

Review the raw data sheets for completeness.

Enter the data into the electronic data sheet.

\section{Calculate the COV for the run.}

Note: The EXCEL datasheet shown as Attachment $\mathrm{C}$ is set up to calculate the COV for each particulate concentration traverse using the average concentration data from all points in the inner two-thirds of the cross section area of the plane (including the center point). 


\section{Compare the observed COV for each run to the acceptance}

criterion.

Note: The test is acceptable if the COV is \#20\% for the inner two-thirds of the stack diameter, and if no point differs from the mean by more than $30 \%$. This is determined by inspecting the average concentration at each measurement point. The COV is 100 times the standard deviation divided by tho moan

\section{Sign and date the data sheet illustrated in Attachment $\mathrm{C}$}

attesting to its validity.

Note: A separate datasheet will be provided and signed-off for each test. 
Figure J.1. Overview of Stack and Injection Setup and Particle Counters

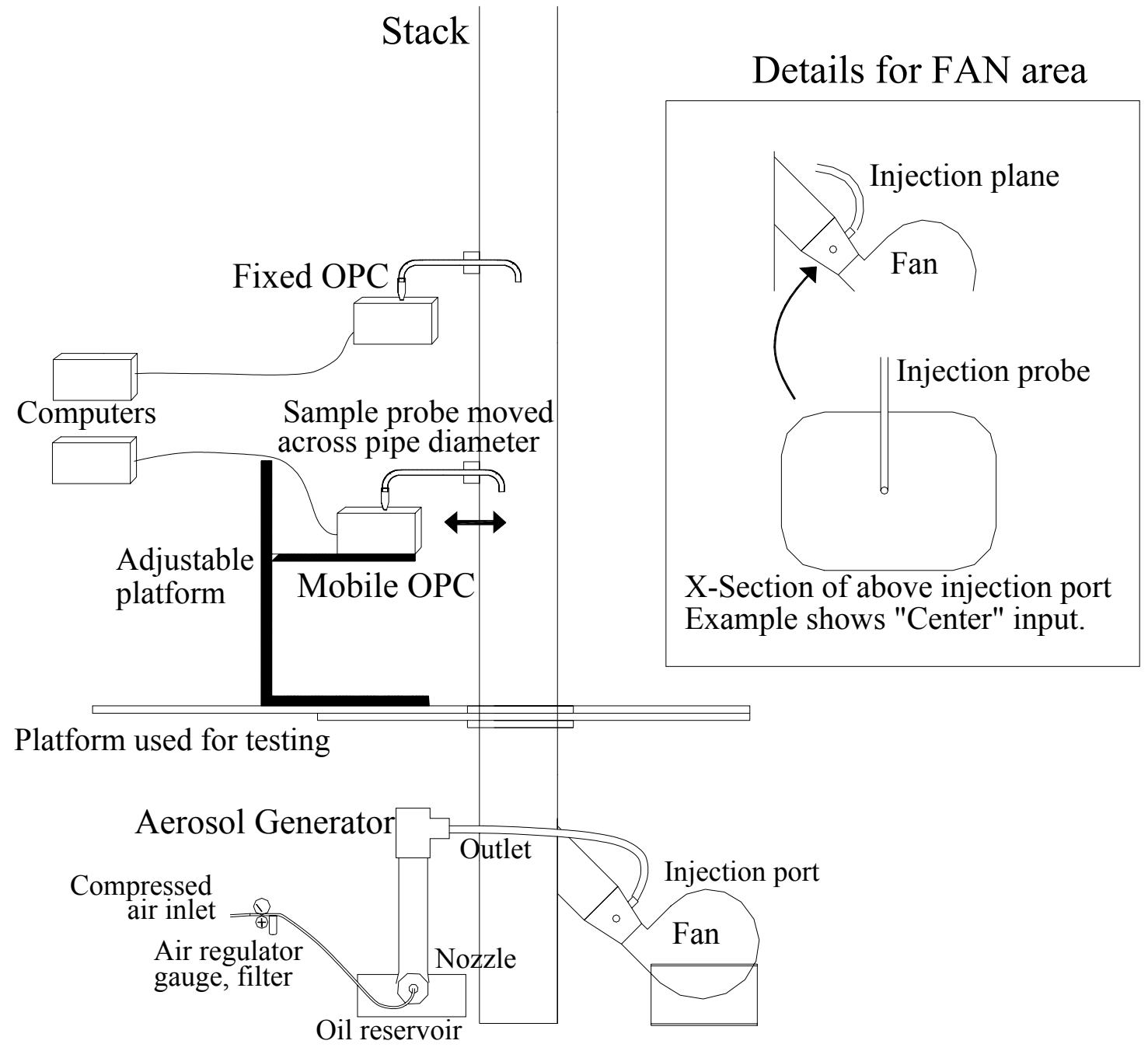




\section{Figure J.2. Illustrative Data Collection Sheet}

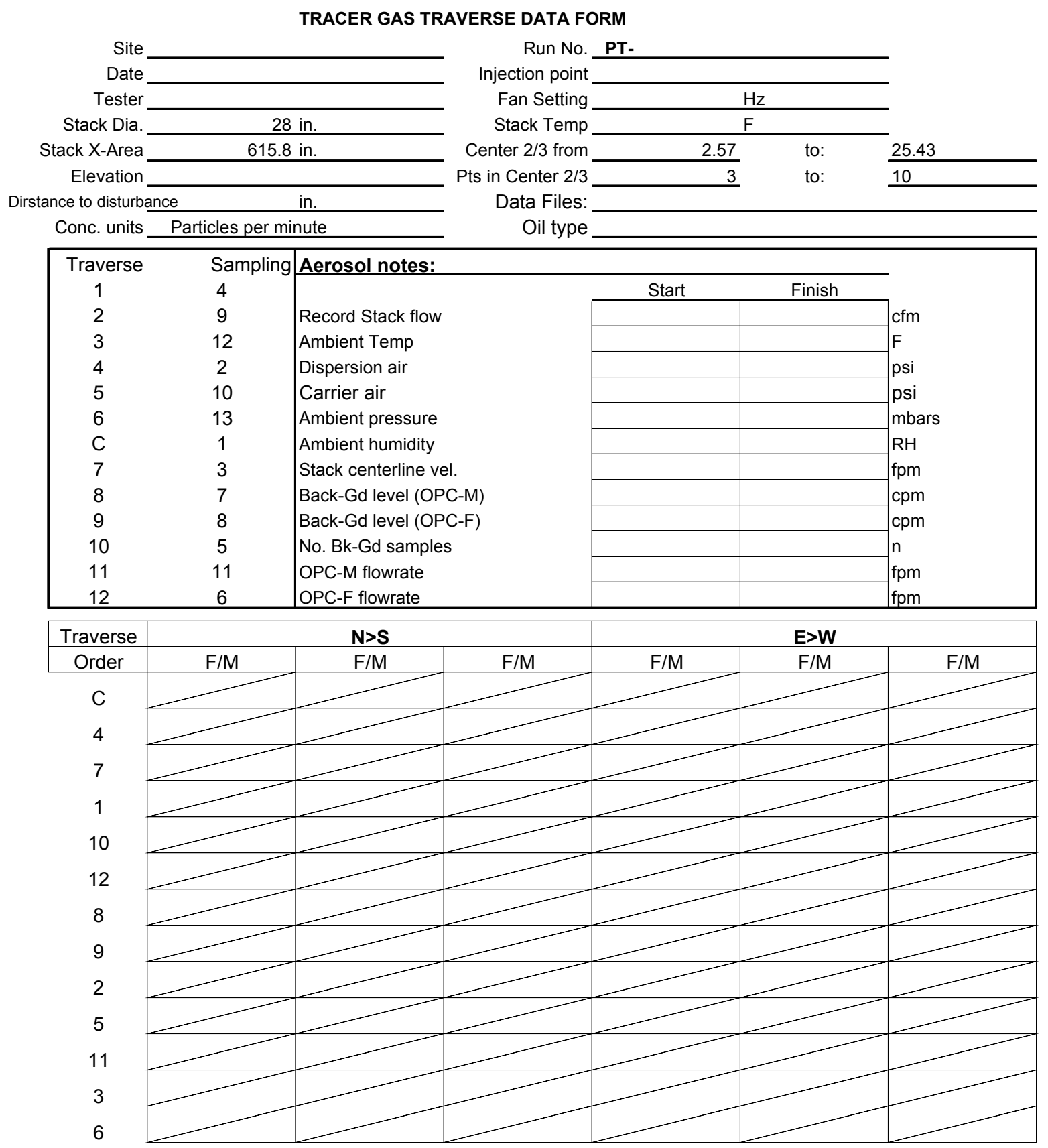

Instuments Used:

Cal Exp. Date:

Solomat Zephyr \#12951472 (stack center velocity)

OPC- A (M/F:

$\mathrm{OPC}-\mathrm{B}(\mathrm{M} / \mathrm{F}$ :

Signing/dating signifies compliance with sections 6.1.1-6.4.5 in the PNNL Procedure No. EMS-JAG-02 (11/10/98)

Signature/Date: 


\section{Figure J.3. Illustrative Data Reporting Form}

\section{PARTICULATE TRAVERSE DATA REPORT FORM}

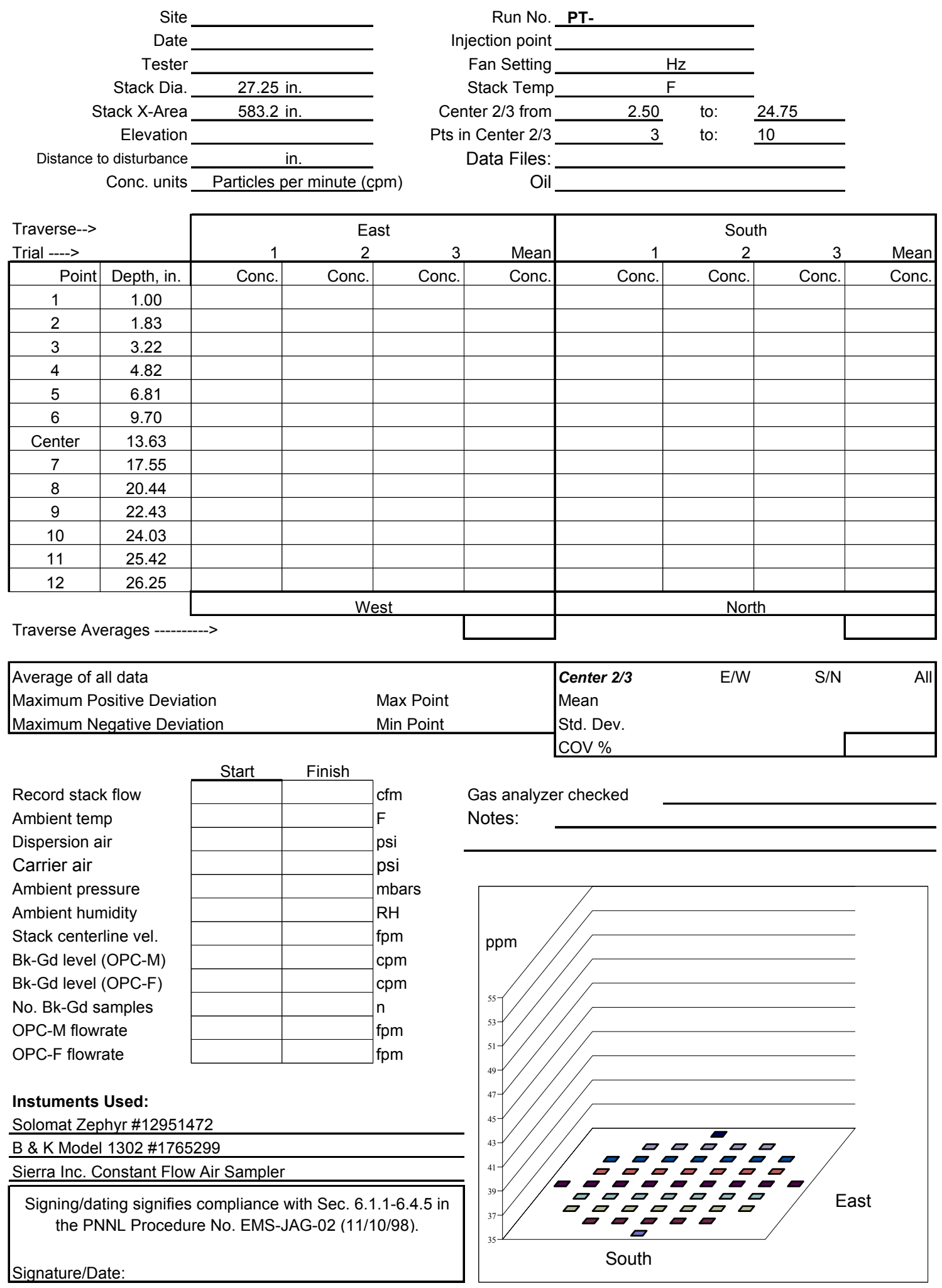


Figure J.4. Illustrative Test Instructions

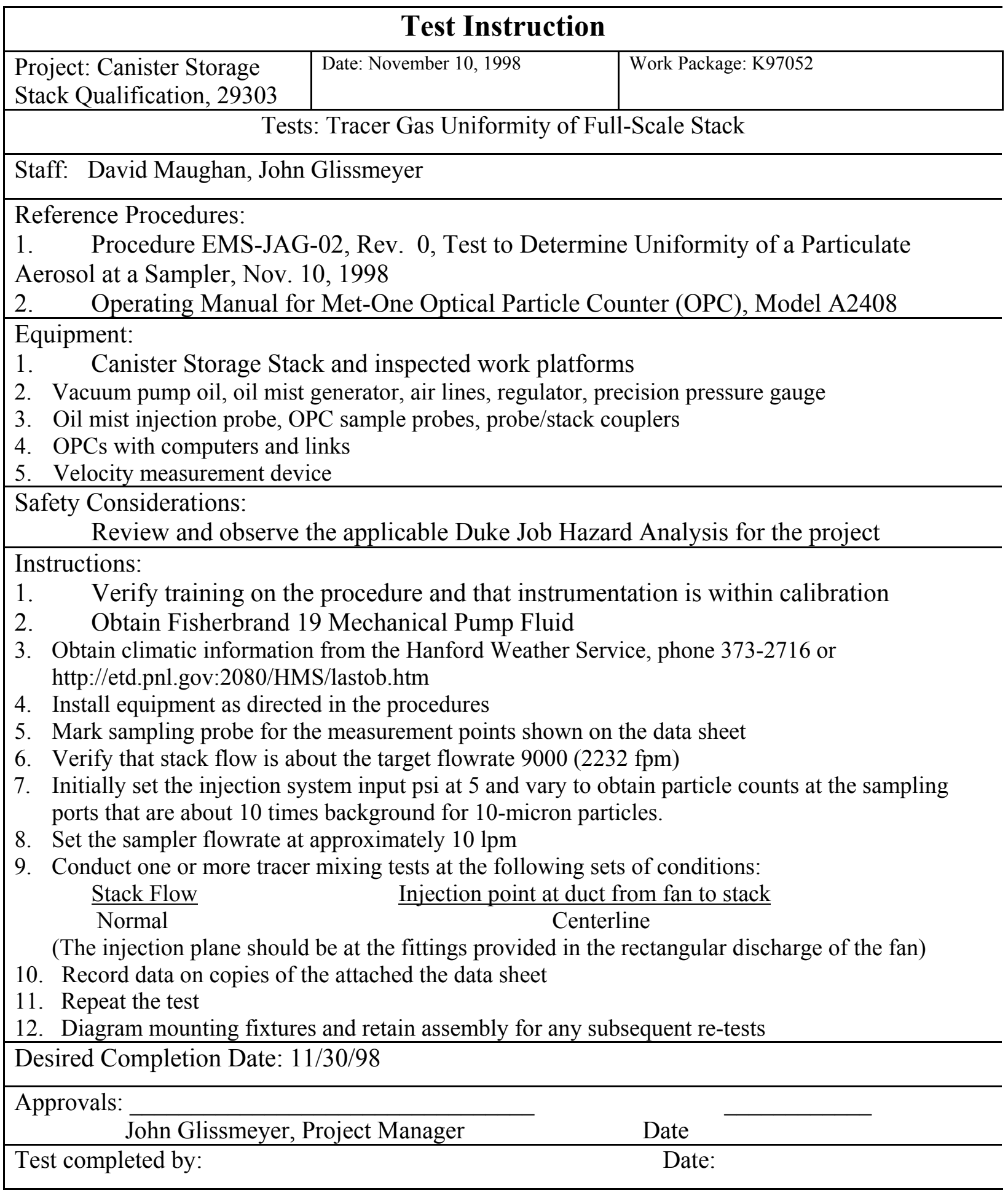


Appendix K

Tracer Particle Uniformity Data Sheets 
PARTICLE TRACER TRAVERSE DATA FORM

Site 291-Z-1 Model Stack

Date 11/5/01

Tester Glissmeyer

Stack Dia.

Stack X-Area 433.7 in.2

Elevation N.A.

Distance to disturbance

Measurement units particles/ft3
Run No. PT-1

Fan configuration 4-fan: EF1, EF4, EF5, EF7

Fan Setting $50 \mathrm{~Hz}$

Stack Temp

Start/End Time 1427/155

Center $2 / 3$ from

Points in Center $2 / 3$

Injection Point Centerline EF-4

\begin{tabular}{|c|c|c|c|c|c|c|c|c|c|}
\hline \multirow{3}{*}{\multicolumn{2}{|c|}{$\begin{array}{l}\text { Traverse--> } \\
\text { Trial ----> }\end{array}$}} & \multicolumn{4}{|c|}{ 2nd } & \multicolumn{3}{|c|}{ 1st } & \multirow[b]{3}{*}{ Mean } \\
\hline & & \multicolumn{4}{|c|}{ West } & \multicolumn{3}{|c|}{ North } & \\
\hline & & \multirow[t]{2}{*}{1} & 2 & 3 & \multirow[t]{2}{*}{ Mean } & 1 & 2 & 3 & \\
\hline Point & Depth, in. & & \multicolumn{2}{|c|}{ particles/ft3 } & & \multicolumn{4}{|c|}{ particles/ft3 } \\
\hline 1 & 0.75 & 323 & 331 & 332 & 328.7 & 290 & 340 & 303 & 311.0 \\
\hline 2 & 2.47 & 341 & 340 & 333 & 338.0 & 296 & 282 & 325 & 301.0 \\
\hline 3 & 4.56 & 332 & 327 & 339 & 332.7 & 288 & 319 & 267 & 291.3 \\
\hline 4 & 7.59 & 374 & 334 & 354 & 354.0 & 332 & 309 & 288 & 309.7 \\
\hline Center & 11.75 & 348 & 362 & 316 & 342.0 & 314 & 292 & 338 & 314.7 \\
\hline 5 & 15.91 & 348 & 338 & 350 & 345.3 & 302 & 316 & 286 & 301.3 \\
\hline 6 & 18.94 & 310 & 328 & 353 & 330.3 & 316 & 320 & 321 & 319.0 \\
\hline 7 & 21.03 & 344 & 316 & 345 & 335.0 & 326 & 325 & 313 & 321.3 \\
\hline 8 & 22.75 & 324 & 344 & 347 & 338.3 & 306 & 287 & 329 & 307.3 \\
\hline Averages --- & $----->$ & 338.2 & 335.6 & 341.0 & 338.3 & 307.8 & 310.0 & 307.8 & 308.5 \\
\hline
\end{tabular}

Averages ----------->

338.2

5.6

338.3

Dev. from mean

$-9.9 \%$
$9.5 \%$

9.5\% COV as \%
$62 \operatorname{deg} F$

556

$\frac{16}{2}$ to: $\frac{21.34}{7}$

\begin{tabular}{|c|c|c|c|c|c|c|c|}
\hline$A / I$ & $\mathrm{pt} / \mathrm{ft} 3$ & Dev. from mean & Center 2/3 & North & West & All & Normlzd \\
\hline Mean & 323.4 & & Mean & 339.6 & 308.3 & 323.98 & 337.37 \\
\hline Min Point & 291.3 & $-9.9 \%$ & Std. Dev. & 8.2 & 10.9 & 18.70 & 10.08 \\
\hline Max Point & 354.0 & $9.5 \%$ & COV as $\%$ & 2.4 & 3.5 & 5.77 & 2.99 \\
\hline
\end{tabular}

Avg Conc $323 \mathrm{pt} / \mathrm{ft} 3$

Instuments Used:

Generator Inlet Press

Stack Temp

Centerline vel.

Ambient pressure

Ambient humidity

Ambient temp

Back-Gd aerosol

No. Bk-Gd samples

\begin{tabular}{|c|c|c|}
\hline Start & Finish & \\
\hline 10 & 10 & psig \\
\hline 62 & 62 & $2 \mathrm{~F}$ \\
\hline w 1829 & n 1889 & $9 \mathrm{fpm}$ \\
\hline 997 & 997.5 & $5 \mathrm{mba}$ \\
\hline 36 & 33 & $\mathrm{RH}$ \\
\hline 58 & 57 & $\mathrm{~F}$ \\
\hline $1 / 3 / 0 / 1 / 0 / 2$ & $0 / 0 / 0 / 0 / 0$ & $\mathrm{pt} / \mathrm{ft} 3$ \\
\hline 6 & 5 & \\
\hline
\end{tabular}

Optical Particle Counters:(Cal due 7/13/02)

OPC A (9/5/01) MetOne A2408-1 Serial No.96258675 The clock on the OPC is 1-hr fast.

Oil Used: FisherBrand 19

After end of run and before aerosol turned off, the following readings were take in succession at position West 4 320, 322, 347, 329, 356

Sequence at North \#4

$1509,1501,1468,1620,1560$

\section{Solmat Zephyr SN 12951472 Cal due 7/26/02}

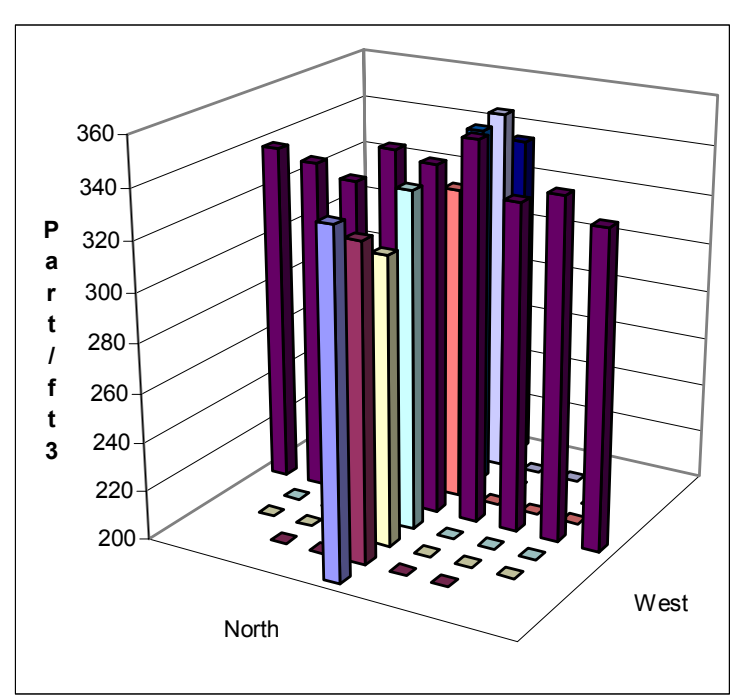


PARTICLE TRACER TRAVERSE DATA FORM

Site 291-Z-1 Model Stack

Date 11/7/01

Tester Glissmeyer

Stack Dia.

23.5 in

Stack X-Area

Elevation N.A.

Distance to disturbance

Measurement units particles/ft

75 inches

75 inches

2nd

\author{
Run No. PT-3
}

Fan configuration 4-fan: EF1, EF4, EF5, EF7

Fan Setting $\mathbf{5 0 ~ \mathbf { ~ H z }}$

Stack Temp

Start/End Time 1456/1610

Center $2 / 3$ from

Points in Center $2 / 3$

Injection Point Centerline EF-7

$\begin{array}{ll}\text { to: } & 21.34 \\ \text { to: } & \end{array}$

\begin{tabular}{|c|c|c|c|c|c|c|c|c|c|}
\hline \multirow{3}{*}{\multicolumn{2}{|c|}{$\begin{array}{l}\text { Traverse--> } \\
\text { Trial ----> }\end{array}$}} & \multirow{2}{*}{\multicolumn{4}{|c|}{ West }} & \multirow{2}{*}{\multicolumn{4}{|c|}{ North }} \\
\hline & & & & & & & & & \\
\hline & & \multirow[t]{2}{*}{1} & \multicolumn{2}{|c|}{2} & \multirow[t]{2}{*}{ Mean } & \multicolumn{2}{|r|}{2} & 3 & Mean \\
\hline Point & Depth, in. & & \multicolumn{2}{|c|}{ particles/ft3 } & & \multicolumn{4}{|c|}{ particles/ft3 } \\
\hline 1 & 0.75 & 1974 & 1891 & 1476 & 1780.3 & 1510 & 1462 & 1411 & 1461.0 \\
\hline 2 & 2.47 & 1926 & 2056 & 1459 & 1813.7 & 1581 & 1542 & 1405 & 1509.3 \\
\hline 3 & 4.56 & 1963 & 1984 & 1611 & 1852.7 & 1506 & 1465 & 1599 & 1523.3 \\
\hline 4 & 7.59 & 2083 & 1965 & 1479 & 1842.3 & 1482 & 1521 & 1654 & 1552.3 \\
\hline Center & 11.75 & 1959 & 1875 & 1515 & 1783.0 & 1484 & 1530 & 1640 & 1551.3 \\
\hline 5 & 15.91 & 2000 & 1692 & 1514 & 1735.3 & 1410 & 1515 & 1554 & 1493.0 \\
\hline 6 & 18.94 & 2072 & 1545 & 1546 & 1721.0 & 1483 & 1578 & 1608 & 1556.3 \\
\hline 7 & 21.03 & 2092 & 1521 & 1555 & 1722.7 & 1573 & 1525 & 1631 & 1576.3 \\
\hline 8 & 22.75 & 1786 & 1437 & 1492 & 1571.7 & 1445 & 1440 & 1472 & 1452.3 \\
\hline Averages --- & $----->$ & 1983.9 & 1774.0 & 1516.3 & 1758.1 & 1497.1 & 1508.7 & 1552.7 & 1519.5 \\
\hline
\end{tabular}

\begin{tabular}{|c|c|c|c|c|c|c|c|}
\hline$A I I$ & $\mathrm{pt} / \mathrm{ft} 3$ & Dev. from mean & Center $2 / 3$ & North & West & All & Normlzd \\
\hline Mean & $\overline{1638.8}$ & & Mean & $1 \overline{781.5}$ & $1 \overline{537.4}$ & $1659 . \overline{48}$ & $\overline{1774.27}$ \\
\hline Min Point & 1452.3 & $-11.4 \%$ & Std. Dev. & 56.4 & 29.6 & 133.83 & 45.34 \\
\hline Max Point & 1852.7 & $13.1 \%$ & cov as $\%$ & 3.2 & 1.9 & 8.06 & 2.56 \\
\hline
\end{tabular}

Avg Conc

$$
1635 \mathrm{pt} / \mathrm{ft} 3
$$

Generator Inlet Press

Stack Temp

Centerline vel.

Ambient pressure

Ambient humidity

Ambient temp

Back-Gd aerosol

No. Bk-Gd samples

\begin{tabular}{|c|c|c|}
\hline Start & Finish & \\
\hline 10 & 10 & psig \\
\hline 53 & 55 & $\mathrm{~F}$ \\
\hline w 1905 & n 1900 & $\mathrm{fpm}$ \\
\hline 1008.4 & 1007.7 & $\mathrm{mba}$ \\
\hline 62 & 67 & $\mathrm{RH}$ \\
\hline 46 & 43 & $\mathrm{~F}$ \\
\hline $1 / 1 / 0 / 1 / 0 / 2 / 1$ & $0 / 0 / 0$ & $\mathrm{pt} / \mathrm{ft} 3$ \\
\hline 7.0 & 3.0 & \\
\hline
\end{tabular}

Optical Particle Counters:(Cal due 7/13/02)

OPC A (9/5/01) MetOne A2408-1 Serial No.96258675

Oil Used: FisherBrand 19

At 1549 the scaffold was at $52 \mathrm{~F}$, the sun was low.

The clock on the OPC is 1-hr fast.

Sequence at North \#4

$1509,1501,1468,1620,1560$

\section{Instuments Used:}

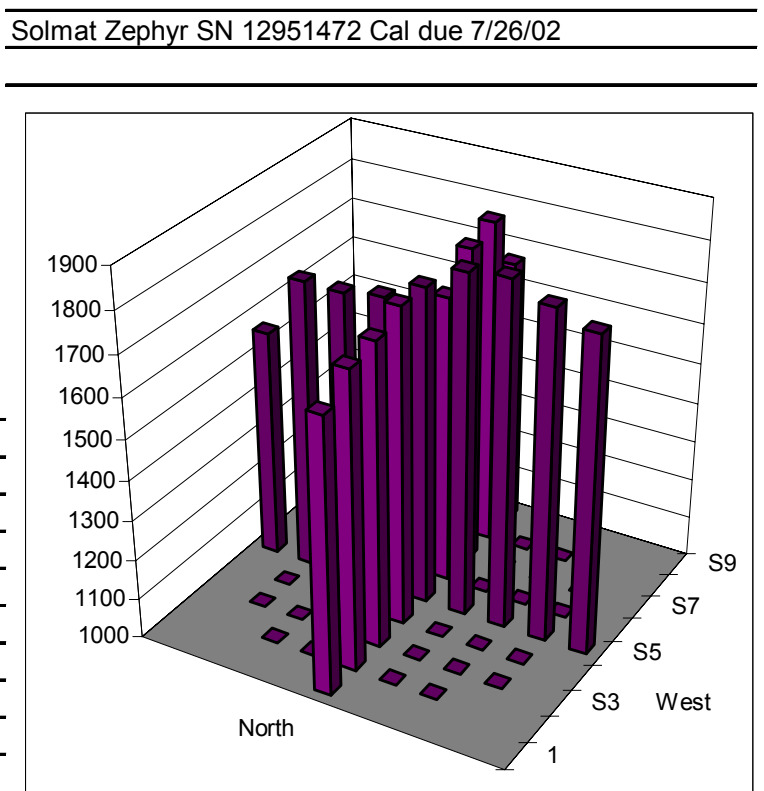


PARTICLE TRACER TRAVERSE DATA FORM

Site 291-Z-1 Model Stack

Date 11/7/01

Tester Glissmeyer

Stack Dia.

Stack X-Area

Elevation N.A

Distance to disturbance

Measurement units particles/ft 3
Run No. PT-2

Fan configuration 4-fan: EF1, EF4, EF5, EF7

Fan Setting $50 \mathrm{~Hz}$

Stack Temp

Start/End Time 1300/1430

Center $2 / 3$ from

Points in Center $2 / 3$ Injection Point EF-7 Centerline

1 st

\begin{tabular}{|c|c|c|c|c|c|c|c|c|c|}
\hline \multirow{3}{*}{\multicolumn{2}{|c|}{$\begin{array}{l}\text { Traverse---> } \\
\text { Trial ----> }\end{array}$}} & \multirow{2}{*}{\multicolumn{4}{|c|}{ West }} & \multirow{2}{*}{\multicolumn{4}{|c|}{ North }} \\
\hline & & & & & & & & & \\
\hline & & 1 & \multicolumn{2}{|r|}{3} & \multirow[t]{2}{*}{ Mean } & 1 & 2 & 3 & Mean \\
\hline Point & Depth, in. & \multicolumn{3}{|c|}{ particles/ft3 } & & \multicolumn{4}{|c|}{ particles/ft3 } \\
\hline 1 & 0.75 & 1799 & 1860 & 1896 & 1851.7 & 1542 & 1590 & 1568 & 1566.7 \\
\hline 2 & 2.47 & 1838 & 1815 & 1892 & 1848.3 & 1488 & 1509 & 1536 & 1511.0 \\
\hline 3 & 4.56 & 1866 & 1908 & 1844 & 1872.7 & 1564 & 1474 & 1562 & 1533.3 \\
\hline 4 & 7.59 & 1935 & 1784 & 1860 & 1859.7 & 1568 & 1705 & 1516 & 1596.3 \\
\hline Center & 11.75 & 1869 & 1819 & 1904 & 1864.0 & 1578 & 1708 & 1562 & 1616.0 \\
\hline 5 & 15.91 & 1912 & 1889 & 1907 & 1902.7 & 1617 & 1578 & 1546 & 1580.3 \\
\hline 6 & 18.94 & 1941 & 1944 & 1924 & 1936.3 & 1696 & 1723 & 1681 & 1700.0 \\
\hline 7 & 21.03 & 1811 & 1988 & 1952 & 1917.0 & 1629 & 1535 & 1626 & 1596.7 \\
\hline 8 & 22.75 & 1861 & 1808 & 1826 & 1831.7 & 1522 & 1648 & 1419 & 1529.7 \\
\hline Averages -- & 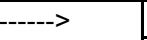 & 1870.2 & 1868.3 & 1889.4 & 1876.0 & 1578.2 & 1607.8 & 1557.3 & 1581.1 \\
\hline
\end{tabular}

\begin{tabular}{|c|c|c|c|c|c|c|c|}
\hline$A / I$ & $\mathrm{pt} / \mathrm{ft} 3$ & Dev. from mean & Center 2/3 & North & West & All & Normlzd \\
\hline Mean & $\overline{1728.6}$ & & Mean & 1885.8 & $1 \overline{1590.5}$ & 1738.17 & 1860.21 \\
\hline Min Point & 1511.0 & $-12.6 \%$ & Std. Dev. & 33.0 & 61.1 & 160.32 & 59.18 \\
\hline Max Point & 1936.3 & $12.0 \%$ & Cov as $\%$ & 1.8 & 3.8 & 9.22 & 3.18 \\
\hline
\end{tabular}

Avg Conc

$$
1727 \mathrm{pt} / \mathrm{ft} 3
$$

Generator Inlet Press

Stack Temp

Centerline vel.

Ambient pressure

Ambient humidity

Ambient temp

Back-Gd aerosol

No. Bk-Gd samples

\begin{tabular}{|c|c|c|}
\hline Start & Finish & \\
\hline 10 & 10 & psig \\
\hline 55 & 53 & $\mathrm{~F}$ \\
\hline n 1800 & w 1905 & $\mathrm{fpm}$ \\
\hline 1008 & 1008.4 & $\mathrm{mba}$ \\
\hline 61 & 62 & $\mathrm{RH}$ \\
\hline 47 & 46 & $F$ \\
\hline $0 / 0 / 2 / 3 / 5 / 4$ & $1 / 1 / 0 / 1 / 0 / 2 / 1$ & $\mathrm{pt} / \mathrm{ft}^{3}$ \\
\hline 6 & 7 & \\
\hline
\end{tabular}

Optical Particle Counters:(Cal due 7/13/02)

OPC A (9/5/01) MetOne A2408-1 Serial No.96258675

The clock on the OPC is 1-hr fast.

Oil Used: $\quad$ FisherBrand 19

Sequence at North \#4

$1509,1501,1468,1620,1560$
Instuments Used:

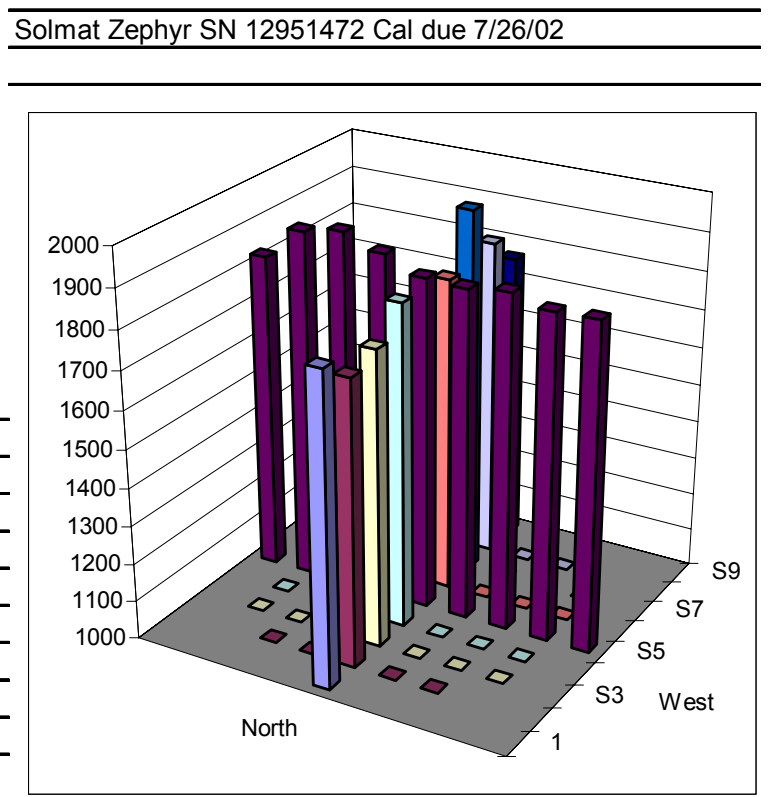


PARTICLE TRACER TRAVERSE DATA FORM

Site 291-Z-1 Model Stack

Date 11/8/01

Tester Glissmeyer

Stack Dia.

Stack X-Area

Elevation N.A

Distance to disturbance

Measurement units particles/ft 3

Traverse-->
Trial ---->
\begin{tabular}{|r|r|}
\hline Point & Depth, in. \\
\hline 1 & 0.75 \\
\hline 2 & 2. \\
\hline 3 & 4. \\
\hline 4 & 7. \\
\hline Center & 11. \\
\hline 5 & 15. \\
\hline 6 & 18. \\
\hline 7 & 21.03 \\
\hline 8 & 22.75 \\
\hline
\end{tabular}

Averages ---------->
23.5 in

433.7 in. 2

75 inches

$1 \mathrm{st}$
Run No. PT-4

Fan configuration 4-fan: EF1, EF4, EF5, EF7

Fan Setting $\mathbf{5 0 ~ \mathbf { ~ z }}$

Stack Temp

Start/End Time 1306/1515

Center $2 / 3$ from

Points in Center $2 / 3$

Injection Point Centerline EF-7 st 2 2nd

\begin{tabular}{|c|c|c|c|c|c|c|c|}
\hline$A / I$ & $\mathrm{pt} / \mathrm{ft} 3$ & Dev. from mean & Center 2/3 & North & West & All & Normlzd \\
\hline Mean & 1353.9 & & Mean & 1511.8 & 1227.8 & $1369 . \overline{81}$ & 1524.11 \\
\hline Min Point & 1154.3 & $-14.7 \%$ & Std. Dev. & 29.7 & 43.2 & 151.60 & 43.77 \\
\hline Max Point & 1563.7 & $15.5 \%$ & COV as $\%$ & 2.0 & 3.5 & 11.07 & 2.87 \\
\hline
\end{tabular}

Instuments Used:

Avg Conc

$1357 \mathrm{pt} / \mathrm{ft} 3$

Generator Inlet Press

Stack Temp

Centerline vel.

Ambient pressure

Ambient humidity

Ambient temp

Back-Gd aerosol

No. Bk-Gd samples

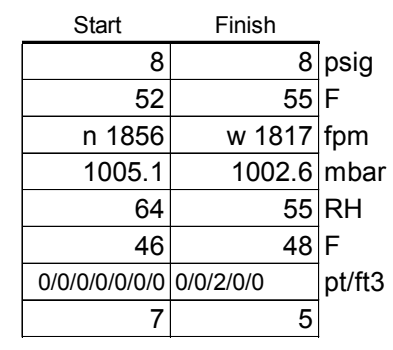

Optical Particle Counters:(Cal due 7/13/02)

OPC A (9/5/01) MetOne A2408-1 Serial No.96258675

The clock on the OPC is 1-hr fast.

Oil Used: FisherBrand 19

Was $53 \mathrm{~F}$ on scaffold at start

Lowered aerosol generator pressure from $10 \mathrm{psi}$ to $8 \mathrm{psi}$ because was getting too much aerosol, resulting in "sensor" light on OPC.

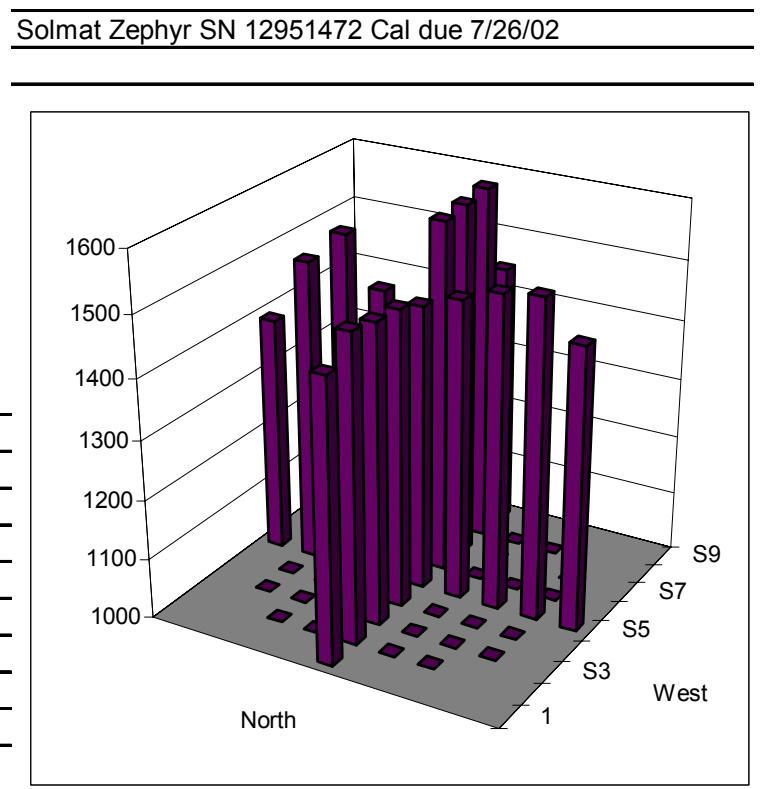


PARTICLE TRACER TRAVERSE DATA FORM

Site 291-Z-1 Model Stack

Date 11/13/01

Tester Glissmeyer

Stack Dia.

$23.5 \mathrm{in}$

Stack X-Area 433.7 in.2

Elevation N.A.

Distance to disturbance

Measurement units particles/ft3
Run No. PT-5

Fan configuration Turbine fan config

Fan Setting $60 \mathrm{~Hz}$

Stack Temp

Start/End Time 1430/1600

Center $2 / 3$ from

Points in Center $2 / 3$

Injection Point Centerline ET-8

\begin{tabular}{|c|c|c|c|c|c|c|c|c|c|}
\hline \multirow{3}{*}{\multicolumn{2}{|c|}{$\begin{array}{l}\text { Traverse---> } \\
\text { Trial ----> }\end{array}$}} & \multicolumn{8}{|c|}{ 1st } \\
\hline & & \multicolumn{4}{|c|}{ West } & \multicolumn{4}{|c|}{ North } \\
\hline & & \multirow[t]{2}{*}{1} & 2 & \multirow[b]{2}{*}{$/ \mathrm{ft} 3$} & \multirow[t]{2}{*}{ Mean } & \multirow{2}{*}{\multicolumn{2}{|c|}{$\frac{2}{\text { particl }}$}} & 3 & \multirow[t]{2}{*}{ Mean } \\
\hline Point & Depth, in. & & particles/ft3 & & & & & particles/ft3 & \\
\hline 1 & 0.75 & 333 & 270 & 306 & 303.0 & 281 & 280 & 266 & 275.7 \\
\hline 2 & 2.47 & 283 & 283 & 268 & 278.0 & 276 & 313 & 288 & 292.3 \\
\hline 3 & 4.56 & 304 & 304 & 274 & 294.0 & 291 & 288 & 236 & 271.7 \\
\hline 4 & 7.59 & 286 & 284 & 325 & 298.3 & 261 & 273 & 292 & 275.3 \\
\hline Center & 11.75 & 306 & 313 & 300 & 306.3 & 285 & 257 & 246 & 262.7 \\
\hline 5 & 15.91 & 327 & 310 & 323 & 320.0 & 294 & 282 & 241 & 272.3 \\
\hline 6 & 18.94 & 339 & 321 & 337 & 332.3 & 296 & 277 & 308 & 293.7 \\
\hline 7 & 21.03 & 308 & 323 & 337 & 322.7 & 253 & 273 & 282 & 269.3 \\
\hline 8 & 22.75 & 301 & 348 & 336 & 328.3 & 273 & 275 & 252 & 266.7 \\
\hline erages ---- & ----> & 309.7 & 306.2 & 311.8 & 309.2 & 278.9 & 279.8 & 267.9 & 275.5 \\
\hline
\end{tabular}

\begin{tabular}{|c|c|c|c|c|c|c|c|}
\hline$A / I$ & $\mathrm{pt} / \mathrm{ft} 3$ & Dev. from mean & Center 2/3 & North & West & All & Normlzd \\
\hline Mean & 292.4 & & Mean & 307.4 & $\overline{276.8}$ & $292 . \overline{07}$ & 315.08 \\
\hline Min Point & 262.7 & $-10.2 \%$ & Std. Dev. & 18.9 & 11.8 & 21.93 & 17.76 \\
\hline Max Point & 332.3 & $13.7 \%$ & COV as $\%$ & 6.1 & 4.2 & 7.51 & 5.64 \\
\hline
\end{tabular}

Avg Conc

$$
293 \mathrm{pt} / \mathrm{ft} 3
$$

Generator Inlet Press

Stack Temp

Centerline vel.

Ambient pressure

Ambient humidity

Ambient temp

Back-Gd aerosol

No. Bk-Gd samples

\begin{tabular}{|c|c|c|}
\hline Start & Finish & \\
\hline 8 & 8 & psig \\
\hline 67 & 65 & $F$ \\
\hline W 1310 & N 1296 & fpm \\
\hline 983.9 & 984.1 & $\mathrm{mbar}$ \\
\hline 44 & 58 & $\mathrm{RH}$ \\
\hline 60 & 57 & $\mathrm{~F}$ \\
\hline $3 / 5 / 1 / 3 / 1 / 4$ & $1 / 0 / 2 / 2$ & $\mathrm{pt} / \mathrm{ft} 3$ \\
\hline 6.0 & 4.0 & \\
\hline
\end{tabular}

Optical Particle Counters:(Cal due 7/13/02)

OPC A (9/5/01) MetOne A2408-1 Serial No.96258675 OPC clock about 1-hr fast

Oil Used: $\quad$ FisherBrand 19

\section{Instuments Used:}

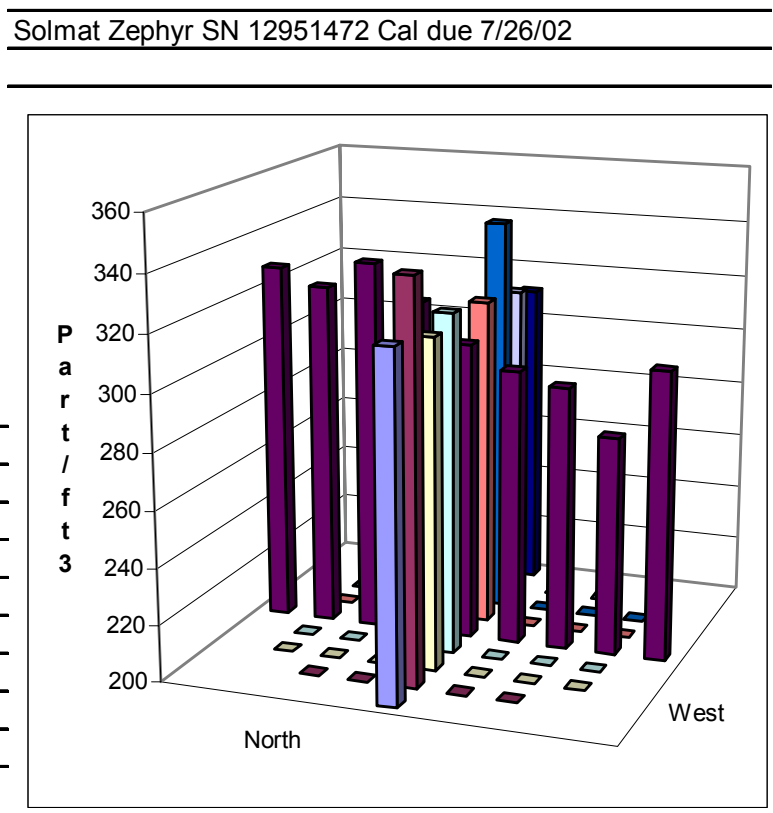


PARTICLE TRACER TRAVERSE DATA FORM

Site 291-Z-1 Model Stack

Date 11/14/01

Tester Glissmeyer

Stack Dia.

Stack X-Area

Elevation N.A

Distance to disturbance

Measurement units particles/ft3
Run No. PT-6

Fan configuration Turbine fan config

Fan Setting $60 \mathrm{~Hz}$

Stack Temp

Start/End Time

Center $2 / 3$ from $72.5 \operatorname{deg} F$

Points in Center $2 / 3$ $\frac{2.16}{2}$ to: $\frac{21.34}{7}$ Injection Point ET9 Centerline

\begin{tabular}{l} 
Traverse--> \\
\cline { 2 - 11 } $\begin{array}{l}\text { Trial } \\
\text { Trial ---> }\end{array}$
\end{tabular}

\begin{tabular}{|c|c|c|c|c|c|c|c|}
\hline$A I I$ & $\mathrm{pt} / \mathrm{ft} 3$ & Dev. from mean & Center $2 / 3$ & North & West & All & Normlzd \\
\hline Mean & $\overline{608.3}$ & & Mean & $\overline{586.8}$ & $\overline{631.1}$ & $608 . \overline{95}$ & 627.6 \\
\hline Min Point & 532.7 & $-12.4 \%$ & Std. Dev. & 37.8 & 32.4 & 40.86 & 35. \\
\hline Max Point & 695.3 & $14.3 \%$ & COV as $\%$ & 6.4 & 5.1 & 6.71 & \\
\hline
\end{tabular}

Avg Conc $\quad 610 \mathrm{pt} / \mathrm{ft} 3$

Generator Inlet Press

Stack Temp

Centerline vel.

Ambient pressure

Ambient humidity

Ambient temp

Back-Gd aerosol

No. Bk-Gd samples

\begin{tabular}{|c|c|c|}
\hline Start & Finish & \\
\hline 5.5 & 5.5 & psig \\
\hline 72 & 73 & $F$ \\
\hline N 1056 & w 935 & fpm \\
\hline 986.3 & 985.9 & $\mid$ \\
\hline 49 & 43 & $\mathrm{RH}$ \\
\hline 64 & 67 & $\mathrm{~F}$ \\
\hline $4 / 11 / 12 / 2 / 9 / 8 / 3$ & $62 / 41 / 16 / 25$ & $5 \mathrm{pt} / \mathrm{f}$ \\
\hline 7.0 & 4.0 & \\
\hline
\end{tabular}

Optical Particle Counters:(Cal due 7/13/02)

OPC A (9/5/01) MetOne A2408-1 Serial No.96258675 OPC clock about 1-hr fast

Oil Used: FisherBrand 19

Had problem getting low enough aerosol output to eliminate censor alarms. See sequence below to determine stability.

Static sequence at west \#1

$642,613,640,605$
Instuments Used:

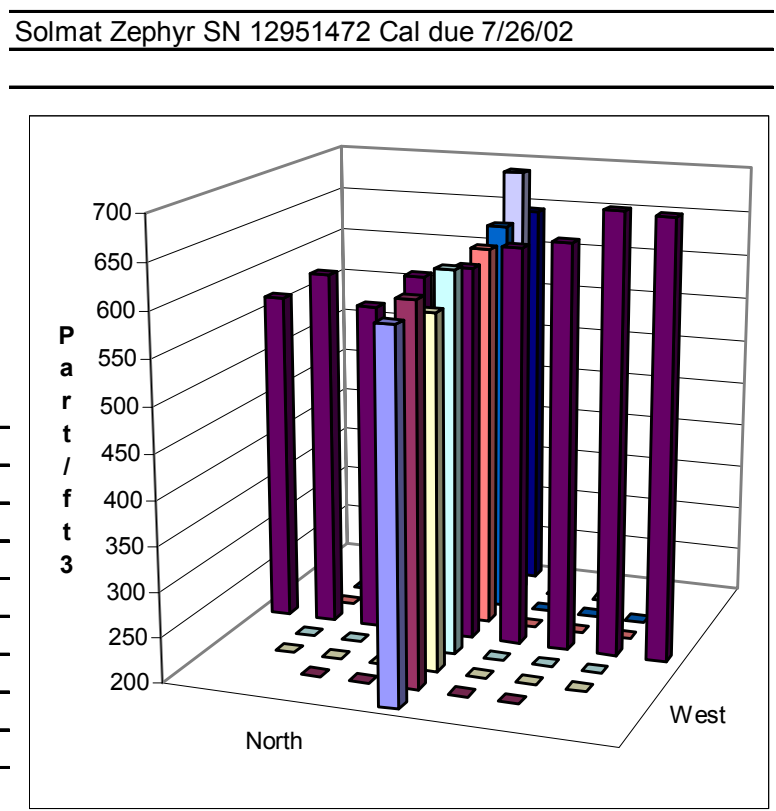


PARTICLE TRACER TRAVERSE DATA FORM

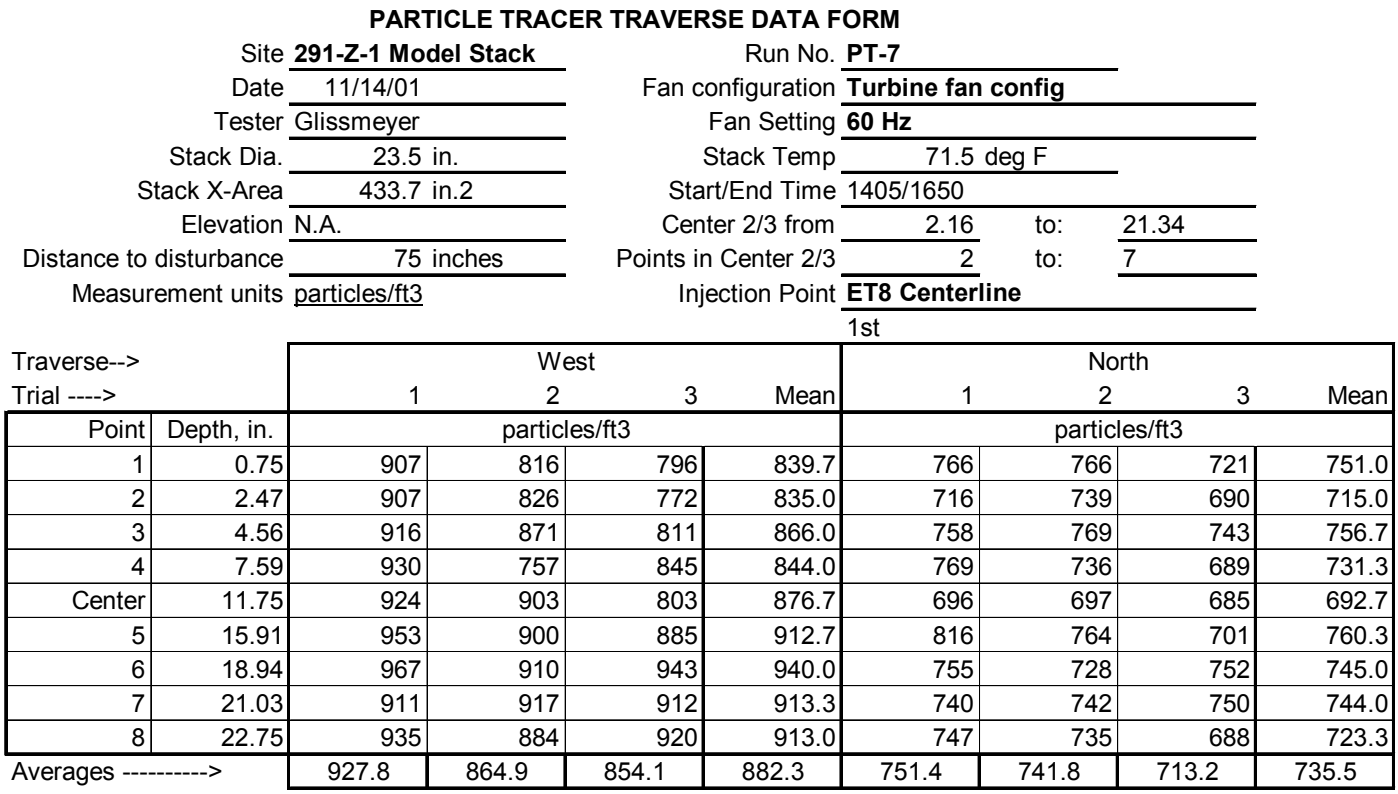

\begin{tabular}{|c|c|c|c|c|c|c|c|}
\hline$A / I$ & $\mathrm{pt} / \mathrm{ft} 3$ & Dev. from mean & Center 2/3 & North & East & All & Normlzd \\
\hline Mean & 808.9 & & Mean & 884.0 & 735.0 & 809.48 & 907.10 \\
\hline Min Point & 692.7 & $-14.4 \%$ & Std. Dev. & 39.2 & 24.1 & 83.37 & 41.42 \\
\hline Max Point & 940.0 & $16.2 \%$ & COV as $\%$ & 4.4 & 3.3 & 10.30 & 4.57 \\
\hline
\end{tabular}

Avg Conc $812 \mathrm{pt} / \mathrm{ft} 3$

Instuments Used:

Generator Inlet Press

Stack Temp

Centerline vel.

Ambient pressure

Ambient humidity

Ambient temp

Back-Gd aerosol

No. Bk-Gd samples

\begin{tabular}{|c|c|c|}
\hline Start & Finish & \\
\hline 3.5 & 3 & psig \\
\hline 73 & 70 & $F$ \\
\hline W 807 & N 788 & fpm \\
\hline 985.9 & 987.2 & $\mathrm{mba}$ \\
\hline 43 & 52 & $\mathrm{RH}$ \\
\hline 67 & 65 & 5 \\
\hline $3 / 6 / 12 / 7 / 15 / 2$ & $1 / 2 / 3 / 2$ & $\mathrm{pt} / \mathrm{f}$ \\
\hline 6.0 & 4.0 & \\
\hline
\end{tabular}

Optical Particle Counters:(Cal due 7/13/02)

OPC A (9/5/01) MetOne A2408-1 Serial No.96258675 OPC clock about 1-hr fast

Very windy, died down just when switched from north to west. Prior to that, wind averaged $15-20 \mathrm{mph}$ with gusts

Oil Used: FisherBrand 19

to $34 \mathrm{mph}$. Prefilters were extremely dirty and reduced the flow considerably.

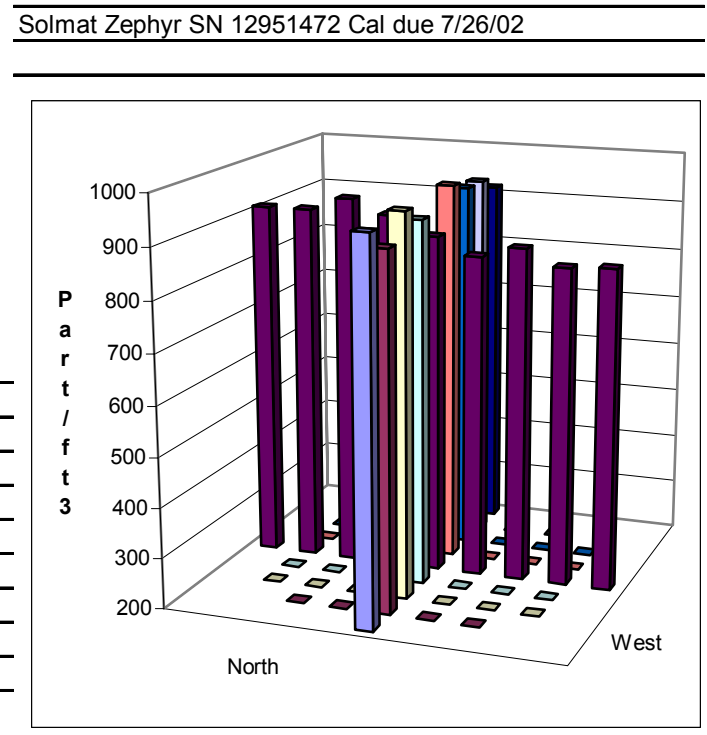


PARTICLE TRACER TRAVERSE DATA FORM

Site 291-Z-1 Model Stack

Date 11/29/01

Tester Glissmeyer

Stack Dia.

Stack X-Area

Elevation N.A.

Distance to disturbance

Measurement units particles/ft3
Run No. PT-8

Fan configuration Turbine fan config, 30 degree port Fan Setting $60 \mathrm{~Hz}$

Stack Temp Estimated as $47 \mathrm{~F}$

Start/End Time 1430/1600

Center $2 / 3$ from

Points in Center $2 / 3$

Injection Point $\overline{\text { ET9 Centerline }}$

\begin{tabular}{|c|c|c|c|c|c|c|c|c|c|}
\hline \multirow{3}{*}{\multicolumn{2}{|c|}{$\begin{array}{l}\text { Traverse---> } \\
\text { Trial ----> }\end{array}$}} & \multicolumn{8}{|c|}{ 1st } \\
\hline & & \multicolumn{4}{|c|}{ West } & \multicolumn{4}{|c|}{ North } \\
\hline & & 1 & 2 & 3 & Mean & 1 & 2 & 3 & Mean \\
\hline Point & Depth, in. & \multicolumn{4}{|c|}{ particles/ft3 } & \multicolumn{4}{|c|}{ particles/ft3 } \\
\hline 1 & 0.75 & 437 & 408 & 431 & 425.3 & 395 & 401 & 378 & 391.3 \\
\hline 2 & 2.47 & 428 & 401 & 425 & 418.0 & 362 & 326 & 352 & 346.7 \\
\hline 3 & 4.56 & 417 & 407 & 409 & 411.0 & 401 & 405 & 384 & 396.7 \\
\hline 4 & 7.59 & 415 & 394 & 448 & 419.0 & 390 & 410 & 394 & 398.0 \\
\hline Center & 11.75 & 368 & 381 & 388 & 379.0 & 363 & 368 & 414 & 381.7 \\
\hline 5 & 15.91 & 379 & 390 & 381 & 383.3 & 406 & 369 & 423 & 399.3 \\
\hline 6 & 18.94 & 384 & 375 & 363 & 374.0 & 423 & 401 & 423 & 415.7 \\
\hline 7 & 21.03 & 378 & 405 & 378 & 387.0 & 401 & 429 & 478 & 436.0 \\
\hline 8 & 22.75 & 367 & 378 & 422 & 389.0 & 407 & 435 & 415 & 419.0 \\
\hline Averages --- & 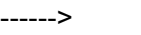 & 397.0 & 393.2 & 405.0 & 398.4 & 394.2 & 393.8 & 406.8 & 398.3 \\
\hline
\end{tabular}

\begin{tabular}{|lrr|lrrrr|r|}
\hline All & $\mathrm{pt} / \mathrm{ft} 3$ & Dev. from mean & Center 2/3 & North & West & & All & Normlzd \\
Mean & 398.3 & & & Mean & 395.9 & 396.3 & 396.10 & 397.49 \\
Min Point & 346.7 & $-13.0 \%$ & Std. Dev. & 19.4 & 27.8 & 23.03 & 23.11 \\
Max Point & 436.0 & $9.5 \%$ & COV as $\%$ & 4.9 & 7.0 & $\mathbf{5 . 8 1}$ & $\mathbf{5 . 8 2}$ \\
\hline
\end{tabular}

Avg Conc $401 \mathrm{pt} / \mathrm{ft} 3$

Generator Inlet Press

Stack Temp*

Centerline vel.*

Ambient pressure

Ambient humidity

Ambient temp

Back-Gd aer pt/ft3

No. Bk-Gd samples

\begin{tabular}{|c|c|c|}
\hline Start & Finish & \\
\hline 5 & 5 & psig \\
\hline $55 / 48$ & $54 / 46$ & $F$ \\
\hline W1365/1360 & N1324/1370 & fpm \\
\hline 975.2 & 978.3 & mbar \\
\hline 68 & 54 & $\mathrm{RH}$ \\
\hline 42 & 40 & $F$ \\
\hline $3 / 1 / 2 / 1 / 1 / 1$ & $16 / 15 / 11 / 7 / 9 / 1 / 0$ & \\
\hline 6 & 7 & \\
\hline
\end{tabular}

Optical Particle Counters:(Cal due 7/13/02)

OPC A (9/5/01) MetOne A2408-1 Serial No.96258675

OPC clock about 1-hr fast

Oil Used: FisherBrand 19

Seqence of readings at point West 3:

467, 415, 433, 413, 414

${ }^{*}$ First readings from Solomat. Second from out of cal TSI Velocicalc SN 305039. Solomat suspected of reading several degrees high. This has no effect on the particle uniformity results.

\section{Instuments Used:}

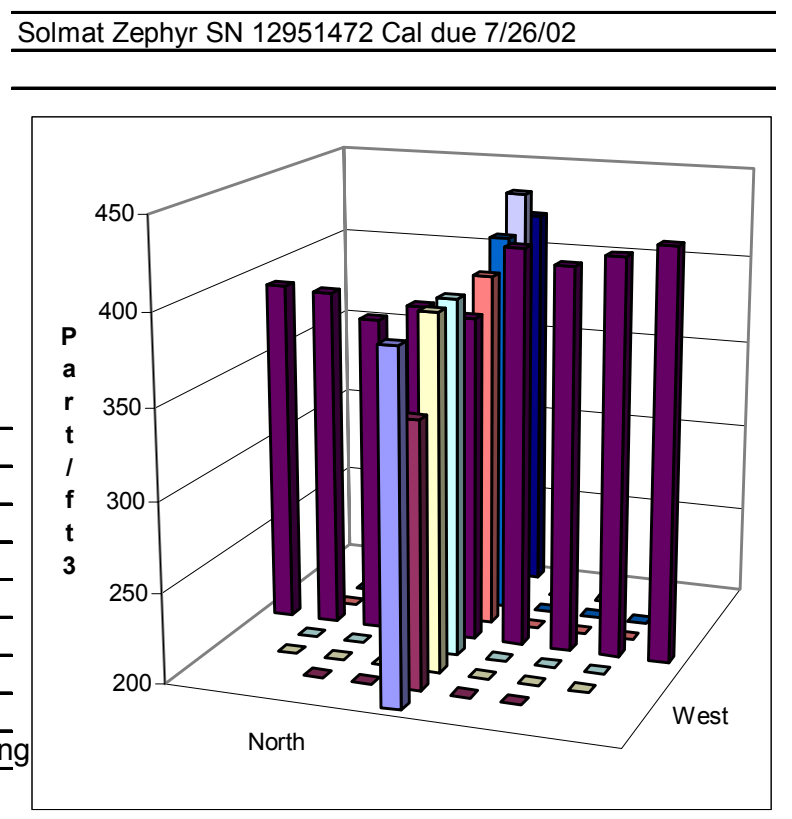




\section{Distribution}

No. of

Copies

OFFSITE

10 DOE Richland Operations Office

R. S. Ollero

L. R. Fitch

J. W. Kelly

C. Stuart

K. A. Hadley (2)

B. B. Nelson-Maki

R. Swan

Public Reading Room (2)
No. of

Copies

10 Pacific Northwest National Laboratory

J. G. Droppo, Jr K6-80

A. D. Maughan K6-80

J. A. Glissmeyer (5) K6-80

T. T. Jarvis K6-80

Hanford Technical Library (2) P8-55

T4-20

T4-25

T5-57

T5-54

T5-54

H2-53

Distr.1 